\title{
Estudo comparativo do tratamento das artroplastias infectadas do quadril sem e com o uso do espaçador de cimento com antibiótico
}

Tese apresentada à Faculdade de Medicina da Universidade de São Paulo para obtenção do título de Doutor em Ciências

Área de concentração: Ortopedia e Traumatologia Orientador: Prof. Dr. Olavo Pires de Camargo

SÃO PAULO

2004 
A verdade é aquilo que todo homem precisa para viver e que ele não pode obter nem adquirir de ninguém. Todo homem deve extraí-la, sempre nova, de seu próprio íntimo, do contrário ele se arruína. A verdade é, talvez, a própria vida.

Franz Kafka 
Para minha amada esposa, Cláudia, que renova a minha alegria todos os dias.

Para nossos meninos, Pedro e Eduardo, significado de nossa existência.

Para meus pais, Mariam e António Pedro, que me ensinaram a viver. 


\section{AGRADECIMENTOS}

Ao saudoso Dr. Fernando Gaspar Miranda, que me iniciou na arte da artroplastia do quadril e que, acima de tudo, era uma pessoa digna e amiga com os colegas e com os pacientes.

Ao Professor Olavo Pires de Camargo, por sua orientação, pelo apoio inestimável ao nosso projeto e por sua amizade.

Ao Professor Alberto Tesconi Croci, por contribuir todos os dias com sua sensatez e com seu incomparável conhecimento acadêmico.

Ao Dr. Antônio Carlos Bernabé, pela confiança em nós depositada, quando persistimos na melhora do tratamento das artroplastias infectadas.

À Dra. Ana Lúcia Lei Munhoz Lima, por sua luta incansável contra o pior inimigo dos médicos: a infecção.

Aos colegas ortopedistas do Instituto de Ortopedia e Traumatologia do Hospital das Clínicas da Faculdade de Medicina, companheiros da melhor escola médica do Brasil.

Aos Residentes e ex-residentes que passaram pelos Grupos de Quadril e de Artroplastias nesses últimos oito anos. Este trabalho apenas foi possível por causa de vocês.

Aos Drs. Carlos Eduardo Jacob e Luiz Antônio Prata de Figueiredo, meus queridos colegas de classe, de Atlética e de Show Medicina, pelo nosso convívio pessoal, familiar e acadêmico.

Ao Dr. Wagner Castropil, grande amigo desde a residência médica e cujo convívio tenho o privilégio de continuar mantendo, tanto no plano pessoal, quanto no profissional.

Aos Drs. Alexandre campos Poltronieri, Fernando Rogério Dimarzio e Luiz Fernando Teochi, ex-residentes do grupo de Quadril e amigos das melhores e das piores horas.

Aos funcionários do Serviço de Arquivo do I.O.T.H.C.F.M.U.S.P., especialmente ao Sr. Ezequiel Reis de Santana, pela presteza do acesso aos prontuários.

Aos funcionários do Centro Cirúrgico do I.O.T.H.C.F.M.U.S.P., pela luta constante em prol da excelência no atendimento aos pacientes. 
À Equipe do Banco de Tecidos do I.O.T.H.C.F.M.U.S.P., Arlete Giovanni, Luiz Augusto Ubirajara Santos, Graziela Guidoni Maragni e Júlio César Shinzato, pela competência e qualidade de seus serviços.

Às assistentes sociais do I.O.T.H.C.F.M.U.S.P., especialmente a Sra. Vera Lúcia Frazão de Souza, por sua paciência e compaixão com a dor dos pacientes.

Ao pessoal da Biotec Projetos e Serviços Itda., Lúcia Maria Evangelista Ferraz, Márcia Salgado da Costa Amaral e Tomaz Puga Leivas, por sua paciência e competência.

À Fundação de Amparo à Pesquisa do Estado de São Paulo - FAPESP, pela oportunidade desta tese ter feito parte da mais renomada instituição de apoio aos estudos no país.

Aos meus sogros, Senhor Leodegário Amarante de Azevedo filho e Sra. Ilka Souza Lima de Azevedo, pela correção ortográfica, pelas orientações, por serem pessoas de incomparável conhecimento científico e literário e conseguirem transmití-lo e, principalmente, por serem os pais da pessoa que mais amo no mundo.

Aos pacientes, especialmente os infectados, vítimas das boas intenções de nós, médicos. Que este trabalho Ihes seja útil na busca da cura e do bem estar. 


\section{SUMÁRIO}

\section{RESUMO}

\section{SUMMARY}

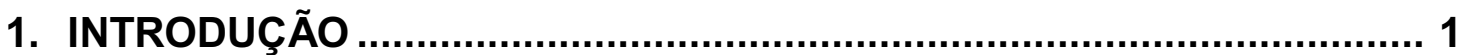

2. REVISÃO DA LITERATURA.......................................................... 7

2.1. CIMENTO IMPREGNADO DE ANTIBIÓTICOS .............................. 8

2.2. TRATAMENTO DA INFECÇÃO EM ARTROPLASTIAS DE QUADRIL 18

2.3. ESPAÇADOR DE CIMENTO COM ANTIBIÓTICOS........................... 38

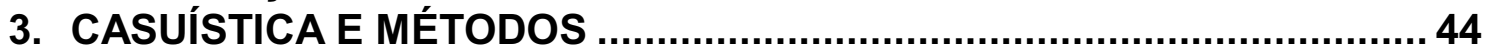

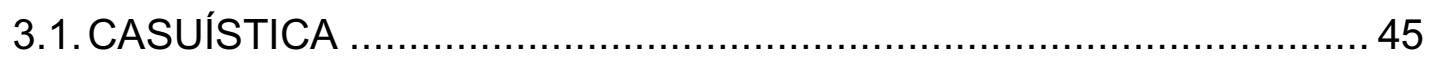

3.2. CRITÉRIOS DE INCLUSÃO....................................................... 45

3.3. CRITÉRIOS PARA DIVISÃO DOS GRUPOS DE ESTUDO ............... 48

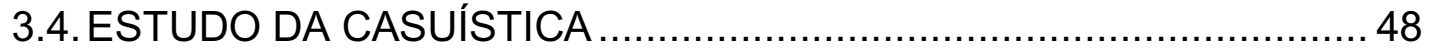

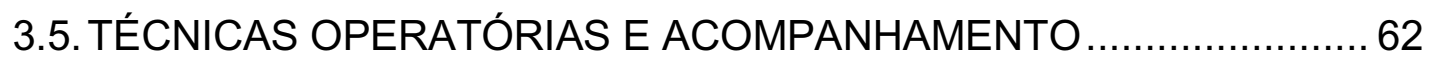

3.5.1. PRIMEIRO TEMPO CIRÚRGICO ......................................... 62

3.5.2. CUIDADOS ENTRE OS DOIS TEMPOS CIRÚRGICOS ............ 69

3.5.3. SEGUNDO TEMPO CIRÚRGICO .......................................... 71

3.5.4. ACOMPANHAMENTO PÓS-OPERATÓRIO ............................. 75

3.6. CRITÉRIOS DE AVALIAÇÃO DOS RESULTADOS …...................... 75

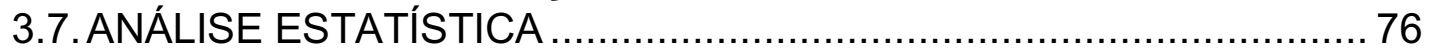

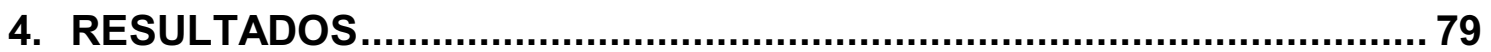

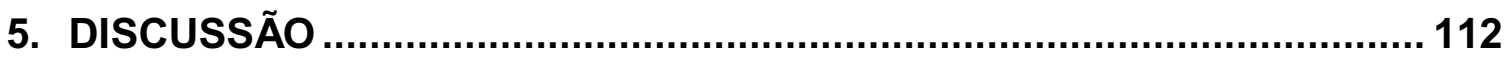

5.1. EVOLUÇÃO GERAL DOS GRUPOS ESTUDADOS ........................... 113

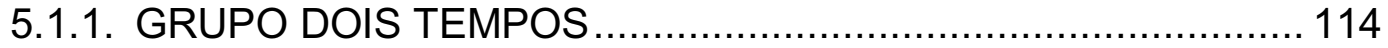

5.1.2. GRUPO ESPAÇADOR .................................................. 115

5.2. ASPECTOS DEMOGRÁFICOS, CLÍNICOS E LABORATORIAIS PRÉ-

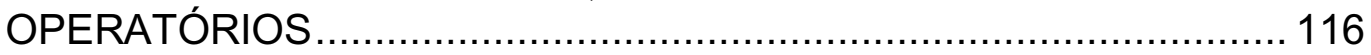

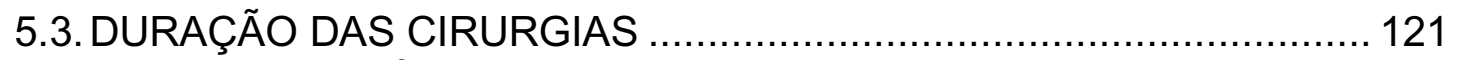

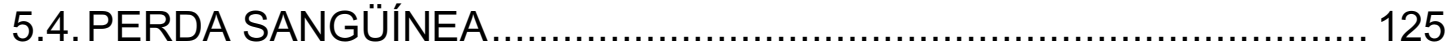

5.5. TEMPO DE INTERNAÇÃO TOTAL E EM UNIDADE DE TERAPIA

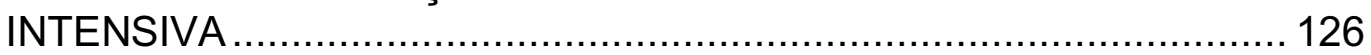

5.6. COMPLICAÇÕES INTRA-OPERATÓRIAS ..................................... 127

5.7. COMPLICAÇÕES APÓS O PRIMEIRO TEMPO CIRÚRGICO ............ 131

5.8. COMPLICAÇÕES APÓS O SEGUNDO TEMPO CIRÚRGICO............. 134

5.9. RECONSTRUÇÃO DO ESTOQUE ÓSSEO ….................................. 140

5.10.BACTERIOLOGIA E ANTIBIOTICOTERAPIA …........................... 142

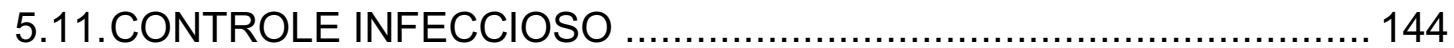

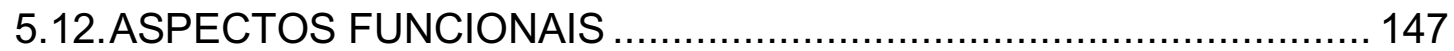

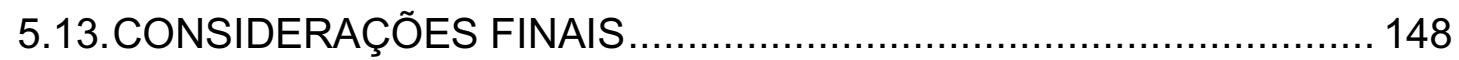

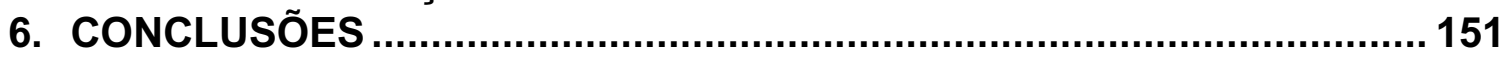

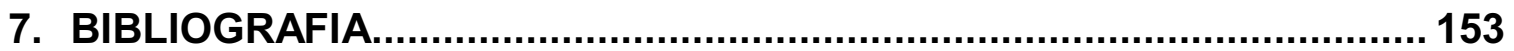

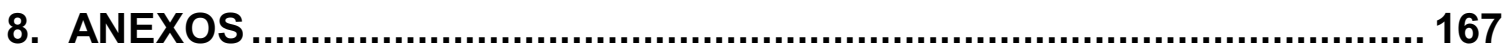




\section{RESUMO}

CABRITA, H.A.B.A. Estudo comparativo do tratamento das artroplastias infectadas do quadril sem e com o uso do espaçador de cimento com antibiótico. São Paulo, 2004. p. Tese (doutorado) Faculdade de Medicina, Universidade de São Paulo.

Em um estudo prospectivo sobre o tratamento das artroplastias de quadril infectadas, com perdas ósseas e fístulas ativas, 25 pacientes foram tratados em dois tempos e 36 pacientes foram tratados em dois tempos com espaçador de cimento impregnado com vancomicina. O acompanhamento médio foi de dois anos e onze meses. Sete pacientes do grupo tratado em dois tempos $(29,2 \%)$ e três pacientes do grupo tratado com espaçador $(8,8 \%)$ apresentaram recidiva infecciosa. Após o segundo tempo cirúrgico, o Escore de Harris para Quadril médio passou de 19,3 para 69,0 pontos nos casos tratados em dois tempos e de 19,7 para 72,2 pontos nos pacientes tratados com espaçador. Ao final do estudo, $86,1 \%$ dos tratados com espaçador e em $33,3 \%$ dos tratados em dois tempos tinham próteses em bom funcionamento e sem infecção. O uso do espaçador de cimento com antibiótico proporciona melhor controle infeccioso e bons resultados funcionais. 


\section{SUMMARY}

CABRITA, H.A.B.A. Prospective study of the treatment of chronically infected hip replacements with and without the use of an antibioticloaded acrylic cement spacer São Paulo, 2004. p. Tese (doutorado) - Faculdade de Medicina, Universidade de São Paulo.

We report a prospective study of 61 patients with chronically deep infected hip replacements with actively discharging sinuses, treated with a two-stage revision protocol, with and without a cement spacer impregnated with vancomycin. The average follow-up was two years and eleven months. Twenty-five patients were treated without a spacer and seven had recurrence of infection. Thirty-three patients were treated with a spacer and three had infective recurrence. Fifteen patients of the non-spacer group and 31 patients from the spacer group had done the second stage. The average Harris Hip score increased from 19,3 to 69,0 on the non-spacer patients and from 19,7 to 75,2 on the spacer group. At the end of the study, the success rate was $86,1 \%$ for the spacer group and $33,3 \%$ for the non-spacer group. The use of the spacer increased the results of the two-stage chronic infected hip replacements. 
1 INTRODUÇÃO 
Nosso trabalho começou em 1996, quando estávamos no quarto ano de residência e fazíamos parte do Grupo de Quadril Adulto do I.O.T.H.C.F.M.U.S.P., sob a supervisão do saudoso Dr. Fernando Gaspar Miranda.

Tomamos conhecimento do trabalho de MØLLER et al. (1996) e ficamos fascinados com a idéia do espaçador de cimento com antibióticos. Àquela época, havia uma quantidade enorme de pacientes com próteses infectadas de quadril, principalmente de outros serviços, que procuravam o grupo para tratamento.

Ao estudarmos o artigo, vimos ali um fio de esperança para conseguir tratar adequadamente as próteses infectadas, especialmente aquelas com grandes perdas ósseas.

A prevalência de infecção profunda, após artroplastia de quadril, vem diminuindo consideravalmente, porém mantém-se em níveis preocupantes.

Casos de infecção têm sido relatados em 1,0 a 3,0\% das próteses primárias de quadril e em 3,0 a $5,0 \%$ dos casos de revisões (SALVATI et al. 2003). Instituições especializadas em cirurgias ortopédicas geralmente apresentam índices por volta de 1,0\% (GARVIN; HANSSEN, 1995).

No Brasil, poucos trabalhos são encontrados sobre índices infecciosos em artroplastias de quadril.

MIRANDA (1995) encontra 1,3\% de infecções em 315 artroplastias totais realizadas no período de 1986 a 1994, no Hospital Beneficência Portuguesa de São Paulo.

LIMA; BARONE (2001) estudam 46 pacientes submetidos à artroplastia total de quadril no período de 1993 a 1995 no Instituto de Ortopedia e Traumatologia do Hospital das Clínicas da Faculdade de Medicina da Universidade de São Paulo (I.O.T.H.C.F.M.U.S.P.). A incidência de infecções profundas é $6,5 \%$.

ERCOLE; CHIANCA (2002) encontram incidência de 1,0\% para infecções profundas e $8,5 \%$ para infecções superficiais em 305 artroplastias de quadril realizadas entre 1992 e 1998, na Santa Casa de Belo Horizonte. 
No I.O.T.H.C.F.M.U.S.P. as taxas de infecção superficial ou profunda após próteses de quadril ou joelho, incluindo artroplastias primárias e revisões, são: 4,2\% em 240 cirurgias, em 2000; 2,1\% em 235 cirurgias, em 2001; 9,7\% em 258 cirurgias, em 2002 e 6,5\% em 247 cirurgias, até outubro de $2003^{*}$.

O tratamento da infecção é de longa duração, muitas vezes requerendo mais de uma cirurgia, levando a sofrimento e a custos financeiros e sociais altíssimos.

Apesar disso, o prognóstico para resolução do processo infeccioso em artroplastias de quadril é de $80 \%$ a $90 \%$ com as técnicas cirúrgicas atuais (GARVIN et al.,1999; HOFMANN, 1999; MITCHELL et al.,2003; SALVATI et al., 2003).

O controle da infecção crônica em artroplastias requer a remoção dos componentes da prótese, pois as bactérias aderem-se à superfície do implante e ao cimento ortopédico, formando um verdadeiro filme biológico a partir da produção de polissacarídeos (GRISTINA; KOLKIN, 1983). Nesta camada, os microorganismos se reproduzem e formam colônias que não são retiradas do material implantado, mesmo com lavagem mecânica (COSTERTON et al., 1987).

A retirada da fonte de infecção e de todo material estranho permite a ação de defesas endógenas, como a fixação do complemento, e o uso de terapias exógenas, como a antibioticoterapia (GRISTINA; KOLKIN, 1983 e GARVIN; HANSSEN, 1995).

Após o desbridamento, podem ser realizados três tipos de condutas (MC DONALD et al.,1989, RAUT et al. ,1994, JACKSON; SCHMALZRIED, 2000 e SALVATI et al., 2003):

1) Fechamento simples da ferida e manutenção do paciente sem 0 implante, conforme a cirurgia de GIRDLESTONE (1943), método seguro quanto ao controle infeccioso, porém com mau resultado funcional (PAGNANO et al.,1997, CASTELLANO et al.,1998 e SCHRODER et al.,1998);

\footnotetext{
* LIMA, A.L.M. (Subcomissão de Controle de Infecção Hospitalar do Instituto de Ortopedia e Traumatologia do Hospital das Clínicas da Faculdade de Medicina da Universidade de São Paulo). Boletim interno, 2003.
} 
2) Colocação imediata de prótese definitiva, chamada de revisão em tempo único, muito usada por autores europeus nas décadas de 1980 e 1990 (BUCHHOLZ et al., 1981, WROBLEWSKI, 1986 e RAUT et al.,1994). Atualmente, este procedimento é contra-indicado em pacientes infectados com fístulas ativas, mau estado de partes moles e perdas ósseas que requerem enxerto de banco de tecidos (LECUIRE et al., 1999, HANSSEN; OSMON, 2000 e JACKSON; SCHMALZRIED, 2000). Sua indicação é condicionada à colocação de componentes cimentados, portanto artroplastias sem cimento não devem ser realizadas em tempo único (URE et al.,1998 e SCHMALZRIED, 1999);

3) A cirurgia em dois tempos é a mais utilizada mundialmente (LENTINO, 2003). O tempo ideal entre a cirurgia inicial e a colocação da nova prótese é controverso. É recomendado desde um mês (COLYER; CAPELLO, 1994 e HADDAD et al.,2000) até mais de um ano (MCDONALD, 1989) de intervalo.

Os melhores resultados com relação ao controle infeccioso são alcançados com a cirurgia em dois tempos (COLYER; CAPELLO, 1994, MORSCHER et al., 1990, HADDAD et al., 2000 e ENGLISH et al., 2002). Entretanto, o procedimento tradicional em dois estágios apresenta várias desvantagens.

No período intermediário os pacientes ficam internados pelo mínimo de três semanas, período necessário de tração esquelética para cicatrização de tecidos moles e início de reabilitação (SALVATI et al., 1982).

O paciente permanece com o membro encurtado, com reabilitação e função prejudicadas no período entre as cirurgias. A perda de mobilidade do paciente aumenta o risco de formação de escaras, osteoporose e tromboembolismo (CHARLTON et al., 2003).

O segundo tempo cirúrgico é mais difícil do que uma revisão asséptica ou infectada em tempo único, porque há retração cicatricial e contraturas musculares pelo encurtamento do membro inferior, sendo difícil identificar as estruturas ósseas durante o ato operatório (MC DONALD et al., 1989). 
A osteoporose de desuso piora as condições mecânicas para a fixação da prótese definitiva e predispõe a fraturas (CLEGG, 1977).

No início da década de 1990, dois autores, independentemente, descrevem a utilização de um bloco de cimento impregnado de antibiótico para preencher grandes cavidades nas regiões acetabular e femoral de pacientes com infecção em artroplastia de quadril e perda óssea grave (ZILKENS et al.,1990; ABENDSCHEIN,1992).

O espaçador consiste de componentes de prótese de quadril revestidos com poli-metilmetacrilato, podendo ser articulado como uma prótese total ou unipolar como uma prótese parcial (KRAAY et al.,1992; DUNCAN; BEAUCHAMP, 1993).

O grupo de Vancouver é o divulgador da PROSTALAC ( Prosthesis of Antibiotic Loaded $\underline{\text { Acrylic }}$ Cement), prótese total provisória montada a partir de moldes de componentes acetabular e femoral (DUNCAN; BEAUCHAMP, 1993, YOUNGER et al., 1997, MASRI; DUNCAN, 1998; WENTWORTH et al.,2002).

O uso do espaçador de cimento impregnado com antibióticos no período intermediário pode resolver os problemas apresentados no tratamento em dois tempos:

1) O espaçador ocupa espaço morto e funciona como um meio de liberação tópica prolongada de antibióticos como a vancomicina, gentamicina ou tobramicina, que podem ser escolhidos de acordo com a sensibilidade das bactérias identificadas em culturas prévias, potencializando a destruição dos microorganismos patogênicos remanescentes (HADDAD et al., 1999);

2) O espaçador é estabilizado na região intramedular femoral, protegendo de fraturas o fêmur proximal deficiente em estoque ósseo e mantendo o comprimento do membro inferior. Esta estabilidade permite a realização de carga parcial pelo paciente e reabilitação precoce, no período entre os dois tempos cirúrgicos (HARTFORD; GOODMAN, 1998);

3) O paciente recebe alta hospitalar ou é transferido para hospital de pequeno porte, logo que possível, pois não é necessária a tração 
esquelética, o que é um importante fator econômico (DUNCAN; BEAUCHAMP, 1993);

4) O tempo de duração e o grau de dificuldade técnica do segundo tempo cirúrgico diminuem, já que o espaçador ocupa o local receptor da prótese e facilita a exposição do fêmur proximal e acetábulo (LEUNIG et al., 1998).

Apesar destas vantagens parecerem evidentes, não há em literatura qualquer referência a dados objetivos que comprovem as vantagens do uso do espaçador na cirurgia em dois tempos (GARVIN; HANSSEN, 1995; WENTWORTH et al., 2002).

Segundo as revisões de FITZGERALD; STEINBERG (1999) e de SALVATI et al. (2003), não há trabalhos prospectivos que avaliem os resultados das diversas formas de tratamento comparados aos grupos de controle.

Nosso objetivo é comparar prospectivamente dois métodos de tratamento da infecção crônica em artroplastias de quadril: cirurgia em dois tempos e cirurgia em dois tempos com uso de espaçador de cimento com antibiótico. 
2 REVISÃO DA LITERATURA 


\subsection{CIMENTO IMPREGNADO DE ANTIBIÓTICOS}

Em 1970, BUCHHOLZ; ENGELBRECHT, trabalhando na Endo-Klinik, em Hamburgo, na Alemanha, descrevem o acréscimo de antibiótico ao cimento ortopédico, com o intuito de prevenir infecções em pacientes submetidos a artroplastias de quadril. Acrescentam gentamicina ao cimento Palacos ${ }^{\circledR}$ e propõem que esta conduta possa diminuir o índice infeccioso em próteses de quadril.

A taxa de infecção de 5,9\% (29 infecções em 489 próteses) em 1968, passa para 0,9\% (quatro em 431 próteses) em 1973 (BUCHHOLZ et al., 1984).

Em seguida ao sucesso da aplicação profilática, o uso terapêutico da liberação local de altas doses de antibióticos é realizado no tratamento de osteomielites e próteses infectadas (MCDONALD et al., 1989).

Numerosos estudos sobre a ciência básica e aplicações clínicas do cimento ortopédico adicionado a antibióticos são publicados nas décadas de 1970 e 1980.

Uma gama grande de antibióticos é testada, sendo misturados a vários tipos de cimento acrílico. Há trabalhos in vitro e in vivo com penicilina, eritromicina, daptomicina, cefalosporinas, aminoglicosídeos, fluoroquinolonas, clindamicina e vancomicina.

A capacidade física da passagem de antibiótico para o meio circundante ao cimento ortopédico é a eluição. Na definição do dicionário HOUAISS (2001), "eluição" é derivado do inglês elution, que provém do latim elutione. O significado literal é "dessorção provocada por um fluxo de líquido ou gás através de um adsorvente". Por sua vez, "dessorção" é definido como o processo inverso da "adsorção", que é a "fixação das moléculas de uma substância (o adsorvato) na superfície de outra 
substância (o adsorvente)". No caso dos estudos que apresentaremos, o adsorvato é o antibiótico e o adsorvente é o cimento ortopédico.

WEINSTEIN et al. (1975) descrevem os efeitos que ocorrem quando antibióticos são adicionados ao polimetilmetacrilato e quando esta mistura é inserida, sob pressão, com pistola injetora. São estudadas as características mecânicas dos cimentos Simplex ${ }^{\circledR}$ e Omniplastic ${ }^{\circledR}$, nas variações radioluzente e opaca, sendo a um grupo adicionado 40,0 mg de prostaphlin ${ }^{\circledR}$ (nome comercial da oxacilina sódica). Os testes de compressão e tensão não demonstram efeitos deletérios da adição de antibiótico ao cimento.

LEVIN (1975) compara a atividade in vitro de seis antibióticos em pó adicionados a cimento acrílico. São testadas eritromicina, cefalotina, gentamicina, tetraciclina e meticilina em dosagens variáveis de 0,5 a $3,0 \mathrm{~g}$ de antibiótico por $40,0 \mathrm{~g}$ de cimento contra Staphylococcus aureus e Staphylococcus epidermidis e gentamicina, colimicina, canamicina, neomicina, polimixina B e carbenecilina contra Escherichia coli e Pseudomonas aeruginosa. A clindamicina inibe o crescimento bacteriano até oito dias, mesmo com a concentração mínima de $0,5 \mathrm{~g}$ por $40,0 \mathrm{~g}$ de cimento. Em menor extensão, a cefalotina demonstra efetividade contra os gram-positivos. Efeito inibitório contra bactérias gram-negativas não é demonstrado nestes testes. A liberação de antibióticos é creditada à reabsorção lenta de água pelas porosidades do cimento acrílico.

LAUTENSCHLAGER et al. (1976a) demonstram que antibióticos em forma líquida adicionados ao cimento ortopédico levam à diminuição na resistência às forças de compressão e de tração do cimento, quando comparado ao cimento simples ou impregnado com antibióticos em pó.

LAUTENSCHLAGER et al. (1976b) acrescentam até $10,0 \mathrm{~g}$ de gentamicina a $40,0 \mathrm{~g}$ de cimento acrílico e estudam as propriedades mecânicas dos compostos. Adição de até $2,0 \mathrm{~g}$ de antibiótico ao cimento 
não altera suas propriedades mecânicas. A partir de então, ocorre diminuição proporcional na resistência à tensão e compressão, de acordo com o aumento da quantidade de antibiótico acrescentado ao cimento, especialmente após adição de 5,0 a 10,0g de quimioterápico.

MARKS et al. (1976) realizam testes in vitro e in vivo com cimentos Simplex ${ }^{\circledR}$ e Palacos ${ }^{\circledR}$ impregnados com oxacilina em pó, cefazolina em pó, gentamicina em pó ou aquosa. Culturas de Staphylococcus aureus, Escherichia coli e Pseudomonas aeruginosa não apresentam halo de inibição ao redor de discos de cimento não impregnados com antibiótico. Discos de cimento impregnados com antibióticos demonstram halos de inibição em todos os casos. Avaliação das propriedades mecânicas de compressão e tensão segundo a ISO (International Standart Organization) para cimentos ósseos não demonstra alteração significativa comparandose o cimento simples e o impregnado com antibiótico. Testes de eluição levam à conclusão de que os quimioterápicos selecionados são estáveis no cimento ortopédico, sendo liberados deste com atividade microbicida. No cimento Palacos $\AA$, os antibióticos apresentam melhor difusão. Testes in vivo em cães demostram concentrações ósseas altas e séricas baixas, nas primeiras 24 horas. O antibiótico continua sendo liberado no osso vizinho, até três semanas depois de sua implantação.

ELSON et al. (1977) confirmam as afirmações de BUCHHOLZ; ENGELBRECHT (1970) sobre o antibiótico impregnado de cimento ser capaz de liberar quimioterápicos em concentrações bactericidas no osso e partes moles adjacentes. Concentrações altas de gentamicina chegam a ser identificadas em osso cortical morto, demonstrando o alto poder de penetração dos antibióticos, a partir da superfície do cimento acrílico.

As características da eluição e da capacidade bactericida dos cimentos Palacos ${ }^{\circledR}$ e $C M W \circledR$ adicionados a três preparações de gentamicina são apreciadas por BAYSTON; MILNER (1982). Compostos diferentes de gentamicina apresentam difusão em graus variáveis, se adicionados ao 
mesmo tipo de cimento. O sulfato de gentamicina é difundido por mais tempo, a partir do cimento Palacos ${ }^{\circledR}$. Nas preparações sódicas a gentamicina difunde-se melhor a partir do Simplex ${ }^{\circledR}$. A dissipação de antibiótico é mais lenta se o meio circundante é ósseo e não fluido, pois o fluxo de líquido, junto ao adsorvente, lava o adsorvato. Apesar das amostras do cimento não apresentarem mais atividade antibacteriana após algum tempo, elas continuam com uma quantidade grande da droga originalmente introduzida. A atividade antibacteriana do cimento impregnado com antibióticos é mantida por tempo indeterminado no cimento que não está exposto à superfície, como comprovado, ao se colocar um fragmento cortado do cimento em uma placa de ágar, o que leva à inibição do crescimento bacteriano ao redor do cimento.

WAHLIG et al. (1984) realizam um estudo aleatório e duplo-cego envolvendo dois grupos de 15 pacientes submetidos a artroplastia total de quadril em que é utilizado cimento Palacos $R \bowtie$ (impregnado industrialmente com gentamicina). A dosagem de gentamicina para cada $40 \mathrm{~g}$ de cimento é de $0,5 \mathrm{~g}$ no primeiro e $1,0 \mathrm{~g}$ no segundo grupo. Não é utilizada antibioticoterapia endovenosa profilática. Determinam os níveis de gentamicina no sangue, urina e líquido drenado, realizando ensaios microbiológicos com Bacilulus subtilis. Os níveis séricos e urinários são praticamente atóxicos. A concentração da gentamicina no líquido drenado da ferida cirúrgica foi alta em ambos os grupos, excedendo a concentração bactericida mínima. O dobro de gentamicina é detectável no grupo em que foi acrescido $1,0 \mathrm{~g}$ a cada pacote de cimento, embora a relevância clínica não possa ser estabelecida.

SALVATI et al. (1986) dosam o soro e o fluido de drenagem de 56 pacientes operados com uso de cimento acrílico impregnado de gentamicina. Encontram níveis séricos baixos, não descartando que estes possam ser nefrotóxicos ou ototóxicos. Não há efeitos colaterais nos pacientes do estudo. Asseguram que acrescentar gentamicina ao cimento acrílico é seguro e produz atividade antibacteriana efetiva in vivo. 
BAKER; GREENHAM (1988) descrevem os mecanismos da eluição da gentamicina, a partir do polimetilmetacrilato. Realizam estudos in vitro e in vivo usando microscopia eletrônica e imunofluorescência. Os testes demonstram que o cimento ortopédico é impermeável à gentamicina, se não houver falhas na sua superfície. A liberação de antibiótico ocorre, apenas, a partir de defeitos e fraturas na superfície do cimento. Nódulos de pó de cimento, material radiopaco e pó de antibiótico aumentam os defeitos na superfície do cimento e aumentam a eluição. Quanto maior a concentração de antibiótico no cimento, mais intensa a sua liberação. Cimentos com maior porosidade apresentam melhor eluição de antibióticos. Métodos de homogeneização do cimento que visam à diminuição de falhas, bolhas e fraturas, como uso de vácuo ou centrifugação, pioram a eluição. $O$ azul de metileno apresenta propriedades semelhantes à gentamicina quanto à eluição, a partir do cimento acrílico.

LANGLAIS et al. (1988) estudam a farmacocinética e a concentração óssea do cimento acrílico impregnado com gentamicina usado na fixação de 26 artroplastias primárias de quadril. As concentrações séricas do antibiótico são sempre baixas e longe dos níveis ototóxicos ou nefrotóxicos. A presença dos antibióticos nos líquidos de drenagem é proporcional à quantidade de pó de antibiótico adicionado ao cimento, alcançando altos níveis nas primeiras 12 horas. $O$ uso da gentamicina no cimento ortopédico é seguro e eficiente.

KUECHLE et al. (1991) estudam a atividade bactericida do cimento acrílico adicionado à vancomicina, daptomicina ou amicacina. Encontram atividade contra gram-positivos nos dois primeiros e contra gram-negativos no último composto, com boas características de eluição. Realizando a mistura em ambiente a vácuo, o que reduz a porosidade do cimento, há redução de $50 \%$ na liberação de antibiótico. O acréscimo de dextrana a $25 \%$ aumenta a porosidade do cimento e facilita a eluição dos antibióticos. 
ADAMS et al. (1992) medem a eluição de antibióticos de pérolas de polimetilmetacrilato impregnado de antibióticos in vivo. Cinco pérolas são implantadas em cavidades ósseas realizadas nas tíbias de cães. Clindamicina, vancomicina e tobramicina exibem boas características de eluição e apresentam níveis teciduais altos e persistentes. A vancomicina e a clindamicina são os únicos antibióticos a atingirem altas concentrações em osso cortical. Os níveis séricos dos antibióticos ficam abaixo das concentrações tóxicas. A tobramicina produz excelentes concentrações em tecido de granulação, porém, baixa concentração óssea. A vancomicina produz baixa concentração em soro circundante e excelente concentração óssea. Pérolas impregnadas com cefazolina, ciprofloxacina e ticarcilina apresentam características desfavoráveis. A clindamicina demonstrou altas concentrações em soro circundante, tecido de granulação e em osso. O emprego de pérolas de cimento impregnadas com antibióticos é um método seguro para alcançar concentrações altas de antibióticos nos tecidos circundantes, sem atingir níveis séricos tóxicos.

BRIEN et al. (1993) estudam características in vivo da vancomicina e da tobramicina adicionados a dois tipos de cimento ortopédico. Formam quatro grupos de dez pacientes, usando dosagens de 1,2g de tobramicina e 500mg de vancomicina adicionados a 40,0g de cada tipo de cimento acrílico como método de fixação de artroplastias primárias de quadril. Outros dois grupos, de cinco pacientes cada, recebem vancomicina ou tobramicina em doses terapêuticas por via endovenosa, sendo realizada artroplastia cimentada habitual. Realizam dosagens séricas, urinárias e nos líquidos de drenagem dos pacientes. As concentrações séricas de tobramicina são de 10 a 20 vezes superiores nos grupos em que são administrados antibióticos endovenosos. A concentração no líquido de drenagem é seis vezes maior nos grupos em que é adicionada tobramicina ao cimento. A vancomicina apresentou características semelhantes à tobramicina nas concentrações séricas e urinárias, porém no líquido de drenagem sua concentração foi baixa e inconstante. 
CHOHFI; LANGLAIS (1994) demonstram que a liberação da vancomicina do cimento acrílico apresenta caráter bifásico, com difusão intensa nas primeiras horas, seguida de uma fase mais lenta de liberação. Ensaios com diversos grupos de amostras mostram que esterilização por raios gama, adição de solução opacificante, variação na quantidade de antibiótico de 2,0 a 3,0g ou granulometria da vancomicina não alteram significativamente a resistência à compressão do composto com o cimento acrílico, estando os valores sempre acima dos requisitados pelas normas internacionais.

HECK et al. (1995) realizam uma pesquisa entre 1015 ortopedistas americanos para avaliar o uso do cimento impregnado com antibióticos. Os antibióticos mais adicionados ao cimento são tobramicina $(70,0 \%)$, gentamicina $(26,0 \%)$, vancomicina $(18,0 \%)$ e cefalosporinas $(15,0 \%)$. Onze por cento dos entrevistados usam antibióticos no cimento em artroplastias primárias. Em revisões infectadas, $81,0 \%$ dos ortopedistas usam antibióticos no cimento. Vinte e oito por cento dos ortopedistas indicam revisão em tempo único como tratamento de artroplastias infectadas e $72,0 \%$ indicam revisão em dois tempos. Os espaçadores são usados por $6,0 \%$ dos ortopedistas. Oitenta e quatro por cento dos ortopedistas não têm acesso a cimentos industrialmente adicionados a antibióticos. Antibióticos em forma líquida são adicionados ao cimento por $11,0 \%$ dos ortopedistas, o que é um erro conceitual. Sugerem a disseminação de informação correta entre os ortopedistas americanos para o uso correto do cimento impregnado com antibióticos.

MASRI et al. (1995) estudam a eluição da tobramicina, a partir de discos de cimento acrílico confeccionados com 2,4g de antibiótico por $40,0 \mathrm{~g}$ de cimento. Realizam três grupos de corpos de prova com mesmo volume, porém com: (1) superfície lisa, (2) superfície rugosa, com maior área de superfície e (3) superfície mais rugosa que (2), porém com mesma área de superfície que este. Demonstram que, no período de dois meses, 
a tobramicina sofre maior eluição nos grupos (2) e (3), que são equivalentes entre si. O aumento da área de superfície e não da rugosidade do cimento é que melhora a eluição da tobramicina. A implicação clínica é que o espaçador deve ter superfície irregular para aumentar a difusão de antibiótico para os tecidos adjacentes, devendo esta prática ser realizada especialmente quando a vancomicina for usada, já que sua capacidade de eluição é menor que a dos aminoglicosídeos.

KENDALL et al. (1996) incubam discos de cimento acrílico impregnados com vancomicina ou tobramicina com cepas de Staphylococcus epidermidis ou Staphylococcus aureus e analisam a presença de organismos viáveis no caldo de cultura e na superfície do cimento. Não encontram bactérias no caldo das 136 amostras após 96 horas. Entretanto, encontram organismos viáveis na superfície do cimento após 96 horas nos discos de ambos antibióticos. A superfície do cimento impregnado com antibióticos é um substrato possível para crescimento bacteriano e seu uso na prática clínica deve ser criterioso.

PENNER et al. (1996) demonstram in vitro que misturando vancomicina e tobramicina ao cimento acrílico ocorre um efeito sinérgico na capacidade de eluição de ambos antibióticos. A dosagem recomendada é de $1,0 \mathrm{~g}$ de vancomicina e $2,4 \mathrm{~g}$ de tobramicina por pacote de $40,0 \mathrm{~g}$ de cimento acrílico.

CHOHFI et al. (1998) estudam as características mecânicas e farmacocinéticas de um cimento comercializado na França que contém $3,0 \mathrm{~g}$ de vancomicina em $40,0 \mathrm{~g}$ de polimetilmetacrilato. A resistência à compressão é semelhante ao cimento normal, alcançando 95,0mPa, acima do ideal de $70,0 \mathrm{mPa}$. Estudos de eluição in vitro são realizados com corpos de prova imersos em solução salina. Após oito semanas, 4,2\% da vancomicina é liberada na solução. Metade desta quantidade é liberada nas primeiras 24 horas. Concentrações ósseas de vancomicina bactericidas são identificadas em ovelhas sacrificadas seis meses após a 
introdução de cimento misturado ao antibiótico. São dosados os níveis de vancomicina em sangue, urina e material de drenagem em dez pacientes submetidos a artroplastias primárias cimentadas com o composto estudado. Não são administrados antibióticos endovenosos. Os níveis séricos de vancomicina não excedem $2,9 \mathrm{mg} / \mathrm{l}$. O pico sérico ocorre após 24 horas de cirurgia e o antibiótico não é mais detectável após 10 dias de cirurgia. Altos índices são encontrados no fluido de drenagem em até quatro dias de pós-operatório. No acompanhamento dos 27 pacientes com uso de vancomicina no cimento, não encontram reações alérgicas ou tóxicas. Recomendam adicionar $2,0 \mathrm{~g}$ de vancomicina para cada $40,0 \mathrm{~g}$ de cimento ortopédico para ação bactericida local e prolongada visando a profilaxia de infecção ou a terapêutica de artroplastias infectadas. O comportamento da vancomicina é semelhante ao da gentamicina quando adicionada ao cimento acrílico.

MASRI ET AL. (1998) encontram efeito sinérgico na eluição da vancomicina quando utilizada em conjunto com tobramicina ao estudar 49 próteses de joelho e quadril infectadas tratadas com PROSTALAC. Dosam as concentrações intra-articulares dos antibióticos de amostras teciduais retiradas no segundo tempo de tratamento, que ocorre em média 118 dias depois do primeiro tempo. Encontram níveis bactericidas nos casos em que são utilizados $3,6 \mathrm{~g}$ de tobramicina por pacote de cimento e níveis abaixo da concentração inibitória mínima se são utilizados 2,4g por pacote de cimento. A eluição da vancomicina não é tão boa quanto a da tobramicina, embora níveis detectáveis de antibiótico sejam identificados na maioria dos pacientes. $O$ aumento da dose de tobramicina de 2,4g para $3,6 \mathrm{~g}$ por pacote de cimento aumenta a eluição da vancomicina. $\mathrm{O}$ aumento da dose de vancomicina acima de $1,0 \mathrm{~g}$ não aumenta a eluição da própria vancomicina ou da tobramicina. Recomendam a utilização de pelo menos $3,6 \mathrm{~g}$ de tobramicina e $1,0 \mathrm{~g}$ de vancomicina a cada $40,0 \mathrm{~g}$ de cimento ortopédico para a confecção de espaçador no tratamento de artroplastias infectadas. 
KLEKAMP et al. (1999) estudam as características físicas e biológicas do cimento acrílico adicionado à tobramicina em pó ou à vancomicina liofilizada. Não notam diferença na resistência compressiva nos vários compostos, com relação ao cimento simples. $O$ acréscimo de vancomicina diminui a resistência à fadiga do cimento acrílico. A vancomicina em pó apresenta pior eluição com relação à tobramicina, embora mantenha concentrações bactericidas no ágar circundante.

VAN DE BELT et al. (2000) notam formação de glicocálice ao redor de amostras de cimento acrílico impregnado com antibiótico. Expõem corpos de prova de cimento acrílico adicionado de tobramicina a cepas de Staphylococcus aureus e notam o crescimento de bactérias resistentes aos aminoglicosídeos. A liberação prolongada de antibiótico acelera o processo de resistência bacteriana. $\mathrm{O}$ uso de antibióticos no cimento nem sempre impede a formação de glicocálice.

GONZÁLEZ DELLA VALLE et al. (2001) estudam a bioatividade da vancomicina e tobramicina eluídas do cimento ortopédico. Coletam fluido de drenagem de três pacientes submetidos à artroplastia de quadril primária cimentada com acréscimo de $1,0 \mathrm{~g}$ de vancomicina e $1,2 \mathrm{~g}$ de tobramicina ao cimento. Realizam, além da dosagem, estudos biológicos da atividade dos antibióticos para estreptococo do grupo B para vancomicina e Escherichia coli para tobramicina. Ambos os antibióticos eluem com boa intensidade e existe efeito sinérgico quando ambos são adicionados ao cimento acrílico.

NEUT et al. (2001) completam in vivo o trabalho de VAN DE BELT (2000), realizando culturas de amostras de pérolas de gentamicina coletadas durante o segundo tempo de tratamentos de artroplastias infectadas. Isolam bactérias em 18 de 20 pacientes, sendo que 12 destes 18 pacientes eram considerados livres de infecção pelas culturas de rotina. Dezenove de 28 cepas identificadas são resistentes à gentamicina, demonstrando a ocorrência da resistência bacteriana. A cultura de tecidos 
é inadequada para a exclusão de infecção, sendo necessárias culturas de amostras do cimento retirado no segundo tempo, para maior segurança.

VAN DE BELT et al. (2001) afirmam que o uso de pérolas de antibiótico e espaçadores de cimento impregnados com antibióticos não é um fator importante para o aumento do perfil de resistência bacteriana porque estes implantes são temporários e são retirados após a finalidade terapêutica. Já a utilização indiscriminada do cimento com antibióticos para a fixação de próteses primárias, ou de revisão, leva ao aparecimento de cepas resistentes aos antibióticos presentes no cimento, que são liberados em baixas doses e por longos períodos, criando o ambiente propício para à mutagênese bacteriana.

PERRY et al. (2002) elaboram um novo tipo de estudo in vitro de diluição de antibióticos a partir do cimento acrílico usando uma câmara de fluxo líquido contínuo. A quantidade de antibiótico eluído dos corpos de prova, na solução em 48 horas, é 14,5\% para gentamicina, 11,7\% para tobramicina, 10,9\% para vancomicina e 6,6\% para amicacina. A gentamicina, que é mais barata, pode substituir a tobramicina como antimicrobiano a ser acrescentado ao cimento, sem prejuízo da atividade bactericida.

\subsection{TRATAMENTO DA INFECÇÃO EM ARTROPLASTIAS DE QUADRIL}

COVENTRY (1975) estuda a história natural das infecções em próteses de quadril. Classifica as infecções em:

la - Infecção aguda que ocorre até três semanas após a cirurgia, com quadro clínico florido e doloroso. O paciente apresenta-se toxêmico e febril;

lb - Hematoma infectado, estágio em que a infecção é questionável e os sintomas são frustros;

II - Infecção insidiosa e subaguda, de difícil diagnóstico, que se torna aparente a partir de dois meses até dois anos após a cirurgia. $\mathrm{O}$ 
quadro clínico é de bom estado geral, dor moderada e velocidade de hemossedimentação alta. Punções articulares geralmente apresentam crescimento bacteriano. A progressão natural é a soltura dos componentes;

III - Infecção hematogênica nova, que ocorre após um ano de cirurgia ou mais comumente após dois anos. Pode ser quadro toxêmico ou subclínico.

Tratamentos que tentam preservar os componentes, como antibioticoterapia sem cirurgia ou limpeza cirúrgica com manutenção dos implantes, apresentam maior taxa de recidiva infecciosa do que a retirada da prótese e desbridamento.

CLEGG (1977) analisa retrospectivamente 29 pacientes com 30 artroplastias infectadas de quadril tratados com retirada dos componentes e limpeza cirúrgica. Controlam a infecção em $80 \%$ dos casos. O encurtamento do membro inferior é de $3,0 \mathrm{~cm}$ a $6,0 \mathrm{~cm}$. Os pacientes apresentam melhora do quadro doloroso, embora funcionalmente estejam comprometidos. Todos usam apoio externo para deambular e apresentam dificuldades para permanecerem sentados, usarem vaso sanitário e tomarem banho. A taxa de recorrência foi fortemente associada à manutenção de fragmentos de cimento após a primeira cirurgia.

FITZGERALD et al. (1977) acompanham 3215 artroplastias de quadril realizadas em 2684 pacientes, de 1969 a 1972, na Clínica Mayo, em Rochester, E.U.A. Encontram uma taxa de infecção de 1,3\% usando antimicrobianos profiláticos em salas de cirurgia comuns. Cirurgias prévias, tempo de cirurgia prolongado (maior que três horas), culturas positivas obtidas durante a cirurgia e infecção urinária não identificada são associados ao quadro séptico. A taxa de infecção é 7,7\% em artroses póstraumáticas, $2,1 \%$ em fraturas do fêmur e 3,1\% em doenças reumatóides. Três pacientes morrem por causas diretamente relacionadas à infecção e, apenas oito, mantêm os componentes originais. Apenas um, de dezoito pacientes, reteve sua prótese após tratamento com limpeza cirúrgica e 
desbridamento. O tratamento mais efetivo é a retirada dos componentes e limpezas sucessivas. O segundo tempo é realizado em cinco pacientes, com recidiva infecciosa em dois deles. O sistema de classificação de COVENTRY (1975) é citado e adaptado, classificando as infecções em:

I - Agudas pós-operatórias, que ocorrem até três meses da cirurgia;

II - Tardias profundas, que podem se manifestar entre três meses e dois anos após a cirurgia;

III - Hematogênicas tardias, que ocorrem após dois anos da cirurgia.

HUNTER; DANDY (1977) estudam a história natural da artroplastia infectada de quadril em 135 casos. Encontram altas taxas de recidiva infecciosa, após a realização de nova artroplastia, em pacientes que tiveram uma prótese infectada, tratada com retirada dos componentes e limpeza cirúrgica. Mesmo sem sinais clínicos de infecção antes da colocação dos novos implantes, dois terços dos pacientes voltam a apresentar infecção. Após a ocorrência de infecção, são necessárias mais quatro cirurgias para a obtenção do controle infeccioso e do quadro doloroso. O resultado final é o controle da infecção, às custas de encurtamento severo do membro inferior e marcha insatisfatória. A perpetuação da infecção é devida à permanência de osso morto e não a cimento acrílico remanescente, após limpeza cirúrgica. No paciente com dor importante e fístulas ativas é indicada a retirada definitiva dos componentes. Não se deve realizar uma nova prótese em pacientes com artroplastia prévia infectada.

CARLSSON et al. (1978) acompanham 59 pacientes operados em tempo único e 18 pacientes operados em dois tempos. Usam cimento impregnado de antibióticos em todos casos e mantêm antibióticos endovenosos por seis meses. Conseguem bons resultados em 78,0\% dos casos. Não conseguem determinar qual dos dois tipos de tratamento é o melhor, pelo pequeno número de casos. Recomendam a revisão em tempo único pela facilidade técnica, pois é difícil colocar a prótese no segundo tempo cirúrgico da cirurgia em dois tempos. 
HOVELIUS; JOSEFSSON (1979) descrevem uma variante da cirurgia em dois tempos ao usar pérolas de gentamicina entre os dois tempos cirúrgicos, diminuindo o espaço morto que é deixado após a retirada dos componentes. As pérolas são colocadas no acetábulo e também no canal femoral. Indicam cirurgia em dois tempos em casos de grande contaminação e perda óssea grave.

HUGHES et al. (1979) tratam 26 infecções com revisão em tempo único ou dois tempos, com recorrência infecciosa em 15,4\% após três anos com ambos os métodos. Os pacientes com perda óssea grave são tratados em dois tempos e, os sem fístula, em tempo único. Antibioticoterapia endovenosa deve ser prolongada e orientada pela identificação do agente infeccioso. Ressaltam a alta incidência e agressividade das infecções por estafilococos coagulase negativos.

AHLGREN et al. (1980) relatam o tratamento com retirada de componentes, limpeza cirúrgica e manutenção sem componentes (em Girdlestone) para 27 quadris infectados com fístulas ativas. Os pacientes permanecem em tração por quatro a seis semanas. Ao exame físico, dois terços dos pacientes obtêm flexão ativa entre 60 e 90 graus. Todos andam com apoio externo e apresentam sinal de Trendelemburg positivo. Todos os pacientes estão satisfeitos com a cirurgia, provavelmente por dois motivos: o alívio de uma dor severa e o desaparecimento de uma fístula supurativa socialmente incapacitante.

FENELON et al. (1980) descrevem a experiência da Endo-Klinik de Hamburgo, Alemanha, serviço de BUCHHOLZ, em 11 desarticulações do quadril por infecção em artroplastias. Seu serviço costuma realizar as revisões infectadas em tempo único. As indicações para amputação são: deterioração de estado geral, febre, toxemia, presença de fístulas ativas e edema com fibrose crônica tecidual, em seis casos; infecção com fístulas secretantes sem ameaça de vida, em quatro casos; a pedido do paciente, 
em um caso. Três pacientes permanecem com fístulas ativas após a cirurgia. A amputação ao nível do quadril é uma solução drástica que é justificada em casos de risco de vida ou infecções refratárias a outros tratamentos.

BUCHHOLZ et al. (1981) relatam a experiência de dez anos com cimento impregnado com antibióticos em 667 artroplastias infectadas de quadril. Salvam $77,0 \%$ dos pacientes com uma revisão em tempo único. Insistindo no tratamento em tempo único, conseguem tratar $90,0 \%$ dos casos. Repetem o procedimento, até cinco vezes, em alguns pacientes. Fatores associados à falha do tratamento incluem etiologia por bactérias gram-negativas e enterococos. Obtêm uma gama grande de complicações, com mortalidade de $1,5 \%$, evolução para desarticulação de quadril em $1,7 \%$ e evolução para cirurgia de Girdlestone definitiva em 3,3\%. A cirurgia em tempo único, se bem executada, deve alcançar sucesso em. pelo menos. $70,0 \%$ dos casos, sendo uma boa alternativa de tratamento para as artroplastias infectadas de quadril.

BITTAR; PETTY (1982) descrevem 14 cirurgias consecutivas tipo Girdlestone para próteses de quadril infectadas. O controle infeccioso é de $85,7 \%$ após seguimento mínimo de dois anos. A função do quadril é muito comprometida, pois o membro inferior permanece encurtado, causando discrepância dos membros inferiores, marcha em Tremdelemburg, dor e instabilidade. Notam que apenas um paciente da série demonstra satisfação com a cirurgia. Apesar da segurança no controle da infecção, a cirurgia de Girdlestone não apresenta bons resultados funcionais e psicológicos.

MILEY et al. (1982) avaliam retrospectivamente 100 pacientes (101 quadris) tratados em tempo único. Um quinto dos pacientes apresenta fístulas ativas. Obtêm $87,0 \%$ de controle infeccioso com seguimento mínimo de 32 meses. A antibioticoterapia dirigida e prolongada promove várias complicações. O paciente ideal para revisão em tempo único é o 
idoso que não suportará dois procedimentos cirúrgicos. As contraindicações incluem infecção severa com necrose tecidual e má vascularização local, fístulas ativas, múltiplas cirurgias prévias, septicemia, perda de estoque ósseo, evidência radiográfica de osteomielite ou infecções por microbiota mista.

SALVATI et al. (1982) avaliam retrospectivamente pacientes que realizam colocação de próteses após infecção em artroplastias de quadril entre 1968 e 1979. Tratamento em tempo único de 31 pacientes obtém sucesso em $91 \%$ dos casos. Oitenta e nove por cento de 28 quadris tratados em dois tempos têm controle infeccioso. Casos com fístulas ou perda de estoque ósseo são tratados em dois tempos. Todo material exógeno, especialmente fragmentos de cimento acrílico, deve ser retirado no desbridamento cirúrgico. A antibioticoterapia endovenosa deve ser dirigida de acordo com as culturas intra-operatórias, permanecendo por seis semanas e mantendo o nível bactericida mínimo do soro na relação $1: 8$.

KOSTUIK; ALEXANDER (1983) descrevem a artrodese de quadril como alternativa após a falha de artroplastia de quadril em 14 pacientes jovens. Sete casos são seqüelas de artroplastias infectadas. A idade média dos pacientes é de 38 anos e todos os casos são unilaterais. Usam placa-cobra lateral após osteotomia de trocanter maior e placa anterior neutralizadora. Consolidação ocorre em $92,8 \%$ dos casos e todos pacientes apresentam alívio do quadro doloroso. A conversão de falha de artroplastia de quadril em atrodese é tecnicamente possível e é compatível com atividades extenuantes.

BOURNE et al. (1984) tratam 33 casos de infecção em artroplastia com retirada dos componentes e manutenção em Girdlestone. A tração femoral é mantida no pós-operatório por três a seis semanas. Não acham que permanência prolongada de tração leva a menor encurtamento. Dez feridas cirúrgicas $(30,0 \%)$ permanecem com drenagem por mais de uma 
semana e $5(15,0 \%)$ mais de um mês. Setenta e nove por cento dos pacientes ficam satisfeitos com o resultado. Quanto ao resultado funcional, apenas $42,0 \%$ estão satisfeitos. A cirurgia de Girdlestone é uma alternativa razoável para pacientes que não devem ser submetidos a nova artroplastia.

BUCHHOLZ et al. (1984) apresentam a atualização de seu trabalho de 1981 sobre o tratamento em tempo único, com $77,0 \%$ de controle infeccioso em 825 artroplastias infectadas de quadril. Encontram piores resultados em infecções por Pseudomonas sp.

CANNER et al. (1984) acompanham o tratamento de 52 pacientes com artroplastia de quadril infectada pelo tempo médio de quatro anos e meio. A antibioticoterapia e a manutenção dos componentes apresentam bom resultado em um caso de 23 tratados. Trinta e três pacientes são tratados com cirurgia de Girdlestone, com erradicação de infecção em $81,8 \%$ e resultado funcional satisfatório em $60,6 \%$.

WEBER; LAUTENBACHET (1986) realizam estudo prospectivo de 33 artroplastias infectadas tratadas com um ou dois tempos cirúrgicos. Dividem os pacientes em três grupos: (1) infecção diagnosticada com contra-indicação cirúrgica e não incluídos no trabalho; (2) infecção diagnosticada e apto à cirurgia e tratados em dois tempos e (3) infecção presumida e revisados em tempo único. Realizam abertura de janela em região lateral da metáfise distal do fêmur, para proceder a fresagem do canal medular com retirada de material contaminado pela janela. Instalam lavagem contínua nos casos tratados em dois tempos. Observam dificuldade técnica em casos operados após oito semanas. Controlam a infecção em metade dos casos tratados em tempo único em $72 \%$ dos tratados com dois tempos.

WROBLEWSKI (1986) trata 102 pacientes com revisão em tempo único. Um terço dos pacientes apresentam fístulas ativas. Ao acrescentar 
gentamicina na proporção de $0,5 \mathrm{~g}$ por pacote de $40,0 \mathrm{~g}$ de cimento acrílico nota um aumento na taxa de resolução de infecção de $75,0 \%$ em uma série antiga para $91,0 \%$, na série atual. O seguimento médio é de três anos e dois meses. As complicações mais comuns são luxações em $12,7 \%$, pseudartrose de trocanter maior em $10,8 \%$ e alergia a drogas em $3,0 \%$. Infecções em artroplastias que haviam sido realizadas primariamente com cimento impregnado com gentamicina apresentam dificuldade para controle infeccioso. A retirada de todo cimento infectado é essencial. Adicionar antibióticos ao cimento aumenta a taxa de controle infeccioso.

GARVIN et al. (1988) em estudo prospectivo clínico, tratam infecções em artroplastias de quadril usando cimento impregnado de gentamicina. Desenvolvem um sistema de critérios para definir uma infecção como suspeita, provável ou definitiva, e o usam para definir o tipo de tratamento. Pacientes, apenas com suspeita de infecção, são tratados em tempo único. Pacientes com infeç̧ão provável ou definitiva são tratados em um ou dois tempos. Seguem os pacientes por 30 meses, em média. A revisão em tempo único controla $94,6 \%$ de 92 casos operados com suspeita infecciosa e $86,0 \%$ de sete pacientes com infecção diagnosticada. $\mathrm{O}$ tratamento em dois tempos alcança controle infeccioso nos 38 pacientes tratados, inclusive 24 com infecção diagnosticada.

SANZÉN et al. (1988) apresentam o seguimento tardio dos casos do mesmo centro do estudo de CARLSSON et al. (1978). Escolhem a realização em tempo único para pacientes imunocompetentes e com bom estoque ósseo com $76,0 \%$ de controle infeccioso e seguimento médio de seis anos. Os pacientes com fístulas ativas e perda óssea são escolhidos para tratamento em dois tempos. O sucesso com dois tempos e pérolas de gentamicina é de $83,0 \%$ de controle infeccioso em 13 casos. Encontram $40,2 \%$ de soltura asséptica em pacientes tratados em dois tempos e $61,0 \%$ para os tratados em tempo único. 
ANTTI-POIKA et al. (1989) estudam retrospectivamente 36 pacientes com artroplastias infectadas de quadril. Vinte e quatro pacientes apresentam fístulas ativas. Retiram componentes de 26 pacientes e realizam segundo tempo em 13 destes, com recorrência em três casos. Não encontram recidiva em três casos operados em tempo único e sem fístulas. Nos dois casos em que um dos componentes foi retido no paciente e realizou-se a retirada do outro componente e limpeza cirúrgica, há recidiva. Ambos os componentes e todo o cimento acrílico devem ser retirados no tratamento de artroplastias infectadas.

GRAUER et al. (1989) tratam 33 pacientes com retirada dos componentes e Girdlestone definitivo. A taxa de controle infeccioso é de $90,9 \%$ após 3,8 anos de seguimento. Os pacientes apresentam encurtamento de $3,0 \mathrm{~cm}$ a $11,0 \mathrm{~cm}$. Todos os pacientes apresentam sinal de Trendelemburg positivo e andam com auxílio externo. Propõem classificar a cirurgia de Girdlestone de acordo com o nível realizado da ressecção, pois este é diretamente relacionado ao resultado funcional e à capacidade de deambulação. Níveis mais proximais levam a melhores resultados funcionais. A cirurgia de Girdlestone continua sendo um procedimento de salvação.

HOPE et al. (1989) analisam retrospectivamente o tratamento de 91 infecções em artroplastias de quadril infectadas por estafilococos coagulase negativos. Em uma série de 246 tratamentos, de 1976 a 1987, identificam $37 \%$ de infecções causadas por estas bactérias. Trinta e oito por cento dos pacientes apresentam fístulas ativas. Setenta e dois pacientes realizam tratamento em tempo único, com recidiva infecciosa de $13 \%$. Os 19 pacientes restantes são submetidos à retirada dos componentes e à colocação de pérolas de gentamicina. Neste grupo não há recidivas, sendo que oito pacientes recebem implantes novamente, sem complicações. A revisão em tempo único é indicada para infecções sem complicações em idosos. Na dúvida sobre a etiologia da infecção, na presença de necrose tecidual extensa ou na necessidade de enxertia 
óssea, deve-se realizar a revisão em dois tempos. Os estafilococos coagulase negativos são microorganismos que, antigamente, eram dados como contaminantes de culturas ou pouco nocivos. Este grupo de bactérias não deve ser subestimado.

MC DONALD et al. (1989) relatam 82 quadris tratados em dois tempos cirúrgicos sem antibióticos adicionados ao cimento na colocação dos implantes definitivos. Após cinco anos e meio de seguimento, 87,0\% dos quadris estão controlados. A presença de cimento residual, avaliada por radiografia após o primeiro tempo cirúrgico é correlacionada à recorrência de infecção, assim como agentes etiológicos, como as bactérias gram-negativas e estreptococos do grupo $D$ (recentemente classificados no gênero Enterococcus). Vinte e sete por cento dos 27 quadris com segundo tempo realizado antes de um ano, após o primeiro tempo cirúrgico, apresentam recidiva infecciosa. A colocação dos implantes deve ser realizada, apenas, após um ano do primeiro tempo cirúrgico.

BERRY et al. (1991) usam enxertos de banco de ossos para reconstruir perdas ósseas no segundo tempo no tratamento de 18 pacientes com artroplastia infectada de quadril. A recorrência infecciosa, após 4,2 anos, é $11,0 \%$. Um terço dos casos necessita ser revisado por soltura asséptica, reabsorção do enxerto ou luxações recorrentes. A existência de infecção e perda óssea concomitantes piora o prognóstico de controle infeccioso e restabelecimento funcional.

COLLINS; MCKENZIE (1991) apresentam o tratamento de 34 pacientes. Em dezenove tentativas de limpeza, desbridamento e manutenção do implante, apenas uma é frutífera. Três pacientes falecem por causas diretamente relacionadas à infecção ou ao seu tratamento. É indicado retirar os componentes e fechar primariamente as feridas cirúrgicas. A persistência de espaço morto leva à drenagem persistente em oito pacientes. O retalho muscular do músculo tensor da fáscia lata é 
usado para preencher o espaço morto em um paciente, com bom resultado. Os retalhos musculares são boa alternativa no tratamento de infecções recalcitrantes.

THOMAS; BANNISTER (1991) tratam 37 pacientes com cirurgia em tempo único, dois tempos ou Girdlestone definitivo. Observam recidiva infecciosa em quatro de 23 cirurgias em que voltam a colocar implantes no paciente $(17,4 \%)$ e em três de 14 pacientes deixados em Girdlestone $(21,4 \%)$, sem diferença estatística. Os resultados funcionais são melhores nos pacientes com prótese, com média do Escore de Harris para Quadril de 72,0 pontos comparados a 47,0 pontos dos pacientes sem prótese. Observam recidiva infecciosa em $40,0 \%$ dos pacientes com etiologia por gram-negativos. Quando tecnicamente possível, a colocação de uma prótese, ao final do tratamento de artroplastias infectadas, leva a melhor resultado funcional.

LOTY et al. (1992) tratam 90 pacientes em tempo único. Dezesseis por cento apresentavam fístulas ativas. Enxerto ósseo é usado em 46 casos. Conseguem controle infeccioso em $85,5 \%$ dos casos após quatro anos e 79,0\% dos casos apresentam boa função do quadril. Infecções por S. aureus e Pseudomonas sp. apresentam pior evolução. O uso de enxertos ósseos no tratamento em tempo único é seguro e não aumenta a recidiva infecciosa.

ELSON (1993) encontra recidiva de infecção em 12,0\% de 243 quadris tratados em tempo único e 3,0\% em 86 tratados em dois tempos. Usam os níveis de proteína C-reativa e velocidade de hemossedimentação como indicativos para realizar o segundo tempo cirúrgico. Adicionar antibióticos ao cimento aumenta a confiança no controle infeccioso. A revisão em tempo único é apropriada para artroplastias cimentadas em pacientes com bom estoque ósseo e com identificação de bactérias que sejam sensíveis a antibióticos administrados por via oral. A cirurgia em dois tempos é indicada em casos com necessidade de enxerto ósseo e é 
obrigatória se quisermos realizar uma artroplastia sem cimento. Apenas centros ortopédicos experientes e com equipamentos adequados devem tratar próteses infectadas de quadril.

COLYER; CAPELLO (1994) montam um protocolo com três tempos cirúrgicos. No primeiro tempo é realizada a retirada dos componentes infectados e do material estranho, por via trocanteriana estendida. As culturas colhidas, preferencialmente de fragmentos ósseos, guiam a antibioticoterapia endovenosa. Após uma semana do primeiro tempo, são realizados, novamente, limpeza e desbridamento, e novamente colhidas culturas. Após quatro semanas, é colocado novo implante. Encontram $14,0 \%$ de recidiva em casos que realizam o terceiro tempo após seis semanas do primeiro tempo e $22,0 \%$ após um ano. Quanto antes for realizada a cirurgia definitiva menor é o índice de recidiva, especialmente em idosos.

GARVIN et al. (1994) comparam retrospectivamente os resultados no tratamento de artroplastias de quadril infectadas, em um ou dois tempos, com cimento simples, ou impregnado com antibióticos. A taxa de sucesso do tratamento em tempo único passou de $71,0 \%$ para $81,0 \%$, com a utilização do cimento impregnado com gentamicina. $O$ tratamento em dois tempos alcança $96,7 \%$ de bons resultados, em 30 pacientes. São relatadas complicações em $30 \%$ dos pacientes. Não há casos de efeito ototóxico ou nefrotóxico. A cirurgia em dois tempos é mais segura, embora apresente desvantagens: imobilidade no leito durante a tração esquelética, dificuldade para deambular sem a prótese no período intermediário e hospitalização prolongada. Cirurgia em tempo único é reservada para idosos que não suportam o período de tração ou duas intervenções cirúrgicas.

LIEBERMAN et al. (1994) estudam retrospectivamente a evolução de 49 quadris, tratados em dois tempos, ou Girdlestone definitivo. Trinta e quatro quadris são submetidos ao segundo tempo e 13 ficam em 
Girdlestone. São critérios para a não realização do segundo tempo: perda óssea acetabular grave, úlceras de decúbito sacrais, colite pseudomembranosa, reinfecção, fratura femoral requerendo fixação ou expectativas de reabilitação limitadas. Nove por cento dos pacientes que realizam o segundo tempo cirúrgico apresentam recidiva infecciosa. Não há recorrência nos pacientes em Girdlestone. Não há associação da recidiva infecciosa com a virulência dos microorganismos, duração de antibioticoterapia ou intervalo para segundo tempo. O intervalo de dois meses entre os dois tempos cirúrgicos é seguro.

MORSCHER (1994) compara funcionalmente os resultados da cirurgia de Girdlestone aos da cirurgia em dois tempos em 64 pacientes. Vinte e três pacientes em Girdlestone apresentam encurtamento médio de $6,1 \mathrm{~cm}$, não podendo andar sem apoio externo. Geralmente necessitam de duas muletas pela sensação de instabilidade no quadril. $O$ gasto energético é maior ao deambular e a amplitude de movimentos é diminuída. Dos 41 pacientes com prótese, 31 não têm dor e 21 não apresentam discrepância de membros inferiores, com bom resultado funcional, especialmente quando o intervalo entre os dois tempos é curto. Sempre que possível deve-se realizar o segundo tempo cirúrgico após a retirada dos componentes e do controle infeccioso.

NESTOR et al. (1994) acompanham retrospectivamente 34 pacientes tratados em três tempos, com artroplastia total sem cimento no terceiro tempo. O primeiro tempo é igual ao da cirurgia em dois tempos. No segundo tempo apenas é feita a reconstrução óssea e os implantes definitivos são colocados no terceiro tempo cirúrgico. Complicações ocorrem em 23 pacientes (68,0\%) com luxações em 17,6\%. Após 47 meses de acompanhamento médio, seis pacientes (18,0\%) apresentam recorrência infecciosa. O emprego de enxerto ósseo no segundo tempo ou a utilização de artroplastias sem cimento no terceiro tempo não altera estatisticamente a incidência de infecção. 
RAUT et al. (1994) relatam controle infeccioso em $86,0 \%$ de 49 pacientes com infecção com fístulas ativas revisados em tempo único, com acompanhamento médio de sete anos e quatro meses. Realizam sempre artroplastias com cimento impregnado de gentamicina. Não referem o grau de perda óssea dos casos. As complicações são relacionadas à via de acesso: fragmentação de trocanter maior em $12,3 \%$ e pseudartrose de trocanter maior em $7,0 \%$ dos casos. A presença de fístula ativa não contraindica a revisão em tempo único.

RAUT et al. (1995) complementam o trabalho anterior (RAUT et al.,1994) com os casos sem fístulas ativas. Após revisão em tempo único de 183 pacientes encontram $84,2 \%$ de controle infeccioso após sete anos e nove meses. Não é indicada a revisão em tempo único, se houver perda óssea, caso em que é indicada ressecção tipo Girdlestone definitiva. O principal fator preditivo de sucesso, após o tratamento de infecção, é a supressão da dor.

SCALVI et al. (1995) avaliam os resultados da cirurgia de Girdlestone em casos infectados e não infectados, ressaltando que o resultado funcional é ruim. A média da avaliação de dor, segundo o Escore de Harris para Quadril, é 33,8 e $5,4 \%$ dos pacientes reclamam de dor incontrolável. O grau de insatisfação com a cirurgia é de 40,8\%. Entretanto, $62,5 \%$ dos pacientes não querem ser submetidos à colocação de nova prótese. Não houve diferença funcional ou de satisfação pessoal quando os casos infectados foram comparados aos não infectados. A cirurgia de Girdlestone continua a ser a mais segura para o tratamento de infecções.

LAl et al. (1996) abrangem o tratamento de quarenta pacientes em Taiwan, com seguimento médio de quatro anos. Os pacientes são tratados em dois tempos com colocação de pérolas de gentamicina. No segundo tempo cirúrgico são usadas próteses totais não cimentadas porosas. $O$ intervalo médio entre as cirurgias é de 48 semanas. A análise de Harris 
passa de 80 pontos em $82,0 \%$ dos pacientes. O controle infeccioso é de $87,2 \%$, comprovando a segurança da realização de artroplastia sem cimento no segundo tempo cirúrgico.

LEE et al. (1996) descrevem o uso do retalho de músculo vasto lateral em 11 quadris infectados, sendo sete após artroplastia de quadril. $O$ retalho é realizado uma semana após a limpeza cirúrgica e colocação de pérolas de cimento acrescido de antibióticos. Após seguimento médio de 28,7 meses a recorrência de infecção é de $27,3 \%$. O pedículo vascular é de dissecção fácil e permite ampla rotação, sendo que as partes remanescentes do quadríceps mantêm boa força de extensão do joelho. $O$ vasto lateral transposto restringe a migração proximal do coto ósseo femoral.

TSUKAYAMA et al. (1996) avaliam retrospectivamente 41 pacientes com infecção crônica tratada em dois tempos com pérolas de gentamicina colocadas no espaço morto e cirurgia definitiva após 110 dias. Após 4,2 anos, há controle infeccioso em $85.0 \%$ dos casos. Não há piores resultados em infecções por gram-negativos. A retirada de todo o cimento no primeiro tempo cirúrgico é essencial.

BRANDT et al. (1997) retrospectivamente analisam 33 infecções em artroplastias de quadril em 30 pacientes infectados por $S$. aureus tratados com limpeza, desbridamento e retenção dos componentes. Cinqüenta e quatro por cento dos casos apresentam recidiva infecciosa antes de um ano de cirurgia e 69,0\% em até dois anos. Próteses tratadas até dois dias após o início dos sintomas apresentam 30,0\% de recidiva infecciosa e as tratadas depois de dois dias, 82,0\%. Desbridamento e retenção dos componentes apresentam alta taxa de recidiva infecciosa em casos com $S$. aureus como agente etiológico.

PAGNANO et al. (1997) estudam a evolução de 34 casos de recidiva infecciosa em pacientes previamente tratados por infecção em 
prótese de quadril. A recidiva ocorre após a média de 2,2 anos, sendo que $79,2 \%$ infectam antes de dois anos. Vinte e um pacientes evoluem para a remoção definitiva dos implantes. Nova infecção após a tentativa de colocação de uma terceira prótese ocorre em oito de onze pacientes. A cirurgia em tempo único é executada em cinco pacientes e todos apresentam recidiva infecciosa. As seqüelas de uma recidiva de infecção após a tentativa de colocação de um novo implante são graves e devem ser consideradas, quando da decisão de se colocar a prótese em um paciente previamente infectado.

WANG et al. (1997) executam cirurgia em dois tempos, com pérolas de gentamicina, em 22 pacientes, com colocação de enxerto homólogo no segundo tempo cirúrgico. Encontram complicações em 45,0\% dos casos, com luxação recorrente em 9,0\%. A recidiva de infecção é de $9,0 \%$ após quatro anos de seguimento, comprovando a segurança do uso de enxerto ósseo, no segundo tempo cirúrgico.

CASTELLANO et al. (1998) estudam 78 pacientes tratados com retirada definitiva dos componentes e submetidos à tração cutânea por três semanas, com reabilitação progressiva. O encurtamento médio é de $4,1 \mathrm{~cm}$. Todos os pacientes andam com auxílio externo e seis não conseguem andar. Controlam $86,0 \%$ das infecções após seguimento médio de cinco anos. Não há relação entre recidiva de infecção e persistência de cimento após a retirada dos componentes, isolamento de bactérias tidas como virulentas, colocação de pérolas de gentamicina ou presença de fatores de risco clínico. A pseudartrose de Girdlestone é uma boa alternativa como cirurgia de salvação quando há perda óssea e os tecidos moles são de má qualidade.

SCHRODER et al. (1998) avaliam as possíveis vantagens ou complicações da colocação uma prótese em um paciente em Girdlestone. Em 16 pacientes é realizada uma nova prótese de quadril. $\mathrm{O}$ encurtamento médio no grupo em Girdlestone é de $4,5 \mathrm{~cm}$ e no grupo com prótese $1,5 \mathrm{~cm}$. 
O sinal de Trendelemburg estava presente em todos casos de Girdlestone e em $63,0 \%$ dos pacientes com prótese. Todos os pacientes sem prótese necessitam de apoio externo para andar. A média do Escore de Harris para Quadril, do grupo em Girdlestone, é 58 e o do grupo com prótese é 64. A recolocação de implantes em uma pseudartrose é tecnicamente difícil e os pacientes devem ser selecionados criteriosamente. Em pacientes jovens e ativos a pseudartrose não é uma solução aceitável como definitiva sendo reservada para pacientes em mau estado geral e para idosos.

URE et al. (1998) acompanham 20 pacientes com infecção em artroplastia de quadril, selecionados para tratamento em tempo único. Três pacientes apresentam fístulas ativas. Após média de 10 anos de acompanhamento, nenhum paciente apresenta recidiva infecciosa e o resultado funcional é bom. Atribuem seu sucesso a quatro fatores: (1) desbridamento meticuloso e exaustivo; (2) uso de cimento adicionado de antibióticos; (3) antibioticoterapia endovenosa e oral prolongada; (4) seleção dos pacientes. Não recomendam a realização de revisão em tempo único em pacientes com lesões extensas de pele ou de partes moles que impossibilitem o fechamento adequado, ou perdas ósseas que necessitem da colocação de enxerto.

CALLAGHAN et al. (1999) apresentam os resultados de 24 pacientes selecionados para tratamento em tempo único, com seis anos de acompanhamento. A recorrência infecciosa é de $8,3 \%$. Indicam tempo único apenas em pacientes sem comprometimento imunológico, sem fístulas, com bom estado de partes moles e adequado estoque ósseo.

LECUIRE et al. (1999) descrevem o tratamento de 57 artroplastias de quadril infectadas tratadas com tempo único ou dois tempos, sendo implantadas sempre próteses sem cimento. Doze casos apresentam fístulas ativas antes do tratamento. Dois casos evoluem com recidiva infecciosa após seis anos de acompanhamento, sendo um de cada grupo. 
Consideram que sua série é heterogênea quanto aos tipos de infecções e de tratamentos, mas que podem chegar às conclusões de que a escolha de realização de um, ou em dois tempos, deve ser baseada no aspecto intra-operatório, especialmente recomendando à realização de tempo único, apenas em pacientes sem fístula e com bom estoque ósseo.

TATTEVIN et al. (1999) analisam retrospectivamente 53 próteses de quadril e 16 de joelho infectadas visando encontrar os fatores que estão associados à recidiva de infecção. O acompanhamento médio é de 19,4 meses. A retirada definitiva da prótese leva à cura da infecção em $81,8 \%$. A limpeza, desbridamento e manutenção da prótese apresentam apenas $38,3 \%$ de bons resultados. A probabilidade de resolução da infecção com manutenção dos implantes é maior se a limpeza cirúrgica for realizada até cinco dias após o início dos sintomas infecciosos.

HANSSEN; OSMON (2000) estudam o tratamento de 37 próteses infectadas de quadril. Tentam basear sua conduta nos critérios atuais da realização de cirurgia em tempo único: paciente saudável com bons tecidos moles, perda óssea mínima e bactéria gram-positiva sensível à meticilina isolada no pré-operatório. Apenas quatro pacientes, ou $11,0 \%$ do total estudado, enquadram-se nos critérios mencionados. Por causa do aumento da incidência de bactérias gram-negativas e cocos gram-positivos resistentes à meticilina e à gravidade das perdas ósseas, a indicação de revisão em tempo único é muito limitada. Uma filosofia de reconstrução em dois tempos é mais adequada.

JACKSON; SCHMALZRIED (2000) analisam os trabalhos realizados sobre o tratamento de artroplastias infectadas de quadril em tempo único, com uso de antibióticos adicionados ao cimento. Com acompanhamento médio de 4,8 anos de 1299 casos, há controle infeccioso em 83,0\%. Os fatores associados ao sucesso do tratamento são: bom estado imunológico do paciente, bom estoque ósseo, ausência de fístulas, etilogia por cocos gram-positivos sensíveis à meticilina e bactérias sensíveis ao antibiótico 
misturado ao cimento. Etiologia por microbiota mista, bacilos gramnegativos ou cocos gram-positivos resistentes à meticilina é associada à recorrência infecciosa.

ENGLISH et al. (2002) avaliam retrospectivamente 53 casos de próteses infectadas tratadas em dois tempos em que é utilizada a técnica de enxerto picado colocado sob impacto e cimentação dos componentes como cirurgia definitiva (técnica de Exeter). Acompanham os pacientes por 53 meses, em média. A mortalidade por causas não relacionadas à cirurgia ou infecção é $13,2 \%$ (quatro pacientes). A taxa de erradicação de infecção relatada é 92,5\%, embora baixe para 90,9\% excluindo os pacientes falecidos. A revisão em dois tempos com técnica de Exeter apresenta resultados funcionais semelhantes às artroplastias primárias, justificando o uso de osso homólogo em revisões infectadas em dois tempos.

KILGUS et al. (2002) estudam 70 artroplastias infectadas de joelho (35) e quadril (35) por Staphyloccus sp. Como tratamento das próteses de quadril infectadas fazem limpeza e retenção dos implantes em cinco casos, revisão em dois tempos, em 17 casos e retirada definitiva dos componentes, em 13 casos. Todos os pacientes são tratados com vancomicina endovenosa, por seis semanas. Advogam intervalo mínimo de oito a doze semanas entre os dois tempos cirúrgicos. Controlam a infecção em $81,0 \%$ dos 16 pacientes com artroplastias de quadril infectadas por bactérias sensíveis à meticilina. Nos 19 pacientes com próteses infectadas por bactérias resistentes à meticilina há controle infeccioso em $48,0 \%$ dos casos.

As pérolas de vancomicina são usadas no período intermediário do tratamento em dois tempos de 26 artroplastias de quadril infectadas por bactérias resistentes à gentamicina por TAGGART et. al. (2002). Identificam estafilococos coagulase negativos ou Enterococcus faecalis resistentes à gentamicina em punções pré-operatórias nestes pacientes, 
com microbiota mista em nove casos. Realizam o segundo tempo após a média de nove meses. Com seguimento médio de 66,8 meses há controle infeccioso em $96,2 \%$ dos pacientes. Não encontram efeitos colaterais pelo uso de vancomicina.

CHARLTON et al. (2003) relatam as complicações associadas à colocação de implantes, em 44 casos de artroplastias infectadas de quadril, em pacientes tratados com cirurgia de Girdlestone prévia. Ocorrem complicações clínicas em $23,0 \%$ e, locais, em 33,0\% dos pacientes. Luxação recorrente é a complicação mais comum, em $11,4 \%$ dos casos. Há $97,6 \%$ de controle infeccioso com a cirurgia em dois tempos. Devido à alta incidência de luxações após o segundo tempo, passam a usar sempre acetábulos constritos. Trinta e nove por cento dos pacientes apresentam sinal de Trendelemburg positivo.

PIRIOU et al. (2003) realizam um trabalho prospectivo para avaliar o valor do controle cintilográfico, para a realização do segundo tempo, em 30 artroplastias infectadas de quadril. Cinco pacientes apresentam fístulas ativas. No acompanhamento, após o primeiro tempo cirúrgico, são realizadas cintilografias comparativas com Gálio e Tecnésio de três em três meses e sua negatividade indica a colocação de novos implantes. No único caso em que é colocada a prótese, com alteração cintilográfica, ocorre recidiva infecciosa. $\mathrm{Na}$ ausência de critérios objetivos para realização do segundo tempo, a pesquisa cintilográfica é um recurso pouco específico, porém sensível.

RUDELLI et al. (2003) realizam revisão em tempo único usando enxerto ósseo em 32 artroplastias infectadas, com perdas ósseas, de julho de 1989 a março de 2000. Nove pacientes apresentam fístulas ativas, seis apresentam fístulas fechadas e 17 têm a pele íntegra. Oito artroplastias são realizadas sem cimento, duas são híbridas e 22 são cimentadas. Usam enxerto autólogo em seis casos, homólogo em 25, e ambos em um 
caso. Com seguimento médio de 64 meses e mínimo de dois anos, encontram recidiva infecciosa de $6,2 \%$. Dos nove casos com fístula ativa, um caso apresenta recidiva, com taxa de controle infeccioso de $88,9 \%$ após acompanhamento médio de 82 meses e mínimo de 37 meses.

\subsection{ESPAÇADOR DE CIMENTO COM ANTIBIÓTICOS}

Após desbridamentos radicais com perda de estoque ósseo, é difícil acreditar que o organismo consiga substituir todo o espaço morto por tecido de granulação, sem aumentar o risco de contaminação e infecção do hematoma. As pérolas de gentamicina são usadas comumente, porém estas estão sujeitas a várias complicações como dificuldade de remoção e esfarelamento.

No tratamento de uma paciente de 29 anos de idade, com soltura séptica e grande falha acetabular, ABENDSCHEIN (1992) coloca uma massa de cimento acrílico, acrescentado de tobramicina, para preencher a perda óssea. A revisão em segundo tempo é realizada após dois meses, com artroplastia total, sem cimento. Após dois anos, a paciente não apresenta recidiva infecciosa e permanece com boa função. As funções do espaçador de cimento impregnado com antibióticos são: fonte de liberação de antibióticos locais, imobilização parcial da articulação e proteção das partes moles e do osso para a reconstrução futura.

KRAAY et al. (1992) realizam um espaçador confeccionado com esqueleto de fios de aço, revestidos por cimento, acrescentado de gentamicina, como coadjuvante no tratamento de cinco infecções, em próteses de quadril. A estabilização do fêmur proximal com o espaçador propicia mobilidade precoce, mesmo em casos com fraturas ou perdas ósseas graves, além de eluir antibióticos em locais infectados. Não há recidiva infecciosa após 15 meses da colocação do novo implante. O espaçador facilita a reconstrução definitiva no segundo tempo.

“RUDELLI, S. (Santa Casa de Misericórdia de São Paulo). Correspondência pessoal, 
DUNCAN; BEAUCHAMP (1993) de Vancouver, Canadá, relatam os primeiros quinze casos tratados com a PROSTALAC - $\underline{\text { PROSThesis of }}$

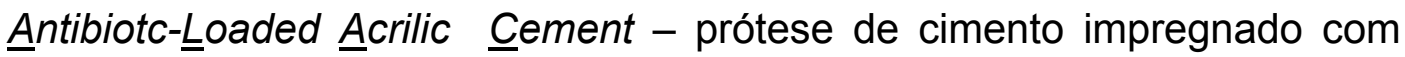
antibióticos. Este tipo de espaçador é articulado, ou seja, é montado com componentes acetabular e femoral. Usam moldes para secagem inicial e modelagem do espaçador. Três espaçadores luxam sem maiores intercorrências. Não encontram dificuldades para realizar o segundo tempo cirúrgico. Controlam a infecção em todos casos, com seguimento mínimo de dois anos.

ALEXEEFF et al. (1996) descrevem a utilização de enxerto estruturado em 11 pacientes tratados com revisão em dois estágios com uso de espaçador de cimento impregnado com antibiótico. O segundo tempo é realizado, em média, após cinco meses e meio do primeiro tempo. São usados enxertos maciços femorais em nove casos, sendo cimentados no enxerto e inseridos sem cimento nos fêmures hospedeiros. Em dois pacientes são aplicados enxertos maciços em grandes defeitos ósseos acetabulares. Todos os enxertos apresentam consolidação radiográfica. Após seguimento médio de 47,8 meses, não há recidiva de infecção. 0 uso de enxertos maciços no segundo tempo do tratamento de uma artroplastia infectada de quadril é seguro e oferece uma solução biológica para a perda óssea grave.

MØLLER et al. (1996) descrevem o uso de espaçador unipolar moldado à mão com cimento impregnado com gentamicina para o tratamento de 11 pacientes com artroplastias infectadas e perdas ósseas. O intervalo médio entre os dois tempos é de 54 dias. Executam artroplastias sem cimento no segundo tempo em todos os casos, com recidiva infecciosa em $9,1 \%$ dos casos após dois anos e dois meses da colocaçào dos implantes.

2003. 
EVANICH et al. (1997) relatam 20 casos de artroplastias de quadril infectadas tratadas com PROSTALAC. Quatro espaçadores luxam no período intermediário. O controle infeccioso, após 35 meses de seguimento, é de 95\%. O Escore de Harris para Quadril, comprovando o bom resultado funcional da técnica, passa de 55,0 para 86,0.

MIGAUD et al. (1997) descrevem a técnica de realização do espaçador de cimento adicionado a antibióticos, sem necessidade dos moldes usados na confecção da PROSTALAC, em três pacientes. Usam placas de compressão moldadas, simulando o ângulo do colo femoral. Moldam a região acetabular inicialmente, aguardando a total secagem deste componente, para realizar a parte femoral do espaçador. Observam carga parcial imediata em dois pacientes e flexão do quadril, média de $60^{\circ}$, durante $\mathrm{o}$ período intermediário. Os pacientes apresentam controle infeccioso com dois anos de seguimento.

YOUNGER et al. (1997) divulgam os resultados de 48 pacientes tratados com PROSTALAC, com seguimento médio de 43 meses. O tempo médio entre as duas cirurgias é de 91 dias. Sete pacientes apresentam culturas positivas no segundo tempo cirúrgico e são submetidos a antibioticoterapia endovenosa, por três semanas, e oral, por mais três semanas. Nenhum deles apresenta recidiva da infecção. A taxa de erradicação da infecção é de $94,0 \%$. Oitenta por cento dos pacientes apresentam Escore de Harris para Quadril maior que 80 pontos ou melhora maior ou igual a 30 pontos. Comentam que o sistema PROSTALAC apresenta vantagens sobre a cirurgia em dois tempos tradicional, pois, no período intermediário, o paciente apresenta-se mais confortável, o comprimento do membro é mantido e há facilidade técnica na realização do segundo tempo.

DONAI; BISCAGLIA (1998) analisam retrospectivamente 35 pacientes com endopróteses de fêmur ou tíbia infectadas. Tratam o espaço morto com pérolas de gentamicina ( 25 casos) ou com espaçadores 
de cimento impregnado com vancomicina (sete casos), cefamandole (dois casos) ou gentamicina (um caso). Alcançam controle infeccioso em 76,0\% dos casos tratados com pérolas de gentamicina e em $90,0 \%$ dos casos tratados com espaçadores, após acompanhamento médio de 96 e 40 meses, respectivamente.

LEUNIG et al. (1998) tratam 12 próteses infectadas de quadril usando espaçador de cimento, impregnado com gentamicina, em bloco único, como uma prótese unipolar. Apesar de cinco espaçadores luxarem e dois fraturarem, não há recidiva infecciosa após dois anos e nove pacientes estão com próteses definitivas com boa função. A colocação do cimento em volta de um material de síntese é indicada para aumentar a resistência a fraturas. O tamanho da cabeça femoral e o ângulo do colo do espaçador devem lembrar a prótese antiga ou o quadril oposto.

HADDAD et al. (2000) tratam consecutivamente 50 pacientes com próteses de quadril infectadas, sendo que 20 apresentam fístulas ativas. Operam em dois tempos, com colocação de pérolas de cimento com antibiótico em canal femoral, e uma bola de cimento na cavidade acetabular. Realizam o segundo tempo com implantes não cimentados, geralmente após três semanas, exceto em casos com perda óssea grave, quando aguardam um ano. Enxerto ósseo homólogo é usado em 18 casos. Após o acompanhamento de 5,8 anos ocorre recidiva infecciosa em 8,0\% dos casos.

Três antibióticos são acrescentados ao cimento de um espaçador unipolar por KOO et al. (2001). São acrescentadas vancomicina para cobertura de bactérias gram-positivas e gentamicina e cefotaxima para atingir bactérias gram-negativas são adicionados, na proporção de $6,0 \mathrm{~g}$ de pó de antibióticos para 40,0g de cimento ortopédico. Realizam o segundo tempo sempre sem cimento, após seis a 12 semanas do primeiro tempo. Após 41 meses de seguimento, controlam a infecção em 95,0\% de 21 casos. Encontram como complicações: formação de hematoma transitória 
em seis pacientes após o primeiro tempo, efeitos colaterais de antibióticos em quatro casos e paralisia do nervo ciático em dois casos. Com o largo espectro dos antibióticos acrescentados ao cimento ficam cobertos especialmente os pacientes com culturas negativas colhidas no primeiro tempo, melhorando a segurança do método.

MAGNAN et al. (2001) tratam 10 pacientes com prótese infectada de quadril com um espaçador em bloco único, imitando uma prótese de Thompson. Indicam a colocação de vancomicina no cimento do espaçador pela alta incidência de estafilococos resistentes à meticilina em artroplastias infectadas. Um espaçador luxa porque sua porção proximal é pequena com relação ao acetábulo. Após acompanhamento médio de três anos, dois casos $(20,0 \%)$ apresentam recidiva infecciosa.

BARRACK (2002) descreve como realizar um espaçador do tipo unipolar, recobrindo pinos de Rush com cimento impregnado com 3,6g de tobramicina e 1,0g de vancomicina. O segundo tempo é executado entre seis a doze semanas, após o primeiro tempo. Doze casos são acompanhados por dois a cinco anos, sem recidiva infecciosa, sem luxações e com bons resultados funcionais.

HANSSEN; OSMON (2002) avaliam um sistema de graduação para 26 artroplastias infectadas de quadril com fístulas ativas. Após a realização do primeiro tempo cirúrgico, executam espaçador em 20 casos, colocando os implantes definitivos, após a média de 159 dias. Há recorrência infecciosa em $20,0 \%$ destes casos, sendo que todos recebem enxerto femoral maciço no segundo tempo. Seis quadris são deixados em Girdlestone no primeiro tempo, sem recidiva infecciosa. Não conseguem concluir se o sistema de graduação apresentado é válido, requerendo maior casuística.

WENTWORTH et al. (2002) realizam a atualização dos resultados do tratamento do grupo de Vancouver (DUNCAN; BEAUCHAMP, 1993) em 
135 pacientes, com sucesso em $82,8 \%$ dos casos. Definem como sucesso a obtenção de culturas negativas no segundo tempo cirúrgico e a ausência de recidiva infecciosa clínica. Observam oito fraturas femorais intraoperatórias. Seis espaçadores luxam no período intermediário. A taxa de luxação, após o segundo tempo, é de 3,7\%. Comparam os resultados com a literatura e encontram níveis semelhantes de recidiva infecciosa.

JAHODA et al. (2003) avaliam os tratamentos realizados por 20 anos na Universidade de Charles, em Praga, República Tcheca. Analisam 62 pacientes tratados com Girdlestone definitivo, $35 \mathrm{com}$ cirurgia em dois tempos e 29 com espaçador de cimento impregnado de antibióticos. As taxas de resolução de infecção são de 91,9\%, 94,3\% e 96,5\%, respectivamente. O Escore de Harris para Quadril aumenta 9,7 pontos nos casos de Girdlestone, 20 pontos na cirurgia em dois tempos e 29 pontos no grupo tratado com espaçador. Enumeram as vantagens do uso do espaçador, como liberação local de antibióticos, estabilização do membro com reabilitação precoce, conforto do paciente, facilidade na realização do segundo tempo e menor discrepância de membros inferiores, ao final do tratamento. Não acham diferença estatisticamente significante entre as taxas de recidiva infecciosa nos tratamentos estudados. 


\section{CASUÍSTICA E MÉTODOS}




\subsection{CASUÍSTICA}

Foram estudados, prospectivamente, 61 pacientes com diagnóstico de artroplastia infectada de quadril, tratados no Instituto de Ortopedia e Traumatologia do Hospital das Clínicas da Faculdade de Medicina da Universidade de São Paulo (IOTHCFMUSP), no período de abril de 1996 a janeiro de 2003.

Os dados pré-operatórios dos pacientes estão relacionados nas listagens 1 e 2 .

\subsection{CRITÉRIOS DE INCLUSÃO}

Foram incluídos no trabalho pacientes submetidos a artroplastia de quadril com diagnóstico de infecção crônica.

Como critérios de inclusão foram necessários todos os seguintes fatores:

1. Cirurgia prévia de prótese total ou parcial de quadril;

2. Diagnóstico de infecção, baseado em identificação de bactéria em cultura de amostras coletadas na primeira cirurgia do tratamento;

3. Tempo mínimo entre a artroplastia e o quadro infeccioso de quatro semanas, definindo as infecções como tipos II e III de COVENTRY (1975) e FITZGERALD et al. (1977) ou tipos III e IV de TSUKAYAMA et al. (1996);

4. Presença de fístula externa comunicante com a prótese;

5. Perda de estoque ósseo;

6. Consentimento, por escrito, do paciente para realização dos procedimentos em estudo, declarando estar ciente do caráter experimental da pesquisa e das possíveis complicações decorrentes dos tratamentos. 


\section{LISTAGEM 1}

\section{DADOS PRÉ-OPERATÓRIOS DO GRUPO DOIS TEMPOS}

\begin{tabular}{|c|c|c|c|c|c|c|c|c|c|c|c|c|c|c|c|c|c|c|}
\hline $\mathbf{N}^{\circ}$ & Id & Sex & L & Cir. & Orig & Etio & D.As & Tipo & T.P/I & T.P/T & T.I. & HHS & Disc & Leuco & VHS & PCR & Ac. & Fem. \\
\hline 1 & 33 & $M$ & $E$ & 2 & $\mathrm{HC}$ & OUT & $\operatorname{sim}$ & CIM & 96 & 108 & 12 & 24 & 3 & 7300 & 56 & 50,5 & 1 & 2 \\
\hline 2 & 50 & $M$ & $\mathrm{E}$ & 3 & FORA & ON & não & $\mathrm{S} / \mathrm{C}$ & 72 & 80 & 8 & 11 & 2 & 800 & 54 & 38,5 & 1 & 1 \\
\hline 3 & 30 & $\mathrm{M}$ & $D$ & 2 & FORA & TR & não & HÍB & 24 & 48 & 24 & 23 & 0 & 8500 & 70 & 45,4 & 2 & 1 \\
\hline 4 & 75 & $\mathrm{M}$ & $E$ & 1 & $\mathrm{HC}$ & TR & $\operatorname{sim}$ & APQ & 18 & 24 & 6 & 10 & 2 & 7000 & 43 & & 1 & 1 \\
\hline 5 & 41 & $\mathrm{~F}$ & $D$ & 2 & FORA & OUT & não & CIM & 120 & 122 & 2 & 39 & 0 & 5000 & 68 & 75,4 & 1 & 4 \\
\hline 6 & 37 & $M$ & $E$ & 2 & FORA & TR & não & HÍB & 20 & 30 & 10 & 18 & 3 & 7700 & 58 & 31 & 1 & 2 \\
\hline 7 & 59 & $M$ & $E$ & 2 & FORA & $O A$ & não & CIM & 3 & 5 & 2 & 25 & 1 & 8400 & 85 & 54,7 & 2 & 2 \\
\hline 8 & 77 & $\mathrm{~F}$ & $E$ & 1 & FORA & TR & $\operatorname{sim}$ & CIM & 36 & 40 & 4 & 5 & 1 & 9000 & 67 & 26,5 & 2 & 1 \\
\hline 9 & 39 & $\mathrm{~F}$ & $D$ & 1 & $\mathrm{HC}$ & OUT & sim & CIM & 120 & 124 & 4 & 12 & 3 & 19800 & 63 & 38,1 & 3 & 3 \\
\hline 10 & 48 & $\mathrm{~F}$ & $E$ & 5 & $\mathrm{HC}$ & REUM & $\operatorname{sim}$ & CIM & 128 & 158 & 30 & 5 & 5 & 6500 & 58 & 34,6 & 4 & 1 \\
\hline 11 & 30 & $\mathrm{~F}$ & $E$ & 1 & FORA & TR & não & $\mathrm{S} / \mathrm{C}$ & 34 & 45 & 11 & 21 & 1 & 8700 & 87 & 37,8 & 1 & 4 \\
\hline 12 & 63 & $M$ & D & 1 & $\mathrm{HC}$ & $O A$ & sim & $\mathrm{S} / \mathrm{C}$ & 60 & 66 & 6 & 30 & 0 & 8900 & 101 & 76,7 & 0 & 2 \\
\hline 13 & 75 & $M$ & D & 1 & FORA & OA & $\operatorname{sim}$ & CIM & 150 & 158 & 8 & 12 & 2 & 4800 & 78 & & 2 & 4 \\
\hline 14 & 63 & $F$ & D & 1 & $\mathrm{HC}$ & OUT & não & CIM & 140 & 150 & 10 & 8 & 2 & 6500 & 69 & & 0 & 4 \\
\hline 15 & 72 & $\mathrm{~F}$ & $D$ & 3 & FORA & TR & não & CIM & 36 & 48 & 12 & 18 & 0 & 6400 & 65 & 54,9 & 4 & 2 \\
\hline 16 & 84 & $M$ & $D$ & 1 & FORA & OUT & $\operatorname{sim}$ & $\mathrm{S} / \mathrm{C}$ & 80 & 92 & 12 & 11 & 5 & 8000 & 56 & 48 & 3 & 4 \\
\hline 17 & 51 & $F$ & D & 3 & FORA & $O A$ & sim & CIM & 48 & 54 & 6 & 20 & 3 & 6600 & 43 & & 4 & 4 \\
\hline 18 & 45 & $M$ & $E$ & 2 & FORA & $O A$ & não & $\mathrm{S} / \mathrm{C}$ & 4 & 8 & 4 & 8 & 0 & 9800 & 78 & 56,8 & 2 & 4 \\
\hline 19 & 58 & $\mathrm{~F}$ & $E$ & 2 & $\mathrm{HC}$ & REUM & $\operatorname{sim}$ & $\mathrm{S} / \mathrm{C}$ & 70 & 76 & 6 & 19 & 2 & 10400 & 58 & 43,6 & 3 & 1 \\
\hline 20 & 72 & $\mathrm{~F}$ & $D$ & 1 & $\mathrm{HC}$ & OUT & $\operatorname{sim}$ & CIM & 60 & 64 & 4 & 20 & 2 & 8800 & 63 & 39,5 & 4 & 3 \\
\hline 21 & 57 & $M$ & $E$ & 4 & FORA & TR & não & CIM & 67 & 77 & 10 & 7 & 4 & 8300 & 45 & 45,7 & 3 & 1 \\
\hline 22 & 50 & $\mathrm{~F}$ & $E$ & 1 & $\mathrm{HC}$ & OA & sim & CIM & 74 & 74 & 0 & 15 & 5 & 7000 & 48 & 27,9 & 2 & 4 \\
\hline 23 & 55 & $M$ & $D$ & 4 & FORA & REUM & $\operatorname{sim}$ & $\mathrm{S} / \mathrm{C}$ & 48 & 54 & 6 & 20 & 0 & 13100 & 60 & 32,8 & 2 & 2 \\
\hline 24 & 72 & $\mathrm{~F}$ & $D$ & 1 & $\mathrm{HC}$ & TR & $\operatorname{sim}$ & $\mathrm{APQ}$ & 12 & 14 & 2 & 13 & 2 & 9700 & 56 & 33 & 0 & 1 \\
\hline 25 & 73 & $M$ & $E$ & 1 & $\mathrm{HC}$ & OA & não & CIM & 96 & 102 & 6 & 6 & 0 & 10200 & 55 & 21,8 & 2 & 2 \\
\hline
\end{tabular}

\section{LEGENDA}

$N^{\circ}$ - Número do caso

Id - Idade (anos)

Sex - Sexo ( $M$ - masculino; $F$ - feminino)

$\mathrm{L}$ - Lado ( $\mathrm{D}$ - direito; $\mathrm{E}$ - esquerdo)

Cir - Número de cirurgias prévias realizadas

Orig - Hospital de origem (HC - HCFMUSP; FORA - outras instituições)

Etio - Etiologia da artroplastia infectada (OA -osteoartrose; REUM - doenças reumáticas; TR - trauma;OUT outras)

D.As - Presença de doenças associadas (sim/não)

Tipo - Tipo de artroplastia realizada (CIM-cimentada; S/C-sem cimento; HíB-híbrida; APQ-prótese parcial; ENDOendoprótese, S/P- sem prótese)

T.P/I - Tempo entre a realização da artroplastia que infectou e o diagnóstico de infecção (meses)

T. P/T - Tempo entre a realização da artroplastia que infectou e o tratamento (meses)

T.I. - Tempo de duração do quadro infeccioso até o tratamento (meses)

HHS - Escore de Harris para quadril (0 a 100 pontos)

Disc - Discrepância de comprimento dos membros inferiores $(\mathrm{cm})$

Leuco - Contagem de leucócitos (leucócitos $/ \mathrm{ml}$ )

VHS - Velocidade de Hemossedimentação $(\mathrm{mm} / \mathrm{h})$

PCR - Nível de Proteína C-reativa (mg/dl)

Ac. - Perda óssea acetabular segundo Gustilo-Pasternak ( 0 a 4 )

Fem. - Perda óssea femoral segundo Gustilo-Pasternak ( 0 a 4 ) 


\section{LISTAGEM 2}

\section{DADOS PRÉ-OPERATÓRIOS DO GRUPO ESPAÇADOR}

\begin{tabular}{|c|c|c|c|c|c|c|c|c|c|c|c|c|c|c|c|c|c|c|}
\hline $\mathbf{N}^{0}$ & Id & Sex & $\mathbf{L}$ & Cir. & Orig & Etio & D.As & Tipo & T.P/I & T.P/T & T.I. & HHS & Disc & Leuco & VHS & PCR & Ac. & Fem. \\
\hline 1 & 81 & $F$ & $\mathrm{D}$ & 1 & $\mathrm{HC}$ & $\mathrm{OA}$ & sim & IM & 12 & 24 & 12 & 5 & 3 & 9600 & 54 & 51 & t & 4 \\
\hline 2 & 40 & $F$ & $\mathrm{E}$ & 1 & DRA & $\mathrm{OA}$ & $\operatorname{sim}$ & HÍB & & 27 & 24 & & 5 & 12800 & 54 & 20,9 & 1 & 4 \\
\hline 3 & 49 & M & $\mathrm{E}$ & 5 & FORA & TR & não & $\mathrm{s} / \mathrm{C}$ & 27 & 49 & 22 & 5 & 5 & 7800 & 23 & 24,4 & 1 & 2 \\
\hline 4 & 35 & $\mathrm{~F}$ & $\mathrm{D}$ & 4 & C & $\mathrm{OU}$ & não & ENDO & 20 & 26 & C & 28 & 15 & 6300 & 58 & 44,6 & 2 & 4 \\
\hline 5 & 63 & $\mathrm{~F}$ & D & 1 & $=$ ORA & $\mathrm{OA}$ & sim & CIM & 60 & 88 & 28 & 19 & 2 & 7900 & 59 & & 2 & 4 \\
\hline 6 & 47 & $\mathrm{~F}$ & $E$ & 14 & FORA & TR & não & CIM & 24 & 60 & 36 & 22 & 5 & 6000 & 68 & 26,7 & 3 & 4 \\
\hline 7 & 37 & M & $\mathrm{E}$ & 3 & FORA & REU & sim & ENDO & 36 & 60 & 24 & 14 & 7 & 8000 & 27 & 37,6 & 4 & 4 \\
\hline 8 & 34 & $F$ & $E$ & 3 & FORA & TR & não & $\mathrm{s} / \mathrm{C}$ & 20 & 26 & 6 & 23 & 3 & 5500 & 58 & 40 & 1 & 4 \\
\hline 9 & 74 & M & $\mathrm{E}$ & 1 & FORA & TR & sim & APQ & 30 & 48 & 18 & 3 & 4 & 10200 & 47 & 9,58 & 1 & 4 \\
\hline 10 & 29 & $F$ & $\mathrm{E}$ & 4 & $\mathrm{HC}$ & OU & não & HÍB & 25 & 48 & 23 & 19 & 2 & 10100 & 47 & & 1 & 1 \\
\hline 11 & 44 & $M$ & $E$ & 3 & $\mathrm{HC}$ & TR & não & HÍB & 6 & 8 & 2 & 34 & 1 & 10500 & 27 & 19,3 & 0 & 1 \\
\hline 12 & 34 & M & $\mathrm{D}$ & 4 & FORA & OU & não & IC & 18 & 144 & 126 & 51 & 1,5 & 11000 & 52 & & 2 & 3 \\
\hline 13 & 72 & M & $\mathrm{D}$ & 2 & $c$ & ON & não & CIM & 6 & 36 & 30 & 6 & 3 & 5300 & 76 & 26,8 & 2 & 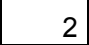 \\
\hline 14 & 79 & M & $\mathrm{D}$ & 3 & FORA & TR & sim & APQ & 24 & 36 & 12 & 7 & 5 & 7800 & 94 & & 2 & 2 \\
\hline 15 & 44 & $F$ & $\mathrm{D}$ & 2 & FORA & ON & não & $\mathrm{s} / \mathrm{C}$ & 156 & 160 & 4 & 18 & 4 & 7700 & 57 & 15,8 & 4 & 4 \\
\hline 16 & 74 & $\mathrm{~F}$ & $\mathrm{E}$ & 2 & FORA & TR & não & CIM & 45 & 56 & 11 & 19 & 0 & 8800 & 90 & 8,9 & 2 & 4 \\
\hline 17 & 62 & $F$ & $\mathrm{D}$ & 4 & FORA & $\mathrm{OA}$ & sim & $\mathrm{CIM}$ & 23 & 49 & 26 & 23 & 3 & 4300 & 50 & 48,4 & 2 & 4 \\
\hline 18 & 76 & $F$ & $\mathrm{E}$ & 4 & FORA & TR & $\operatorname{sim}$ & CIM & 3 & 12 & 9 & 4 & 8 & 3950 & 45 & 23 & 2 & 3 \\
\hline 19 & 46 & $M$ & $\mathrm{E}$ & 3 & FORA & REU & sim & $\mathrm{s} / \mathrm{C}$ & 84 & 120 & 36 & 18 & 2 & 15900 & 60 & 26 & 0 & 4 \\
\hline 20 & 70 & $M$ & $\mathrm{D}$ & 3 & FORA & TR & não & $\mathrm{s} / \mathrm{C}$ & 5 & 11 & 6 & 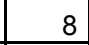 & 1 & 8800 & 60 & 45,9 & 2 & 0 \\
\hline 21 & 32 & M & $\mathrm{E}$ & 2 & $\mathrm{HC}$ & TR & não & CIM & 12 & 24 & 12 & 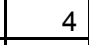 & 4 & 7300 & 68 & 59 & 2 & 4 \\
\hline 22 & 31 & $M$ & $\mathrm{D}$ & 1 & $\mathrm{HC}$ & OU & não & $S / C$ & 13 & 22 & 9 & 30 & 2 & 7600 & 15 & 29,7 & 1 & 2 \\
\hline 23 & 59 & M & $E$ & 4 & FORA & TR & não & $\mathrm{s} / \mathrm{C}$ & 18 & 96 & 78 & G & 5 & 11800 & 67 & 178 & 2 & 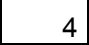 \\
\hline 24 & 80 & $M$ & $\mathrm{D}$ & 1 & FORA & TR & não & CIM & 6 & 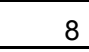 & 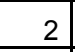 & 24 & 1 & 8400 & 68 & 54 & 1 & 1 \\
\hline 25 & 49 & $\mathrm{M}$ & $\mathrm{E}$ & 6 & FORA & OU & não & CIM & 12 & 24 & 12 & 4 & 2 & 9000 & 60 & 45 & 1 & . \\
\hline 26 & 41 & $F$ & D & 2 & $\mathrm{HC}$ & REU & sim & $\mathrm{s} / \mathrm{C}$ & 48 & 61 & 13 & 47 & 3 & 5300 & 22 & & 2 & 3 \\
\hline 27 & 72 & $F$ & $\mathrm{D}$ & 3 & FORA & $\mathrm{OA}$ & sim & CIM & 90 & 97 & 7 & 38 & 2 & 8500 & 56 & 37,8 & 3 & 4 \\
\hline 28 & 55 & $M$ & $\mathrm{E}$ & 2 & $\mathrm{HC}$ & ON & não & $\mathrm{s} / \mathrm{C}$ & 24 & 26 & I & 21 & 0 & 8600 & 43 & 32 & 1 & 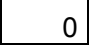 \\
\hline 29 & 50 & $F$ & $E$ & 2 & $\mathrm{HC}$ & REU & sim & $\mathrm{s} / \mathrm{C}$ & 3 & 18 & 15 & 20 & 0 & 7400 & 97 & 79,2 & 1 & 2 \\
\hline 30 & 56 & $M$ & $\mathrm{D}$ & 1 & FORA & $\mathrm{OA}$ & não & CIM & 12 & 24 & 12 & 25 & 2 & 7000 & 32 & 13 & 1 & 1 \\
\hline 31 & 16 & $M$ & D & 4 & $\mathrm{HC}$ & $\mathrm{OU}$ & não & $\mathrm{s} / \mathrm{C}$ & 6 & 18 & 12 & 45 & 1 & 8000 & 50 & 35 & 2 & $\underline{0}$ \\
\hline 32 & 54 & $M$ & $\mathrm{D}$ & 1 & $\mathrm{HC}$ & ON & sim & $\mathrm{s} / \mathrm{C}$ & 24 & 39 & 15 & 7 & 1 & 5800 & 83 & 103 & 1 & 5 \\
\hline 33 & 69 & $F$ & $\mathrm{E}$ & 2 & FORA & $O A$ & sim & HIIB & 80 & 110 & 30 & 5 & 0 & 7300 & 91 & 13,6 & 3 & 2 \\
\hline 34 & 68 & M & D & 1 & FORA & $\mathrm{OA}$ & sim & APQ & 30 & 34 & 4 & 34 & 2 & 6500 & 80 & 65,9 & 1 & 3 \\
\hline 35 & 54 & $M$ & $\mathrm{D}$ & 2 & FORA & $\mathrm{OA}$ & $\operatorname{sim}$ & $\mathrm{S} / \mathrm{P}$ & 12 & 36 & 24 & 20 & 5 & 11000 & 66 & & 2 & 3 \\
\hline 36 & 45 & $M$ & $\mathrm{E}$ & 6 & $\mathrm{HC}$ & $\mathrm{OA}$ & não & $S / P$ & 1 & 4 & 3 & 4 & 3 & 13000 & 70 & 23,6 & 2 & \\
\hline
\end{tabular}




\subsection{CRITÉRIOS PARA DIVISÃO DOS GRUPOS DE ESTUDO}

Os pacientes foram divididos em dois grupos, de acordo com o tratamento a ser realizado.

Foram escolhidos, preferencialmente, para o tratamento com espaçador, os pacientes mais graves, definidos como aqueles com:

1) Tempo de processo infeccioso maior que seis meses;

2) Mais de duas cirurgias prévias;

3) Perdas ósseas femorais graus III e IV segundo GUSTILO; PASTERNAK (1988);

4) Discrepância de comprimento de membros inferiores maior que $2,0 \mathrm{~cm}$.

Vinte e cinco pacientes foram selecionados para tratamento em dois tempos (grupo controle) e 36 pacientes foram selecionados para cirurgia em dois tempos com colocação de espaçador de cimento com antibiótico (grupo de estudo).

Para facilitar a análise dos dados, os grupos foram denominados "Dois Tempos" para o grupo controle e "Espaçador" para o grupo do tratamento em estudo.

\subsection{ESTUDO DA CASUÍSTICA}

A idade média dos pacientes foi de 54,6 anos, não havendo diferença entre os dois grupos (tabela 1 e gráfico1).

A distribuição por sexo encontra-se na tabela 2 e no gráfico 2.

A distribuição por lado acometido encontra-se na tabela 3 e no gráfico 3 .

As etiologias que levaram à atroplastia primária encontram-se na tabela 4 e no gráfico 4 . 
TABELA 1 ESTATÍSTICA DESCRITIVA DA IDADE (ano) DOS PACIENTES DE ACORDO COM O GRUPO, DOIS TEMPOS E ESPAÇADOR, E TOTAL. COMPARAÇÃO PELO TESTE U DE MANN-WHITNEY $(\alpha=0,05)$

\begin{tabular}{lccc}
\hline & \multicolumn{3}{c}{ IDADE (ano) } \\
\cline { 2 - 4 } & DOIS TEMPOS & ESPAÇADOR & TOTAL \\
\hline \hline M & 56,4 & 53,4 & 54,6 \\
DP & 16,0 & 17,0 & 16,6 \\
EPM & 3,2 & 2,8 & 2,1 \\
MAX & 84,0 & 81,0 & 84,0 \\
MIN & 30,0 & 16,0 & 16,0 \\
N & 25 & 36 & 61 \\
\hline U de Mann-Whitney & & $\mathrm{U}=400,5$ &
\end{tabular}

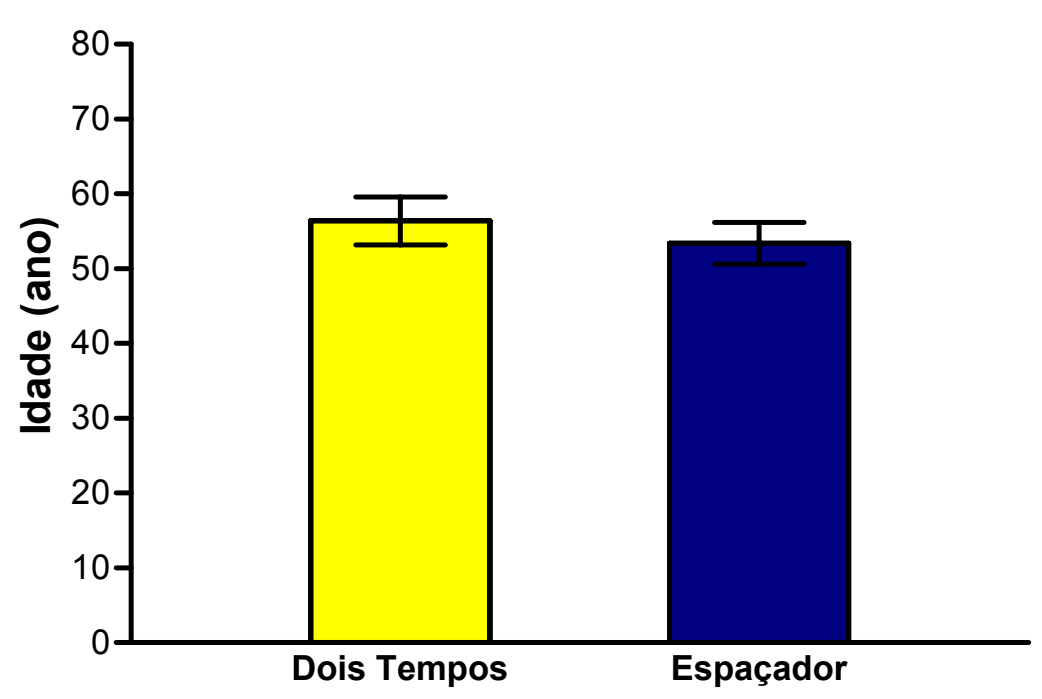

GRÁFICO 1 Idade (ano) dos pacientes 
TABELA 2 DISTRIBUIÇÃO DE FREQÜÊNCIA, ABSOLUTA (n) E RELATIVA (\%), DO SEXO DOS PACIENTES DE ACORDO COM O GRUPO, DOIS TEMPOS E ESPAÇADOR. COMPARAÇÃO PELO TESTE DE QUIQUADRADO $(\alpha=0,05)$

\begin{tabular}{|c|c|c|c|c|c|c|}
\hline \multirow{2}{*}{ SEXO } & \multicolumn{2}{|c|}{ DOIS TEMPOS } & \multicolumn{2}{|c|}{ ESPAÇADOR } & \multicolumn{2}{|c|}{ TOTAL } \\
\hline & $\mathrm{n}$ & $\%$ & $\bar{n}$ & $\%$ & $\bar{n}$ & $\%$ \\
\hline Feminino & $\overline{12}$ & 19,7 & 15 & 24,6 & 27 & 44,3 \\
\hline Masculino & 13 & 21,3 & 21 & 34,4 & 34 & 55,7 \\
\hline$\overline{\text { TOTAL }}$ & 25 & 41,0 & 36 & 59,0 & 61 & 100,0 \\
\hline
\end{tabular}

Dois Tempos

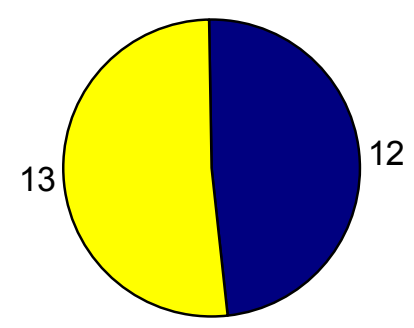

—Feminino

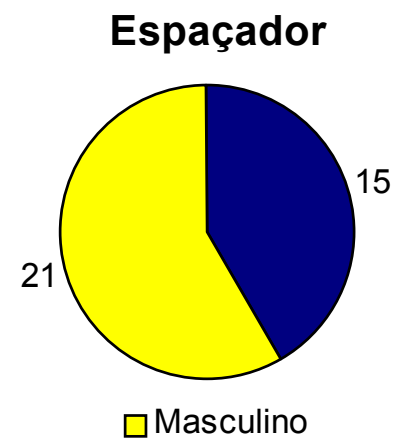

$\square$ Masculino

GRÁFICO 2 Sexo dos pacientes 
TABELA 3 DISTRIBUIÇÃO DE FREQÜÊNCIA, ABSOLUTA (n) E RELATIVA (\%), DO LADO INFECTADO DE ACORDO COM O GRUPO, DOIS TEMPOS E ESPAÇADOR. COMPARAÇÃO PELO TESTE DE QUI-QUADRADO $(\alpha=$ $0,05)$

\begin{tabular}{|c|c|c|c|c|c|c|}
\hline \multirow{2}{*}{ LADO } & \multicolumn{2}{|c|}{ DOIS TEMPOS } & \multicolumn{2}{|c|}{ ESPAÇADOR } & \multicolumn{2}{|c|}{ TOTAL } \\
\hline & $\mathrm{n}$ & $\%$ & $\mathrm{n}$ & $\%$ & $\bar{n}$ & $\%$ \\
\hline Direito & 12 & 19,7 & 18 & 29,5 & 30 & 49,2 \\
\hline Esquerdo & 13 & 21,3 & 18 & 29,5 & 31 & 50,8 \\
\hline TOTAL & 25 & 41,0 & 36 & 59,0 & 61 & 100,0 \\
\hline
\end{tabular}

Dois Tempos

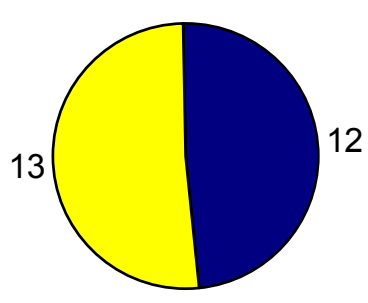

Direito
Espaçador

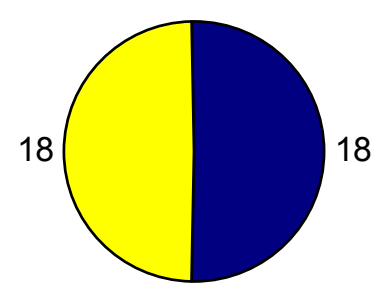

口Esquerdo

GRÁFICO 3 Lado infectado 
TABELA 4 DISTRIBUIÇÃO DE FREQÜÊNCIA, ABSOLUTA (n) E RELATIVA (\%), DA ETIOLOGIA QUE LEVOU À ARTROPLASTIA INFECTADA DE ACORDO COM O GRUPO, DOIS TEMPOS E ESPAÇADOR

\begin{tabular}{|c|c|c|c|c|c|c|}
\hline \multirow{2}{*}{$\begin{array}{l}\text { ETIOLOGIA } \\
\text { PRIMÁRIA }\end{array}$} & \multicolumn{2}{|c|}{ DOIS TEMPOS } & \multicolumn{2}{|c|}{ ESPAÇADOR } & \multicolumn{2}{|c|}{ TOTAL } \\
\hline & $\mathrm{n}$ & $\%$ & $\mathrm{n}$ & $\%$ & $\mathrm{n}$ & $\%$ \\
\hline Trauma & 8 & 13,1 & 12 & 19,7 & 20 & 32,8 \\
\hline Osteoartrose & 7 & 11,5 & 10 & 16,4 & 17 & 27,9 \\
\hline Reumática & 3 & 4,9 & 4 & 6,6 & 7 & 11,5 \\
\hline Osteonecrose & 1 & 1,6 & 4 & 6,6 & 5 & 8,2 \\
\hline Outra & 6 & 9,8 & 6 & 9,8 & 12 & 19,7 \\
\hline TOTAL & 25 & 41,0 & 36 & 59,0 & 61 & 100,0 \\
\hline
\end{tabular}

Dois Tempos

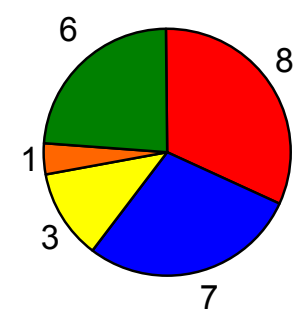

$\square$ Trauma
Osteoartrose

$\square$ Reumática

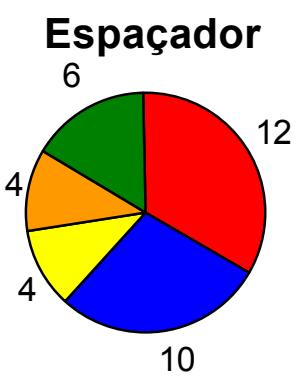

$\square$ Osteonecrose

GRÁFICO 4 Etiologia que levou à artroplastia infectada 
Os tipos de artroplastias infectadas (cimentada, sem cimento ou híbrida) encontram-se na tabela 5 e no gráfico 5.

O intervalo de tempo entre a realização da prótese infectada e o diagnóstico de infecção está representado na tabela 6 e no gráfico 6.

A duração do quadro infeccioso (tempo entre o diagnóstico de infecção e o tratamento) encontra-se na tabela 7 e no gráfico 7 .

A maioria dos casos dos dois grupos $(60,6 \%)$ era proveniente de outros serviços (anexo A, tabela 1 e gráfico 1).

Os pacientes do grupo Dois Tempos haviam sido submetidos a 1,9 cirurgias, em média, e os do grupo Espaçador, a três cirurgias,em média, antes do tratamento (anexo $\mathrm{A}$, tabela 2 e gráfico 2).

Treze pacientes $(52,0 \%)$ do grupo Dois Tempos e 25 pacientes $(69,4 \%)$ do grupo controle haviam sido submetidos a 61 tentativas de tratamento da infecção (anexo A, tabelas e gráficos 3 e 4).

A incidência de doenças associadas e sua freqüência encontram-se nas tabelas e gráficos 5 e 6 do anexo $A$.

A avaliação funcional pré-operatória dos pacientes foi realizada segundo o Escore de Harris para Quadril(HARRIS, 1969),representado no apêndice A.

A avaliação funcional pré-operatória média não apresentou diferença entre os grupos (anexo A, tabela 7 e gráfico 7).

A discrepância de comprimento dos membros inferiores pré-operatória está na tabela 8 e no gráfico 8 .

Avaliamos as perdas ósseas seguindo a classificação de GUSTILO; PASTERNAK (1988), difundida em nosso meio por BERNABÉ (1996). A descrição da classificação encontra-se no apêndice B e o grau de perda óssea após a retirada dos componentes estão nas tabelas e gráficos 9 e 10.

As bactérias isoladas no primeiro tempo cirúrgico podem ser vistas na tabela 11 e no gráfico 11.

A contagem de leucócitos, a velocidade de hemossedimentação e a dosagem de proteína C-reativa são apresentadas nas tabelas e gráficos 8 a 11 do anexo $\mathrm{A}$. 
TABELA 5

DISTRIBUIÇÃO DE FREQÜÊNCIA, ABSOLUTA (n) E RELATIVA (\%), DA PRÓTESE RETIRADA NO PRIMEIRO TEMPO CIRÚRGICO DE ACORDO COM O GRUPO, DOIS TEMPOS E ESPAÇADOR PRÓTESE RETIRADA NO PRIMEIRO TEMPO CIRÚRGICO

\begin{tabular}{|c|c|c|}
\hline $\begin{array}{c}\text { DOIS } \\
\text { TEMPOS }\end{array}$ & ESPAÇADOR & TOTAL \\
\hline$\%$ & $\%$ & 7 \\
\hline
\end{tabular}

\begin{tabular}{lcccccc}
\hline \hline Total Cimentada & 14 & 23,0 & 12 & 19,7 & 26 & 42,6 \\
Total sem Cimento & 7 & 11,5 & 13 & 21,3 & 20 & 32,8 \\
Total Híbrida & 2 & 3,3 & 4 & 6,6 & 6 & 9,8 \\
Parcial Cimentada & 2 & 3,3 & 3 & 4,9 & 5 & 8,2 \\
Endoprótese Cimentada & 0 & 0,0 & 2 & 3,3 & 2 & 3,3 \\
Sem Prótese & 0 & 0,0 & 2 & 3,3 & 2 & 3,3 \\
\hline TOTAL & $\mathbf{2 5}$ & $\mathbf{4 1 , 0}$ & $\mathbf{3 6}$ & $\mathbf{5 9 , 0}$ & $\mathbf{6 1}$ & $\mathbf{1 0 0 , 0}$ \\
\hline
\end{tabular}

\section{Dois Tempos}

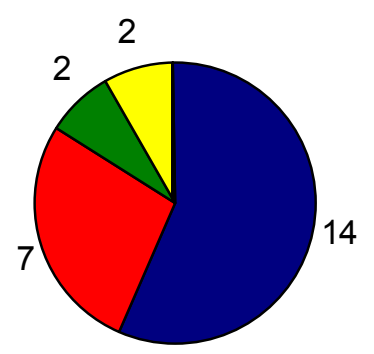

Total Cimentada

Total Híbrida
Total sem Cimento $\square$ Parcial Cimentada

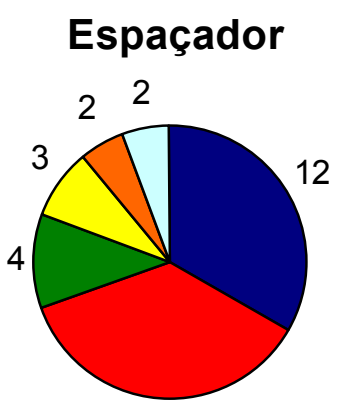

13

$\square$ Endoprótese Cimentada $\square$ Sem Prótese

GRÁFICO 5 Prótese retirada no primeiro tempo cirúrgico 
TABELA 6

ESTATISTICA DESCRITIVA DO TEMPO (mês) DECORRIDO ENTRE A REALIZACÃO DA ARTROPLASTIA INFECTADA E O DIAGNÓSTICO DE INFECÇÃO DE ACORDO COM O GRUPO, DOIS TEMPOS E ESPAÇADOR. COMPARAÇÃO PELO TESTE U DE MANN WHITNEY $(\alpha=0,05)$

PERÍODO ENTRE REALIZAÇÃO DA ARTROPLASTIA E DIAGNÓSTICO DE INFECÇÃO (mês)

\begin{tabular}{lcc}
\cline { 2 - 3 } & DOIS TEMPOS & ESPAÇADOR \\
\hline \hline M & 64,6 & 28,3 \\
DP & 43,2 & 31,6 \\
EPM & 8,6 & 5,2 \\
MAX & 150 & 156 \\
MIN & 3 & 1 \\
N & 25 & 36 \\
\hline Ude Mann Whitney & $U=211,5$ & $p \cong 0,00^{*}$
\end{tabular}

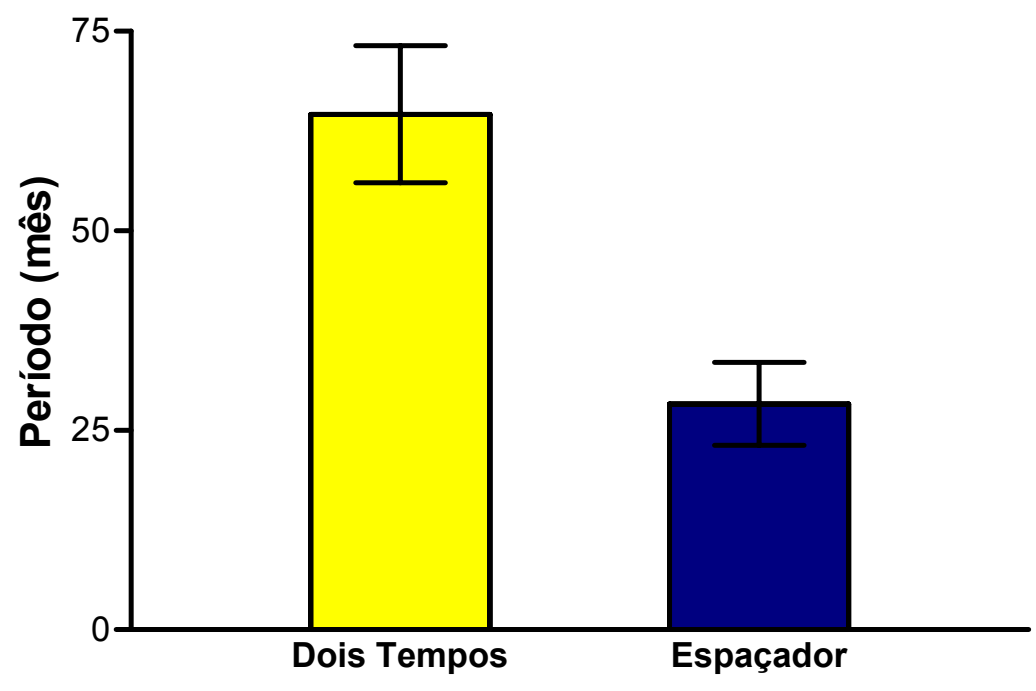

GRÁFICO 6 Período de tempo (mês) decorrido entre a realização da artroplastia que infectou e o diagnóstico de infecção 
TABELA 7

ESTATÍSTICA DESCRITIVA DO TEMPO (mês) DECORRIDO ENTRE O DIAGNÓSTICO E O TRATAMENTO DA INFECÇÃO (PRIMEIRO TEMPO CIRÚRGICO) DE ACORDO COM O GRUPO, DOIS TEMPOS E ESPAÇADOR. COMPARAÇÃO PELO TESTE U DE MANN WHITNEY $(\alpha=0,05)$

PERÍODO ENTRE DIAGNÓSTICO E TRATAMENTO (mês)

\begin{tabular}{lcc}
\cline { 2 - 3 } & DOIS TEMPOS & ESPAÇADOR \\
\hline \hline M & 8,2 & 19,8 \\
DP & 6,7 & 23,2 \\
EPM & 1,3 & 3,9 \\
MAX & 30 & 126 \\
MIN & 0 & 2 \\
$N$ & 25 & 36 \\
\hline U de Mann Whitney & $U=243,5$ & $p=0,002^{*}$
\end{tabular}

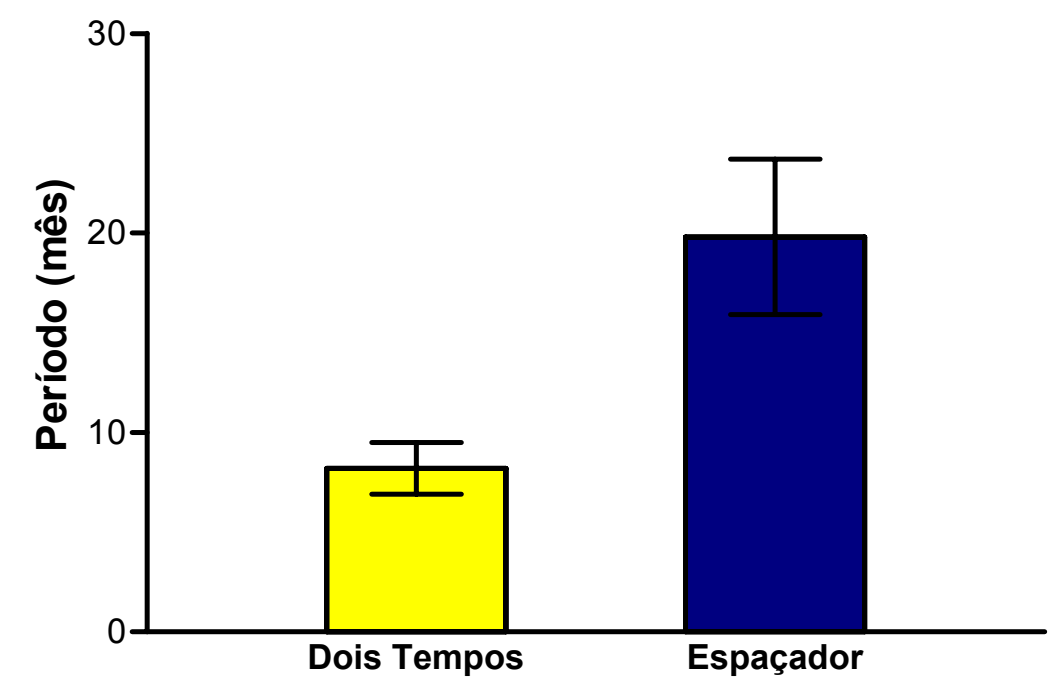

GRÁFICO 7 Período de tempo (mês) decorrido entre o diagnóstico e o tratamento (primeiro tempo cirúrgico) 
TABELA 8

ESTATÍSTICA DESCRITIVA DA DISCREPÂNCIA DO COMPRIMENTO $(\mathrm{cm})$ DOS MEMBROS INFERIORES ANTES DO PRIMEIRO TEMPO CIRÚRGICO DE ACORDO COM O GRUPO, DOIS TEMPOS E ESPAÇADOR. COMPARAÇÃO PELO TESTE U DE MANN WHITNEY $(\alpha=0,05)$

DISCREPÂNCIA ENTRE OS MEMBROS INFERIORES

ANTES DO PRIMEIRO TEMPO CIRÚRGICO $(\mathrm{cm})$

\begin{tabular}{lcc}
\cline { 2 - 3 } & DOIS TEMPOS & ESPAÇADOR \\
\hline \hline M & 1,9 & 3,1 \\
DP & 1,7 & 2,8 \\
EPM & 0,3 & 0,5 \\
MAX & 5 & 15 \\
MIN & 0 & 0 \\
N & 25 & 36 \\
\hline Ude Mann Whitney & $U=331,0$ & $p=0,08$
\end{tabular}

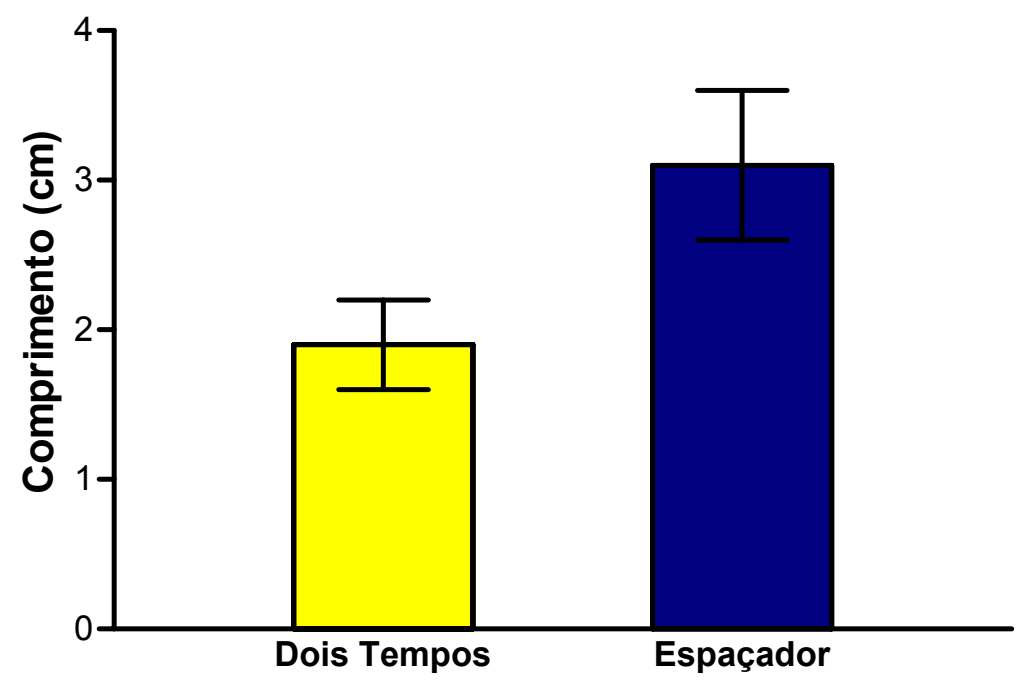

GRÁFICO 8 Discrepância do comprimento $(\mathrm{cm})$ dos membros inferiores antes do primeiro tempo cirúrgico 
TABELA 9 DISTRIBUIÇÃO DE FREQÜÊNCIA, ABSOLUTA (n) E RELATIVA (\%), DO GRAU DE PERDA ÓSSEA ACETABULAR AVALIADA DURANTE O ATO CIRÚRGICO SEGUNDO A CLASSIFICAÇÃO DE GUSTILO-PASTERNAK DE ACORDO COM O GRUPO, DOIS TEMPOS E ESPAÇADOR. COMPARAÇÃO PELO TESTE DE QUI-QUADRADO $(\alpha=0,05)$

PERDA ÓSSEA ACETABULAR

(GUSTILO-PASTERNAK)

Dois Tempos

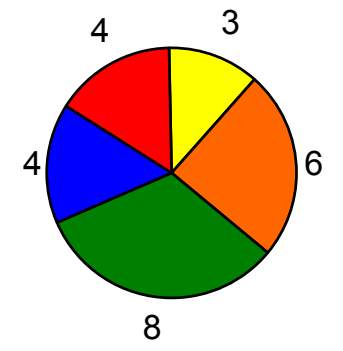

$\square 0 \quad \square 1 \quad \square 2$

\section{Espaçador}

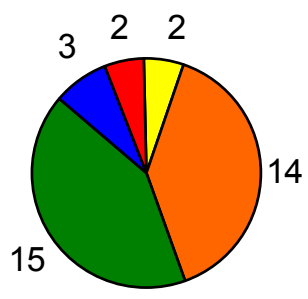

$\square^{3} \square 4$

GRÁFICO 9 Grau de perda óssea acetabular avaliada no ato cirúrgico segundo a classificação de Gustilo-Pasternak 
TABELA 10

DISTRIBUIÇÃO DE FREQÜÊNCIA, ABSOLUTA (n) E RELATIVA (\%), DO GRAU DE PERDA ÓSSEA FEMORAL AVALIADA DURANTE O ATO CIRÚRGICO SEGUNDO A CLASSIFICAÇÃO DE GUSTILOPASTERNAK DE ACORDO COM O GRUPO, DOIS TEMPOS E ESPAÇADOR. COMPARAÇÃO PELO TESTE DE QUI-QUADRADO $(\alpha=0,05)$

PERDA ÓSSEA FEMORAL

(GUSTILO-PASTERNAK)

CLASSE

\begin{tabular}{|c|c|c|}
\hline DOIS TEMPOS & ESPAÇADOR & TOTAL \\
\hline
\end{tabular}

\begin{tabular}{lcccccc}
\hline \hline 0 & 0 & 0,0 & 3 & 4,9 & 3 & 4,9 \\
1 & 8 & 13,1 & 4 & 6,6 & 12 & 19,7 \\
2 & 7 & 11,5 & 7 & 11,5 & 14 & 23,0 \\
3 & 2 & 3,3 & 5 & 8,2 & 7 & 11,5 \\
4 & 8 & 13,1 & 17 & 27,9 & 25 & 41,0 \\
\hline TOTAL & $\mathbf{2 5}$ & $\mathbf{4 1 , 0}$ & $\mathbf{3 6}$ & $\mathbf{5 9 , 0}$ & $\mathbf{6 1}$ & $\mathbf{1 0 0 , 0}$ \\
\hline
\end{tabular}

Qui-quadrado $(0,1$ e 2$) \leftrightarrow(3$ e 4$) \quad \chi^{2}=2,64$

$p=0,10$

\section{Dois Tempos}

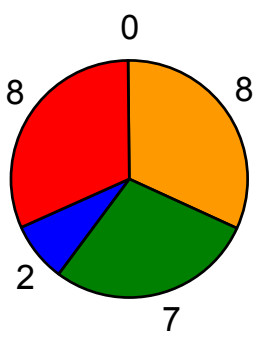

$\square 0$

$\square 1$

$\square^{2}$

घ3

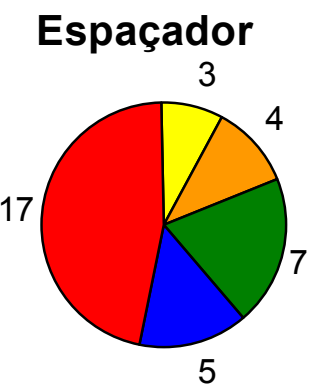

$\square 4$

GRÁFICO10 Grau de perda óssea femoral avaliada no ato cirúrgico segundo a classificação de Gustilo-Pasternak 
TABELA 11

DISTRIBUIÇÃO DE FREQÜÊNCIA, ABSOLUTA (n) E RELATIVA (\%), DAS BACTÉRIAS ISOLADAS NO PRIMEIRO TEMPO CIRÚRGICO

BACTÉRIAS ISOLADAS NO

PRIMEIRO TEMPO

CIRÚRGICO

$\mathrm{n}$
$\%$

\begin{tabular}{|c|c|c|}
\hline \multicolumn{3}{|c|}{ BACTÉRIAS GRAM-POSITIVAS } \\
\hline Staphylococcus aureus & 23 & 31,5 \\
\hline $\begin{array}{l}\text { Staphylococcus epidermidis, Staphylococcus cohnii e } \\
\text { Staphylococcus sp. coagulase negativo }\end{array}$ & 10 & 13,7 \\
\hline Enterococcus faecalis & 10 & 13,7 \\
\hline Streptococcus viridans & 3 & 4,1 \\
\hline Streptococcus agalactiae & 2 & 2,7 \\
\hline Corinebacterium sp. & 1 & 1,4 \\
\hline Streptococcus mitis & 1 & 1,4 \\
\hline TOTAL DE BACTÉRIAS GRAM POSITIVAS & 50 & 68,5 \\
\hline \multicolumn{3}{|c|}{ BACTÉRIAS GRAM-NEGATIVAS } \\
\hline Escherichia coli & 4 & 5,5 \\
\hline Enterobacter cloacae & 4 & 5,5 \\
\hline Proteus mirabilis & 3 & 4,1 \\
\hline Serratia marcenses & 3 & 4,1 \\
\hline Klebsiella sp. & 3 & 4,1 \\
\hline Acinetobacter baumannii & 1 & 1,4 \\
\hline Aeromonas hydrophilia & 1 & 1,4 \\
\hline Citrobacter diversus & 1 & 1,4 \\
\hline Pseudomonas aeruginosa & 1 & 1,4 \\
\hline Providencia sp. & 1 & 1,4 \\
\hline Stenotrophomonas maltophilia & 1 & 1,4 \\
\hline TOTAL DE BACTÉRIAS GRAM NEGATIVAS & 23 & 31,5 \\
\hline TOTAL & 73 & 100,0 \\
\hline
\end{tabular}




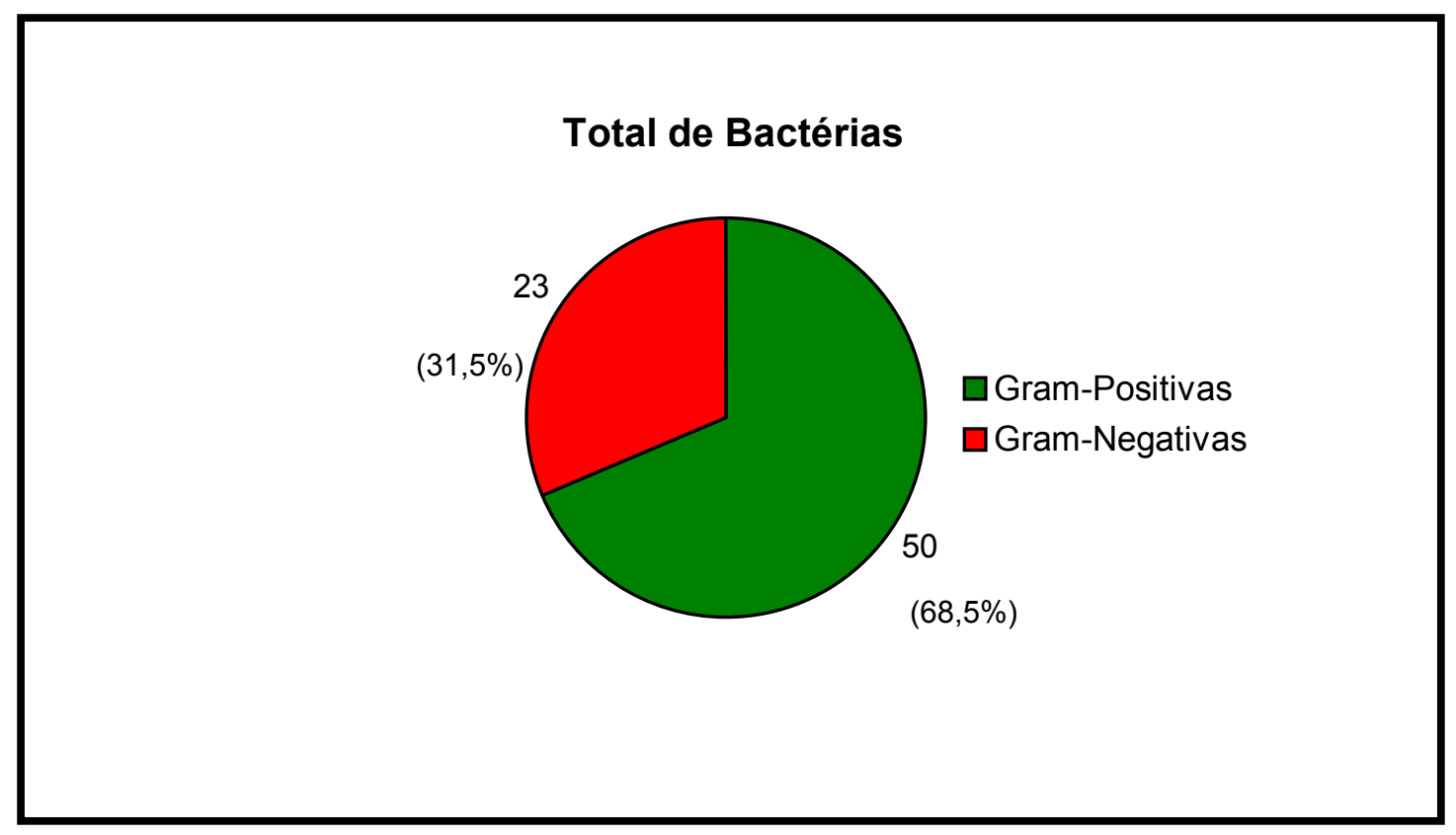

GRÁFIC011 Bactérias isoladas (total) no primeiro tempo cirúrgico 


\subsection{TÉCNICAS OPERATÓRIAS E ACOMPANHAMENTO}

\subsubsection{Primeiro tempo cirúrgico}

Durante a indução anestésica é realizada antibioticoterapia endovenosa empírica conforme orientação da Subcomissão de Controle de Infecção Hospitalar do IOTHCFMUSP. Atualmente, são utilizadas a vancomicina na dosagem de $1,0 \mathrm{~g}$ e a ceftazidima na dosagem de 2,0g.

A sondagem vesical de demora é realizada como rotina, devido à duração prolongada da cirurgia, para o controle volêmico peri-operatório.

O paciente é posicionado em decúbito lateral e fixado à mesa operatória.

A anti-sepsia é realizada com solução de gluconato de clorexidina degermante a $4,0 \%$ e solução alcoólica a $0,5 \%$, novamente seguindo orientação da SCIH-IOTHCFMUSP.

A colocação de campos cirúrgicos estéreis obedece às normas gerais de isolamento do local.

Montamos duas mesas cirúrgicas, utilizadas em diferentes passos da cirurgia:

Mesa 1: Instrumental para retirada da fístula e seu trajeto, via de acesso, desbridamento, retirada dos componentes e limpeza mecânica.

Mesa 2: Permanece coberta durante a retirada do material contaminado. Composta de material para fechamento, material para confecção de espaçador de cimento - se for o caso - e dreno de sucção.

Os acessos cirúrgicos variam de acordo com o planejamento préoperatório e condições intra-operatórias, geralmente incluindo o trajeto da fístula em sua extensão. 
As vias de acesso mais utilizadas são a via lateral direta (HARDINGE, 1982), a via de Gibson modificada pelo Prof. Dr. Flávio Pires de Camargo (SCHWARTSMANN, 1984), a osteotomia do trocanter maior (CHANRLEY, 1979) e a osteotomia estendida do trocanter maior (CALLAGHAN apud STEINBERG, 1999).

Evitamos dissecar, inicialmente, o plano entre a fáscia lata e a musculatura profunda para evitar contaminação do mesmo.

A ressecção da fístula é orientada por injeção de $10,0 \mathrm{ml}$ de azul de metileno com sonda naso-gástrica estéril (figura 1), sendo realizado fechamento do orifício de saída com auxílio de pinça Allis, para evitar contaminação do campo cirúrgico. Dissecamos o trajeto da fístula até a região óssea, ressecando uma margem de segurança de $1,0 \mathrm{~cm}$.

Amostras para culturas são coletadas em cada plano de dissecção, sendo devidamente identificadas e enviadas prontamente para análise laboratorial.

São colhidos de seis a 10 pares de culturas. Os materiais mais adequados para isolar os agentes etiológicos são, de acordo com GRISTINA;KOLKIN (1983) e COLYER; CAPELLO (1994):

a) fragmentos ósseos desvitalizados;

b) tecido de granulação profundo;

c) fragmentos de cimento acrílico;

d) pedaços de fios metálicos, parafusos ou outros implantes metálicos;

e) tecido de granulação intramedular e acetabular;

f) cápsula articular.

São retirados os componentes das próteses, inclusive todo cimento acrílico identificável, com eventual realização de janelas ósseas ou osteotomias estendidas.

É essencial que todo material estranho seja retirado, sendo indicadas radiografias intra-operatórias para a localização de fragmentos de cimento acrílico ou de corpos metálicos. 

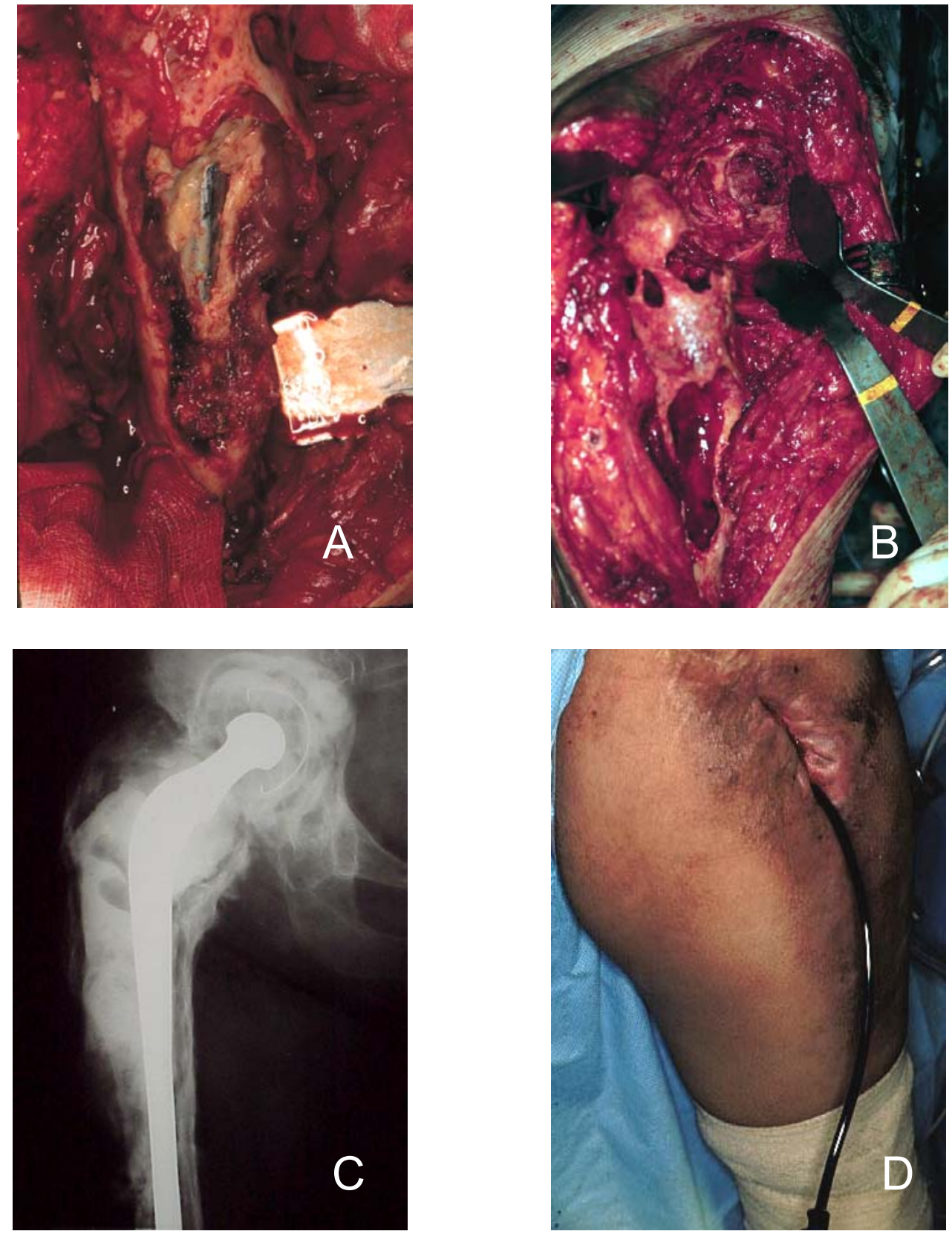

FIGURA 1 Aspectos do primeiro tempo cirúrgico. A - Radiografia demonstrando soltura séptica de ambos componentes. B Injeção de azul de metilieno, através de sonda naso-gástrica, para marcação do trajeto da fístula. C - Falha óssea femoral grau IV, expondo o cimento acrílico e a haste femoral. D Aspecto das falhas ósseas, após a retirada dos componentes. 
As partes moles inviáveis e material ósseo desvascularizado são retirados.

São anotadas as falhas ósseas e realizada a classificação conforme GUSTILO; PASTERNAK (1988).

$\mathrm{Na}$ dúvida de contaminação do canal femoral, deve-se realizar janela na região lateral da metáfise distal femoral para adequada irrigação do compartimento.

A lavagem com soro fisiológico a $0,9 \%$ é copiosa e realizada durante todo o ato cirúrgico, usando-se 10,0 a 15,0l, habitualmente.

A ferida cirúrgica deve ficar de tal maneira que, se um cirurgião entrar na sala cirúrgica no final do desbridamento, este deverá achar que está sendo realizada uma revisão asséptica e que nos encontramos prestes a colocar os componentes.

Neste ponto, são retirados os campos cirúrgicos contaminados e a equipe cirúrgica escova-se novamente, colocando novos paramentos.

A ferida cirúrgica é protegida por compressas estéreis colocadas por um membro da equipe que já tenha trocado os paramentos. É realizada nova anti-sepsia da pele e campos estéreis são colocados para a realização do fechamento (grupo controle) ou do espaçador (grupo de estudo).

Ao optar-se pela cirurgia em dois tempos é realizada a dissecção do plano entre a fáscia lata e a musculatura profunda, para facilitar o fechamento. Coloca-se dreno de sucção com duas vias profundas, de calibre 3,2 mm. O fechamento é realizado com fio não absorvível unifilar em todos os planos, geralmente náilon dois ou três zeros.

Após a realização do curativo, o paciente é colocado em decúbito dorsal e é instalada tração esquelética na tíbia proximal, que é mantida ao nível do leito. 
O espaçador é semelhante a uma prótese unipolar tipo Thompson (Figura 2), sendo confeccionado em dois estágios, acetabular e femoral, conforme MIGAUD et al. (1997) e BARRACK (2002).

É usado como esqueleto um componente femoral retirado de alguma revisão e esterilizado ou, idealmente, uma haste femoral tipo Küntscher dobrada, de acordo com o ângulo original entre o colo e diáfise do fêmur do paciente.

É checada a possibilidade de restabelecimento do comprimento do membro inferior, realizando teste com o material a ser usado como esqueleto.

Utilizamos $1,0 \mathrm{~g}$ de cloridrato de vancomicina em pó ${ }^{*}$ por pacote de $40,0 \mathrm{~g}$ de cimento acrílico ${ }^{*}$, conforme preconizado por PENNER et al. (1996) e MASRI et al. (1998).

Tipicamente, são utilizados dois pacotes de cimento para a confecção da porção acetabular e dois a quatro pacotes, para a parte femoral. Duas unidade do pó e do líquido do polimetilmetacrilato são misturadas, inicialmente, com 2,0ml de azul de metileno - solução injetável a $1 \%$ - para identificação do cimento acrílico, no segundo tempo.

Quando o cimento atinge o início da fase de endurecimento, é adicionado o antibiótico.

O componente acetabular é moldado, usando uma luva cirúrgica em volta da bola de cimento para adequada moldagem do espaçador, evitando contato entre o cimento acrílico e o osso. A estrutura, que é usada como esqueleto, é inserida no meio do cimento quase ao final do tempo de cura (figuras 3-A e 3-B).

\footnotetext{
"Vancocina CP®, Eli Lilly, São Paulo, São Paulo, Brasil.

** Simplex $P \circledast$, Striker Howmedica Osteonics, Rutherford, New Jersey, Estados Unidos da América.
} 

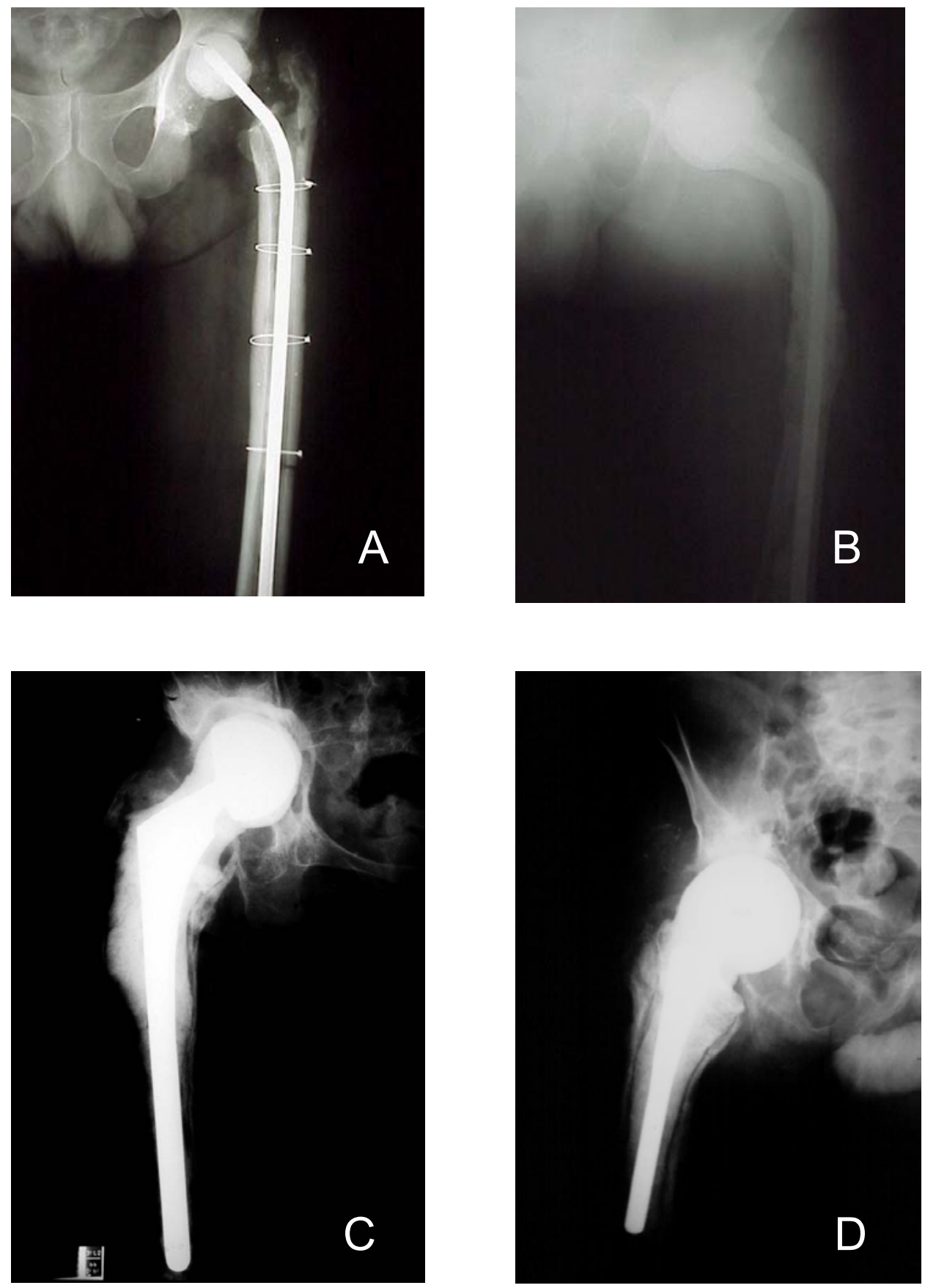

FIGURA 2 Diferentes tipos de espaçadores. Notar a forma globosa proximal, que visa o deslizamento suave com o osso acetabular e o preenchimento do canal femoral, sem fixação óssea. A e B - Espaçadores em que foram usadas hastes de Küntscher envergadas, conforme o ângulo entre a diáfise e o colo femorais, para estabilizar o implante. $C$ e D Espaçadores confeccionados com o cimento recobrindo próteses de quadril esterilizadas 

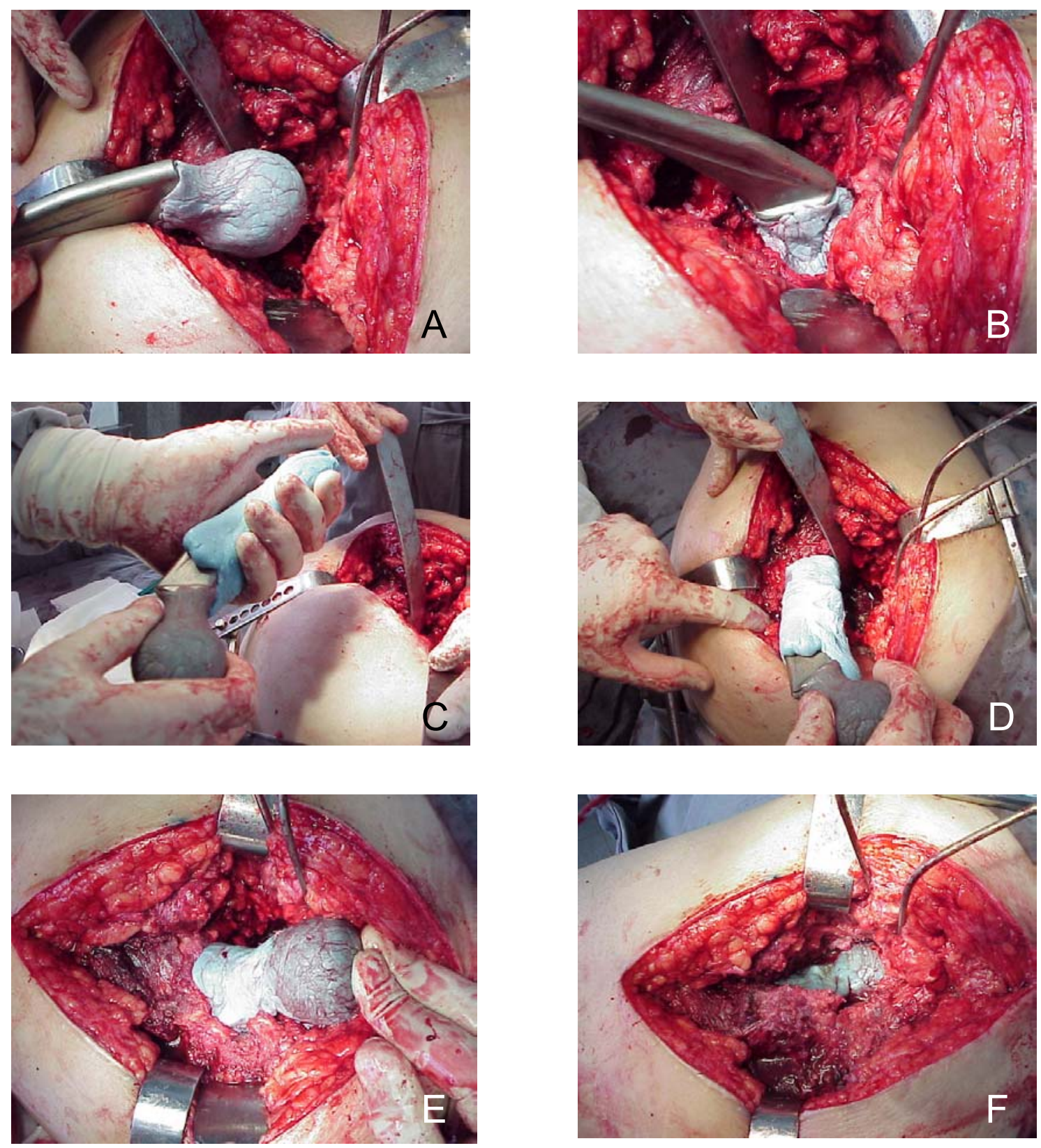

FIGURA 3 Confecção do espaçador. A - Realização do segmento proximal do espaçador, com o cimento misturado à vancomicina e ao azul de metileno recobrindo o esqueleto metálico, no caso, uma haste tipo Müller. B - Moldagem da região proximal no acetábulo, até a secagem total do cimento. C - Confecção da região distal do espaçador, com aplicação do cimento à haste femoral. D Moldagem da região femoral, com movimentos de vaivém para evitar a fixação do espaçador no canal femoral. E - Secagem final do cimento. Nota-se as diferentes tonalidades de azul, nos dois segmentos de cimento que compões o espaçador F - Redução do espaçador na cavidade acetabular. 
Após a secagem total da parte acetabular, novamente é checado o comprimento do membro inferior e marcada a profundidade em que deve ficar o espaçador.

A parte femoral é realizada com a colocação do cimento impregnado com antibiótico, em estágio de início de endurecimento, em volta de toda a superfície metálica (figura 3-C).

A porção femoral é introduzida no canal femoral com movimentos de vaivém, evitando a fixação do componente no osso hospedeiro, para facilitar sua remoção no segundo tempo cirúrgico (figura 3-D).

Ao final do processo de secagem, o espaçador deve estar estável no canal femoral, com pequeno grau de movimento em relação ao fêmur (figura $3-\mathrm{E})$.

O espaçador é reduzido para o acetábulo e são checadas a estabilidade e a amplitude de movimentos (figura 3-F).

É realizada a dissecção do plano entre a fáscia lata e o plano muscular profundo, tomando cuidado para obter uma aproximação, sem tensão, para adequado fechamento. $\mathrm{O}$ fechamento e a colocação de drenos são idênticos à técnica em dois tempos.

Após o curativo final, o paciente permanece em decúbito dorsal e é colocado o coxim de abdução entre os membros inferiores.

\subsubsection{Cuidados entre os dois tempos cirúrgicos}

A antibioticoterapia endovenosa segue sendo empírica até a identificação do agente infeccioso, que ocorre tipicamente após quatro, cinco dias da cirurgia.

A cobertura antibiótica deve ser modificada apenas sob a orientação do infectologista.

Geralmente, o paciente recebe antibióticos por via parentereral até o final da internação. 
Antibióticos via oral são indicados por seis meses após o primeiro tempo cirúrgico, independentemente da realização ou não do segundo tempo. No caso de germes sensíveis somente a antibióticos administrados por via endovenosa, o paciente pode receber a medicação em casa, com cuidados adequados de enfermagem, ou ser transferido para hospitais auxiliares.

Os drenos de sucção são retirados se apresentam drenagem menor que $50,0 \mathrm{ml}$ em 24 horas ou após 48 horas, independentemente do volume de drenagem (DRINKWATER; NEIL, 1995).

Os pontos de pele são retirados após 10 a 14 dias.

A profilaxia da trombose venosa profunda é realizada mecanicamente, com mobilização precoce após a cirurgia e com o uso de meias elásticas longas de média compressão.

Como profilaxia medicamentosa são administrados diariamente $40,0 \mathrm{mg}$ de enoxaparina sódica subcutânea pelo período de três semanas após a cirurgia.

No grupo Dois Tempos os pacientes permanecem em tração esquelética tibial ao nível do leito. por três semanas, conforme MC DONALD et al. (1989) e BOURNE et al. (1984).

A reabilitação do quadril é realizada com movimentos leves no leito até a retirada da tração, não sendo permitida a descarga de peso no quadril ressecado.

O paciente recebe alta após a retirada da tração esquelética, continuando a reabilitação em casa ou em clínica fisioterápica.

No grupo tratado com espaçador de cimento com antibiótico, a reabilitação é iniciada no primeiro dia de pós-operatório, seguindo o protocolo de uma revisão asséptica.

O coxim de abdução é solto no primeiro dia de pós-operatório e o paciente é incentivado a sentar-se no leito. 
A flexão ativa e passiva do quadril até $70^{\circ}$ é incentivada pelos fisioterapeutas a partir do segundo dia de pós-operatório, evitando-se rotações, adução e abdução ativas e passivas.

A descarga de peso pode ser permitida de modo parcial, de acordo com a estabilidade do espaçador e a condição óssea, a partir do terceiro dia de pósoperatório.

O paciente recebe alta quando o infectologista encerra a antibioticoterapia endovenosa e quando houver consentimento do ortopedista e do clínico responsáveis. A reabilitação prossegue sendo realizada em casa ou em clínica fisioterápica.

Durante a internação são realizados, semanalmente, as coletas de hemograma completo, velocidade de hemossedimentação e dosagem de proteína C-reativa.

O paciente retorna ao ortopedista e ao infectologista, após duas semanas da alta hospitalar. Os retornos e os controles radiográficos e laboratoriais são realizados mensalmente. A cada retorno são acompanhados: o aspecto clínico da ferida cirúrgica, a presença de quadro doloroso, o aspecto radiográfico do tratamento e os exames laboratoriais.

É estudada a forma de reconstrução a ser empregada no segundo tempo cirúrgico, planejando a via de acesso, o tipo de prótese a ser utilizada e a necessidade do uso de enxerto ósseo homólogo.

\subsubsection{Segundo tempo cirúrgico}

Para a realização do segundo tempo cirúrgico espera-se a normalização dos valores das provas de fase ativa, nomeadamente a velocidade de hemossedimentação e a dosagem de proteína C-reativa.

Em caso de dúvida, ou na persistência de elevação dos valores das provas de fase ativa, são colhidas amostras de punção intra-articular em ambiente estéril de centro cirúrgico, com auxílio de radioscopia, para 
bacterioscopia e culturas. Havendo crescimento bacteriano não é realizado o segundo tempo cirúrgico (COLYER; CAPELLO, 1994; WANG et al., 1995; MC PHERSON, 2002).

Além dos exames de rotina e de provas de fase ativa, são realizados ainda urina tipo I e urocultura para descartarmos uma eventual infecção urinária sub-clínica. A antibioticoterapia profilática empírica é iniciada na indução anetésica. Os antimicrobianos e suas dosagens são os mesmos empregados no primeiro tempo cirúrgico ou ajustados conforme a bactéria isolada no primeiro tempo cirúrgico. A sonda vesical de demora é instalada como rotina e o paciente é posicionado e preparado conforme descrito no primeiro tempo.

A via de acesso planejada é executada, dissecando o plano entre a fáscia lata e musculatura profunda. A coleta de seis culturas de material adequado é realizada para confirmação da esterilidade do campo cirúrgico.

No caso do grupo Dois Tempos, a identificação dos rebordos acetabulares é facilitada pela realização de radiografias intra-operatórias (figura 4).

A reconstrução óssea é realizada com uso de enxerto homólogo, se for necessário. A fixação dos implantes definitivos é realizada, com colocação de drenos de sucção e fechamento habitual.

No caso do grupo Espaçador, retira-se o espaçador e também quaisquer fragmentos de cimento, identificados pela sua coloração azulada (figuras 5 e $6)$. 

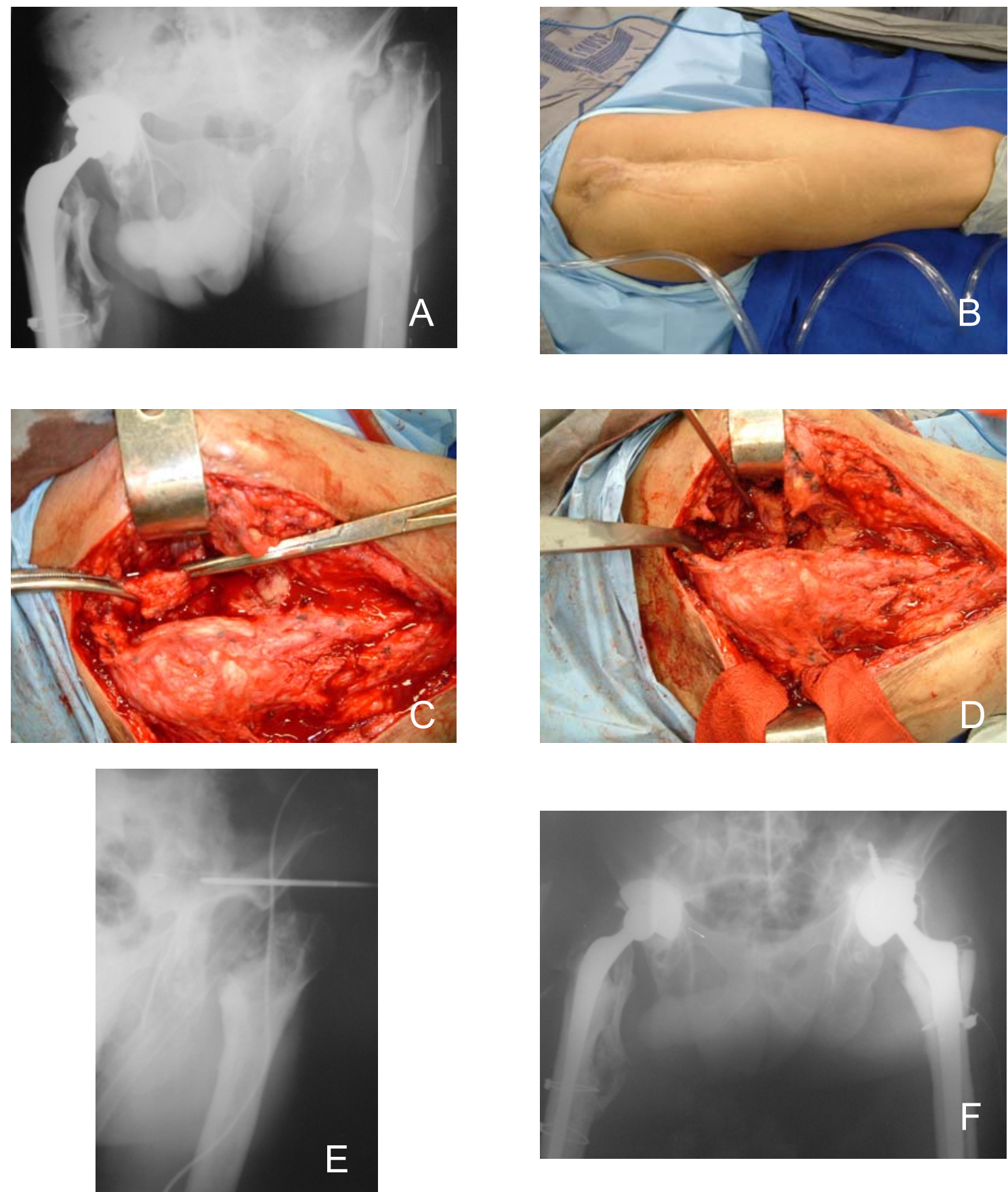

FIGURA 4 Segundo tempo cirúrgico, após primeiro tempo cirúrgico sem o uso do espaçador. A - Radiografia pré-operatória. Encurtamento do membro inferior esquerdo. B - Aspecto da pele do paciente. C - Plano fibrótico sendo dissecado. D - Colocação de fio de Steinmann para localização dos acidentes ósseos. E Radiografia intra-operatória. Fio de aço colocado na borda acetabular. F - Radiografia pós-operatória, com os componentes colocados sem cimento. 

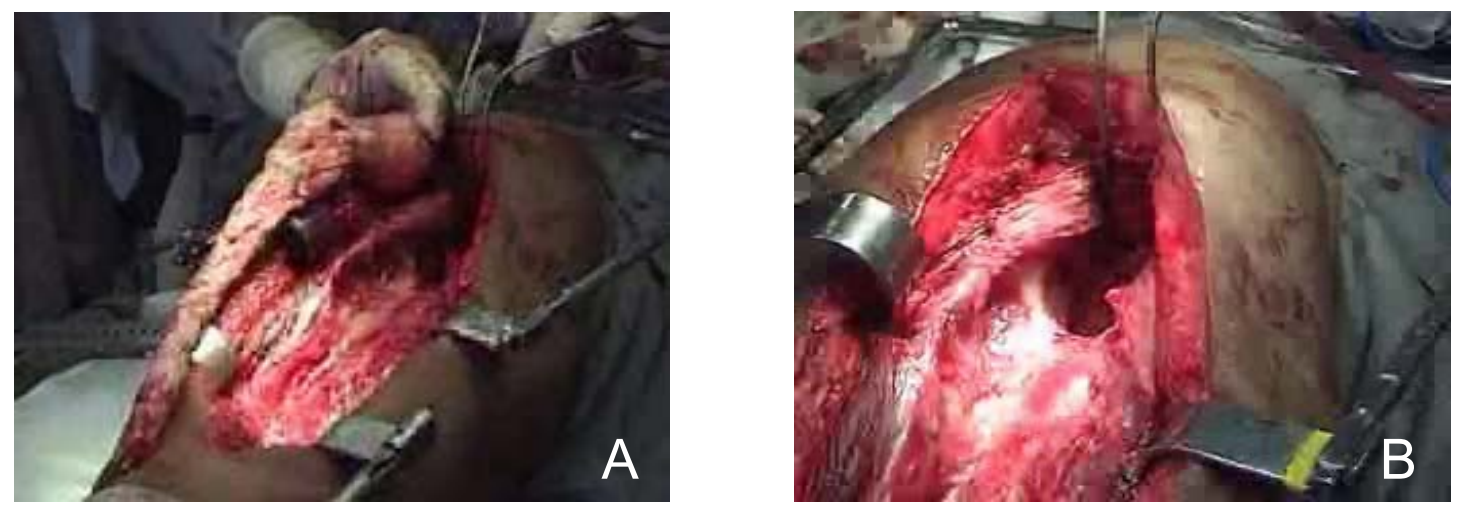

FIGURA 5 Segundo tempo cirúrgico, após primeiro tempo cirúrgico com o uso do espaçador. A - Retirada do espaçador, com envólucro fibroso ao seu redor. B - Detalhe do envólucro fibroso, na região acetabular e no femoral proximal.
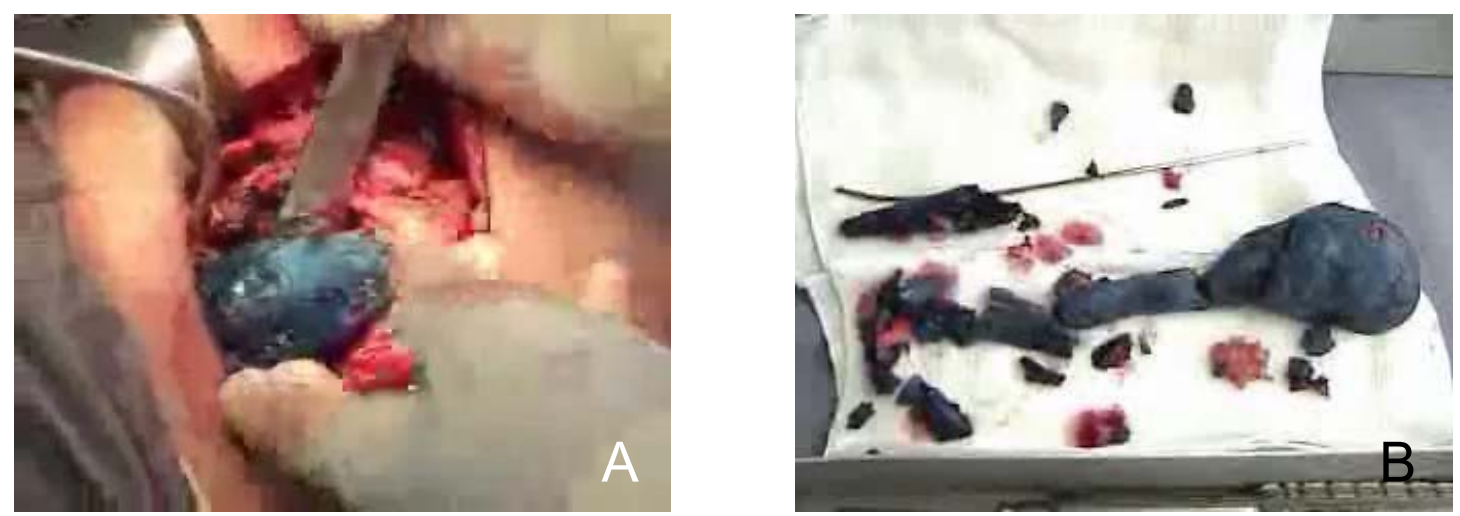

FIGURA 6 Retirada do espaçador, no segundo tempo cirúrgico. A - Retirada da porção proximal, após a luxação do espaçador. B - Espaçador fragmentado. O espaçador realizado tinha, como esqueleto de sustentação , um fio de Steinmann, o que propriciou a fragmentaçào do cimento à sua retirada. Os fragmentos foram identificados por sua coloração azulada. 


\subsubsection{Acompanhamento pós-operatório}

A antibioticoterapia profilática é mantida até o resultado das culturas colhidas no ato cirúrgico. Em caso de resultado negativo, os antibióticos são suspensos. Em caso de identificação bacteriana, é seguida a conduta do infectologista responsável. Se o segundo tempo for realizado antes do período de seis meses após o primeiro tempo - período estipulado para a manutenção da antibioticoterapia via oral - o antimicrobiano escolhido volta a ser administrado até completar-se o tratamento.

Assim que possível, a reabilitação é iniciada, de acordo com a técnica cirúrgica empregada.

A alta hospitalar, sob a supervisão do infectologista, é indicada quando o paciente está em processo de reabilitação adequado e clinicamente estável.

O paciente retorna para acompanhamento após duas e seis semanas, dois, três, seis, nove e doze meses e, depois, anualmente. A cada retorno são avaliados o aspecto da ferida cirúrgica, a presença de dor e o Escore de Harris para Quadril. São realizados estudos radiográficos e colhidos os exames de velocidade de hemossedimentação e a proteína C-reativa, periodicamente.

A ficha protocolar de coleta de dados é apresentada no anexo B.

\subsection{CRITÉRIOS DE AVALIAÇÃO DOS RESULTADOS}

Para a comparação dos dois métodos, anotamos os seguintes parâmetros, em ambos os tempos cirúrgicos:

1) Tempo de duração das cirurgias;

2) Quantidade de papas de hemácias infundidas durante as internações;

3) Volume de sangue acumulado pelos drenos de sucção;

4) Tempo total das hospitalizações;

5) Tempo de permanência em unidade de terapia intensiva; 
6) Incidência de complicações intra e pós-operatórias;

7) Incidência de recidiva infecciosa;

8) Intervalo entre o tempo cirúrgico e o diagnóstico de infecção;

9) Mortalidade relacionada ao método ou ao quadro infeccioso.

Para a avaliação funcional, foi usada a variação entre os valores do Escore de Harris para Quadril (HARRIS, 1969) avaliado antes do primeiro tempo cirúrgico e os valores do último seguimento. Foi avaliada a discrepância de comprimento dos membros inferiores no último seguimento.

Para avaliação geral dos resultados, seguimos os critérios de BUCHHOLZ et al. (1981):

BOM RESULTADO: Paciente com artroplastia de quadril realizada no segundo tempo cirúrgico, com boa função e sem recidiva da infecção.

MAU RESULTADO: Recidiva da infecção (incluindo fistulização, soltura séptica ou outras manifestações);

Realização de cirurgia de Girdlestone;

Presença de artroplastia não funcionante no último seguimento;

Morte relacionada ao processo infeccioso ou ao tratamento.

\subsection{ANÁLISE ESTATÍSTICA}

Para análise dos dados enumerativos (atributos), realizou-se a distribuição de freqüência, absoluta $(n)$ e relativa (\%, entre) das características nominais (qualitativas). 
As freqüências da ocorrência de cada atributo (qualidade) são apresentadas em tabelas de contingência e as proporções de cada atributo (\%, dentre) são representadas em gráficos de setores.

Nas comparações das freqüências das classes entre os grupos (amostras), grupo Dois Tempos (controle) e espaçador (estudo), utilizou-se o teste de Qui-quadrado $\left(\chi^{2}\right)$ para tabelas de contingência e, na sua impossibilidade, o teste exato de Fisher.

Para a análise das grandezas específicas (variáveis), realizou-se a estatística descritiva das características ordinais (quantitativas): média ( $M$ ), desvio padrão (DP), erro padrão da média (EPM), valores máximo (MAX) e mínimo (MIN) e número de casos $(\mathrm{N})$.

A estatística descritiva das grandezas, de acordo com os grupos (amostras), foi apresentada em tabelas estatísticas e representada na forma de gráficos de coluna (média \pm erro padrão de média).

Nas comparações das grandezas (dados quantitativos) entre as amostras dos grupos Dois Tempos e Espaçador, utilizou-se o teste t de student para as amostras que apresentassem distribuições paramétricas e 0 teste $U$ de Mann-Whitney para as não-paramétricas. Para as comparações de uma grandeza de uma mesma amostra em dois instantes diferentes, pré e póstratamento, foi utilizada a prova de Wilcoxon (amostras não paramétricas relacionadas ou pareadas).

Admitiu-se, previamente, que os grupos e o tratamento eram equivalentes nas comparações das tabelas. A hipótese inicial foi de que os resultados seriam iguais e adotaram-se, por isso, testes bidimensionais ou binocaudais nas comparações entre os grupos $\left(\mathrm{H}_{0}=\mu_{1}-\mu_{2}=0\right)$.

As diferenças comprovadas estatisticamente foram evidenciadas nas tabelas por asteriscos $\left(^{*}\right)$. Adotou-se o nível de confiança de $5 \%(\alpha=0,05)$.

Foi feito uso do programa estatístico GraphPad Prism ${ }^{\circledR}$, versão 2.01 (1996). 
Adotou-se o arredondamento científico e os resultados foram apresentados com uma casa após a vírgula nas tabelas e duas significativas, ou até o primeiro número significativo, nos resultados estatísticos.

Empregaram-se a terminologia estatística e as definições de acordo com - GUIA PARA EXPRESSÃO DA INCERTEZA DE MEDIÇÃO, Segunda Edição Brasileira do Guide to the Expression of Uncertainty in Measurement (BIPM, IEC, IFCC, ISSO, IUPAC, IUPAP, OIML, 1983). Edição Revisada (Agosto de 1998) - Rio de Janeiro: ABNT, INMETRO, SBM, 1998. 


\section{RESULTADOS}


TABELA 12 ESTATÍSTICA DESCRITIVA DO INTERVALO (dia) ENTRE OS DOIS TEMPOS CIRÚRGICOS DE ACORDO COM O GRUPO, DOIS TEMPOS E ESPAÇADOR. COMPARAÇÃO PELO TESTE U DE MANN WHITNEY $(\alpha=0,05)$ INTERVALO ENTRE OS TEMPOS CIRÚRGICOS (dia)

DOIS TEMPOS

ESPAÇADOR

\begin{tabular}{lcc}
\hline \hline M & 226,9 & 162,8 \\
DP & 152,8 & 76,8 \\
EPM & 39,5 & 13,8 \\
MAX & 610 & 350 \\
MIN & 70 & 60 \\
N & $15^{(1)}$ & $31^{(2)}$ \\
\hline
\end{tabular}

U de Mann Whitney

$\mathrm{U}=188,5$

$p=0,31$

(1) 1 caso de óbito intra-operatório no primeiro tempo cirúrgico, 2 casos mantidos em Girdlestone e 7 casos com recidiva de infecção

(2) 2 casos de óbito e 3 casos de recidiva de infecção

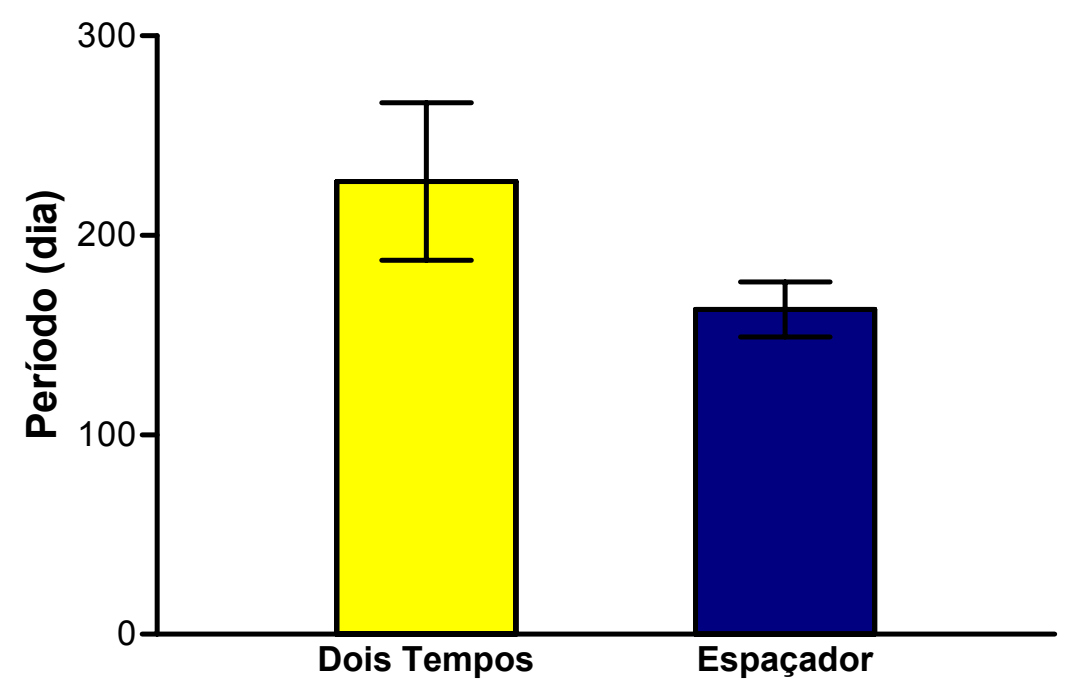

GRÁFICO12 Intervalo(dia) entre os dois tempos cirúrgicos 
TABELA 13

ESTATÍSTICA DESCRITIVA DO TEMPO (dia) DE SEGUIMENTO, DESDE O PRIMEIRO TEMPO CIRÚRGICO ATÉ O ÚLTIMO RETORNO, DE ACORDO COM O GRUPO, DOIS TEMPOS E ESPAÇADOR E TOTAL. COMPARAÇÃO PELO TESTE U DE MANNWHITNEY $(\alpha=0,05)$

\begin{tabular}{|c|c|c|c|}
\hline & \multicolumn{3}{|c|}{ PERÍODO TOTAL DE SEGUIMENTO (dia) } \\
\hline & DOIS TEMPOS & ESPAÇADOR & TOTAL \\
\hline M & 1165,1 & 844,2 & 966,7 \\
\hline DP & 628,4 & 354,6 & 497,8 \\
\hline EPM & 137,1 & 60,8 & 67,1 \\
\hline MAX & 2502 & 1516 & 2502 \\
\hline MIN & 365 & 266 & 266 \\
\hline $\mathrm{N}$ & $21^{(1)}$ & 34 & 55 \\
\hline $\begin{array}{l}\text { U deMann-Whitney } \\
\text { (1) } 4 \text { casos de óbito } \\
\text { (2) } 2 \text { casos de óbito }\end{array}$ & $U=251,0$ & & \\
\hline
\end{tabular}

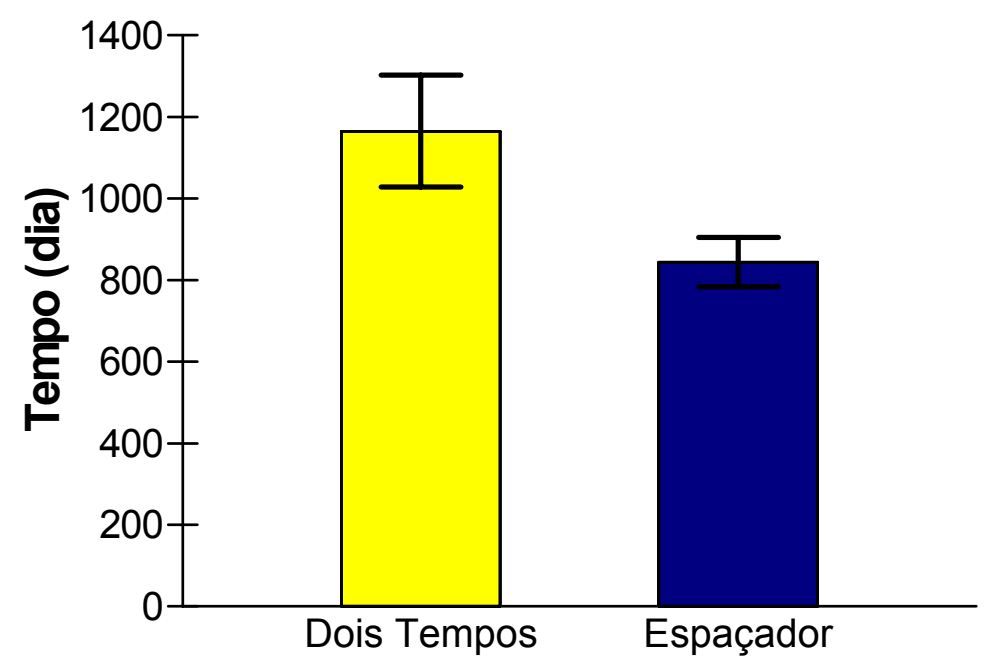

GRÁFICO13 Total de tempo (dia) de seguimento desde o primeiro tempo cirúrgico até o último retorno 
TABELA 14

ESTATÍSTICA DESCRITIVA DO TEMPO (dia) DE SEGUIMENTO, DESDE O SEGUNDO TEMPO CIRÚRGICO ATÉ O ÚLTIMO RETORNO, PARA OS PACIENTES QUE REALIZARAM O SEGUNDO TEMPO CIRÚRGICO, DE ACORDO COM O GRUPO, DOIS TEMPOS E ESPAÇADOR. COMPARAÇÃO PELO TESTE U DE MANN WHITNEY $(\alpha=0,05)$

PERÍODO ENTRE O SEGUNDO TEMPO CIRÚRGICO

E O ÚLTIMO RETORNO (dia)

DOIS TEMPOS $\quad$ ESPAÇADOR

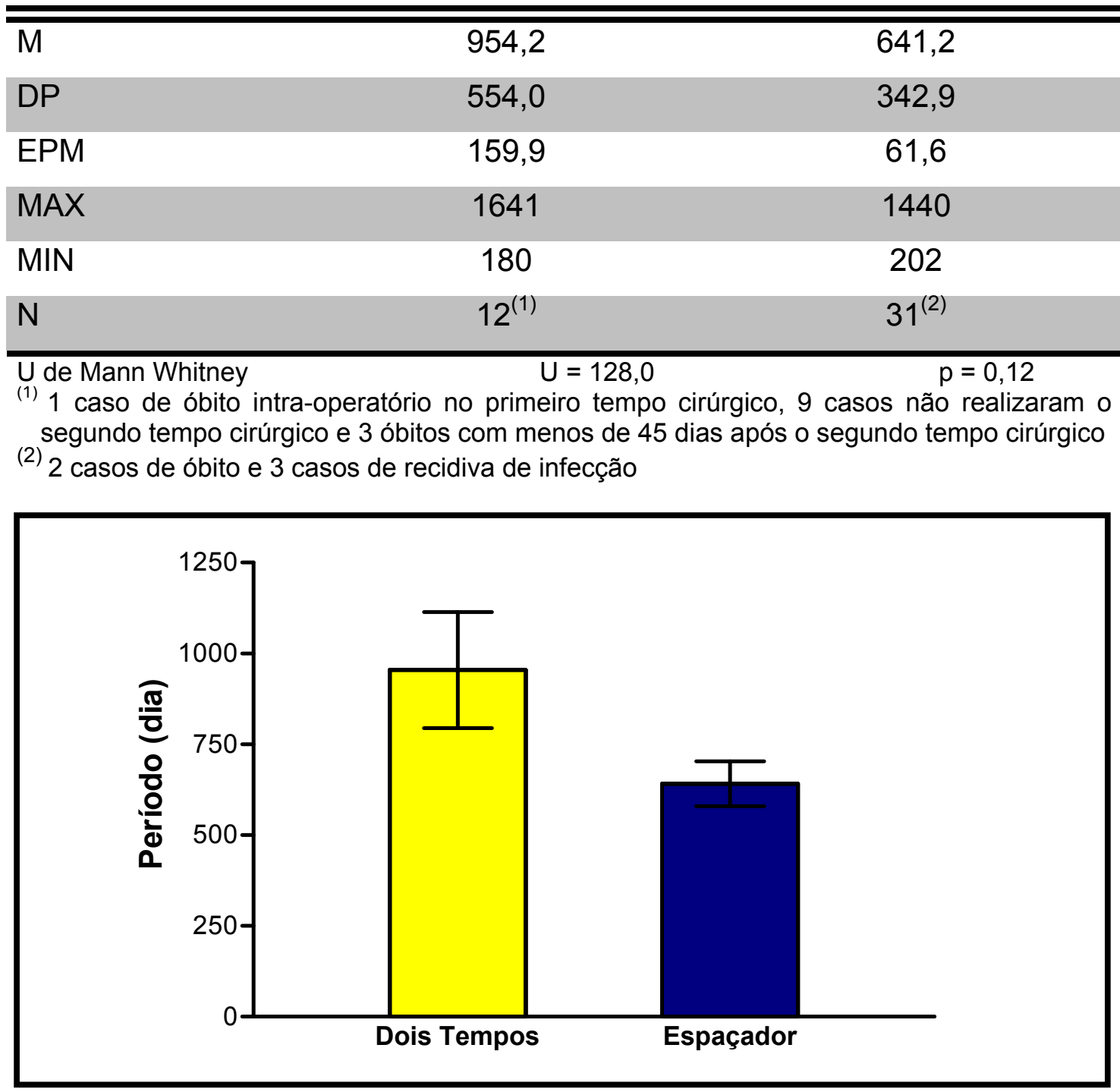

GRÁFICO14 Tempo (dia) de seguimento desde o segundo tempo cirúrgico até o último retorno 
TABELA 15 ESTATÍSTICA DESCRITIVA DO TEMPO DE DURAÇÃO (min) DO PRIMEIRO TEMPO CIRÚRGICO DE ACORDO COM O GRUPO, DOIS TEMPOS E ESPAÇADOR. COMPARAÇÃO PELO TESTE t DE STUDENT $(\alpha=0,05)$ DURAÇÃO DO PRIMEIRO TEMPO CIRÚRGICO (min)

\begin{tabular}{lcc}
\cline { 2 - 3 } & DOIS TEMPOS & ESPAÇADOR \\
\hline \hline M & 192,0 & 232,1 \\
DP & 54,4 & 67,0 \\
EPM & 10,9 & 11,2 \\
MAX & 380 & 450 \\
MIN & 120 & 150 \\
N & 25 & 36 \\
\hline tde student & $\mathrm{t}=2,48$ & $\mathrm{p}=0,02^{*}$
\end{tabular}

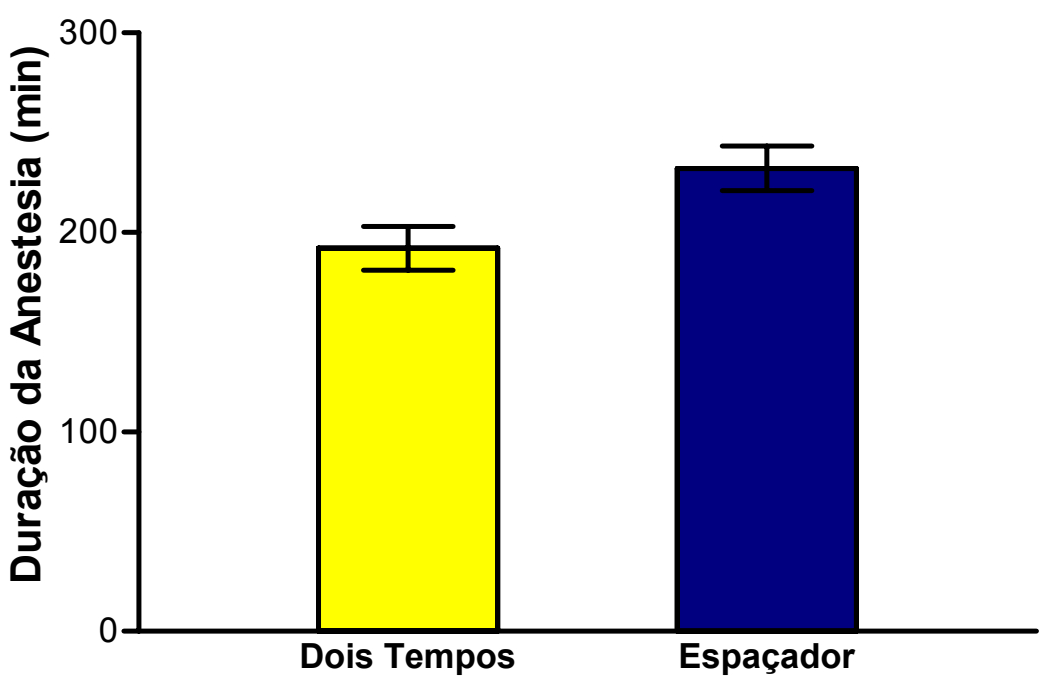

GRÁFICO15 Tempo de duração (min) do primeiro tempo cirúrgico 
TABELA 16 ESTATÍSTICA DESCRITIVA DO TEMPO DE DURAÇÃO (min) DO SEGUNDO TEMPO CIRÚRGICO DE ACORDO COM O GRUPO, DOIS TEMPOS E ESPAÇADOR. COMPARAÇÃO PELO TESTE t DE STUDENT $(\alpha=0,05)$ DURAÇÃO DO SEGUNDO TEMPO CIRÚRGICO (min) DOIS TEMPOS ESPAÇADOR

\begin{tabular}{lcc}
\hline \hline M & 265,3 & 202,9 \\
DP & 56,8 & 56,2 \\
EPM & 14,7 & 10,1 \\
MAX & 400 & 330 \\
MIN & 180 & 120 \\
$\mathrm{~N}$ & $15^{(1)}$ & $31^{(2)}$ \\
\hline
\end{tabular}

t de student

$\mathrm{t}=3,52$

$p=0,001^{*}$

(1) 1 caso de óbito intra-operatório no primeiro tempo cirúrgico, 2 casos mantidos em Girdlestone e 7 casos com recidiva de infecção

${ }^{(2)} 2$ casos de óbito e 3 casos de recidiva de infecção

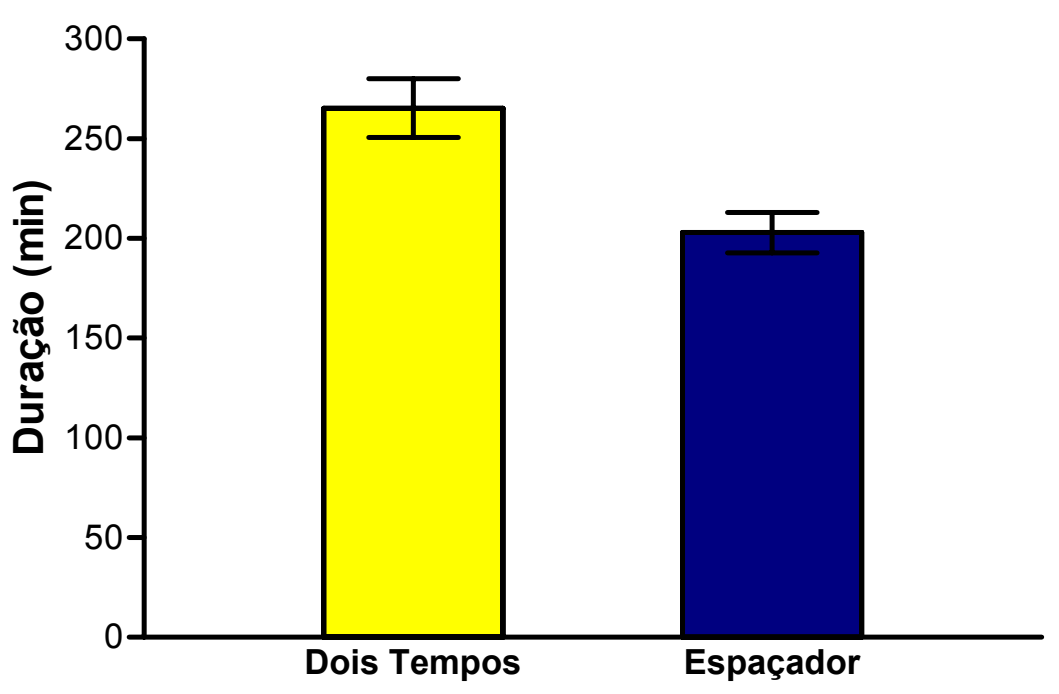

GRÁFICO16 Tempo de duração (min) do segundo tempo cirúrgico 
TABELA 17

ESTATÍSTICA DESCRITIVA DO NÚMERO DE UNIDADES DE PAPAS DE HEMÁCIAS UTILIZADAS PARA A REPOSIÇÃO SANGÜÍNEA NOS PERÍODOS INTRA E PÓS-OPERATÓRIO DO PRIMEIRO TEMPO CIRÚRGICO DE ACORDO COM O GRUPO, DOIS TEMPOS E ESPAÇADOR. COMPARAÇÃO PELO TESTE U DE MANN WHITNEY $(\alpha=0,05)$

REPOSIÇÃO SANGÜÍNEA NO INTRA E NO

PÓS-OPERATÓRIO DO PRIMEIRO TEMPO

CIRÚRGICO

(UNIDADES DE PAPAS DE HEMÁCIAS)

\begin{tabular}{lcc}
\cline { 2 - 3 } & DOIS TEMPOS & ESPAÇADOR \\
\hline \hline M & 4,1 & 3,1 \\
DP & 2,6 & 2,4 \\
EPM & 0,5 & 0,4 \\
MAX & 9 & 9 \\
MIN & 0 & 0 \\
N & 25 & 36 \\
\hline U de Mann Whitney & $\mathrm{U}=340,0$ & $\mathrm{p}=0,12$
\end{tabular}

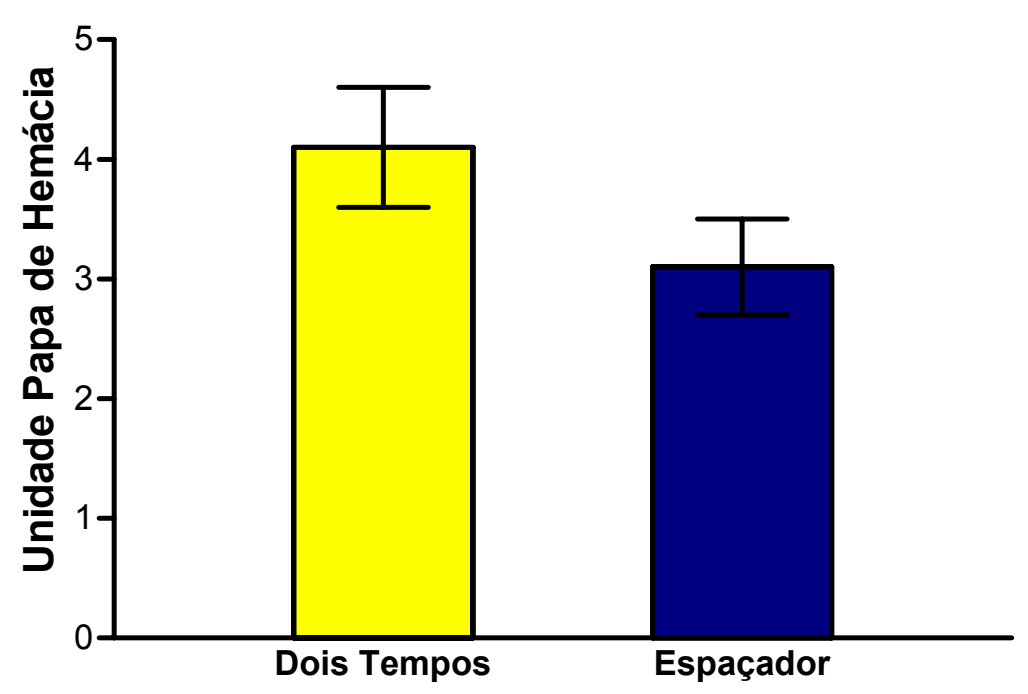

GRÁFICO17 Número de unidades de papas de hemácias utilizadas para a reposição sangüínea nos períodos intra e pós-operatório do primeiro tempo cirúrgico 
TABELA 18 ESTATÍSTICA DESCRITIVA DO NÚMERO DE UNIDADES DE PAPAS DE HEMÁCIAS UTILIZADAS PARA A REPOSIÇÃO SANGÜÍNEA NOS PERÍODOS INTRA E PÓS-OPERATÓRIO DO SEGUNDO TEMPO CIRÚRGICO DE ACORDO COM O GRUPO, DOIS TEMPOS E ESPAÇADOR. COMPARAÇÃO PELO TESTE U DE MANN WHITNEY $(\alpha=0,05)$

$$
\text { REPOSIÇÃO SANGÜÍNEA NO INTRA E NO }
$$

PÓS-OPERATÓRIO DO SEGUNDO TEMPO CIRÚRGICO

(UNIDADES DE PAPAS DE HEMÁCIAS)

DOIS TEMPOS ESPAÇADOR

\begin{tabular}{|c|c|c|}
\hline $\bar{M}$ & 3,9 & 2,6 \\
\hline DP & 2,7 & 2,0 \\
\hline EPM & 0,7 & 0,4 \\
\hline MAX & 10 & 8 \\
\hline MIN & 0 & 0 \\
\hline $\mathrm{N}$ & $15^{(1)}$ & $31^{(2)}$ \\
\hline $\begin{array}{l}\text { U de Mann Whitney } \\
\text { (1) } 1 \text { caso de óbito } \\
\text { Girdlestone e } 7 \text { casos } \\
\text { (2) } 2 \text { casos de óbito e }\end{array}$ & $\begin{array}{l}\quad U=171,5 \\
\text { no primeiro tempo } \\
\text { e infecção } \\
\text { diva de infecção }\end{array}$ & $\begin{array}{c}p=0,16 \\
\text { asos mantidos em }\end{array}$ \\
\hline
\end{tabular}

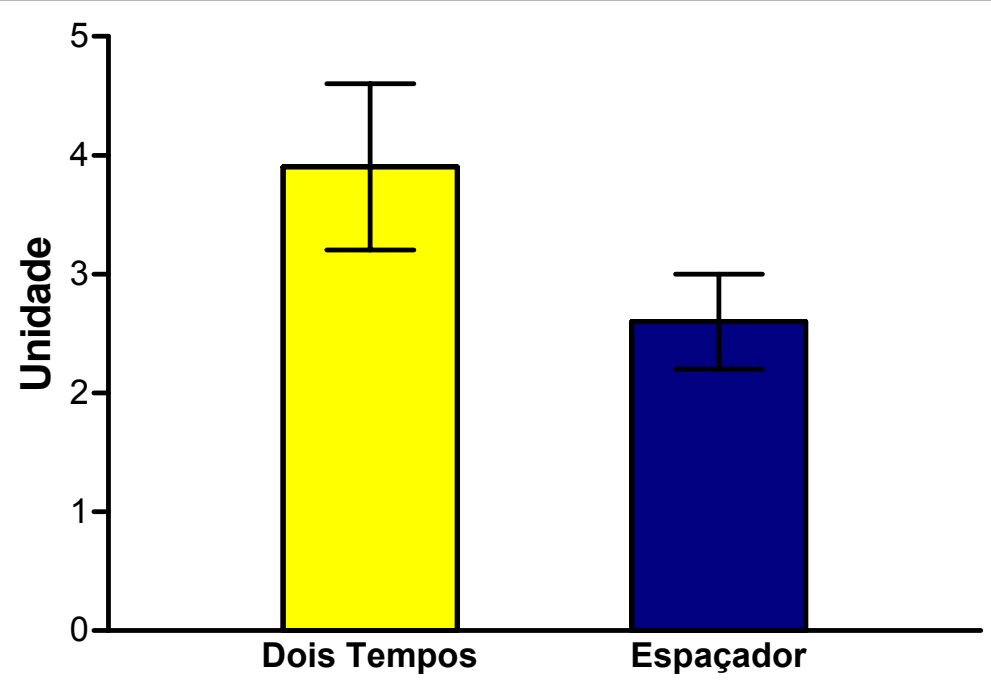

GRÁFIC018 Unidades de papas de hemácias utilizadas para a reposição SANGÜÍNEA nos períodos intra e pós-operatório do segundo tempo cirúrgico 
TABELA 19

ESTATÍSTICA DESCRITIVA DO VOLUME DRENADO (ml) APÓS O PRIMEIRO TEMPO CIRÚRGICO DE ACORDO COM O GRUPO, DOIS TEMPOS E ESPAÇADOR. COMPARAÇÃO PELO TESTE U DE MANN WHITNEY $(\alpha=0,05)$

VOLUME DRENADO APÓS O

PRIMEIRO TEMPO CIRÚRGICO (ml)

\begin{tabular}{lcc}
\cline { 2 - 3 } & DOIS TEMPOS & ESPAÇADOR \\
\hline \hline M & 677,3 & 501,8 \\
DP & 270,3 & 301,2 \\
EPM & 55,2 & 50,2 \\
MAX & 1310 & 1550 \\
MIN & 200 & 100 \\
N & $24^{(1)}$ & 36 \\
\hline U de Mann Whitney & U $=254,0$ & $\mathrm{p}=0,007^{*}$
\end{tabular}

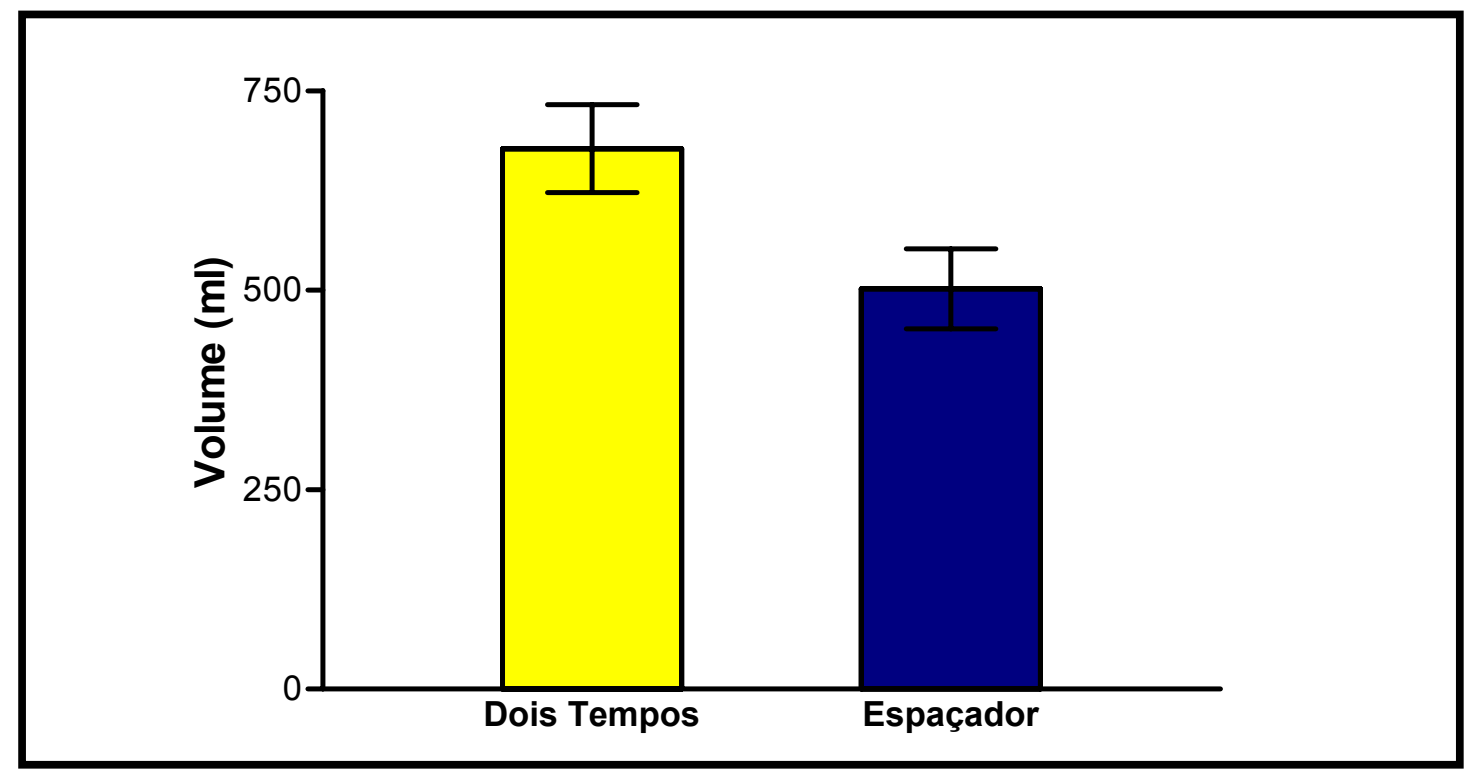

GRÁFICO19 Volume drenado (ml) após o primeiro tempo cirúrgico 
TABELA 20 ESTATÍSTICA DESCRITIVA DO VOLUME DRENADO (ml) APÓS O SEGUNDO TEMPO CIRÚRGICO DE ACORDO COM O GRUPO, DOIS TEMPOS E ESPAÇADOR. COMPARAÇÃO PELO TESTE U DE MANN WHITNEY $(\alpha=$ $0,05)$

\begin{tabular}{|c|c|c|}
\hline & \multicolumn{2}{|c|}{$\begin{array}{c}\text { VOLUME DRENADO APÓS O SEGUNDO } \\
\text { TEMPO CIRÚRGICO }(\mathrm{ml})\end{array}$} \\
\hline & DOIS TEMPOS & ESPAÇADOR \\
\hline $\bar{M}$ & 633,3 & 415,8 \\
\hline DP & 228,7 & 185,7 \\
\hline EPM & 59,1 & 33,3 \\
\hline MAX & 1100 & 780 \\
\hline MIN & 290 & 0 \\
\hline $\mathrm{N}$ & $15^{(1)}$ & $31^{(2)}$ \\
\hline $\begin{array}{l}\text { U de Mann Whitney } \\
\text { (1) } 1 \text { caso de óbito in } \\
\text { Girdlestone e } 7 \text { caso } \\
\text { (2) } 2 \text { casos de óbito }\end{array}$ & $\begin{array}{l}U=1 \\
\text { Ório no primeiro tem } \\
\text { idiva de infecção } \\
\text { de recidiva de infecs }\end{array}$ & $\begin{array}{l}\qquad p=0,01^{*} \\
\text { sos mantidos em }\end{array}$ \\
\hline
\end{tabular}

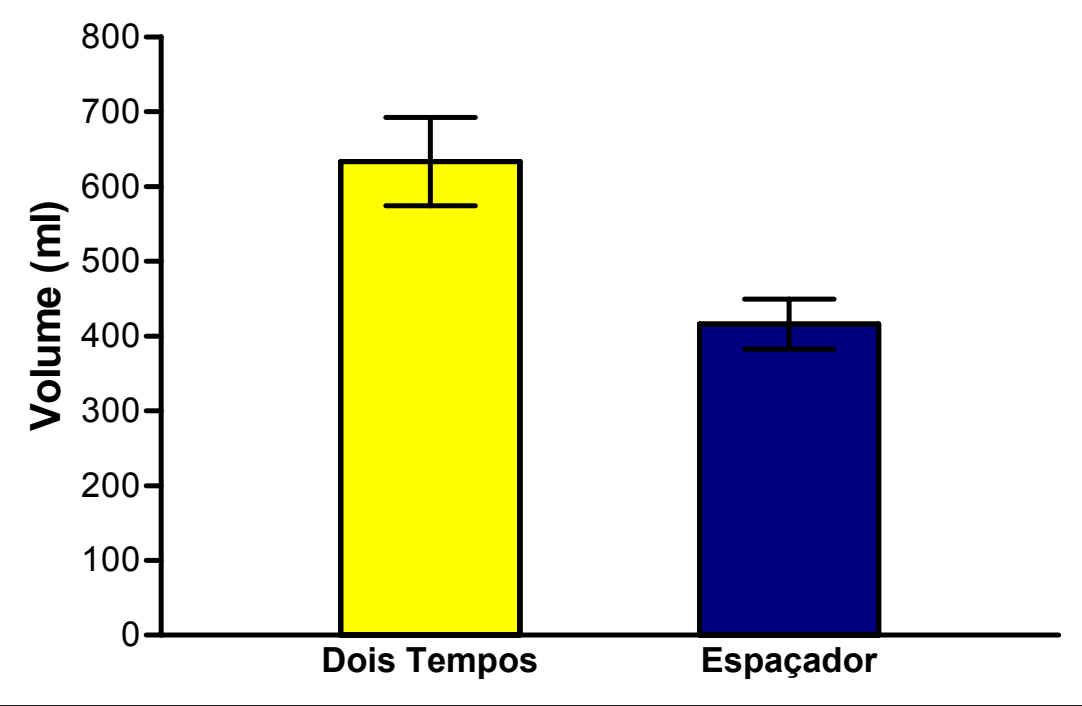

GRÁFICO20 Volume drenado $(\mathrm{ml})$ após o segundo tempo cirúrgico 
TABELA 21

ESTATÍSTICA DESCRITIVA DO TEMPO (dia) DE HOSPITALIZAÇÃO APÓS O PRIMEIRO TEMPO CIRÚRGICO DE ACORDO COM O GRUPO, DOIS TEMPOS E ESPAÇADOR. COMPARAÇÃO PELO TESTE U DE MANN WHITNEY $(\alpha=0,05)$

TEMPO DE HOSPITALIZAÇÃO APÓS O

PRIMEIRO TEMPO CIRÚRGICO (dia)

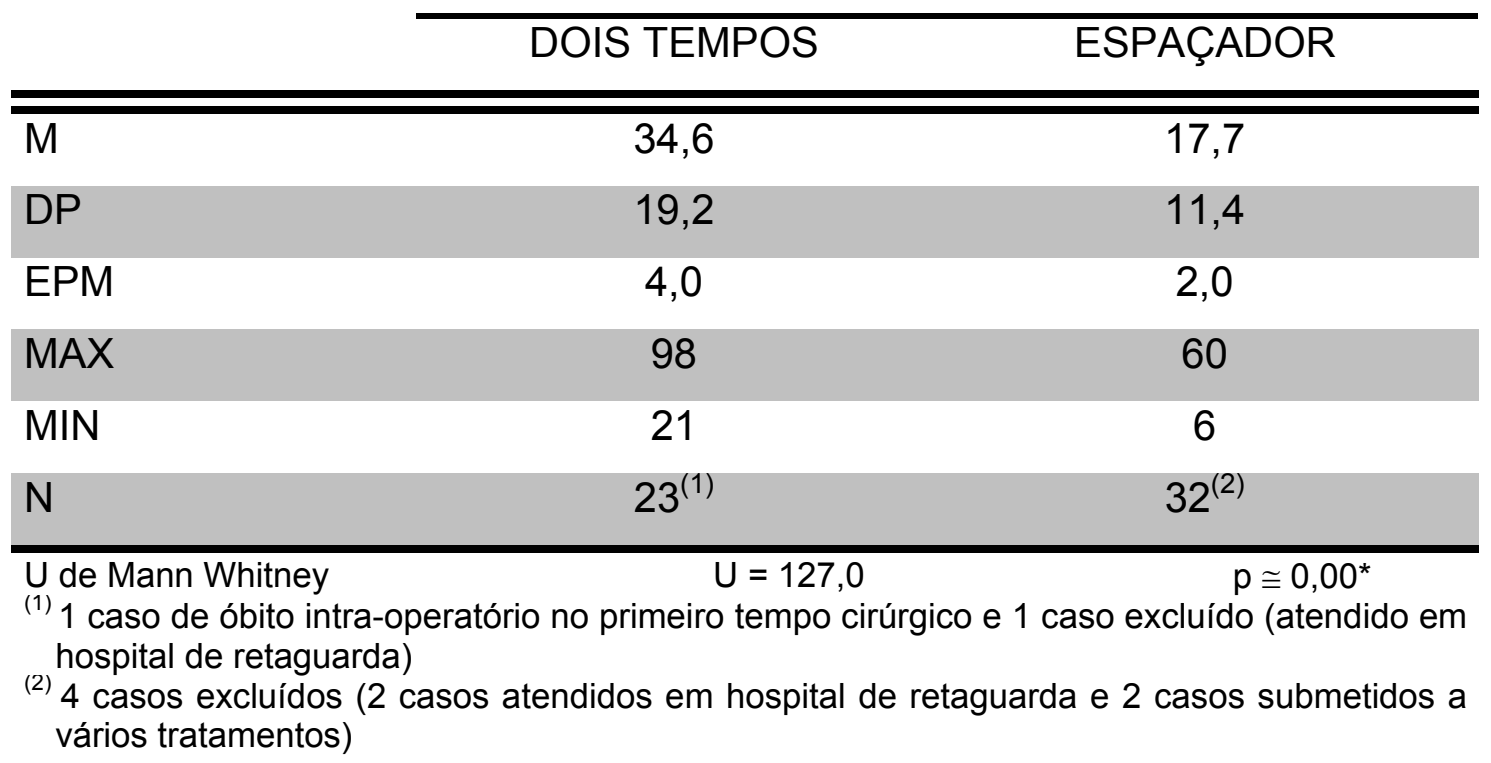

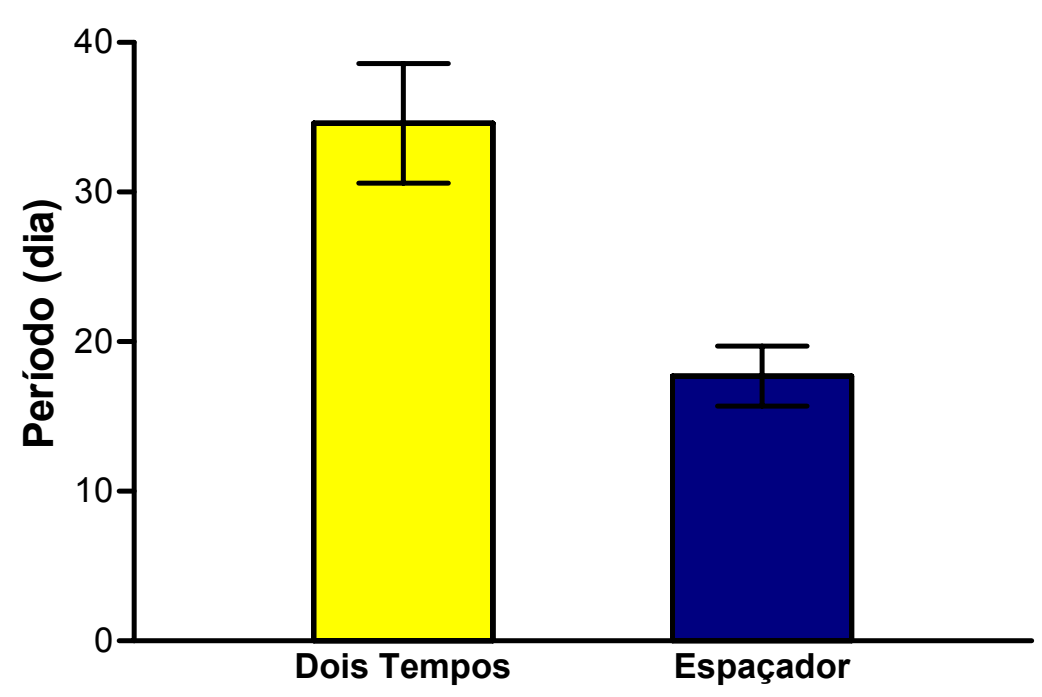

GRÁFICO21 Período de tempo (dia) de hospitalização após o primeiro tempo cirúrgico 
TABELA 22 ESTATÍSTICA DESCRITIVA DO TEMPO (dia) DE HOSPITALIZAÇÃO APÓS O SEGUNDO TEMPO CIRÚRGICO DE ACORDO COM O GRUPO, DOIS TEMPOS E ESPAÇADOR. COMPARAÇÃO PELO TESTE U DE MANN WHITNEY $(\alpha=0,05)$ TEMPO DE HOSPITALIZAÇÃO APÓS O SEGUNDO TEMPO CIRÚRGICO (dia)

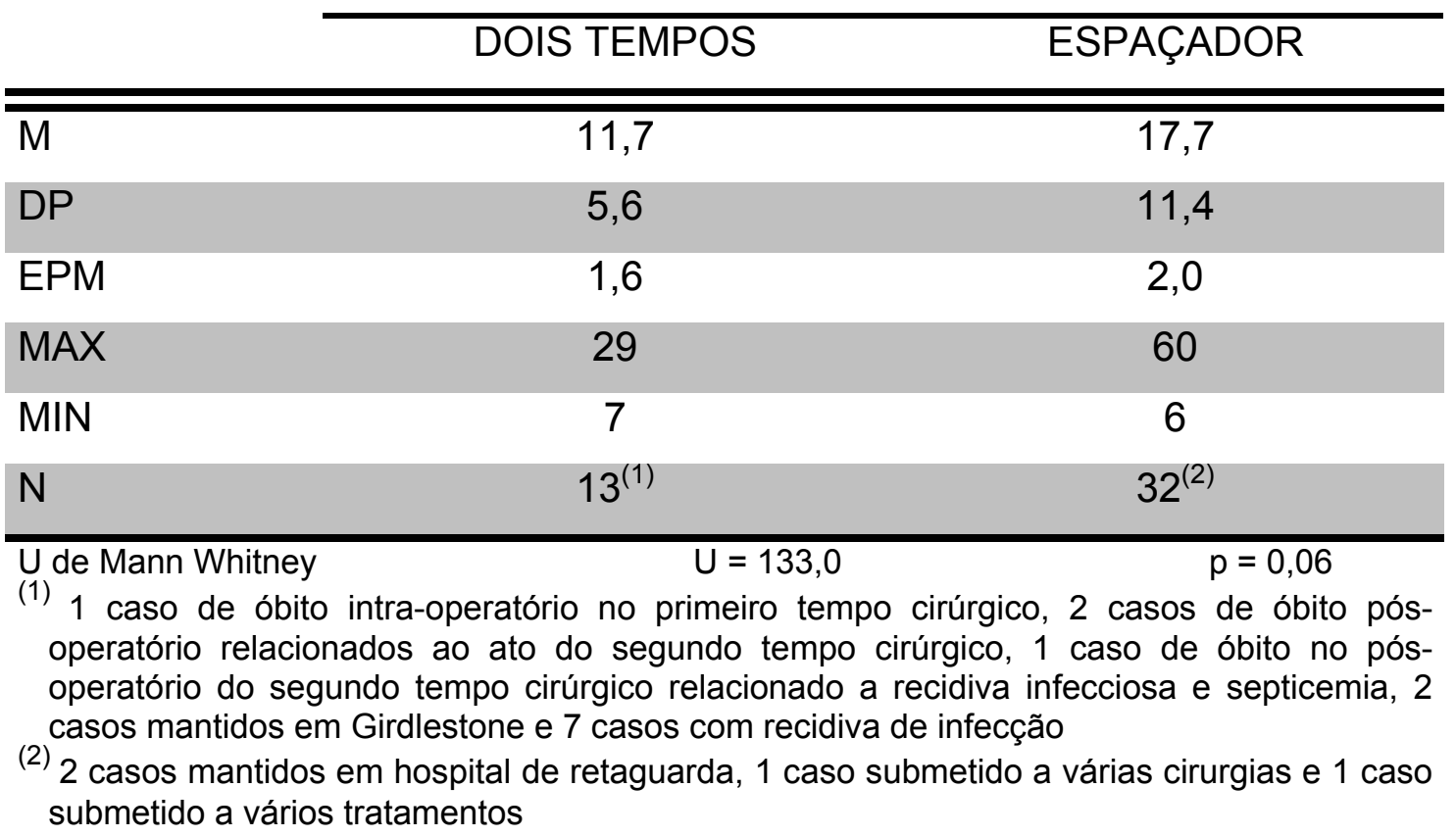

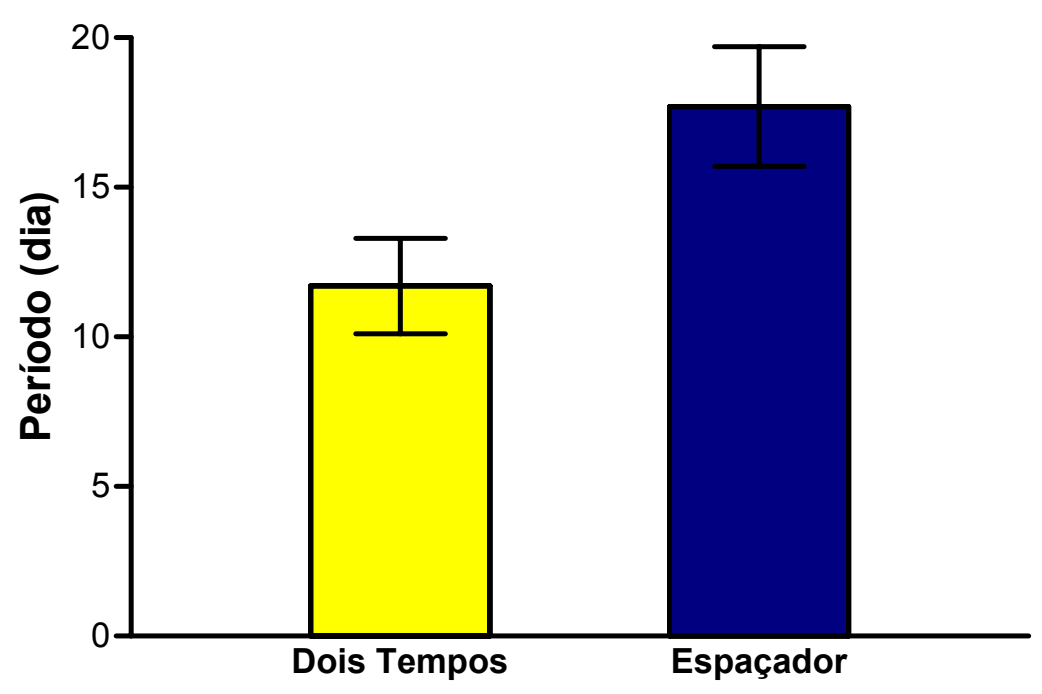

GRÁFICO22 Tempo (dia) de hospitalização após o segundo tempo cirúrgico 
TABELA 23

ESTATÍSTICA DESCRITIVA DA PERMANÊNCIA (dia) EM INTERNAÇÃO EM UNIDADE DE TERAPIA INTENSIVA APÓS O PRIMEIRO TEMPO CIRÚRGICO DE ACORDO COM O GRUPO, DOIS TEMPOS E ESPAÇADOR. COMPARAÇÃO PELO TESTE U DE MANN WHITNEY $(\alpha$ $=0,05)$

PERMANÊNCIA EM UNIDADE DE TERAPIA INTENSIVA APÓS O PRIMEIRO TEMPO CIRÚRGICO (dia)

\begin{tabular}{lcc} 
& DOIS TEMPOS & ESPAÇADOR \\
\hline \hline M & 2,0 & 1,4 \\
DP & 1,3 & 1,3 \\
EPM & 0,3 & 0,2 \\
MAX & 4 & 7 \\
MIN & 0 & 0 \\
$\mathrm{~N}$ & $24^{(1)}$ & 36 \\
\hline U de Mann Whitney & & $\mathrm{p}=0,06$
\end{tabular}

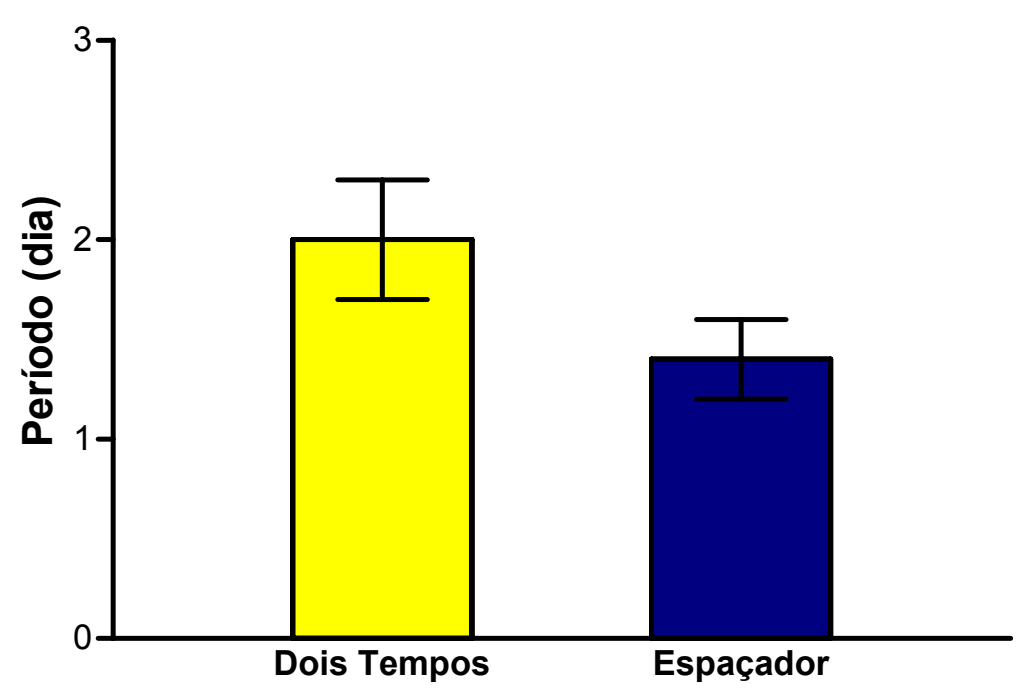

GRÁFICO23 Tempo de permanência (dia) em unidade de terapia intensiva após o primeiro tempo cirúrgico 
TABELA 24 ESTATÍSTICA DESCRITIVA DA PERMANÊNCIA (dia) EM INTERNAÇÃO EM UNIDADE DE TERAPIA INTENSIVA APÓS O SEGUNDO TEMPO CIRÚRGICO DE ACORDO COM O GRUPO, DOIS TEMPOS E ESPAÇADOR. COMPARAÇÃO PELO TESTE U DE MANN WHITNEY $(\alpha=$ $0,05)$

PERMANÊNCIA EM UNIDADE DE TERAPIA INTENSIVA

APÓS SEGUNDO TEMPO CIRÚRGICO (dia)

\begin{tabular}{lcc}
\cline { 2 - 3 } & DOIS TEMPOS & ESPAÇADOR \\
\hline \hline M & 4,1 & 1,4 \\
DP & 7,0 & 1,4 \\
EPM & 1,8 & 0,2 \\
MAX & 29 & 7 \\
MIN & 1 & 0 \\
$N$ & $15^{(1)}$ & $31^{(2)}$ \\
\hline Ude Mann Whitney & U = 111,5 & $p=0,004^{*}$ \\
(1) 1 caso de óbito intra-operatório no primeiro tempo cirúrgico, 2 casos mantidos em \\
Girdlestone e 7 casos com recidiva de infeç̧ão & \\
(2) 2 casos de óbito e 3 casos de recidiva de infecção &
\end{tabular}

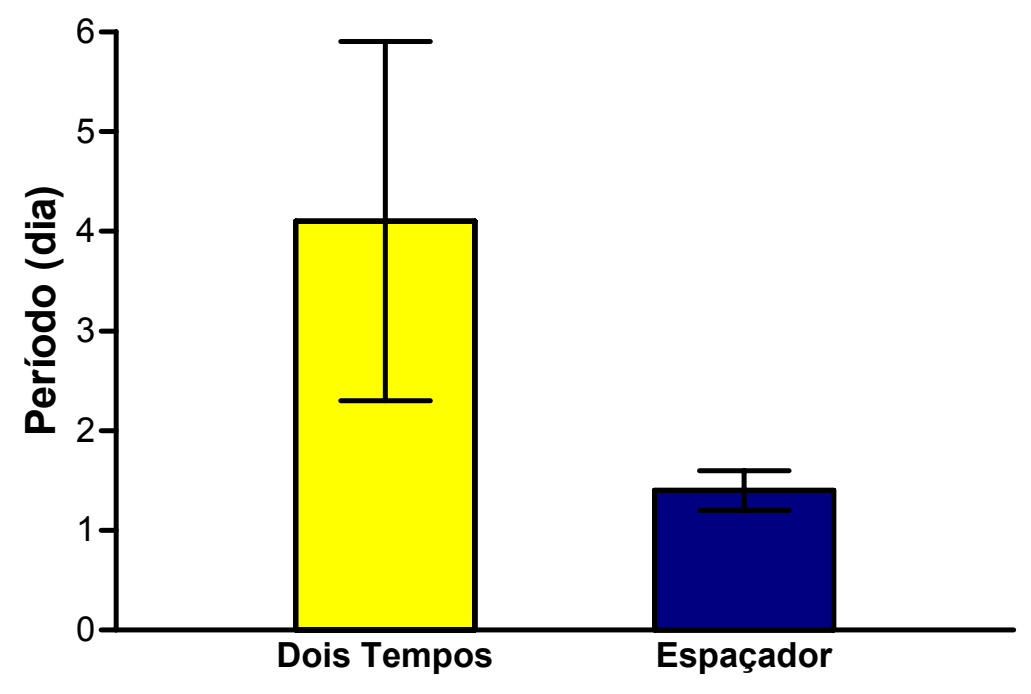

GRÁFICO24 Tempo de permanência (dia) em unidade de terapia intensiva após o segundo tempo cirúrgico 
TABELA 25

DISTRIBUIÇÃO DE FREQÜÊNCIA ABSOLUTA (n) E RELATIVA (\%) DA OCORRÊNCIA DE COMPLICAÇÕES DURANTE O PRIMEIRO TEMPO CIRÚRGICO DE ACORDO COM O GRUPO, DOIS TEMPOS E ESPAÇADOR. COMPARAÇÃO PELO TESTE EXATO DE FISHER $(\alpha=0,05)$

COMPLICAÇÕES DURANTE O

PRIMEIRO TEMPO CIRÚRGICO

\begin{tabular}{|c|c|c|}
\hline DOIS TEMPOS & ESPAÇADOR & TOTAL \\
\hline
\end{tabular}

\begin{tabular}{lcccccc}
\hline \hline Sim & 5 & 8,2 & 5 & 8,2 & 10 & 16,4 \\
Não & 20 & 32,8 & 31 & 50,8 & 51 & 83,6 \\
\hline TOTAL & $\mathbf{2 5}$ & $\mathbf{4 1 , 0}$ & $\mathbf{3 6}$ & $\mathbf{5 9 , 0}$ & $\mathbf{6 1}$ & $\mathbf{1 0 0 , 0}$ \\
\hline Fisher & & $\mathrm{p}=0,73$ & & & &
\end{tabular}

Dois Tempos

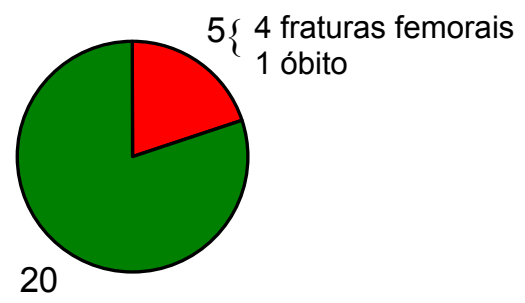

$\square \operatorname{Sim}$

\section{Espaçador}

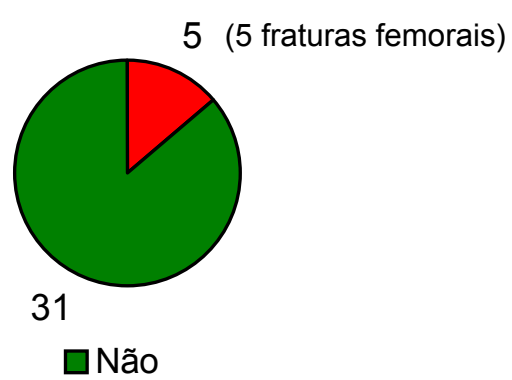

GRÁFICO25 Complicações durante o primeiro tempo cirúrgico 
TABELA 26 DISTRIBUIÇÃO DE FREQÜÊNCIA ABSOLUTA (n) E RELATIVA (\%) DA OCORRÊNCIA DE COMPLICAÇÕES DURANTE O SEGUNDO TEMPO CIRÚRGICO DE ACORDO COM O GRUPO, DOIS TEMPOS E ESPAÇADOR. COMPARAÇÃO PELO TESTE EXATO DE FISHER $(\alpha=0,05)$

COMPLICAÇÕES DURANTE O SEGUNDO TEMPO CIRÚRGICO

\begin{tabular}{|c|c|c|c|c|c|}
\hline \multicolumn{2}{|c|}{ DOIS TEMPOS } & \multicolumn{2}{|c|}{ ESPAÇADOR } & \multicolumn{2}{|c|}{ TOTAL } \\
\hline $\mathrm{n}$ & $\%$ & $\mathrm{n}$ & $\%$ & $\mathrm{n}$ & $\%$ \\
\hline 2 & 3,6 & 2 & 3,6 & 4 & 7,1 \\
\hline 13 & 23,2 & 29 & 51,8 & 52 & 92,9 \\
\hline $15^{(1)}$ & 26,8 & $31^{(2)}$ & 55,4 & 56 & 100,0 \\
\hline
\end{tabular}

Fisher $\quad p=0,59$

(1) 1 caso de óbito intra-operatório no primeiro tempo cirúrgico, 2 casos mantidos em Girdlestone e 7 casos com recidiva de infecção

(2) 2 casos de óbito e 3 casos de recidiva de infecção

\section{Dois Tempos}

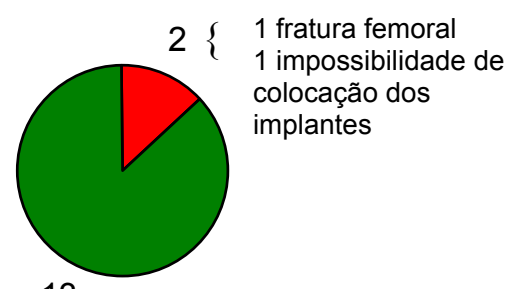

13

$\square \operatorname{Sim}$

\section{Espaçador}

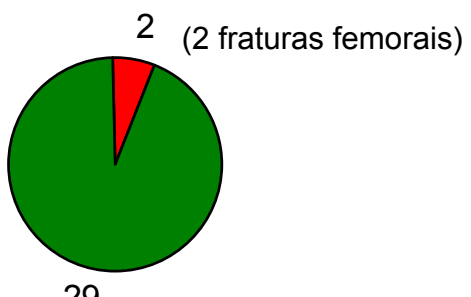

29

\ão

GRÁFICO26 Complicações durante o segundo tempo cirúrgico 
TABELA 27

DISTRIBUIÇÃO DE FREQÜÊNCIA ABSOLUTA (n) E RELATIVA (\%) DA OCORRÊNCIA DE COMPLICAÇÕES APÓS O PRIMEIRO TEMPO CIRÚRGICO DE ACORDO COM O GRUPO, DOIS TEMPOS E ESPAÇADOR. COMPARAÇÃO PELO TESTE DE QUI-QUADRADO $(\alpha=$ $0,05)$

\begin{tabular}{|c|c|c|c|c|c|c|}
\hline & \multicolumn{6}{|c|}{ COMPLICAÇÕES APÓS O } \\
\hline & \multicolumn{2}{|c|}{ DOIS TEMPOS } & \multicolumn{2}{|c|}{ ESPAÇADOR } & \multicolumn{2}{|c|}{ TOTAL } \\
\hline & $\bar{n}$ & $\%$ & $\bar{n}$ & $\%$ & $\bar{n}$ & $\%$ \\
\hline Sim & 11 & 18,0 & $\overline{10}$ & 16,4 & 21 & 34,4 \\
\hline Não & 14 & 23,0 & 26 & 42,6 & 40 & 65,6 \\
\hline$\overline{\text { TOTAL }}$ & 25 & 41,0 & $\overline{36}$ & 59,0 & 61 & $\overline{100,0}$ \\
\hline
\end{tabular}

Dois Tempos

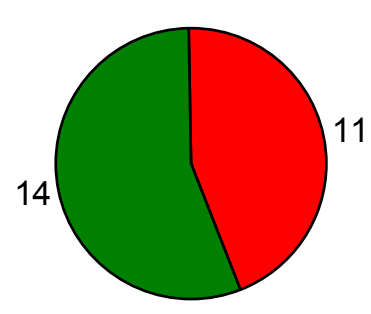

$\square \operatorname{Sim}$

\section{Espaçador}

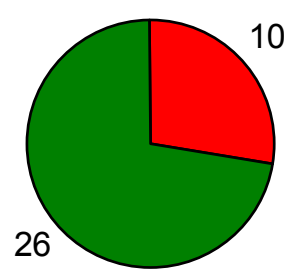

$\square$ Não

GRÁFICO27 Complicações após o primeiro tempo cirúrgico 
TABELA 28

DISTRIBUIÇÃO DE FREQÜÊNCIA ABSOLUTA (n) E RELATIVA (\%) DAS COMPLICAÇÕES APÓS O PRIMEIRO TEMPO CIRÚRGICO COMPLICAÇÕES APÓS O

PRIMEIRO TEMPO CIRÚRGICO

\begin{tabular}{|c|c|c|}
\hline $\begin{array}{c}\text { DOIS } \\
\text { TEMPOS }\end{array}$ & ESPAÇADOR & TOTAL \\
\hline$\%$ & $\%$ & $\%$ \\
\hline
\end{tabular}

\begin{tabular}{lcccccc}
\hline \hline Recidiva infecciosa & 7 & 17,9 & 3 & 7,7 & 10 & 25,6 \\
Delírio & 3 & 7,7 & 3 & 7,7 & 6 & 15,4 \\
Luxação do espaçador & 0 & 0,0 & 4 & 10,3 & 4 & 10,3 \\
\hline Alergia a antibiótico & 2 & 5,1 & 1 & 2,6 & 3 & 7,7 \\
Abscesso em coxa & 2 & 5,1 & 0 & 0,0 & 2 & 5,1 \\
Vômito e náusea & 1 & 2,6 & 1 & 2,6 & 2 & 5,1 \\
Pneumonia & 1 & 2,6 & 1 & 2,6 & 2 & 5,1 \\
Fratura do espaçador & 0 & 0,0 & 1 & 2,6 & 1 & 2,6 \\
Óbito relacionado ao tratamento & 0 & 0,0 & 1 & 2,6 & 1 & 2,6 \\
Abscesso retroperitoneal & 1 & 2,6 & 0 & 0,0 & 1 & 2,6 \\
Fratura de fêmur & 1 & 2,6 & 0 & 0,0 & 1 & 2,6 \\
\hline Edema escrotal & 0 & 0,0 & 1 & 2,6 & 1 & 2,6 \\
Insuficiência renal aguda & 0 & 0,0 & 1 & 2,6 & 1 & 2,6 \\
Herpes Zoster & 0 & 0,0 & 1 & 2,6 & 1 & 2,6 \\
Obstipação intestinal & 0 & 0,0 & 1 & 2,6 & 1 & 2,6 \\
Colecistite aguda, sepse e óbito & 0 & 0,0 & 1 & 2,6 & 1 & 2,6 \\
\hline Hemorragia aguda e hipotermia & 0 & 0,0 & 1 & 2,6 & 1 & 2,6 \\
\hline TOTAL & $\mathbf{1 8}$ & $\mathbf{4 6 , 2}$ & $\mathbf{2 1}$ & $\mathbf{5 3 , 1}$ & $\mathbf{3 9}$ & $\mathbf{1 0 0 , 0}$ \\
\hline
\end{tabular}


TABELA 29 DISTRIBUIÇÃO DE FREQÜÊNCIA ABSOLUTA (n) E RELATIVA (\%) DA OCORRÊNCIA DE COMPLICAÇÕES APÓS O SEGUNDO TEMPO CIRÚRGICO DE ACORDO COM O GRUPO, DOIS TEMPOS E ESPAÇADOR. COMPARAÇÃO PELO TESTE DE QUI-QUADRADO $(\alpha=$ $0,05)$

\begin{tabular}{|c|c|c|c|c|c|c|}
\hline & \multicolumn{6}{|c|}{$\begin{array}{c}\text { COMPLICAÇÕES APÓS O } \\
\text { SEGUNDO TEMPO CIRÚRGICO }\end{array}$} \\
\hline & \multicolumn{2}{|c|}{ DOIS TEMPOS } & \multicolumn{2}{|c|}{ ESPAÇADOR } & \multicolumn{2}{|c|}{ TOTAL } \\
\hline & $\mathrm{n}$ & $\%$ & $\mathrm{n}$ & $\%$ & $\mathrm{n}$ & $\%$ \\
\hline Sim & 8 & 14,3 & 8 & 14,3 & 16 & 28,6 \\
\hline Não & 7 & 12,5 & 23 & 41,1 & 40 & 71,4 \\
\hline TOTAL & $15^{(1)}$ & 26,8 & $31^{(3)}$ & 55,4 & 56 & 100,0 \\
\hline $\begin{array}{l}\text { Qui- quadrado } \\
\text { (1) } 1 \text { caso de óbitc } \\
\text { girdlestone e } 7 \\
\text { (2) } 2 \text { casos de óbi }\end{array}$ & atc & $\begin{array}{l}\chi^{2}=3,38 \\
\text { 10 primeiro } \\
\text { a de infeç } \\
\text { cidiva de in }\end{array}$ & cirúrc & $\begin{array}{c}p=0 \\
\text { casos }\end{array}$ & ido & \\
\hline
\end{tabular}

Dois Tempos

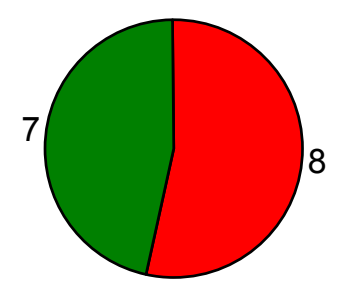

$\square \operatorname{Sim}$

\section{Espaçador}

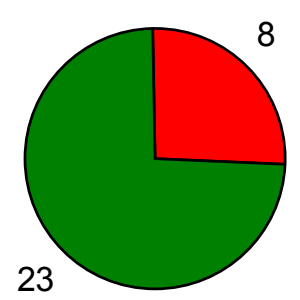

$\square$ Não

GRÁFICO29 Complicações após o segundo tempo cirúrgico 
TABELA 30

DISTRIBUIÇÃO DE FREQÜÊNCIA ABSOLUTA (n) E RELATIVA (\%) DAS COMPLICAÇÕES APÓS O SEGUNDO TEMPO CIRÚRGICO

COMPLICAÇÕES APÓS O

SEGUNDO TEMPO CIRÚRGICO

\begin{tabular}{|c|c|c|}
\hline $\begin{array}{c}\text { DOIS } \\
\text { TEMPOS }\end{array}$ & ESPAÇADOR & TOTAL \\
\hline $\begin{array}{ll}\mathrm{n} & \%\end{array}$ & $\%$ & $\%$ \\
\hline
\end{tabular}

\begin{tabular}{lcccccc}
\hline \hline Recidiva infecciosa & 4 & 16,4 & 0 & 0,0 & 4 & 16,4 \\
Óbito & 3 & 12,0 & 0 & 0,0 & 3 & 12,0 \\
Luxação & 1 & 4,0 & 2 & 8,0 & 3 & 12,0 \\
Hematoma drenado & 0 & 0,0 & 2 & 8,0 & 2 & 8,0 \\
Lesão nervosa & 2 & 8,0 & 0 & 0,0 & 2 & 8,0 \\
Delírio & 1 & 4,0 & 0 & 0,0 & 1 & 4,0 \\
Dor persistente & 1 & 4,0 & 0 & 0,0 & 1 & 4,0 \\
Edema escrotal & 1 & 4,0 & 0 & 0,0 & 1 & 4,0 \\
Insuficiência renal por antibiótico & 1 & 4,0 & 0 & 0,0 & 1 & 4,0 \\
Cefaléia & 0 & 0,0 & 1 & 4,0 & 1 & 4,0 \\
Choque anafilático por morfina & 0 & 0,0 & 1 & 4,0 & 1 & 4,0 \\
Pneumonia & 0 & 0,0 & 1 & 4,0 & 1 & 4,0 \\
Pseudartrose em diáfise femoral & 0 & 0,0 & 1 & 4,0 & 1 & 4,0 \\
Trombose venosa profunda & 0 & 0,0 & 1 & 4,0 & 1 & 4,0 \\
Soltura acetabular asséptica & 0 & 0,0 & 1 & 4,0 & 1 & 4,0 \\
Soltura femoral asséptica & 0 & 0,0 & 1 & 4,0 & 1 & 4,0 \\
\hline TOTAL & $\mathbf{1 4}$ & $\mathbf{5 6 , 0}$ & $\mathbf{1 1}$ & $\mathbf{4 4 , 0}$ & $\mathbf{2 5}$ & $\mathbf{1 0 0 , 0}$ \\
\hline
\end{tabular}


TABELA 31

DISTRIBUIÇÃO DE FREQÜÊNCIA ABSOLUTA (n) E RELATIVA (\%) DO TIPO DE PRÓTESE UTILIZADA NO SEGUNDO TEMPO CIRÚRGICO DE ACORDO COM O GRUPO, DOIS TEMPOS E ESPAÇADOR

$$
\begin{gathered}
\text { PRÓTESE NO SEGUNDO } \\
\text { TEMPO CIRÚRGICO }
\end{gathered}
$$

\begin{tabular}{|c|c|c|c|c|c|c|}
\hline & \multicolumn{2}{|c|}{ DOIS TEMPOS } & \multicolumn{2}{|c|}{ ESPAÇADOR } & \multicolumn{2}{|c|}{ TOTAL } \\
\hline & $\bar{n}$ & $\%$ & $\bar{n}$ & $\overline{\%}$ & $\bar{n}$ & $\overline{\%}$ \\
\hline Cimentada & 6 & 13,3 & 11 & 24,4 & 17 & 37,8 \\
\hline Sem Cimento & 4 & 8,9 & 13 & 28,9 & 17 & 37,8 \\
\hline Híbrida & 3 & 6,7 & 7 & 15,6 & 10 & 22,2 \\
\hline Híbrida (Inversa) & 1 & 2,2 & 0 & 0,0 & 1 & 2,2 \\
\hline TOTAL & $14^{1}$ & $\overline{31,1}$ & 31 & 68,9 & 45 & $\overline{100,0}$ \\
\hline
\end{tabular}

(1) 1 caso não realizado por dificuldade técnica, 1 caso de óbito intra-operatório no primeiro tempo cirúrgico, 2 casos mantidos em Girdlestone e 7 casos com recidiva de infecção e 1 caso em que não foi possível a colocação da prótese no segundo tempo

(2) 2 casos de óbito e 3 casos de recidiva de infecção

Dois Tempos

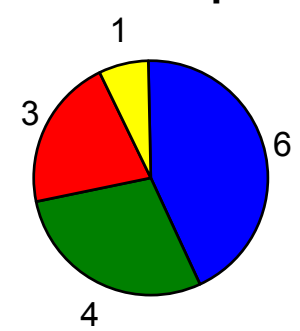

Cimentada
Sem Cimento

\section{Espaçador}

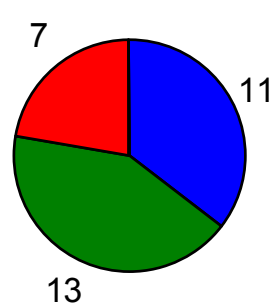

$\square$ Híbrida (Inversa)

GRÁFICO31 Tipo de prótese utilizada no segundo tempo cirúrgico 
TABELA 32 DISTRIBUIÇÃO DE FREQÜÊNCIA ABSOLUTA (n) E RELATIVA (\%) DA UTILIZAÇÃO DE ENXERTO HOMÓLOGO (BANCO DE TECIDOS) DE ACORDO COM O GRUPO, DOIS TEMPOS E ESPAÇADOR. COMPARAÇÃO PELO TESTE DE QUI-QUADRADO $(\alpha=$ $0,05)$

\begin{tabular}{|c|c|c|c|c|c|c|}
\hline & \multicolumn{6}{|c|}{ ENXERTO DE BANCO DE TECIDOS } \\
\hline & \multicolumn{2}{|c|}{ DOIS TEMPOS } & \multicolumn{2}{|c|}{ ESPAÇADOR } & \multicolumn{2}{|c|}{ TOTAL } \\
\hline & $\bar{n}$ & $\%$ & $\bar{n}$ & $\%$ & $\mathrm{n}$ & $\%$ \\
\hline Sim & 8 & 17,4 & 20 & 43,5 & 28 & 60,9 \\
\hline Não & 7 & 15,2 & 11 & 23,9 & 18 & 39,1 \\
\hline TOTAL & $15^{(1)}$ & 32,6 & $31^{(2)}$ & 67,4 & 46 & 100,0 \\
\hline
\end{tabular}

(1) 1 caso de óbito intra-operatório no primeiro tempo cirúrgico, 2 casos mantidos em Girdlestone e 7 casos com recidiva de infecção

(2) 2 casos de óbito e 3 casos de recidiva de infecção

Dois Tempos

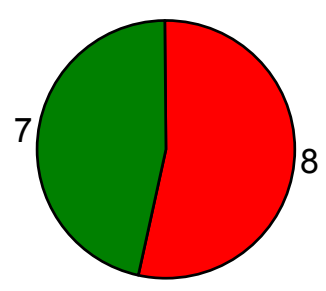

$\operatorname{Sim}$

\section{Espaçador}

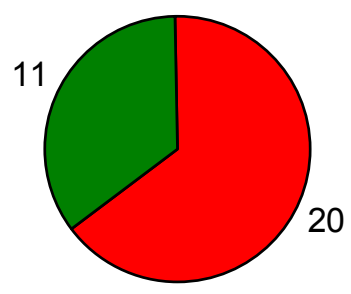

Não

GRÁFICO32 Utilização de enxerto de banco de tecidos 
TABELA 33

DISTRIBUIÇÃO DE FREQÜÊNCIA ABSOLUTA (n) E RELATIVA (\%) DA RECIDIVA DE INFECÇÃO APÓS O PRIMEIRO TEMPO CIRÚRGICO. COMPARAÇÃO PELO TESTE DE QUI-QUADRADO $(\alpha=0,05)$

$$
\text { RECIDIVA DE INFECÇÃO }
$$

APÓS O PRIMEIRO TEMPO CIRÚRGICO

\begin{tabular}{|c|c|c|}
\hline DOIS TEMPOS & ESPAÇADOR & TOTAL \\
\hline$\%$ & $\%$ & $\%$ \\
\hline
\end{tabular}

\begin{tabular}{lcccccc}
\hline \hline $\operatorname{Sim}$ & 7 & 12,1 & 3 & 5,2 & 10 & 17,2 \\
\hline Não & 17 & 29,3 & 31 & 53,4 & 48 & 82,8 \\
\hline TOTAL & $\mathbf{2 4}^{(1)}$ & $\mathbf{4 1 , 4}$ & $\mathbf{3 4}^{(2)}$ & $\mathbf{5 8 , 6}$ & $\mathbf{5 8}$ & $\mathbf{1 0 0 , 0}$
\end{tabular}

Qui-quadrado

(1) 1 caso de óbito intra-operatório

$\chi^{2}=4,08$

$p=0,04^{*}$

(2) 2 casos de óbito pós-operatórios

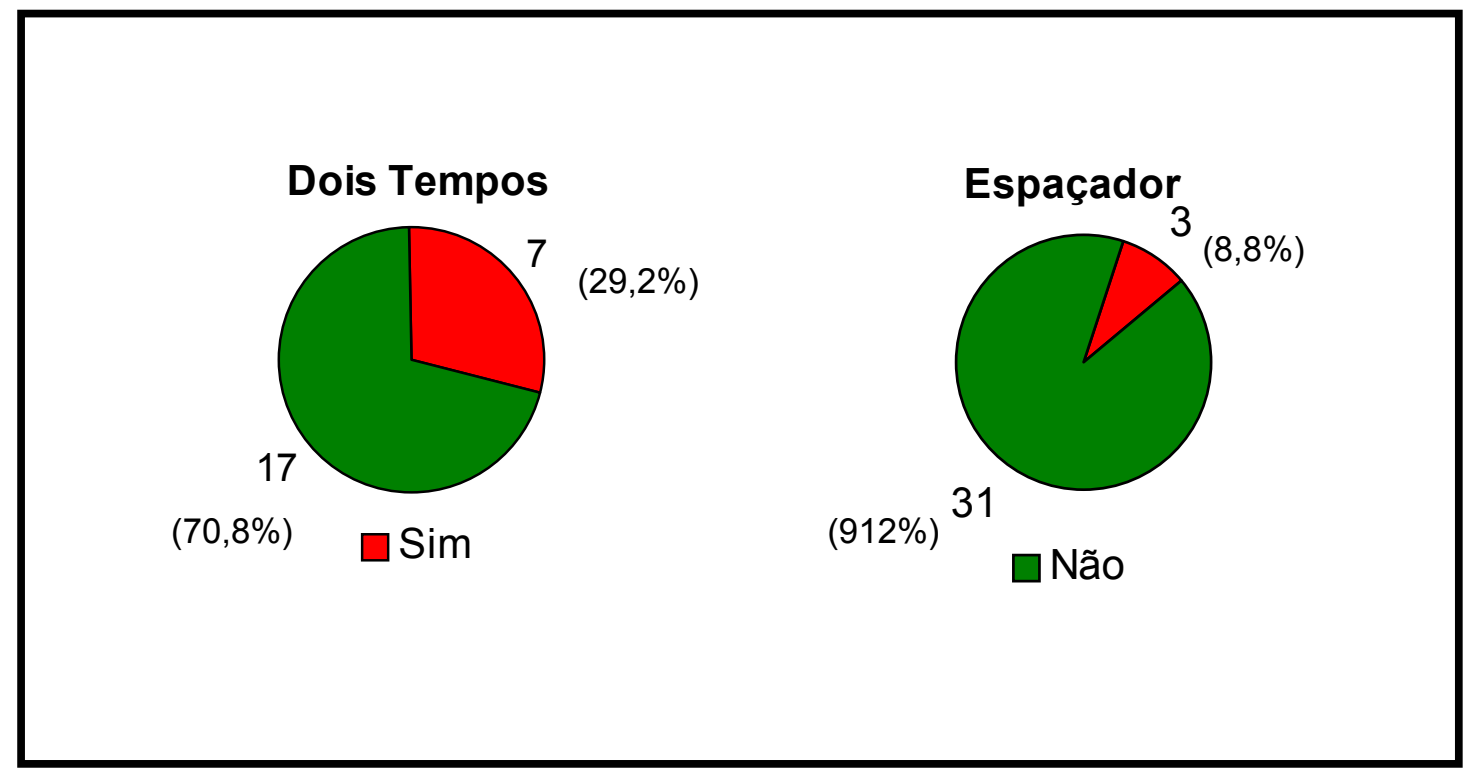

GRÁFICO33 Recidiva de infecção após o primeiro tempo cirúrgico 
TABELA 34 ESTATÍSTICA DESCRITIVA DO PERÍODO DE TEMPO (dia) ENTRE O PRIMEIRO TEMPO CIRÚRGICO E A RECIDIVA DA INFECÇÃO DE ACORDO COM O GRUPO, DOIS TEMPOS E ESPAÇADOR, E TOTAL. COMPARAÇÃO PELO TESTE U DE MANN WHITNEY $(\alpha$ $=0,05)$

PERÍODO ENTRE O PRIMEIRO TEMPO CIRÚRGICO E A RECIDIVA DA INFECÇÃO (dia)

\begin{tabular}{lccc} 
& DOIS TEMPOS & ESPAÇADOR & TOTAL \\
\hline \hline M & 36,0 & 28 & 33,6 \\
DP & 37,1 & 25,2 & 32,8 \\
EPM & 14,0 & 14,6 & 10,4 \\
MAX & 112 & 56 & 112 \\
MIN & 7 & 7 & 7 \\
N & 7 & 3 & 10 \\
\hline U de Mann-Whitney & & $\mathrm{U}=9,5$ &
\end{tabular}

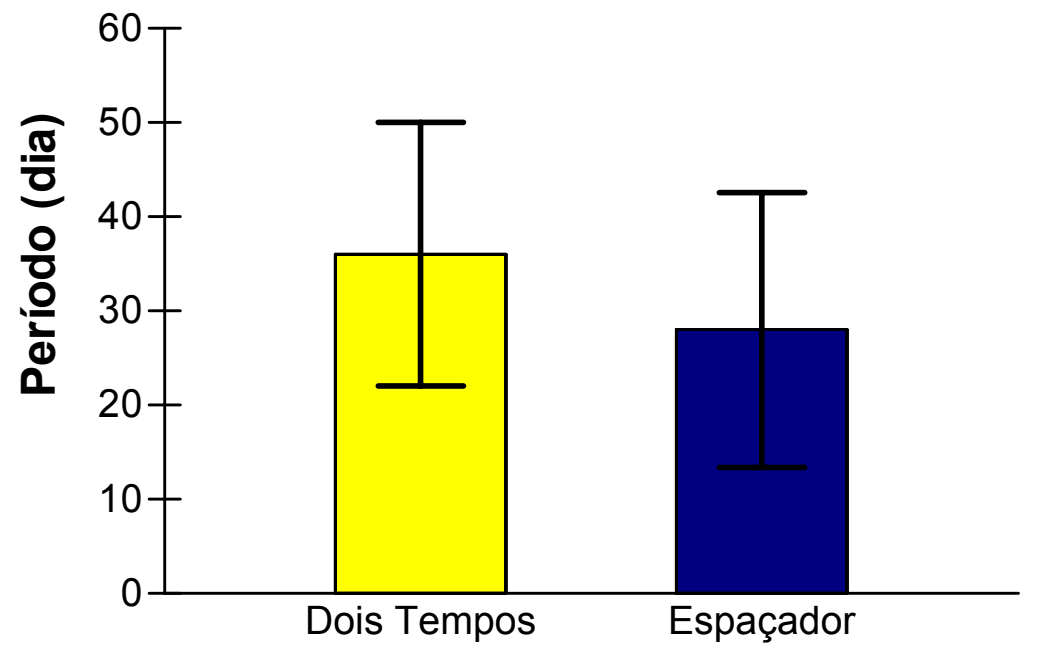

GRÁFICO34 Tempo (dia) entre o primeiro tempo cirúrgico e a recidiva da infecção 
TABELA 35

DISTRIBUIÇÃO DE FREQÜÊNCIA ABSOLUTA (n) E RELATIVA (\%) DA RECIDIVA DE INFECÇÃO APÓS O SEGUNDO TEMPO CIRÚRGICO. COMPARAÇÃO PELO TESTE EXATO DE FISHER $(\alpha=0,05)$ RECIDIVA DE INFECÇÃO

APÓS O SEGUNDO TEMPO CIRÚRGICO

\begin{tabular}{|c|c|c|c|c|c|c|}
\hline & \multicolumn{2}{|c|}{ DOIS TEMPOS } & \multicolumn{2}{|c|}{ ESPAÇADOR } & \multicolumn{2}{|c|}{ TOTAL } \\
\hline & $\mathrm{n}$ & $\%$ & $\mathrm{n}$ & $\%$ & $\mathrm{n}$ & $\%$ \\
\hline Sim & 4 & 8,7 & 0 & 0 & 4 & 8,7 \\
\hline Não & 11 & 23,9 & 31 & 67,4 & 42 & 91,3 \\
\hline TOTAL & $15^{(1)}$ & 32,6 & $31^{(2)}$ & 67,4 & 46 & 100,0 \\
\hline
\end{tabular}

(1) 1 caso de óbito intra-operatório no primeiro tempo cirúrgico, 2 casos mantidos em Girdlestone e 7 casos com recidiva de infecção

(2) 2 casos de óbito e 3 casos de recidiva de infecção

Dois Tempos

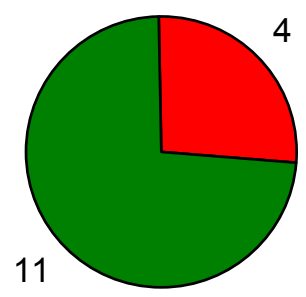

$(73,3 \%) \quad \square \operatorname{Sim}$
Espaçador

$(26,7 \%)$

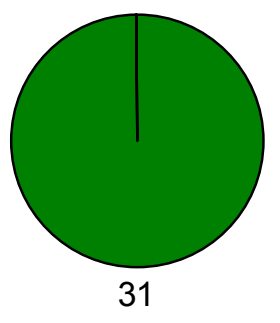

$\square$ Não

GRÁFICO35 Recidiva de infecção após o segundo tempo cirúrgico 
TABELA 36

ESTATÍSTICA DESCRITIVA DO PERÍODO DE TEMPO (dia) ENTRE O SEGUNDO TEMPO CIRÚRGICO E O DIAGNÓSTICO DE INFECÇÃO NO GRUPO DOIS TEMPOS

PERÍODO ENTRE SEGUNDO TEMPO E O

DIAGNÓSTICO DE INFECÇÃO (dia)

DOIS TEMPOS

\begin{tabular}{lc}
\hline \hline M & 118,8 \\
DP & 213,0 \\
EPM & 106,5 \\
MAX & 438 \\
MIN & 5 \\
N & $4^{(1)}$ \\
\hline (1) 1 caso de óbito intra-operatório no primeiro tempo cirúrgico, 9 casos não realizaram o \\
\multicolumn{2}{r|}{ segundo tempo cirúrgico e 11 casos não apresentaram recidiva infecciosa }
\end{tabular}

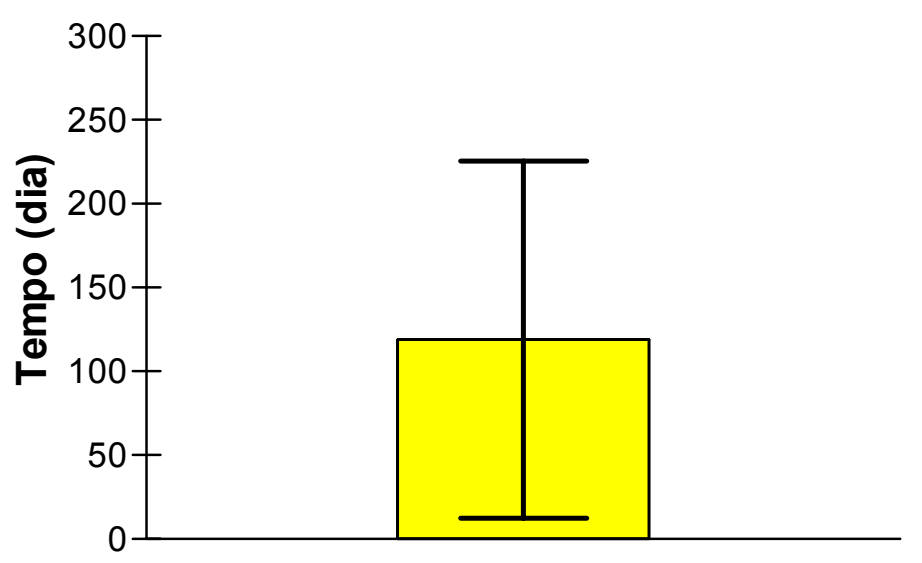

Dois Tempos

GRÁFICO36 Tempo (dia) entre o segundo tempo cirúrgico e o diagnóstico de infecção 
TABELA 37 DISTRIBUIÇÃO DE FREQÜÊNCIA ABSOLUTA (n) E RELATIVA (\%) DO CONTROLE INFECCIOSO APÓS A REALIZAÇÃO DO TRATAMENTO DE ACORDO COM OS GRUPOS DOIS TEMPOS E ESPAÇADOR. COMPARAÇÃO PELO TESTE EXATO DE FISHER $(\alpha=$ $0,05)$

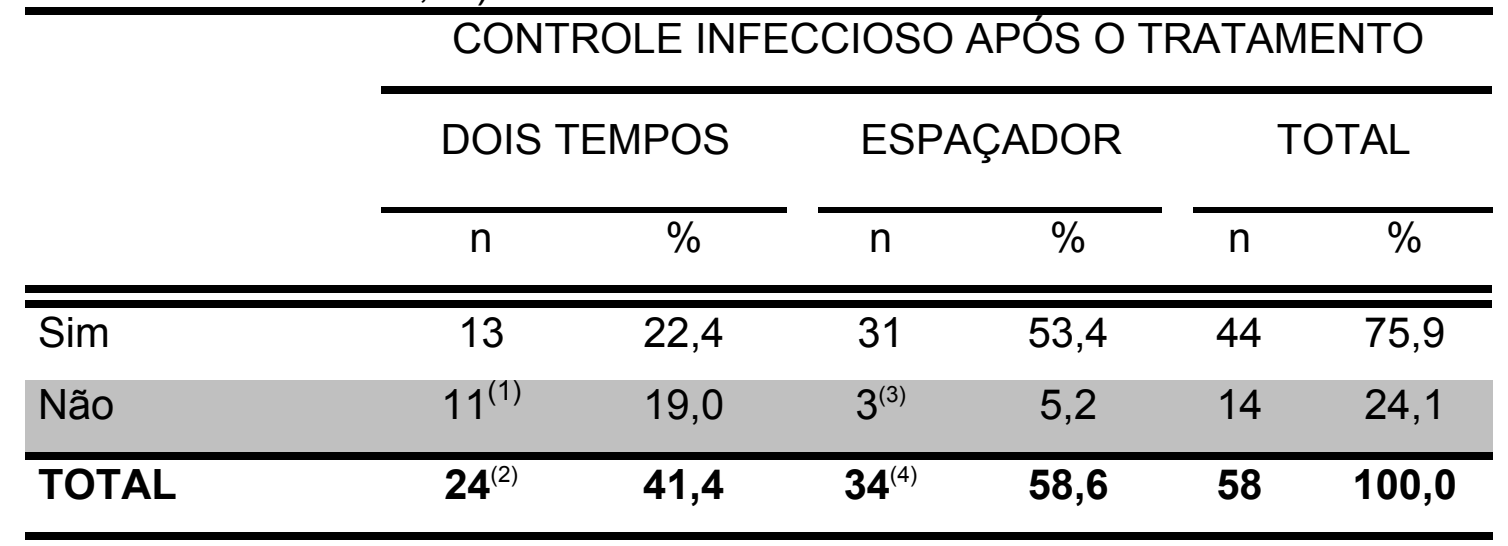

Fisher $p=0,002^{*}$

(1) 7 casos com infecção após o primeiro tempo cirúrgico e 4 após o segundo tempo cirúrgico

(2) 1 caso de óbito intra-operatório no primeiro tempo cirúrgico

(3) 3 casos de infecção após o primeiro tempo cirúrgico

(4) 2 casos de óbito após o primeiro tempo cirúrgico

Dois tempos

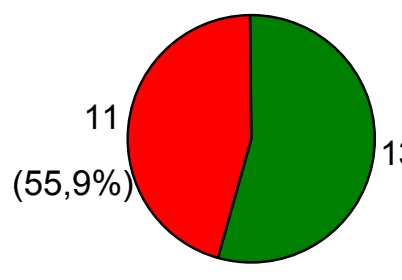

Sim
(54,1\%)

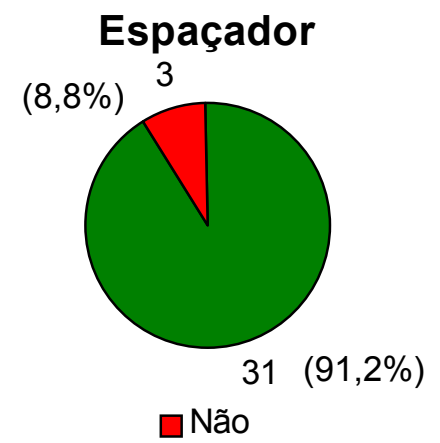

GRÁFICO37 Controle infeccioso após o tratamento 
TABELA 38

DISTRIBUIÇÃO DE FREQÜÊNCIA ABSOLUTA (n) E RELATIVA (\%) DO CONTROLE INFECCIOSO APÓS O TRATAMENTO PARA PACIENTES COM ACOMPANHAMENTO MÍNIMO DE 24 MESES DE ACORDO COM OS GRUPOS DOIS TEMPOS E ESPAÇADOR. COMPARAÇÃO PELO TESTE EXATO DE $\operatorname{FISHER}(\alpha=0,05)$

$$
\text { CONTROLE INFECCIOSO APÓS }
$$

ACOMPANHAMENTO MÍNIMO DE 24 MESES

\begin{tabular}{|c|c|c|}
\hline DOIS TEMPOS & ESPAÇADOR & TOTAL \\
\hline
\end{tabular}

\begin{tabular}{lcccccc}
\hline \hline Sim & 8 & 20,5 & 17 & 43,6 & 25 & 64,1 \\
Não & 11 & 28,2 & 3 & 7,7 & 14 & 35,9 \\
\hline TOTAL & $\mathbf{1 9}^{(1)}$ & $\mathbf{4 8 , 7}$ & $\mathbf{2 0}^{(2)}$ & $\mathbf{5 1 , 3}$ & $\mathbf{3 9}$ & $\mathbf{1 0 0 , 0}$ \\
\hline Fisher & $p=0,008^{*}$ \\
\hline & (1) 1 caso de óbito intra-operatório no primeiro tempo cirúrgico e 5 casos com menos de 24 \\
meses de acompanhamento & (2) 2 casos de óbito e 14 casos com menos de 24 meses de acompanhamento
\end{tabular}

Dois Tempos

$(57,9 \%)$

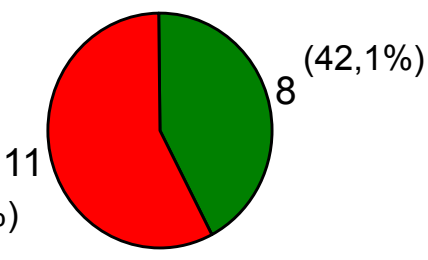

$\operatorname{Sim}$

\section{Espaçador}

$(15,0 \%) 3$

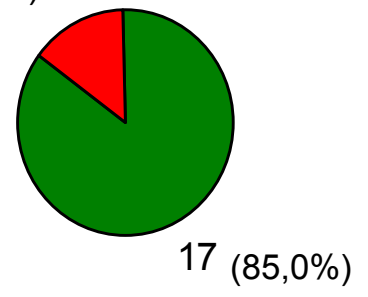

Não

GRÁFICO38 Controle infeccioso após acompanhamento mínimo de 24 meses 
TABELA 39

DISTRIBUIÇÃO DE FREQÜÊNCIA ABSOLUTA (n) E RELATIVA (\%) DO CONTROLE INFECCIOSO AO FINAL DO SEGUIMENTO, APÓS O TRATAMENTO COM VÁRIAS CIRURGIAS, DE ACORDO COM O GRUPO, DOIS TEMPOS E ESPAÇADOR. COMPARAÇÃO PELO TESTE EXATO DE FISHER $(\alpha=0,05)$

CONTROLE INFECCIOSO APARENTE APÓS

TRATAMENTO COM VÁRIAS CIRURGIAS

\begin{tabular}{|c|c|c|c|c|c|}
\hline \multicolumn{2}{|c|}{ DOIS TEMPOS } & \multicolumn{2}{|c|}{ ESPAÇADOR } & \multicolumn{2}{|c|}{ TOTAL } \\
\hline $\mathrm{n}$ & $\%$ & $\bar{n}$ & $\%$ & $\mathrm{n}$ & $\%$ \\
\hline 18 & 32,7 & 34 & 61,8 & 52 & 94,5 \\
\hline 3 & 5,5 & 0 & 0,0 & 3 & 5,5 \\
\hline $21^{11}$ & 38,2 & $34^{(2)}$ & $\begin{array}{ll}61,8 \\
\end{array}$ & 55 & 100,0 \\
\hline
\end{tabular}

Fisher

(1) 4 casos de óbito

(2) 2 casos de óbito

Dois Tempos

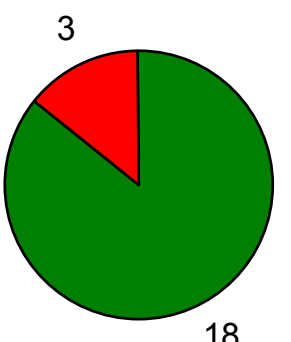

$\square \operatorname{Sim}$

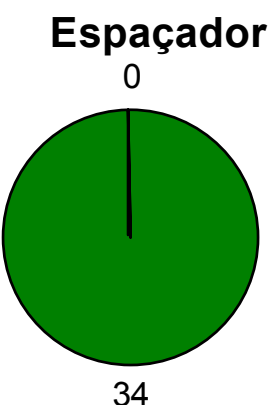

$\square$ Não

GRÁFICO39 Controle infeccioso ao final do seguimento, após várias cirurgias 
TABELA 40 ESTATÍSTICA DESCRITIVA E VARIAÇÃO ABSOLUTA DO ESCORE DE HARRIS PARA QUADRIL (HHS) PRÉOPERATÓRIO E NO ÚLTIMO RETORNO NOS PACIENTES QUE COMPARECERAM COM PRÓTESE E SEM INFECÇÃO DE ACORDO COM O GRUPO, DOIS TEMPOS E ESPAÇADOR. COMPARAÇÕES PELOS TESTES DE WILCOXON (RELACIONADOS) E U DE MANN-WHITNEY $(\alpha=$ $0,05)$

\begin{tabular}{|c|c|c|c|c|c|c|}
\hline & \multicolumn{6}{|c|}{ ESCORE DE HARRIS PARA QUADRIL (HHS) } \\
\hline & \multicolumn{3}{|c|}{ DOIS TEMPOS } & \multicolumn{3}{|c|}{ ESPAÇADOR } \\
\hline & $\begin{array}{c}\text { Pré- } \\
\text { operatório }\end{array}$ & Atual & $\Delta$ & $\begin{array}{c}\text { Pré- } \\
\text { operatório }\end{array}$ & Atual & $\Delta$ \\
\hline $\mathrm{M}$ & 19,3 & 69,0 & 49,7 & 19,7 & 75,2 & 55,5 \\
\hline $\mathrm{DP}$ & 10,0 & 10,3 & 10,0 & 13,8 & 14,1 & 17,7 \\
\hline EPM & 3,3 & 3,4 & 3,3 & 2,5 & 2,5 & 3,2 \\
\hline MAX & 39 & 81 & 68 & 51 & 94 & 88 \\
\hline MIN & 8 & 50 & 37 & 3 & 40 & 16 \\
\hline$N$ & 9 & 9 & 9 & 31 & 31 & 31 \\
\hline
\end{tabular}

Wilcoxon W $W=496 \mathrm{p} \cong 0,00^{*} \quad W=45 \quad p=0,004^{*}$

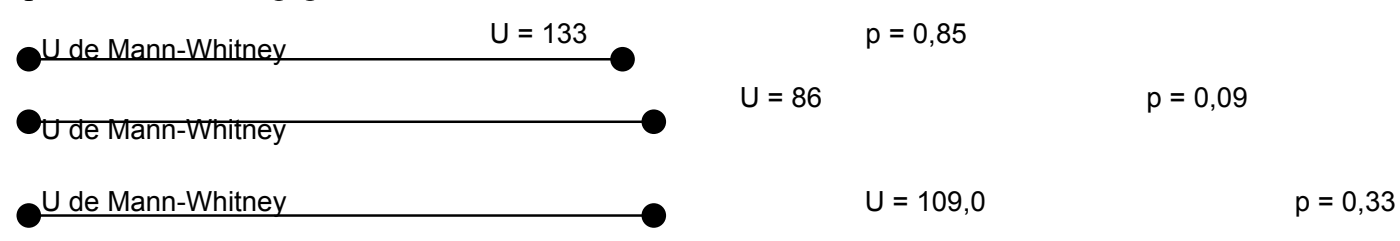

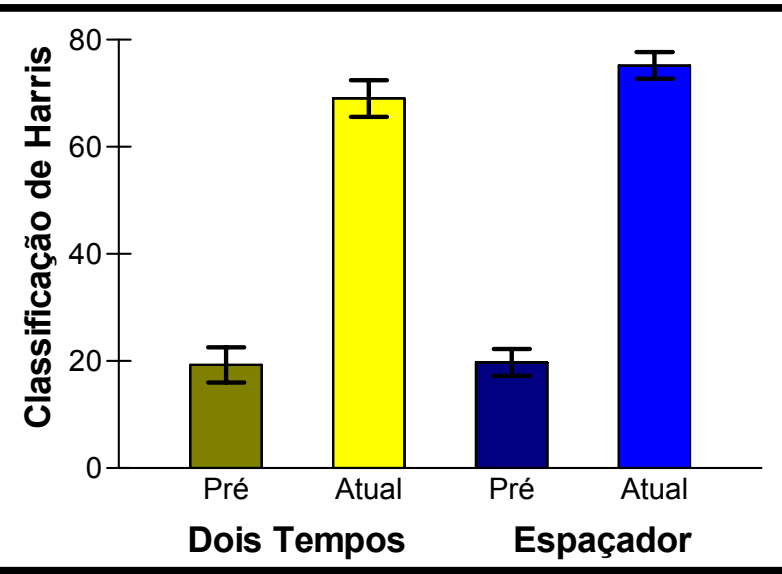

GRÁFICO40 Escore de Harris para quadril (HHS) pré-operatório e atual 
TABELA 41 ESTATÍSTICA DESCRITIVA DA DISCREPÂNCIA FINAL DO COMPRIMENTO (cm) DOS MEMBROS INFERIORES NOS PACIENTES COM IMPLANTES MANTIDOS NO ÚLTIMO RETORNO DE ACORDO COM O GRUPO, DOIS TEMPOS E ESPAÇADOR. COMPARAÇÃO PELO TESTE U DE MANN WHITNEY $(\alpha=0,05)$

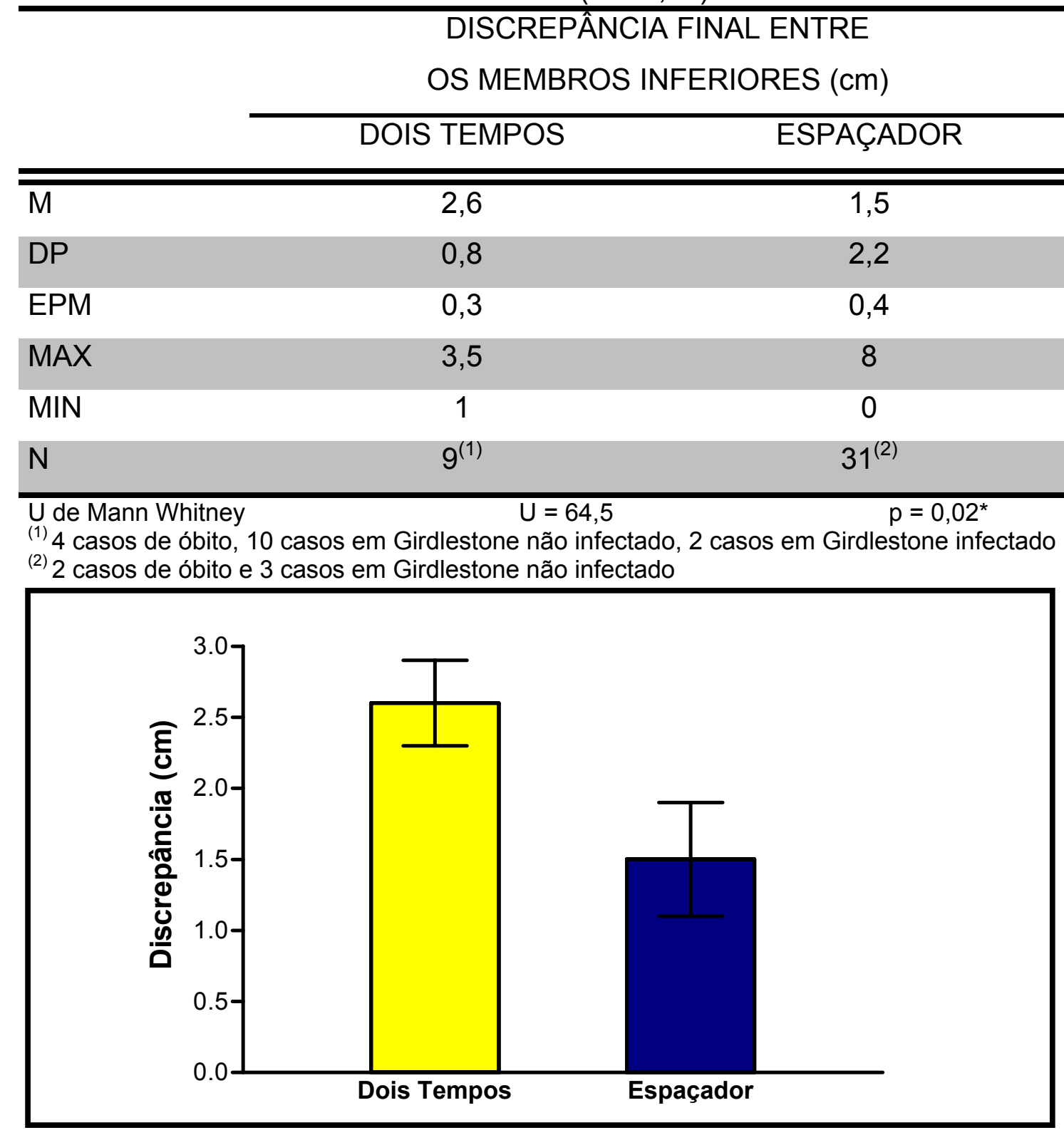

GRÁFICO41 Discrepância final do comprimento $(\mathrm{cm})$ dos membros inferiores nos pacientes com implantes mantidos no último seguimento 
TABELA 42

DISTRIBUIÇÃO DE FREQÜÊNCIA ABSOLUTA (n) E RELATIVA (\%) DO RESULTADO FINAL DE ACORDO COM O GRUPO, DOIS TEMPOS E ESPAÇADOR

\begin{tabular}{|c|c|c|c|c|c|c|}
\hline & \multicolumn{6}{|c|}{ RESULTADO FINAL } \\
\hline & \multicolumn{2}{|c|}{ DOIS TEMPOS } & \multicolumn{2}{|c|}{ ESPAÇADOR } & \multicolumn{2}{|c|}{ TOTAL } \\
\hline & $\mathrm{n}$ & $\%$ & $\mathrm{n}$ & $\%$ & $\mathrm{n}$ & $\%$ \\
\hline Prótese Funcionante & 8 & $\overline{13,1}$ & 31 & 50,8 & 39 & 63,9 \\
\hline Prótese Luxada & 0 & 0,0 & 1 & 1,6 & 1 & 1,6 \\
\hline Prótese Infectada & 1 & 1,6 & 0 & 0,0 & 1 & 1,6 \\
\hline Girdlestone & 8 & 13,1 & 2 & 3,3 & 10 & 17,4 \\
\hline $\begin{array}{l}\text { Girdlestone e Retalho } \\
\text { Vasto Lateral }\end{array}$ & 2 & 3,3 & 1 & 1,6 & 3 & 4,9 \\
\hline Girdlestone Infectado & 2 & 3,3 & 0 & 0,0 & 2 & 3,3 \\
\hline Óbito não Relacionado & 1 & 1,6 & 0 & 0,0 & 1 & 1,6 \\
\hline Óbito Relacionado & 3 & 4,9 & 1 & 1,6 & 4 & 6,6 \\
\hline$\overline{\text { TOTAL }}$ & 25 & 41,0 & 36 & 59,0 & 61 & $\overline{100,0}$ \\
\hline
\end{tabular}


TABELA 43

DISTRIBUIÇÃO DE FREQÜÊNCIA ABSOLUTA (n) E RELATIVA (\%) DO RESULTADO FINAL DE ACORDO COM O GRUPO, DOIS TEMPOS E ESPAÇADOR. COMPARAÇÃO PELO TESTE DE QUI-QUADRADO $(\alpha=$ $0,05)$

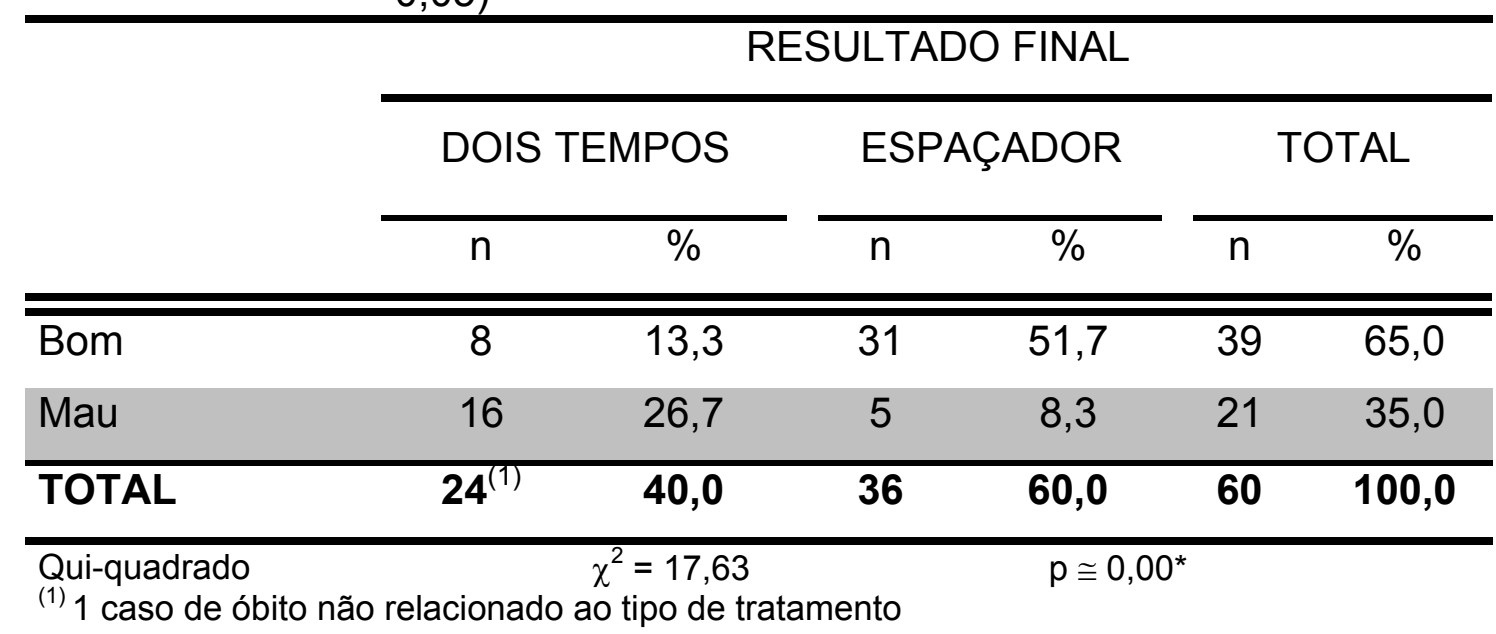

$(66,4 \%)$

Dois Tempos

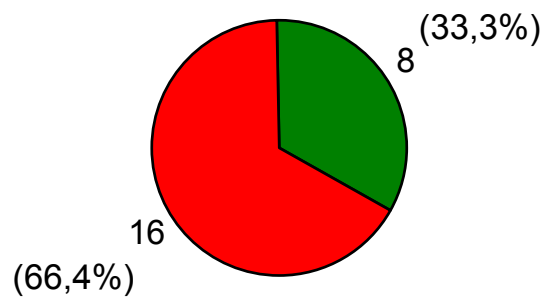

$\square$ Bom $\square \mathrm{Mau}$

\section{Espaçador}

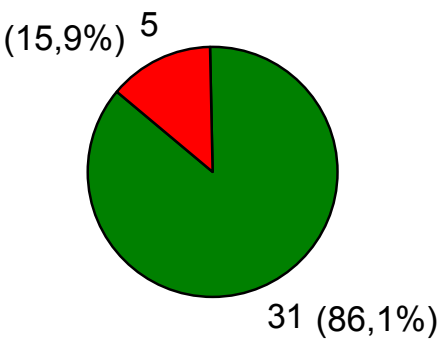

$\square$ Bom $\square \mathrm{Mau}$

GRÁFICO43 Resultado final 


\section{DISCUSSÃO}


Persiste a dúvida sobre qual método é o mais eficaz no controle da infecção em artroplastias de quadril e qual deles pode proporcionar reabilitação mais rápida, com custo econômico e social mais baixo.

Há várias dificuldades para analisar os resultados das diferentes modalidades de tratamento. O método de diagnóstico da infecção, as bactérias isoladas, a seleção dos pacientes, a descrição acurada da técnica cirúrgica empregada, o tipo de artroplastia realizada, o tipo e duração da antibioticoterapia, o método de avaliação funcional, a validade dos resultados e a duração do acompanhamento são aspectos muito variados e nem sempre abrangidos pelos autores.

Há evidências de que o risco de infecção recorrente continua alto mesmo após muitos anos e que a taxa de recidiva aumenta com o correr do seguimento (RAUT et al., 1995; WENT et al.,1995). Se estas recidivas são devidas à recorrência da infecção original (reinfecção) ou representam uma nova infecção continua incerto, mas ambos mecanismos devem ser importantes.

A maioria das publicações adota como acompanhamento mínimo o período de dois anos após a última cirurgia realizada para afirmar-se que há controle infeccioso, embora atualmente haja uma tendência para aumentar este tempo para cinco anos (WROBLEWSKI, 1986; RUDELLI, 2003).

\subsection{EVOLUÇÃO GERAL DOS GRUPOS ESTUDADOS}

Para facilitar a análise dos grupos, descreveremos brevemente a evolução dos pacientes a partir do primeiro tempo cirúrgico, para, a seguir, discutirmos cada um dos aspectos do tratamento. Os dados gerais do trtatamento e seu acompanhamento estão nas listagens 1 e 2 do anexo $C$.

O intervalo de tempo entre os cirúrgicos foi equivalente para os dois grupos, com média de 226,9 dias para o grupo e 162,8 dias para o grupo Espaçador (tabela 12 e gráfico 12).

O tempo médio de acompanhamento, desde a realização do primeiro tempo cirúrgico até o final do trabalho para todos os pacientes vivos, foi de dois anos e 11 meses para os dois grupos. O acompanhamento do grupo foi de três 
anos e dois meses, sendo equivalente estatisticamente ao do grupo Espaçador, que foi de dois anos e três meses (tabela 13 e gráfico 13).

\subsubsection{Grupo Dois Tempos}

Vinte e cinco pacientes participaram do grupo tratado em dois tempos.

Uma paciente que havia sido selecionada para tratamento neste grupo faleceu durante o primeiro tempo cirúrgico por lesão vascular na retirada do componente acetabular. Como a sua morte não teve relação com o tipo de método de tratamento infeccioso, esta paciente foi excluída da análise estatística.

Sete pacientes apresentaram recidiva infecciosa entre sete a 112 dias (média de 36,0 dias) depois do primeiro tempo cirúrgico (tabelas e gráficos 33 e 34). Estes pacientes foram tratados com limpezas cirúrgicas sucessivas, retalhos musculares ou espaçador de cimento com antibiótico. Ao final do estudo, apenas dois pacientes continuavam infectados.

Em dois pacientes foi optado pela manutenção em Girdlestone, um por apresentar más condições clínicas e outro por apresentar amputação ao nível do joelho. Um paciente recusou a colocação de nova prótese. Ao final do trabalho estes três pacientes estavam em Girdlestone e com controle infeccioso.

Quinze pacientes foram submetidos ao segundo tempo cirúrgico entre 70 e 610 dias depois do primeiro tempo cirúrgico (tabela 12 e gráfico 12).

Em um paciente não foi possível implantar os componentes por dificuldade técnica.

Um paciente faleceu por recidiva infecciosa e sépsis, 43 dias após o segundo tempo cirúrgico.

Dois pacientes faleceram por complicações hemorrágicas decorrentes do segundo tempo cirúrgico.

Dos onze pacientes com implantes colocados com sucesso, três apresentaram recidiva infecciosa em menos de seis meses (tabela56). Um paciente, que foi tratado com múltiplas cirurgias, continua infectado. Um paciente foi submetido à retirada da prótese e limpeza cirúrgica, com controle infeccioso, há mais de dois anos. Um paciente foi tratado com antibioticoterapia 
endovenosa e via oral prolongada e não apresenta fístulas ou sinais de soltura séptica radiográficos com um ano de seguimento.

Oito casos mantinham suas próteses com boa função e sem sinais de recidiva infecciosa. após acompanhamento médio de dois anos e sete meses (tabela 14 e gráfico 14).

\subsubsection{Grupo Espaçador}

Trinta e seis pacientes participaram do grupo tratado em dois tempos com uso de espaçador de cimento com antibiótico.

Um paciente faleceu por migração pélvica do espaçador e foi contado como falha do método.

Um paciente faleceu por causas não relacionadas ao tratamento (colecistite aguda), quatro meses após o segundo tempo.

Três pacientes apresentaram recidiva infecciosa após o primeiro tempo cirúrgico (tabelas e gráficos 33 e 34 ). Um paciente abandonou 0 acompanhamento e parou a antibioticoterapia oral um mês após o primeiro tempo cirúrgico, retornando com infecção, quatro meses após a cirurgia. $O$ espaçador foi retirado e a infecção estava controlada no último acompanhamento. Os outros dois pacientes ficaram internados por 95 dias e 359 dias, respectivamente, sendo submetidos a várias cirurgias e ficaram em Girdlestone definitivo, com controle infeccioso, até o último seguimento.

Foi realizado o segundo tempo cirúrgico em 31 pacientes com 60 a 350 dias de intervalo entre os dois tempos (tabela 12 e gráfico 12).

Nenhum paciente apresentou sinais de infecção até o último acompanhamento, que ocorreu em média um ano e nove meses após o segundo tempo cirúrgico (tabela 14 e gráfico 14).

Dois pacientes apresentaram luxações recidivantes e foram tratados cirurgicamente; um deles permaneceu com a prótese luxada e, conseqüentemente, sem função.

Um paciente evoluiu com soltura acetabular asséptica após três meses do segundo tempo cirúrgico. O componente foi revisado após nove meses do primeiro tempo, com culturas intra-operatórias negativas. Este paciente faleceu por tumor maligno, com três anos e dois meses de seguimento, sem sinais de 
infecção. Este caso entrou em nossa análise estatística por apresentar mais de dois anos de seguimento.

Um paciente apresentou sinais de soltura radiográfica da haste femoral cimentada após quatro anos de seguimento, sem quadro doloroso.

Trinta e um casos mantinham suas próteses com boa função e sem sinais de recidiva infecciosa no último acompanhamento.

\subsection{ASPECTOS DEMOGRÁFICOS, CLÍNICOS E LABORATORIAIS PRÉ- OPERATÓRIOS}

A idade média dos dois grupos é de 54,6 anos. O paciente mais jovem é um rapaz de 16 anos vítima de displasia epifisária e o mais idoso, um senhor de 84 anos, com displasia fibrosa.

Com relação à literatura, a maioria dos trabalhos analisados trata de uma população mais idosa, com média de idade variando entre 52,0 a 73,9 anos. Os trabalhos orientais (LEE et al.1996; WANG; CHEN,1997; KOO et al.,2001) envolvem uma população mais jovem, devido à alta incidência de osteonecrose e fraturas em seu meio.

Em nosso caso, os fatores etiológicos que levaram à realização da prótese primária influíram diretamente na idade da população.

A incidência conjunta de seqüelas de trauma, osteonecrose e doenças reumáticas, que ocorrem em população mais jovem, somou $52,5 \%$, ao passo que osteoartrose, característica dos mais idosos, contribuiu com 27,9\% (tabela 4 e gráfico 4).

A maioria $(60,6 \%)$ dos pacientes havia realizado a artroplastia que infectou em outras instituições (anexo A, tabela 1 e gráfico 1).

Segundo ELSON (1998), a maioria das infecções tratadas em centros especializados é de outros hospitais.

Oitenta por cento dos 659 pacientes da série de BUCHHOLZ et al. (1981) são de outros hospitais e esta é uma constante nos trabalhos que analisam esta questão: 56,5\% em ANTTI-POIKA et al. (1989), 57,0\% em MCDONALD et al. (1989), 71,5\% em RAUT et al. (1995) e 92,5\% em ENGLISH et al. (2002). 
Toda a população do estudo apresentou infecções tipos II e III segundo COVENTRY (1975) e FITZGERALD et al. (1977) ou tipos III e IV de TSUKAYAMA et al. (1996).

Em vários artigos são tratadas infecções dos tipos la e lb de COVENTRY (1976), I de FITZGERALD et al. (1977) e I e II de TSUKAYAMA et al. (1996), caracterizadas como infecções agudas, conjuntamente com os outros tipos, sem serem separados os grupos na análise estatística. Este fato prejudica a comparação adequada de nossos resultados aos desses trabalhos.

Todos os pacientes apresentavam fístulas ativas ao exame físico, o que caracteriza a cronicidade e gravidade das infecções (HUNTER; DANDY, 1977).

Ao revisar a literatura, poucos artigos mencionam a existência ou não de fístulas ativas ao exame físico dos pacientes.

AHLGREN et al. (1980), RAUT et al. (1995), ALEXEEFF et al. (1996) e TSUKAYAMA et al. (1996) publicam trabalhos envolvendo somente pacientes com fístulas ativas.

A presença de fístulas ativas contra-indica a realização de revisão em tempo único para HUNTER; DANDY (1977), HUGHES et al. (1979), MILEY et al. (1982), SALVATI et al. (1982), GARVIN et al. (1988), SANZÉN et al. (1988), ELSON (1993), DUNCAN; BEAUCHAMP (1993), GARVIN et al. (1994), URE et al. (1998), CALLAGHAN et al. (1999), LECUIRE et al. (1999), JACKSON; SCHMALZRIED (2000) e HANSSEN; OSMON (2002).

Por outro lado, CARLSSON et al. (1978), BUCHHOLZ et al. (1981), WROBLEWSKI (1986), RAUT et al. (1994) e RUDELLI et al. (2003) executam revisão em tempo único, mesmo com fístulas ativas.

Doze pacientes do grupo Dois Tempos haviam sido submetidos, cada um, a 1,6 procedimentos, em média, na tentativa de erradicar a infecção. Do mesmo modo, 25 pacientes do grupo Espaçador haviam sido operados em média 1,8 vezes cada um, na tentativa de tratar o processo infeccioso.

Os pacientes de CLEGG (1977) são operados, cada um, de duas a oito vezes antes de serem trados com Girdlestone. Cada um dos pacientes de BERRY; CHANDLER (1991) é operado 3,9 vezes, em média, antes de ser 
realizado o tratamento em dois tempos. Os pacientes de CHARLTON et al (2003) são operados em média 3,5 vezes antes da colocação das próteses definitivas.

De um modo geral, esta quantidade grande de tentativas de tratamento reflete o grau de dificuldade do controle infeccioso, especialmente nos casos com perda óssea associada.

São imprescindíveis a avaliação e o acompanhamento clínicos rigorosos durante todo o tratamento do processo infeccioso, pois notamos que metade dos pacientes apresentou doenças sistêmicas associadas (anexo $A$, tabelas e gráficos 5 e 6 ).

A contagem de leucócitos média em ambos os grupos foi de 8425,4 leucócitos $/ \mathrm{ml}$ (anexo A, tabelas e gráficos 8 e 9). Treze pacientes (21,3\%) apresentavam contagem acima de 10000 leucócitos $/ \mathrm{ml}$.

CANNER et al. (1984) encontram leucocitose em 15,1\% de seus pacientes; MCDONALD et al. (1989) em 16,9\%; TSUKAYAMA et al. (1996) em 16,0\%; WANG; CHEN (1997) em 31,9\% e TATTEVIN et al. (1999) em 27,5\%.

Estas médias são semelhantes à nossa e comprovam que a contagem de leucócitos não se encontra alterada na maioria dos pacientes com infecção crônica (HUGHES et al. 1979).

A velocidade de hemossedimentação é uma medida da capacidade dos eritrócitos em aglutinarem pela presença de proteínas de fase aguda no soro, sendo uma medida indireta de atividade inflamatória.

O valor normal da velocidade de hemossedimentação é amplo, podendo ser elevado em várias condições não infecciosas, como anemia severa, leucemia, linfoma, tumores metastáticos, doenças reumáticas e do colágeno, pancreatite aguda, colecistite, peritonite, pielonefrite, síndrome nefrótica, hipotiroidismo, sarcoidose e anemia falciforme (SHIH et al.,1986; SANZÉN; SUNDBERG, 1997).

SPANGEHL et al. (1999) encontram sensibilidade de $82,0 \%$ e especificidade de $85,0 \%$ para a velocidade de hemossedimentação, com valor

"RUDELLI, S. (Santa Casa de Misericórdia de São Paulo). Correspondência pessoal, 2003. 
preditivo negativo de 95,0\% para diagnóstico de infecção após seis meses de uma artroplastia.

A velocidade de hemossedimentação ficou acima de 40,0 mm/h em 55 pacientes $(90,2 \%)$, entre $20,0 \mathrm{~mm} / \mathrm{h}$ e $40,0 \mathrm{~mm} / \mathrm{h}$ em cinco pacientes $(8,2 \%)$ e abaixo de $20,0 \mathrm{~mm} / \mathrm{h}$ em um paciente $(1,6 \%)$.

Vários trabalhos utilizam a velocidade de hemossedimentação como parâmetro para diagnóstico e controle infecciosos. HUGHES et al. (1979) apontam valores acima pré-operatórios de $20 \mathrm{~mm} / \mathrm{h}$ em $84,6 \%$ dos pacientes; CANNER et al. (1984) em 60,6\%; MCDONALD et al. (1989) em 75\%; WANG; CHEN (1997) em 91\%; TATTEVIN et al. (1999) em 71\% e KOO et al. (2001) em $95,4 \%$.

A média da velocidade de hemossedimentação foi de $60,0 \mathrm{~mm} / \mathrm{h}$ em ambos os grupos (anexo A, tabelas e gráficos 8 e 10). Os dados são semelhantes aos de TSUKAYAMA et al. (1996); LEUNIG et al. (1998), HADDAD et al. (2000) e $\mathrm{KOO}$ et al. (2001) que observam respectivamente médias de 60,0; 50,0; 59,0 e 77,0 na velocidade de hemossedimentação.

A proteína C-reativa deve seu nome à capacidade de precipitar o polissacarídeo $\mathrm{C}$ do pneumococo na presença de cálcio. Ela é uma proteína de fase aguda produzida pelo fígado, sendo uma medida direta da inflamação.

Elevações não infecciosas da proteína C-reativa são encontradas em doenças neoplásicas, reumáticas, pielonefrite, infarto do miocárdio, uso de contraceptivos orais e no terceiro trimestre da gravidez (DINARELLO, 2000).

O valor preditivo positivo de alterações nos níveis de proteína C-reativa para infecção é de $74,0 \%$, porém o valor preditivo negativo é de $99 \%$. A sensibilidade é de $96,0 \%$ e a especificidade é de 92,0\% (SPANGHEL et al., 1999).

O pico da proteína C-reativa ocorre após dois a três dias da cirurgia. Elevação constante da proteína C-reativa após o terceiro dia sugere permanência do processo infeccioso (NISKANEN et al. 1996).

Os níveis de proteína C-reativa retornam ao normal em três semanas após o ato cirúrgico (SANZÉN; CARLSSON, 1989), enquanto que a velocidade de hemossedimentação pode permanecer elevada até um ano após a cirurgia (AALTO et al., 1983; SHIH et al., 1986). 
Não foi colhido exame para medição de proteína C-reativa em 10 de nossos casos por problemas técnicos de nosso serviço. Nos 51 restantes a média foi de $42,2 \mathrm{mg} / \mathrm{l}$ (anexo A, tabelas e gráficos 8 e 11), sendo que todos os casos apresentavam níveis acima dos valores normais (abaixo de 5,0 mg/dl).

Níveis acima de $10 \mathrm{mg} / \mathrm{dl}$ de proteína C-reativa são registrados em 69,6\% dos pacientes de TATTEVIN et al. (1999), 54\% de HADDAD et al.. (2000) e 96,7\% de PIRIOU et al. 2003, comparados a 96,1\% em nossa série.

SANZÉN; CARLSSON (1989) observam velocidade de hemossedimentação e níveis de proteína C-reativa normais em 33 pacientes operados por revisão asséptica. Em pacientes tratados por infecção profunda pelo menos um destes valores está alterado em 22 de 23 (95,6\%) casos.

A combinação de velocidade de hemossedimentação e níveis de proteína C-reativa normais exclui infecção em $100 \%$ dos casos. Quando ambos estão alterados, o valor preditivo positivo é de 83\% (SPANGEHL et al., 1999).

A velocidade de hemossedimentação e os níveis de proteína C-reativa foram parâmetros importantes na monitorização infecciosa e indicação da realização do segundo tempo cirúrgico. Em cinco casos de persistência de elevação dos parâmetros infecciosos, realizamos a punção da articulação e cultura da amostra para averiguar a segurança da realização da prótese definitiva, procedimento com $80,0 \%$ de sensibilidade segundo Gould et al. (1990) e que deve ser realizado em pacientes selecionados e não em todos os casos, conforme BARRACK; HARRIS (1993).

A evolução natural da infecção em artroplastias é a soltura dos componentes pelo processo inflamatório intenso e perda óssea progressiva, devida aos fatores osteolíticos secretados pelas bactérias e pelas células de defesa do organismo (ALEXEEFF et al.,1996). Os componentes soltos atritam com o osso remanescente provocando corrosão mecânica e acelerando o desgaste. A perda óssea pode ser agravada também pelas técnicas de retirada dos componentes fixos, especialmente os não cimentados (WANG; CHEN, 1997).

A incidência alta de perdas femorais graves (tabelas e gráficos 9 e 10), chegando a 17 casos no grupo Espaçador, demonstra a longa duração da 
atividade infecciosa nos pacientes. As perdas ósseas graves dificultam ainda mais o tratamento, pois elas necessitam de técnicas reconstrutivas mais elaboradas a serem realizadas no segundo tempo cirúrgico.

O grau de perda óssea é pouco relatado nos trabalhos das décadas de 1970 e 1980. Notamos uma incidência maior de falhas ósseas graves em trabalhos das décadas de 1990 e 2000. A comparação com nossa casuística é difícil, pela diversidade de sistemas de classificação utilizados e pelas poucas referências a perdas ósseas.

De um modo geral, trabalhos que adotam como conduta a cirurgia de Girdlestone definitiva apresentam perdas ósseas maiores (CLEG, 1977; AHLGREN et al.,1980; BITTAR; PETTY, 1982; BOURNE et al., 1984; MORSCHER, 1994; LEE et al., 1996; CASTELLANOS et al. ,1998; JAHODA et al., 2003).

Estudando a revisão em dois tempos com enxerto ósseo em 22 casos, WANG; CHEN (1997) encontram perda cavitária acetabular em 90,1\%, segmentar acetabular em 9,9\%, cavitária femoral em $45,4 \%$ e segmentar femoral em $18,1 \%$.

BERRY; CHANDLER (1991) e ENGLISH et al. (2002) apontam perda óssea variável em os todos casos e ALEXEEFF et al.(1996) encontra graves perdas ósseas femorais em 11 casos.

RUDELLI et al (2003) ${ }^{*}$ encontram, do lado acetabular: seis perdas ósseas do tipo I, seis do tipo II, 14 do tipo III e seis do tipo IV. Do lado femoral encontram duas do tipo I, 17 do tipo II, nove do tipo III e quatro do tipo IV.

$\mathrm{O}$ espaçador preencheu adequadamente o espaço morto deixado pelas perdas ósseas, especialmente as mais graves, e permitiu maior segurança para mobilizar precocemente o paciente (figuras 7 e 8 ).

\subsection{DURAÇÃO DAS CIRURGIAS}

A duração média das cirurgias do primeiro tempo cirúrgico sempre foi maior que duas horas (tabela e gráfico 15), refletindo a dificuldade técnica e os cuidados cirúrgicos minuciosos, sempre com atenção para causar o mínimo de

\footnotetext{
"RUDELLI, S. (Santa Casa de Misericórdia de São Paulo). Correspondência pessoal, 2003.
} 

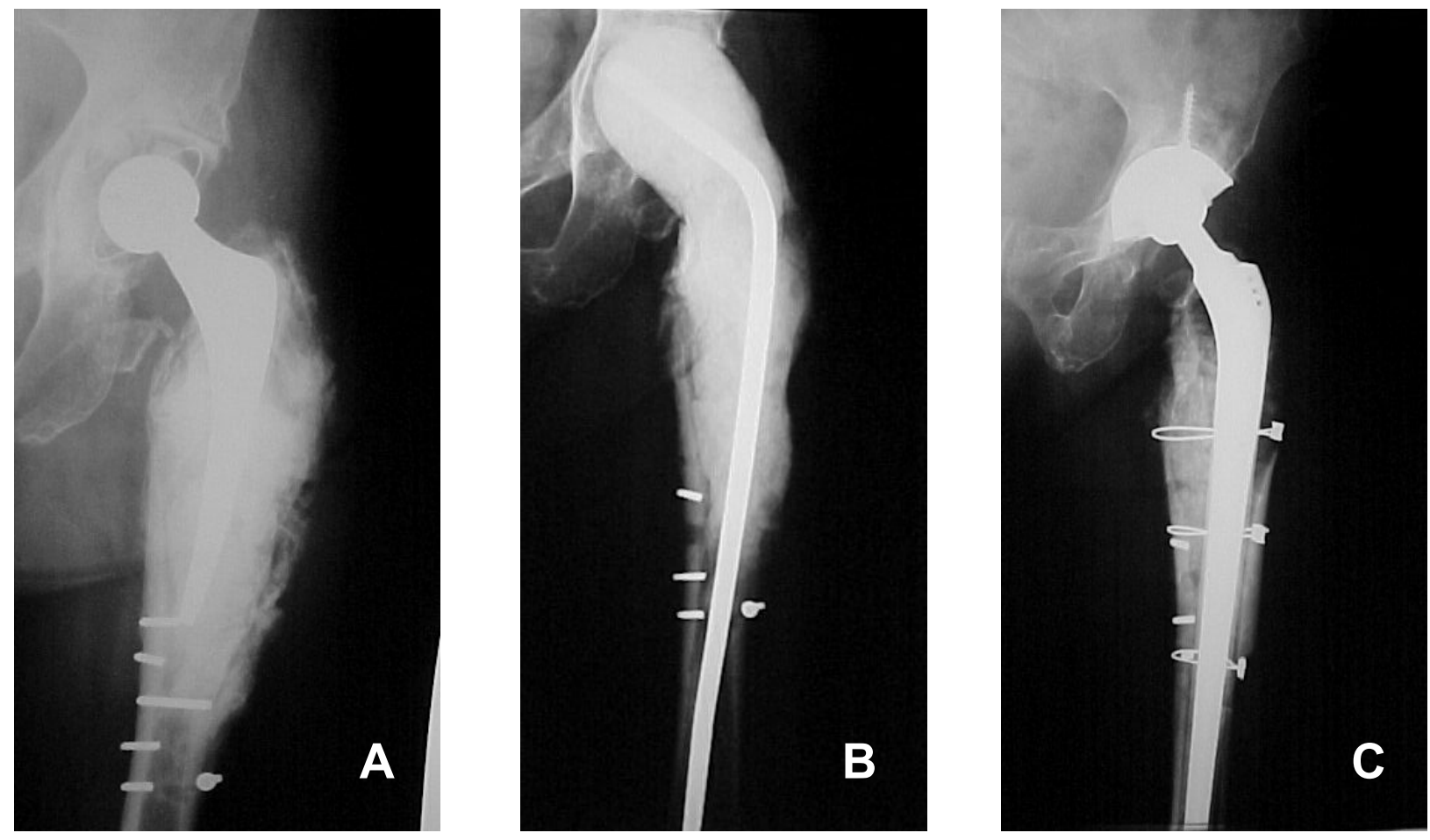

FIGURA 7 Caso 16 do grupo Espaçador. Paciente de 74 anos, com artroplastia após pseudartrose de fratura intertrocanteriana. A - Perda óssea femoral grau IV , sem perda óssea acetabular. B - Espaçador com haste de Küntscher dobrada, simulando o colo femoral. Notou-se, durante o ato cirúrgico, que não havia parede lateral do fêmur, com três cloacas na região. A paciente apresentou sangramento intraoperatório grave, a partir de artéria em região da linha áspera. C Radiografia do último retorno. Foi colocada haste femoral sem cimento , fixada com cimento ao enxerto maciço de terço proximal de fêmur e sem cimento no osso hospedeiro. Após um ano e meio, a paciente apresenta Escore de Harris para Quadril de 84, com boa função, sem dor ou sinais de recidiva infecciosa. 

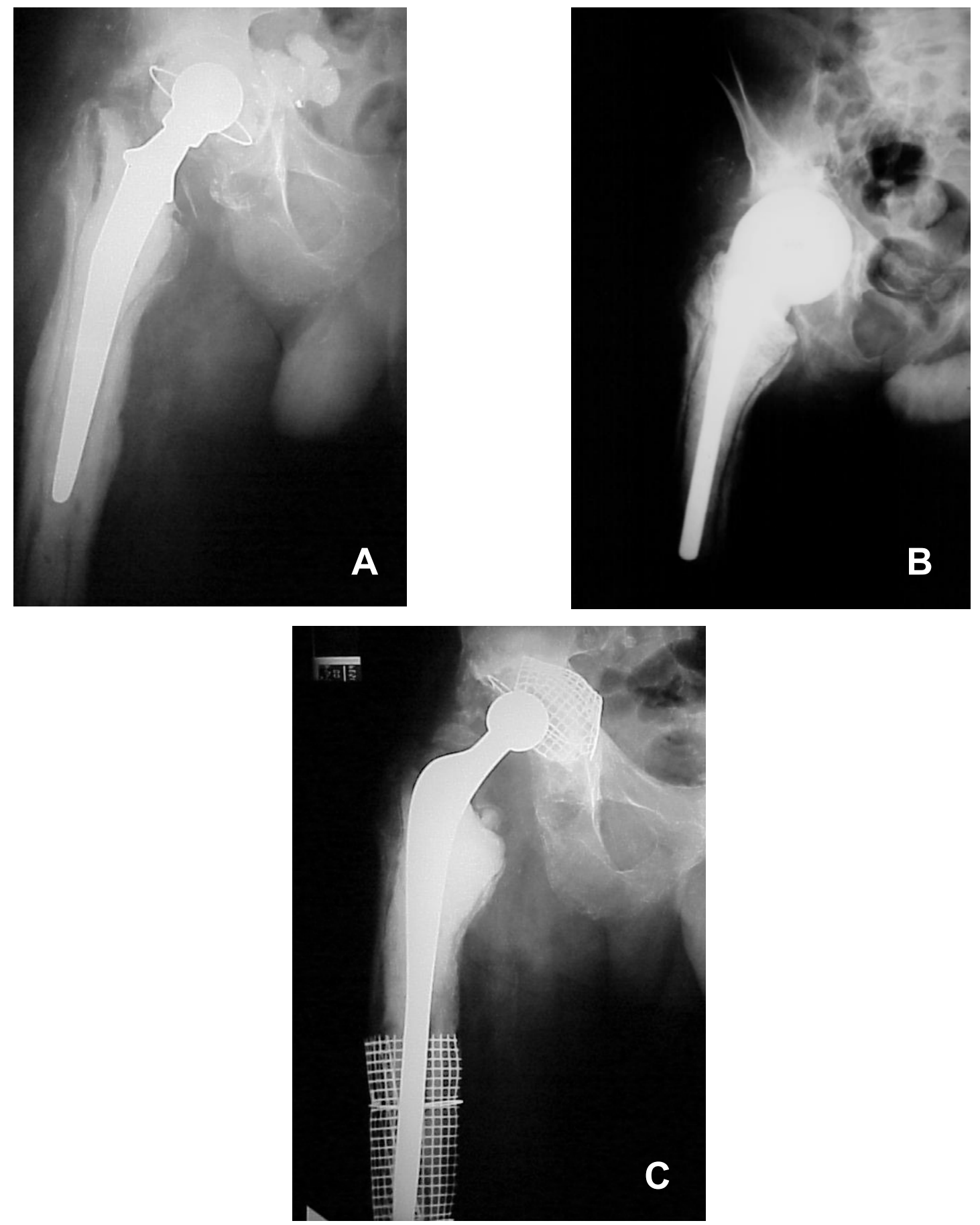

FIGURA 8 Caso 14 do grupo espaçador. Paciente de 79 anos, vítima de fratura do colo do fêmur, com três cirurgias prévias antes do tratamento. A Radiografia pré-operatória, com extrusão do cimento do componente acetabular para a pelve interna. B - Espaçador confeccionado com haste PCA esterilizada. C - Radiografia do retorno após dois anos e meio do segundo tempo cirúrgico. Foram realizadas técnicas de enxerto impactado no fêmur proximal e no acetábulo. Não há sinais de soltura asséptica. 
destruição óssea na retirada dos componentes e desbridar todos os tecidos inviáveis.

A realização da fistulografia pré-operatória nos orientou na busca do trajeto das fístulas, especialmente em localizações de fístulas nas regiões glútea posterior e fêmur distal posterior, regiões anatômicas íntimas a vasos e nervos importantes.

A injeção de azul de metileno no trajeto fistuloso demarcou os tecidos adjacentes a serem desbridados e confirmou a comunicação entre a prótese e o meio externo.

O primeiro tempo cirúrgico foi mais rápido no grupo Dois Tempos (tabela 15 e gráfico 15), resultado que demonstra que a confecção do espaçador aumentou o tempo cirúrgico em 40,1 minutos, em média.

Já no segundo tempo cirúrgico, observamos o inverso (tabela 16 e gráfico 16), sendo a duração média da cirurgia no grupo Espaçador praticamente uma hora a menos que no grupo Dois Tempos.

Nos pacientes operados em Dois Tempos, houve dificuldade para encontrar os planos cirúrgicos e para identificar as estruturas ósseas. Construir o leito receptor da prótese na fibrose tecidual extensa encontrada prolongou o tempo cirúrgico.

Nos casos de cirurgia em dois tempos convém fixar fios de Steinmann ao osso exposto e realizar radiografias intra-operatórias para identificar os acidentes ósseos com maior facilidade.

Quando incisamos os pacientes do grupo Espaçador, encontramos uma capa fibrosa envolvendo todo o cimento ortopédico, com dissecção e identificação de planos muito facilitada.

Notamos que a coloração azul do cimento (devido ao acréscimo de azul de metileno ao cimento no primeiro tempo cirúrgico) era mais fraca na retirada do espaçador do que quando da colocação deste, por liberação do corante para os tecidos adjacentes, que não estavam corados.

A identificação de fragmentos de cimento soltos foi muito facilitada pela coloração azul, diferenciando o polimetilmetacrilato dos tecidos ósseos e partes moles. 
A luxação do espaçador da cavidade acetabular para sua retirada não foi difícil, embora tenha ocorrido fratura de diáfise femoral em um caso de manobra rotacional intempestiva.

A retirada do espaçador nem sempre foi fácil. Especialmente nos casos de espaçadores longos, a retirada femoral teve que ser realizada com fragmentação do cimento e, em seguida, a retirada da haste.

\subsection{PERDA SANGÜÍNEA}

Não houve diferença no volume de sangue infundido após o primeiro (tabela 17 e gráfico 17) ou o segundo (tabela 18 e gráfico 18) tempos cirúrgicos em ambos os grupos, com uma tendência para repor-se mais sangue no grupo Dois Tempos. Foram infundidas no primeiro tempo 4,1 unidades de papas de hemácias em cada paciente do grupo Dois Tempos contra 3,1 unidades em cada paciente do grupo Espaçador, em média. No segundo tempo cirúrgico foram infundidas 3,9 unidades no grupo Dois Tempos e 2,6 unidades no grupo Espaçador, em média.

O volume de drenagem foi maior no grupo Dois Tempos em ambos os tempos cirúrgicos (tabelas e gráficos 19 e 20). O volume drenado no segundo tempo cirúrgico foi $217,5 \mathrm{ml}$ maior no grupo Dois Tempos, em média.

Não anotamos a reposição volêmica realizada nos pacientes, o que pode explicar a aparente discordância entre ter havido uma perda sangüínea maior no grupo Dois Tempos, embora com número de papas de hemácias repostas semelhante.

É importante notar que sangramentos graves aconteceram no segundo tempo cirúrgico do grupo Dois Tempos, com dois faclecimentos diretamente relacionados à hemorragia aguda (casos 19 e 20).

O espaço morto deixado após a retirada dos componentes é substituído por hematoma, quando não é colocado o espaçador. A partir desta coleção hemática, ocorre perda sangüínea contínua, difícil de ser controlada. Este hematoma organizado forma o extenso tecido fibrótico encontrado no segundo tempo cirúrgico. A dissecção desta fibrose é o motivo do maior sangramento observado na colocação dos implantes no grupo Dois Tempos em comparação ao grupo Espaçador. 


\subsection{TEMPO DE INTERNAÇÃO TOTAL E EM UNIDADE DE TERAPIA INTENSIVA}

Apesar da importância econômica e social da duração da internação dos pacientes, poucos trabalhos apresentam dados objetivos sobre a questão.

Geralmente, a cirurgia em tempo único requer menor tempo de internação, seguida pelos tratamento em dois tempos com espaçador, pelo Girdlestone definitivo e pela cirurgia em dois tempos (MASTERSON et al., 1998).

Os pacientes de GRAUER et al. (1989), tratados com artroplastia de ressecção, permanecem internados por 52 dias, em média. Já os pacientes submetidos a tempo único de RAUT et al. (1994) ficam internados 23 dias, em média. TSUKAYAMA et al. (1996) realizam cirurgia em dois tempos, com média de hospitalização de 32 dias.

Após o primeiro tempo cirúrgico, os pacientes do grupo Dois Tempos ficaram internados, em média, quase o dobro do tempo daqueles pacientes do grupo Espaçador (tabela 21 e gráfico 21).

O uso do espaçador realmente diminuiu o tempo de internação, pois o período de tração é obrigatório para a cicatrização de partes moles, nos pacientes tratados no grupo Dois Tempos. O tempo de tração esquelética foi de 23,6 dias, em média (anexo $D$, tabela e gráfico 1).

Realizado o segundo tempo cirúrgico, não houve diferença significativa na duração da internação dos pacientes (tabela 22 e gráfico 22).

Não encontramos referências ao tempo de permanência em unidade de terapia intensiva em literatura, mas este dado, além de ser importante do ponto de vista econômico, reflete um período de instabilidade clínica do paciente.

Não houve diferença entre os grupos na quantidade de dias em que os pacientes ficaram sob os cuidados de terapia intensiva após o primeiro tempo cirúrgico, embora haja tendência para um maior tempo de internação no grupo Dois Tempos, com dois dias em média contra 1,4 dias para o grupo Espaçador (tabela 23 e gráfico 23).

O uso do espaçador possibilita ao paciente permanecer menos tempo na unidade de terapia intensiva após o segundo tempo cirúrgico (tabela 24 e 
gráfico 24). Quando não é usado espaçador, a dissecção do tecido fibrótico leva à perda sangüínea e à instabilidade hemodinâmica.

\subsection{COMPLICAÇÕES INTRA-OPERATÓRIAS}

A incidência de complicações intra-operatórias durante o primeiro tempo não foi diferente entre os grupos (tabela 25 e gráfico 25 ).

No primeiro tempo cirúrgico, tivemos dificuldade na retirada de componentes femorais fixos, com fraturas do fêmur em nove casos $(14,7 \%)$. Estas fraturas ocorreram ou no ato da retirada do cimento, ou na realização de janela óssea, ou na manipulação após retirada dos componentes, especialmente os não cimentados.

O paciente 15 do grupo Dois Tempos faleceu por hemorragia aguda devido à ruptura da artéria ilíaca externa, que estava aderida ao componente acetabular. Caso semelhante é relatado por KILGUS et al. (2002) ao retirarem um componente acetabular infectado que havia migrado para a pelve.

Recomendamos realizar arteriografia de rotina em pacientes que realizam revisão de artroplastias em que o componente acetabular esteja protruso à linha de Köeler e, se necessário, retirar estes componentes por via de acesso ílio-inguinal, com presença de um cirurgião vascular na sala cirúrgica.

Houve três fraturas femorais durante o primeiro tempo cirúrgico, complicações relatadas por CARLSSON et al. (1978), com 10 fraturas em 77 pacientes.

BOURNE et al. (1984) chegam a abandonar a retirada de todo cimento acrílico por medo de fraturar o fêmur em cinco de 33 casos. WEBER; LAUTENBACH (1986) produzem nove perfurações corticais na retirada dos componentes em 33 pacientes e LIEBERMAN et al. (1994) produzem quatro perfurações femorais e duas fraturas femorais.. LANGLAIS (2003) encontra $15,0 \%$ de fraturas de fêmur no tratamento em dois tempos e $5,0 \%$ no tratamento em tempo único.

A osteotomia estendida do trocanter maior (CALLAGHAN apud STEINBERG, 1999) pode ser realizada para facilitar a extração dos componentes fixos e evitar fraturas (figuras 9,10 e 11). 

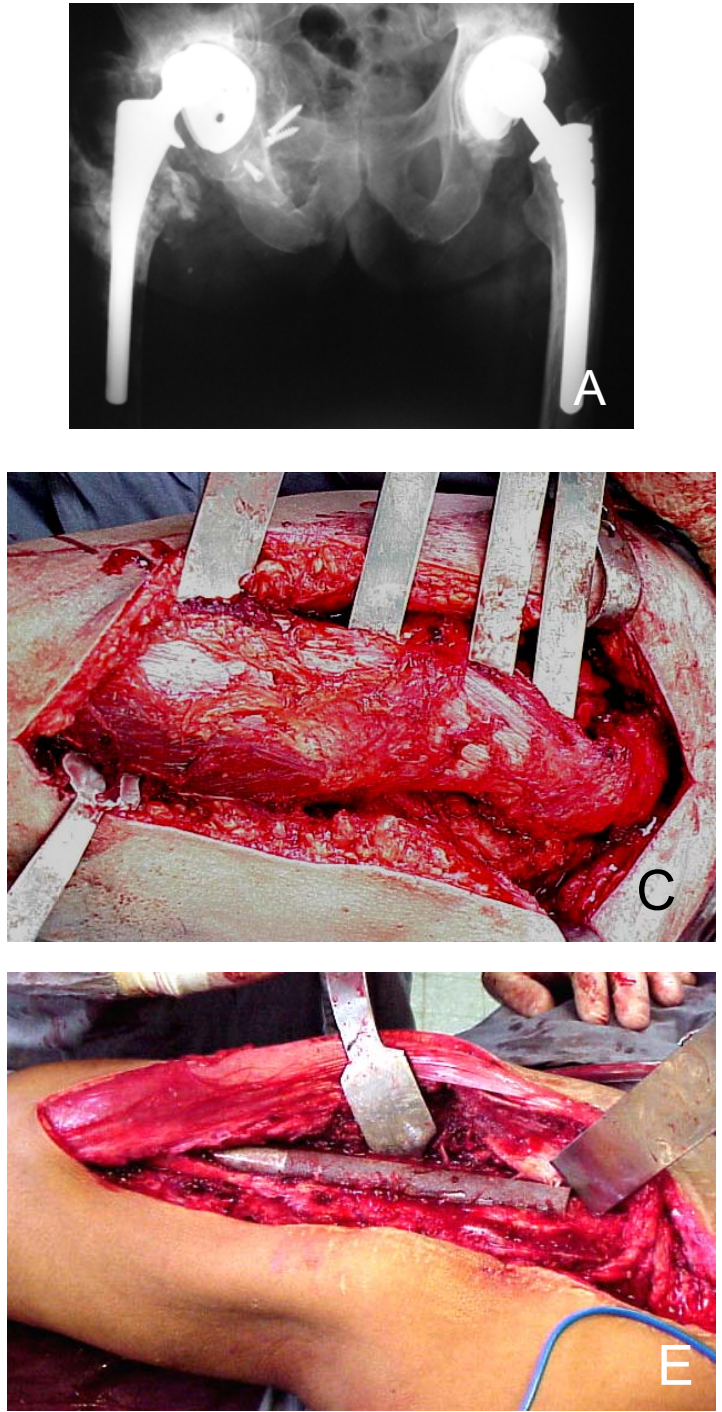
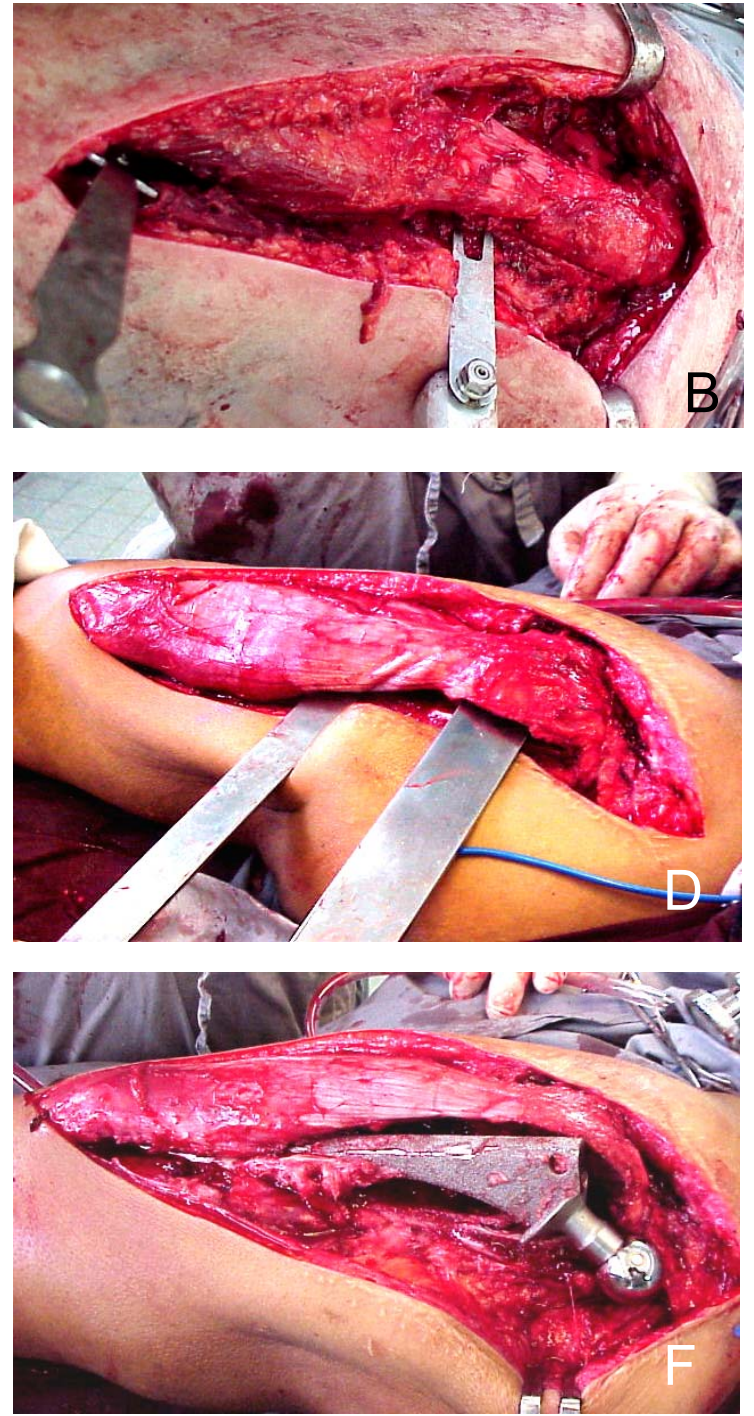

FIGURA 9 Osteotomia estendida do trocanter maior para retirada de componentes sem cimento fixos. A - Radiografia pré-operatória. Componente Femoral fixo e componente acetabular solto à direita, com protrusão para a pelve. B - Osteotomia, com uso de serra, da linha áspera do fêmur. C - Osteotomia, com formões, da região anterior da epífise, metáfise e diáfise do fêmur. D - Elevação do segmento longitudinal da região lateral do fêmur. E - Exposição do componente femoral, ainda fixo em sua região medial. F - Retirada do componente femoral. 

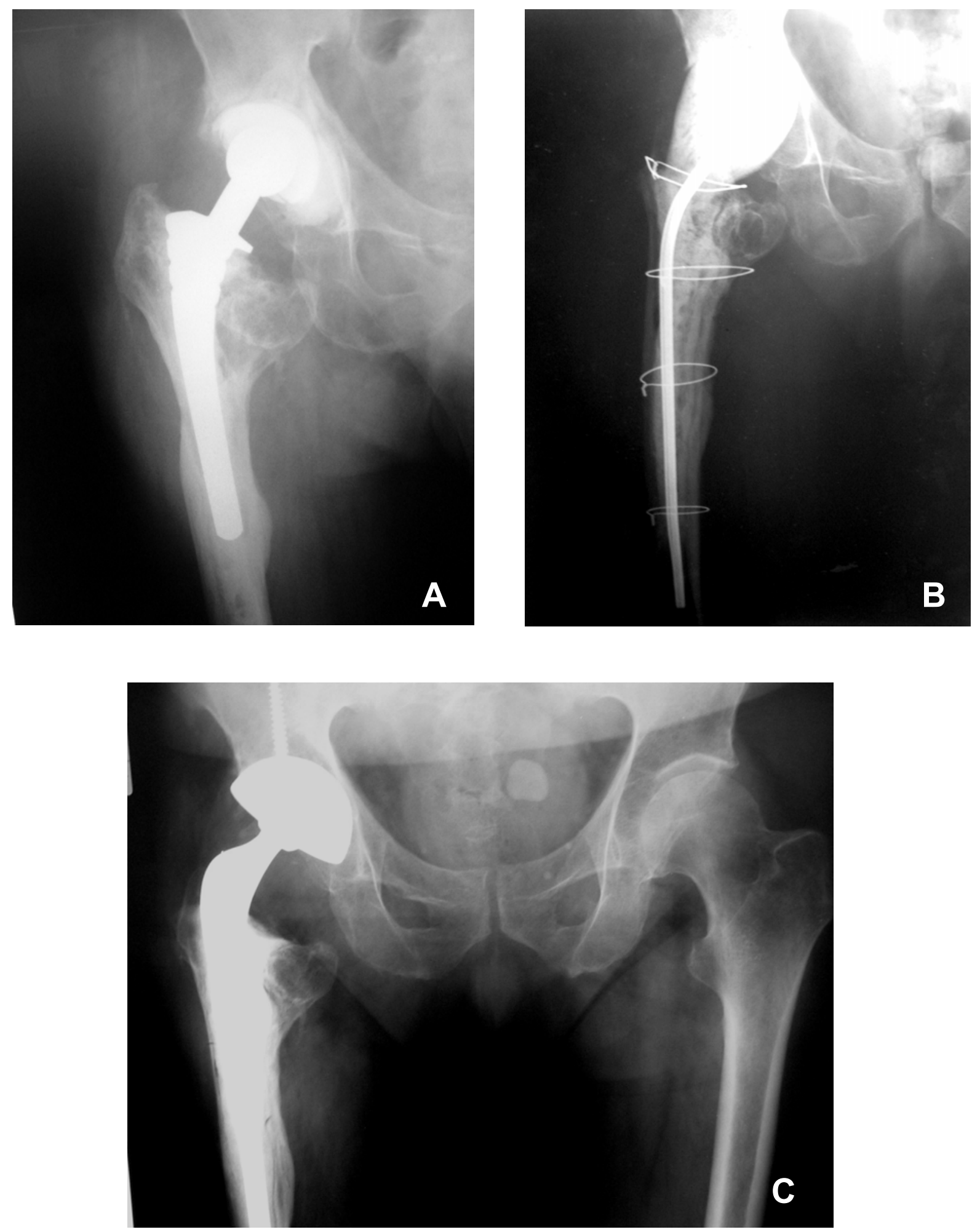

FIGURA 10 Caso 20 do grupo Espaçador. Paciente de 70 anos, vítima de fratura intertrocanteriana. A - Componente acetabular solto, com perda óssea grau II. Componente femoral cimentado fixo. B - Realizada osteotomia estendida para retirada de todo o cimento. Colocado espaçador com haste de Küntscher. C Artroplastia híbrida colocada no segundo tempo cirúrgico, com boa eqüalização dos membros inferiores 

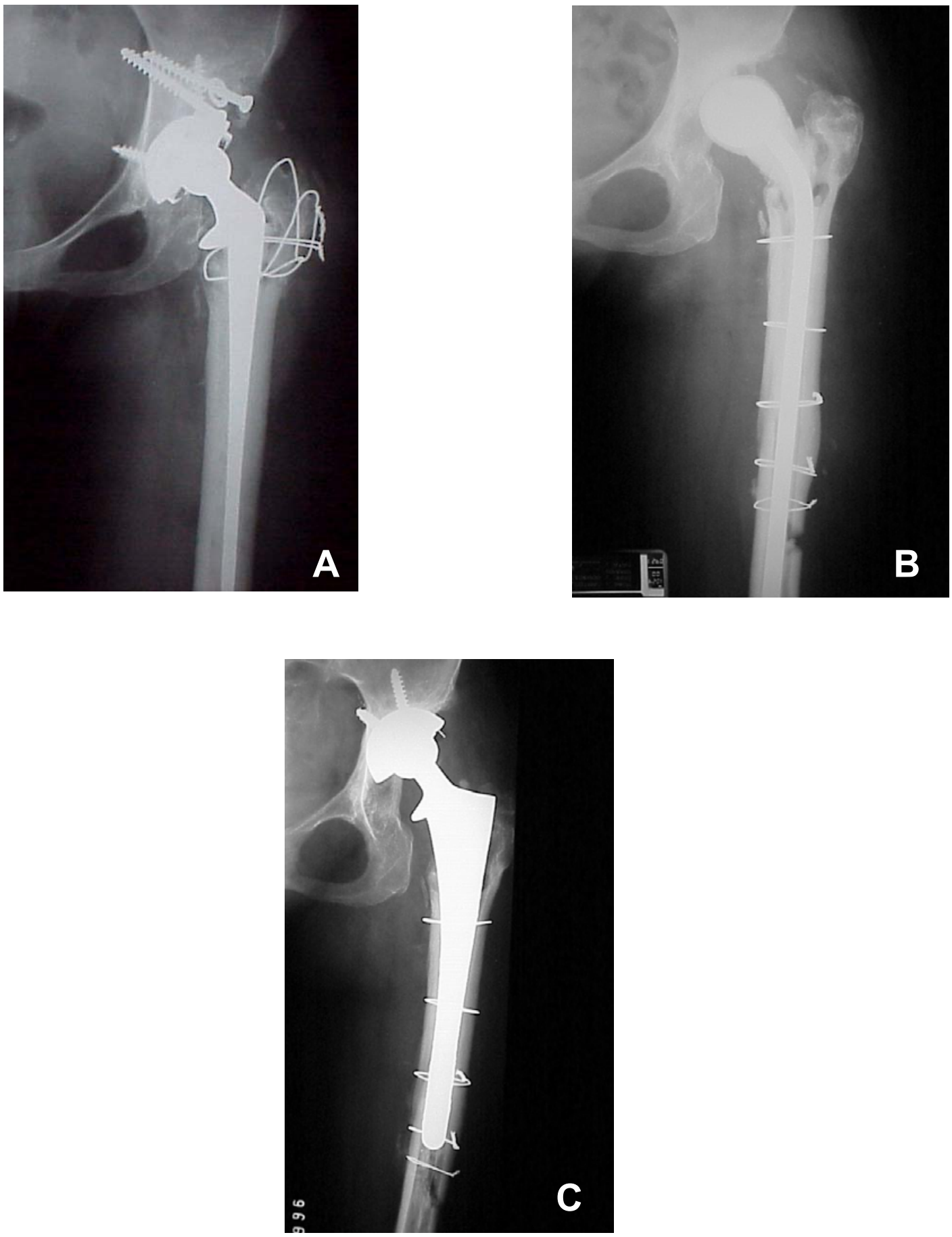

FIGURA 11 Caso 10 do grupo Espaçador. Paciente de 29 anos, artroplastia realizada por seqüela de doença de luxação congênita do quadril. A - Haste cimentada fixa na região femoral, com cloaca na diáfise do fêmur. B - Espaçador colocado, com osteotomia estendida do trocanter maior como via de acesso. C - Radiografia seis meses após o segundo tempo cirúrgico. Pseudartrose em região da osteotomia com dor local. Após um ano de cirurgia houve consolidação do foco, com sintomas dolorosos regredidos. 
Durante o segundo tempo cirúrgico, novamente ocorreram fraturas femorais, por manipulação excessiva do fêmur proximal.

Ao retirar o espaçador do acetábulo, não se deve insistir em movimentos rotacionais, ao sentir resistência. A fragmentação da parte acetabular do espaçador facilita sua retirada e evita fraturas por rotação excessiva.

A impossibilidade técnica de realizar a artroplastia definitiva durante 0 segundo tempo cirúrgico ocorreu em um paciente do grupo Dois Tempos e é também relatada por FITZGERALD (1995) e CHARLTON et al. (2003). Esta dificuldade é característica no segundo tempo cirúrgico das cirurgias sem espaçador, quando é difícil dissecar os planos musculares e identificar os acidentes ósseos.

\subsection{COMPLICAÇÕES APÓS O PRIMEIRO TEMPO CIRÚRGICO}

A gravidade das complicações clínicas (tebela 27 e gráfico 27) reflete a gravidade dos casos e as condições críticas em que se encontravam os pacientes antes do tratamento. Lembramos que os pacientes estavam infectados, em média, há 8,2 meses no grupo Dois Tempos e 19,8 meses no grupo Espaçador. O paciente 12 do grupo Espaçador estava com secreção ativa em quadril há mais de 10 anos.

LIEBERMAN et al. (1994) acompanham 46 pacientes e encontram quatro complicações relacionadas à antibioticoterapia, três úlceras de decúbito, uma trombose venosa profunda, um tromboembolismo pulmonar e uma morte por hemorragia aguda. WANG; CHEN (1997) relatam 45,0\% de complicações clínicas em 22 pacientes. HADDAD et al. (2000) encontram 18,0\% de infecções urinárias e 4,0\% de complicações cardíacas em 50 pacientes estudados. CHARLTON et al. (2003) detectam complicações clínicas em 23,0\% dos casos.

Ocorreram seis complicações relacionadas ao espaçador: três luxações, duas migrações pélvicas e uma fratura.

Dois dos espaçadores que luxaram eram de cirurgias realizadas no início do estudo. Notamos que os colos destes espaçadores eram muito valgos, o que facilitou a migração lateral (figura 12). 

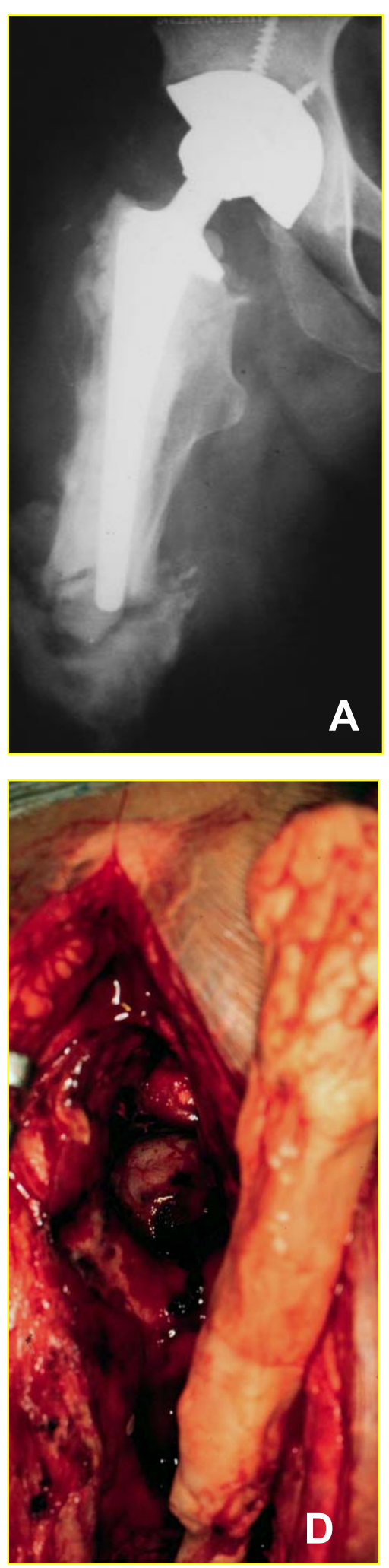
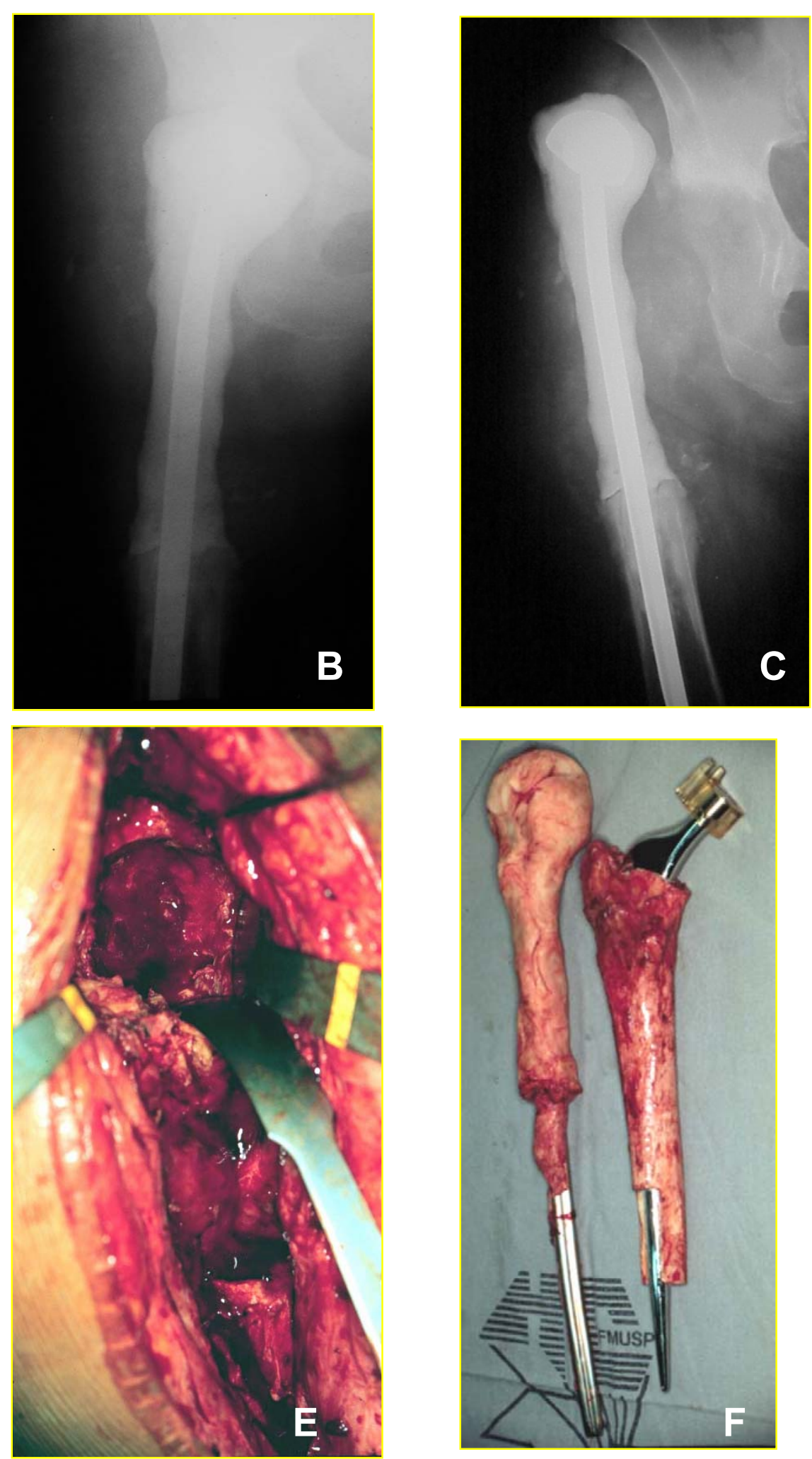

FIGURA 12 Caso 2. Paciente de 40 anos com osteoartrose secundária a doença de Pèrthes. A - Pseudartrose de Fêmur proximal com infarto ósseo extenso. B - Espaçador com o colo muito valgo. C Luxação do espaçador. D - Retirada do espaçador. E - Perda óssea femoral grau IV. F - Enxerto de terço proxinal de fêmur cimentado em haste longa tipo Exeter (cont.). 

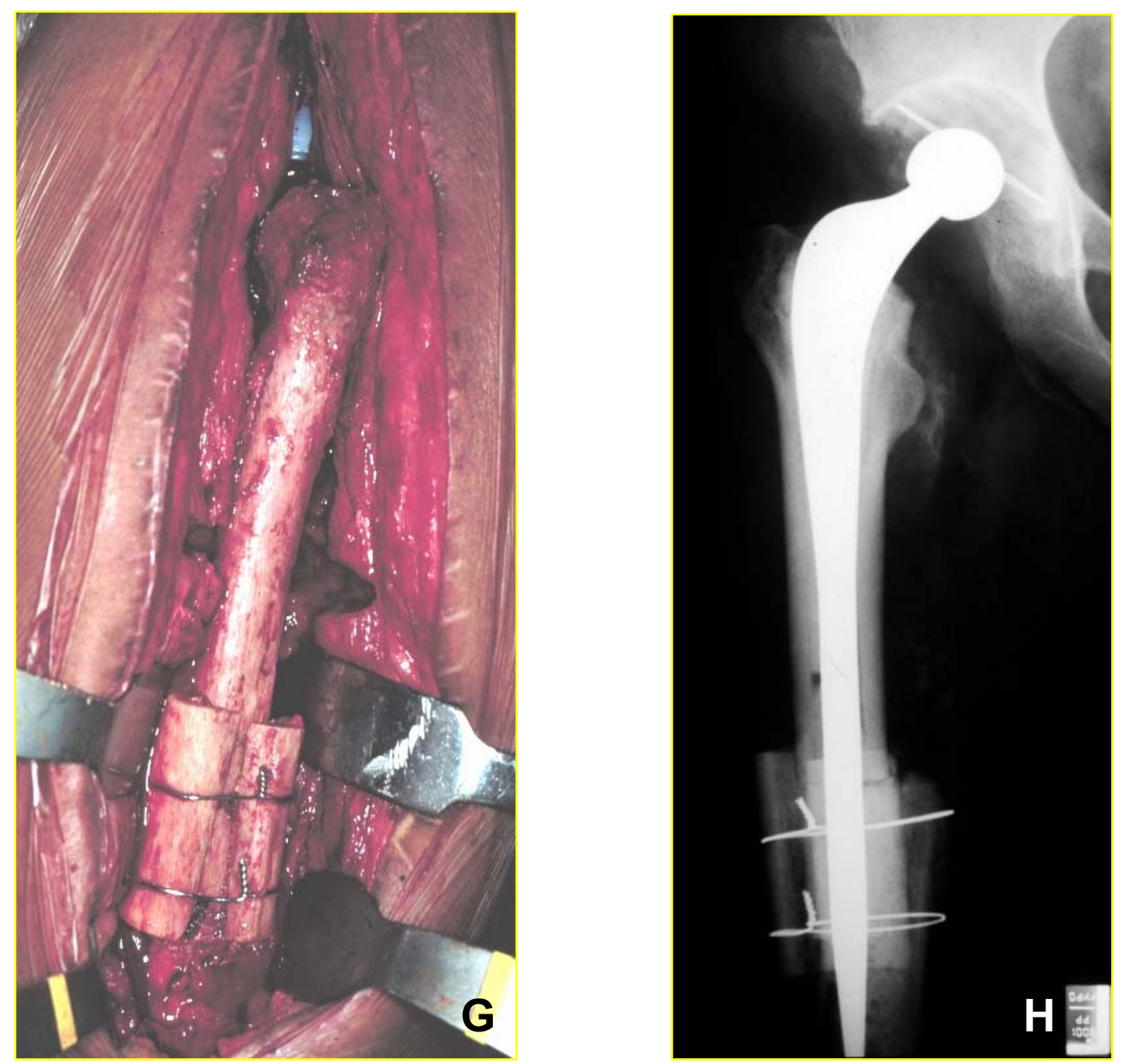

FIGURA 12 (cont.) G - Enxerto fixado com cimento ao osso hospedeiro e com paliçada de enxertos corticais reforçando a transição entre haste e osso remanescente. $\mathrm{H}$ - Radiografia com três anos de seguimento, apresentando consolidação da transição entre o enxerto e o fêmur distal do paciente. 
Apesar de estes dois espaçadores permanecerem luxados, os pacientes não apresentaram quadro doloroso importante e não houve dificuldades para realização do segundo tempo cirúrgico.

DUNCAN; BEAUCHAMP (1993) na experiência inicial da PROSTALAC, relatam três casos de luxação do espaçador em 15 pacientes. Na revisão de 135 casos (WENTWORTH et al., 2002), após nove anos, há apenas mais duas destas complicações, o que demonstra que a experiência adquirida com a realização do método evita a ocorrência das luxações.

Devido à ocorrência da migração pélvica e subseqüente lesão dos vasos ilíacos e falecimento da paciente 29 do grupo Espaçador, não realizamos mais o espaçador como uma prótese unipolar em pacientes com fraqueza óssea acetabular, especialmente em obesos e reumatóides. Indicamos a colocação de uma bola de cimento com antibiótico, preenchendo a cavidade acetabular, que articula com o componente implantado na região femoral(figuras $13,14,15$ ).

\subsection{COMPLICAÇÕES APÓS O SEGUNDO TEMPO CIRÚRGICO}

As complicações clínicas após o segundo tempo cirúrgico ocorreram em menor quantidade em comparação ao primeiro tempo cirúrgico, em ambos grupos (tabela 29 e gráfico 29). Isto se deve ao melhor estado geral dos pacientes, curados do processo infeccioso.

A mortalidade relacionada ao tratamento ou à falha deste foi de $12,5 \%$ no grupo Dois Tempos e a de 2,8\%, no grupo Espaçador (anexo D, tabela e gráfico 5). Estes dados são similares aos da literatura.

FENELON et al (1980) relatam o falecimento de três pacientes entre 11 tratados com desarticulação de quadril para controle infeccioso. BUCHHOLZ et al. (1981) encontram mortalidade de $0.9 \%$ em 747 revisões em tempo único; $7,7 \%$ na realização de cirurgias de Girdlestone e $8,3 \%$ em desarticulações do quadril. TSUKAYAMA et al. (1996) registram duas mortes relacionadas à infecção em 98 pacientes. FISMAN et al. (2001) estimam a mortalidade em prótese infectada de quadril em $0,4 \%$ a $1,2 \%$ para pacientes com 65 anos e de $2,0 \%$ a $7,0 \%$ para pacientes com 80 anos. Durante os três meses após a realização da retirada da prótese e limpeza cirúrgica a mortalidade dobra para 

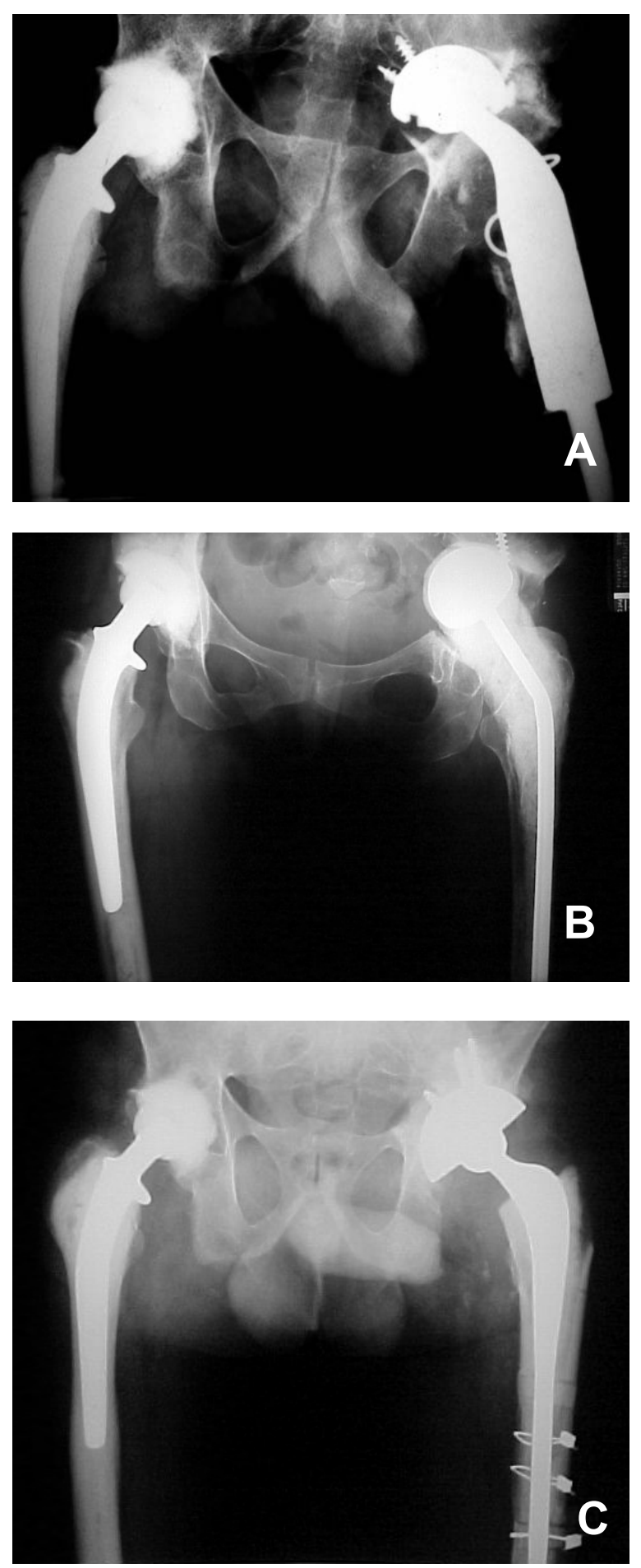

FIGURA 13 Caso 7 do grupo Espaçador. Paciente com 37 anos, portador de espondilite anquilosante. Havia realizado duas revisões da artroplastia do quadril esquerdo. A - Protrusão pélvica do componente acetabular sem cimento. Perdas ósseas grau IV em acetábulo e fêmur. B - Espaçador migrado para região pélvica, sem conseqüencias clínicas. C - Radiografia após dois anos do segundo tempo cirúrgico. Componente acetabular sem cimento e enxerto de fêmur proximal fixado com cimento e em bom estado. 


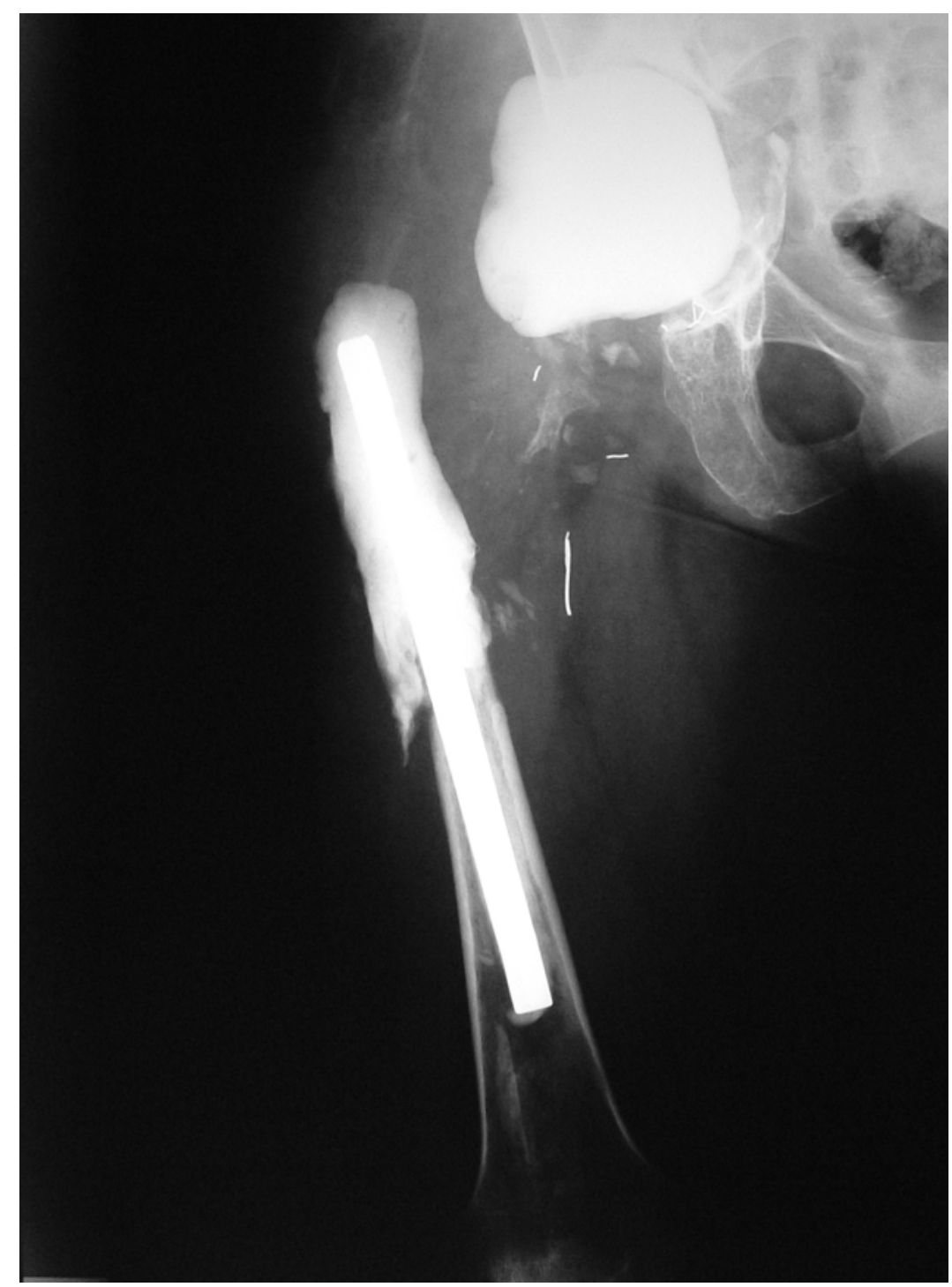

FIGURA 14 Tipo de espaçador que deve ser montado em casos de fraqueza da parede acetabular. Devido à fragilidade da tábua óssea, o atrito da cabeça do espaçador pode romper a parede, pondo em risco as estruturas intra-pélvicas e os vasos ilíacos. A massa de cimento, no formato do acetábulo, preenche o espaço morto, no caso, de volume considerável. A porção femoral do espaçador é colocada para manter pérvio o canal do fêmur e facilitar a fixação do componente no segundo tempo cirúrgico. 

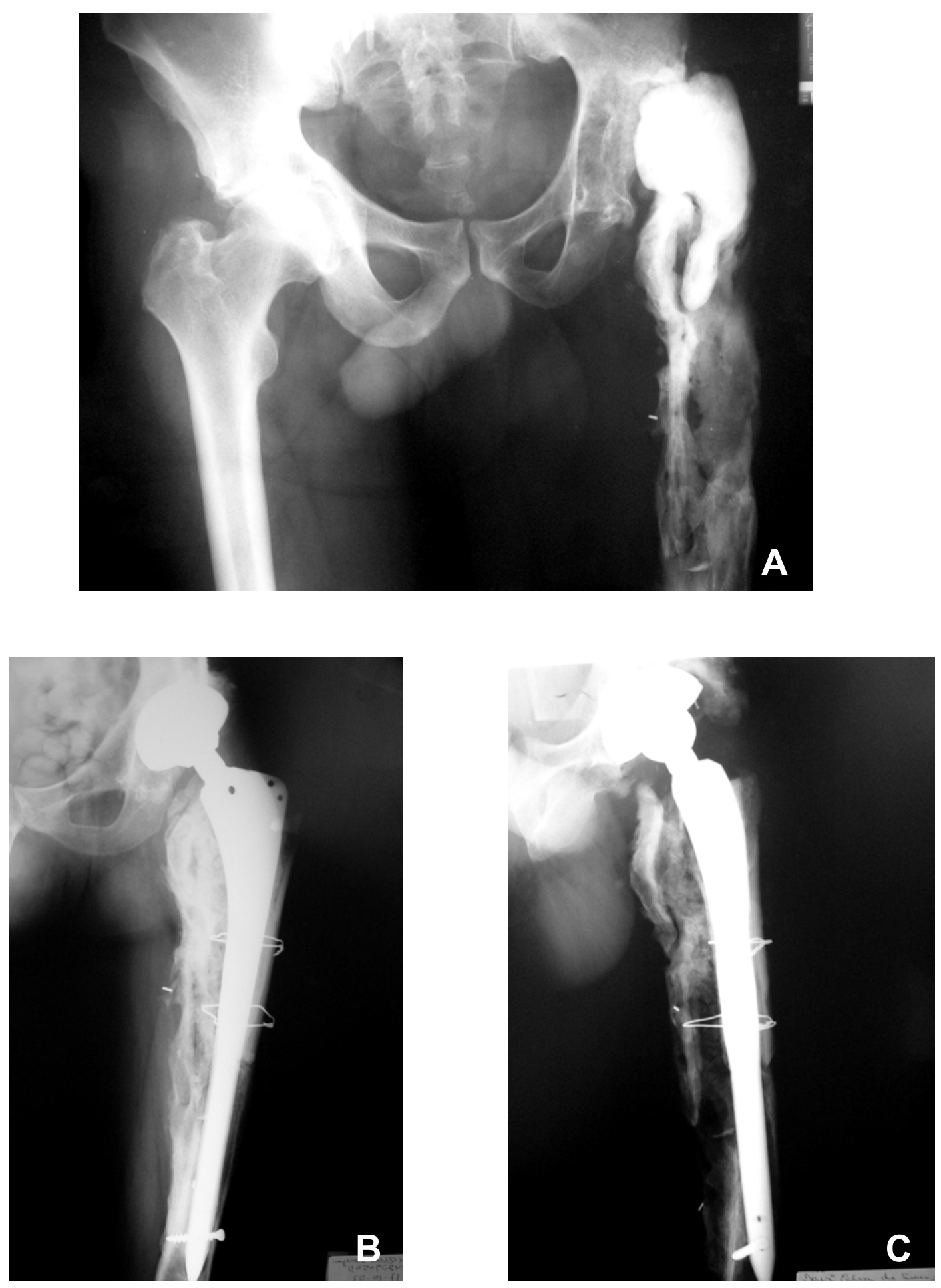

FIGURA 15 Paciente de 49 anos, com seqüela de epifisiolistese. A Espaçador com formato globoso em região acetabular, confeccionado devido à dúvida quanto a resistência da parede acetabular. B e C - Aspecto radigráfico após seis meses do segundo tempo cirúrgico. Foram colocados componente acetabular sem cimento e femoral sem cimento longo, com enxerto de fêmur proximal cimentado à região proximal da haste. 

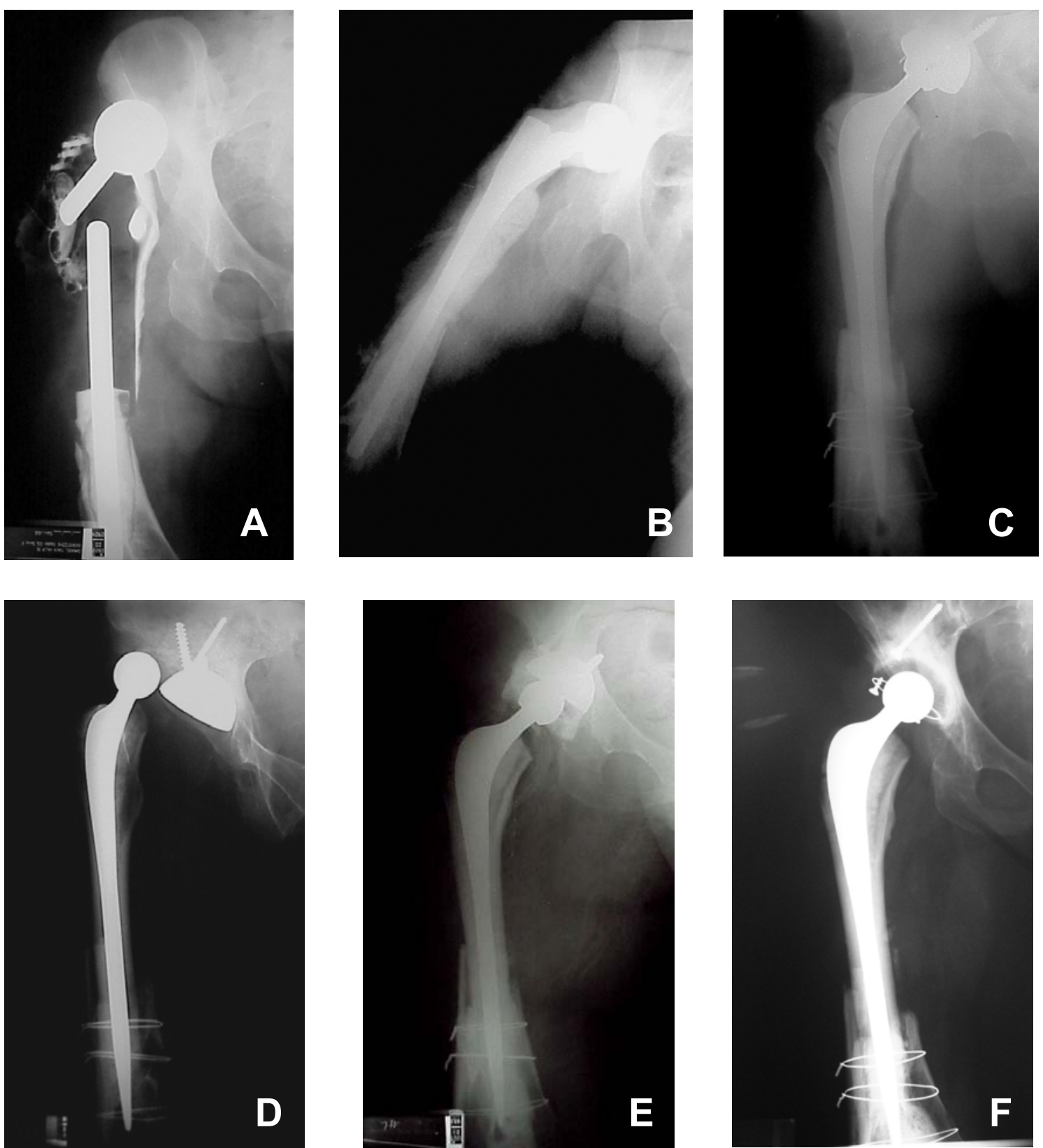

FIGURA 16 Caso 4 do grupo Espaçador. Paciente de 37 anos, com seqüelas de ressecção de condrossarcoma em fêmur proximal. Toda musculatura abdutora foi retirada para o controle tumoral. A Fistulografia marcando a comunicação entre o meio externo e a endoprótese luxada. B - Espaçador encaixado em região acetabular. C - Segundo tempo cirúrgico. Colocada haste longa cimentada com enxerto femoral longo. Acetábulo sem cimento. D - Luxação da prótese. E - após três reduções incruentas foi colocado acetábulo constrito. Houve soltura entre a taça cimentada e a taça sem cimento, que havia sido mantida, após sete meses. F - Acetábulo constrito cimentado colocado há nove meses. Paciente evoluiu sem novas luxações. 
os dois tipos de pacientes. LENTINO (2003) encontra taxa de mortalidade de até $2,5 \%$ em artroplastias infectadas.

A mortalidade nos grupos estudados foi multifatorial. Dois pacientes eram portadores de artrite reumatóide, doença relacionada a altos índices de complicações (CALLAGHAN et al., 1999; HADDAD et al., 2000; HANSSEN; OSMOND, 2002; MCPHERSON et al., 2002). Além disso, os quatro pacientes que faleceram por causas relacionadas ao método apresentavam falhas ósseas graves. Em dois casos do grupo Dois Tempos houve dificuldades técnicas para identificação das estruturas no ato operatório, com sangramento identificado como anormal, o que oslevou, em última instância, ao falecimento por hemorragia. Esta dificuldade é inerente à cirurgia em dois tempos.

Houve um caso $(6,7 \%)$ de luxação recorrente no grupo Dois Tempos e dois casos $(6,4 \%)$ no grupo Espaçador - resultados semelhantes aos da literatura.

De um modo geral, a incidência de luxações após o tratamento de artroplastias infectadas é uma complicação que ocorre com qualquer método e é devida à extensa lesão de partes moles, com incompetência da musculatura abdutora, e à perda óssea (figura 16), que leva a dificuldades técnicas para fixação do trocanter maior. O encurtamento do membro também leva à insuficiência dos abdutores e à reconstrução inadequada da biomecânica do quadril.

WROBLEWSKI, 1986 encontra 12,7\% de luxações em casos de tempo único. SANZÉN et al. (1988) apontam 6,9\% para o tratamento em tempo único ou dois tempos sem diferenciar os dois; MCDONALD et al. (1989) registram 7,3\% em dois Tempos; WANG; CHEN (1997), 9,0\% em dois tempos; YOUNGER et al. (1997), 10,4\% em PROSTALAC; LEUNIG et al. (1998), 10\% em espaçador unipolar; LECUIRE et al. (1999), 7,0\% em dois tempos e tempo único; HADDAD et al. (2000), 8,0\% em dois tempos; WENTWORTH et al. (2002), 3,7\% em PROSTALAC; CHARLTON et al. (2003), 11,4\% em dois tempos; e LANGLAIS (2003), 12,0\% em dois tempos.

Dois pacientes do grupo Dois Tempos apresentaram lesão neurológica. Uma lesão de nervo femoral evoluiu com resolução após seis meses e uma lesão de nervo ciático foi definitiva. 
Relato semelhante é descrito por NESTOR et al. (1994), com uma lesão definitiva e LAl et al. (1996), com três paralisias do nervo ciático.

As lesões neurológicas são devidas geralmente à manipulação excessiva e ao alongamento do membro inferior (LAl et al., 1996). Ambos fatores estão envolvidos na realização do segundo tempo quando não é usado espaçador.

\subsection{RECONSTRUÇÃO DO ESTOQUE ÓSSEO}

Enxertos ósseos do banco de tecidos do I.O.T.H.C.F.M.U.S.P. foram usados em $60,9 \%$ do total de casos (tabela 32 e gráfico 32 ).

Este dado espelha a incidência alta de perdas ósseas relatadas nas tabelas e gráficos 9 e 10 .

O uso de enxerto ósseo estruturado no segundo tempo de tratamento de artroplastias infectadas não é associado à recorrência infecciosa segundo MORSCHER et al. (1990), BERRY et al. (1991), LIEBERMAN et al. (1994), NESTOR et al. (1994), ALEXEEF et al. (1996) e WANG; CHEN (1997).

LOTY et al (1992) aplicam enxerto ósseo em 46 casos de revisões infectadas em tempo único com três recidivas infecciosas. ALEXEEFF et al. (1996) usam enxerto femoral maciço em nove casos, sem recidiva infecciosa, após quatro anos de seguimento. A técnica de Exeter é utilizada por ENGLISH et al. (2002) com resolução de infecção em $92,5 \%$ de 44 casos e bons resultados funcionais. HANSSEN; OSMON (2002) encontram quatro recidivas infecciosas em sete pacientes reconstruídos com enxerto estruturado de fêmur proximal. RUDELLI et al. (2003) usam enxerto ósseo homólogo em 36 casos tratados em tempo único, sendo nove com fístulas ativas. Encontram $88,9 \%$ de controle infeccioso, com tempo mínimo de seguimento de dois anos nos casos com fístulas*.

Em nossos casos, não houve complicações mecânicas com enxertos maciços ou picados (figura 17). A reconstrução do estoque ósseo é muito importante para a estabilidade dos implantes e para preencher o espaço morto deixado pelas perdas ósseas e musculares. As endopróteses ocupam este

\footnotetext{
"RUDELLI, S. (Santa Casa de Misericórdia de São Paulo). Correspondência pessoal, 2003.
} 

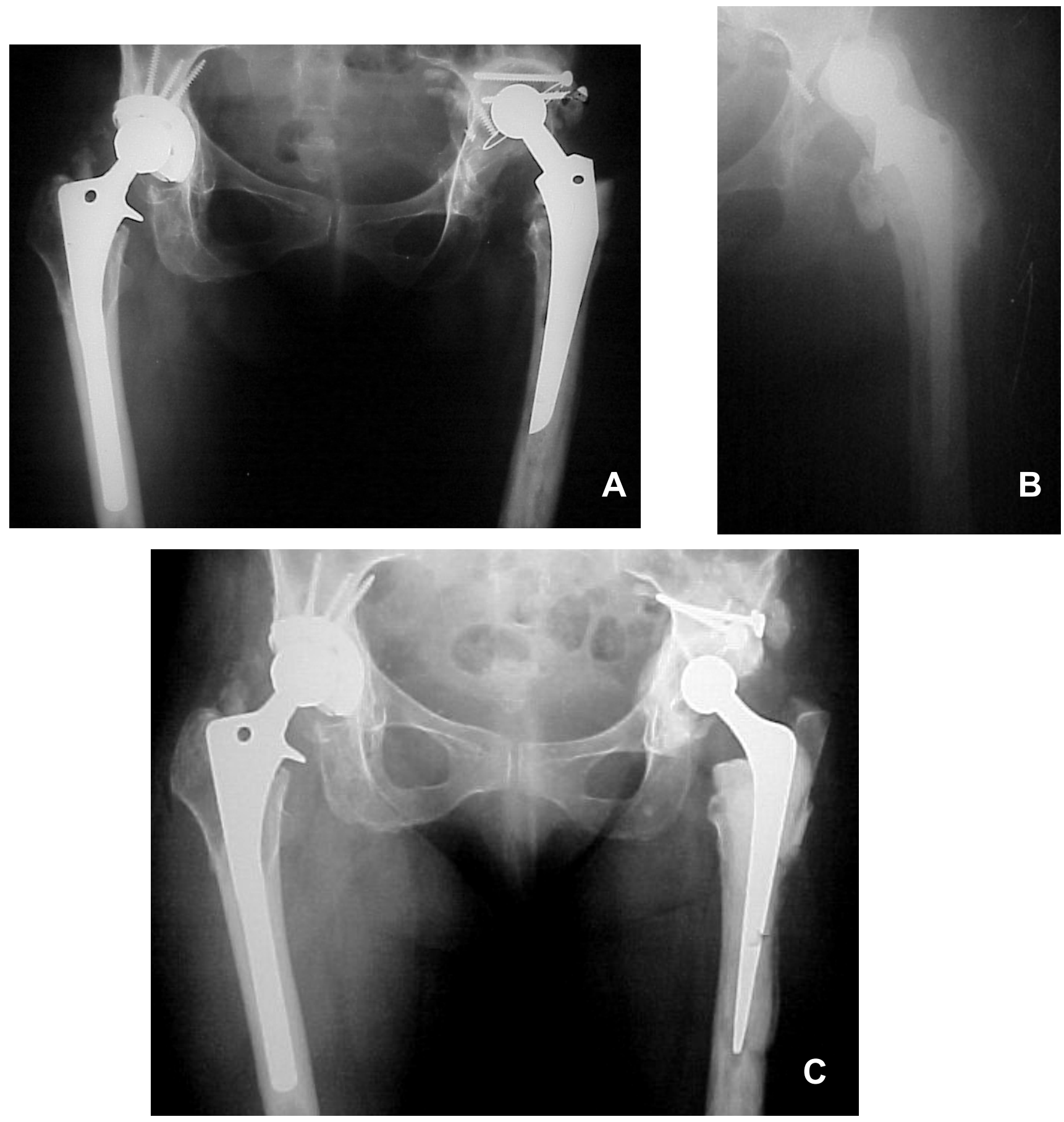

FIGURA 17 Caso 6 do grupo Espaçador. Paciente de 47 anos, com 14 cirurgias prévias, sendo 9 revisões. Seqüela de fratura do colo do fêmur. A Componente acetabular solto, com perda óssea grau III. Perda óssea femoral grau III. B - Espaçador confeccionado com haste femoral esterilizada. C Radiografia após um ano de seguimento. Paciente sem dor e com boa função. O Escore de Harris para Quadril evoluiu de 22 para 87. 
espaço com mais material metálico, sem atividade biológica, apenas aumentando a superfície em que as bactérias possam adsorver.

A manutenção e a reconstrução do estoque ósseo são essenciais nos pacientes jovens, que ainda serão submetidos a novas revisões e que necessitam de uma arquitetura óssea mecanicamente resistente, para a troca dos componentes desgastados.

\subsection{BACTERIOLOGIA E ANTIBIOTICOTERAPIA}

Vários autores chamam a atenção para a identificação do agente infeccioso para planejar o tratamento adequado de uma infecção em prótese de quadril (HANSEEN; RAND, 1999).

O espectro bacteriano depende, principalmente, do tempo decorrido entre a colocação da prótese e a instalação do quadro infeccioso. Infecções que ocorrem até os primeiros meses depois da cirurgia, classificadas segundo COVENTRY,1975 e FITZGERALD,1977 como tipo I, geralmente são relacionadas à contaminação peri-operatória. Os microorganismos hospitalares são os agentes mais comuns, especialmente o $S$. aureus, muitas vezes com padrão de alta resistência a antibióticos (KAMME; LINBERG, 1981).

As infecções do tipo II ou tardias são causadas geralmente por bactérias da microbiota normal da pele, como Staphylococcus epidermidis (SPANGEHL et al., 1999).

Dois anos após a artroplastia, as infecções geralmente são hematogênicas. Nestes casos, a microbiota é determinada pela aparente fonte de bactérias: infecções dentárias estão associadas às bacteremias por $S$. viridans e anaeróbios. Celulites e abcessos cutâneos são associados a $S$. aureus ou estreptococos. As enterobactérias são originárias do trato gastrointestinal e gênito-urinário (LENTINO, 2003).

É imprescindível que a cobertura antimicrobiana seja feita por um infectologista experiente. Freqüentemente os laboratórios clínicos não testam todos os antibióticos para determinado microorganismo, não estando apto o ortopedista a decidir a conduta. O infectologista é quem interpreta e avalia as bactérias isoladas e antibiogramas. Ele é a pessoa adequada para desenvolver a programação de cada caso. 
Os dados sobre o tempo de duração da antibioticoterapia nos pacientes (anexo D, tabelas 2 e 3 ) confirmaram que nosso objetivo, de manter os antibiíticos por via endovenosa por três a seis semanas, em seguida passando para antibioticoterapia por via oral por seis meses, foram cumpridos, em ambos os grupos.

Os estafilococos coagulase negativos, identificados em dez pacientes, são freqüentes agentes de infecções protéticas, sendo considerados altamente nocivos por HOPE et al.(1989), embora antigamente fossem tidos apenas como contaminantes de culturas.

Notou-se alta incidência de Enterococcus faecalis (nove casos), espécie que até 1980 era classificada com os estreptococos do grupo D.

Bactérias gram-positivas foram encontradas em $68,1 \%$ das culturas, o que demonstra uma boa cobertura pela vancomicina que foi adicionada ao cimento acrílico, pois os microorganismos eram sensíveis à vancomicina.

A vancomicina é um glicopeptídeo tricíclico que não se relaciona estruturalmente com outros antibióticos, sendo útil para o paciente alérgico às penicilinas e cefalosporinas (AMATO NETO et al.,2000).

A vancomicina possui ação bactericida por inibição da síntese da parede celular das bactérias sensíveis, que envolve bactérias gram-positivas, particularmente estafilococos, pneumococos, estreptococos, corinebactérias e clostrídios. As micobactérias, os bacilos gram-negativos, as clamídias, os epiroquetídeos, os micoplasmas e as riquétsias são resistentes a vancomicina (MIMS et al., 1999; AMATO NETO et al., 2000).

O uso indiscriminado da vancomicina é preocupante, pois sua eluição crônica, a partir do espaçador, pode predispor ao surgimento de Enterococcus sp. resistentes à vancomicina no intestino (MASTERSON ET AL.,1998). Esta resistência é intermediada por plasmídeos e é transmissível (MIMS et al.,1999). Entretanto, os níveis séricos do antibiótico, após o uso de cimento impregnado com vancomicina, são desprezíveis (CHOHFI et al.,1996) e a associação entre o uso de vancomicina no cimento e o isolamento de Enterococcus sp. multirresistente não foi demonstrada, até o momento.

A identificação de bactérias gram-negativas em 22 casos não interfere com a validade do uso da vancomicina. Este grupo não é sensível a um único tipo 
de antibiótico, comportamento adotado pelas bactérias gram-positivas frente à vancomicina. O espectro de sensibilidade dos bacilos gram-negativos varia entre aminoglicosídeos, cefalosporinas de primeira a quarta gerações e quinolonas, portanto é difícil a escolha de um antibiótico para cobrir todas as bactérias gram-negativas.

$\mathrm{KOO}$ et al. (2001) tentam solucionar este problema adicionando vancomicina, gentamicina e cefotaxima ao cimento acrílico. Embora encontrem controle infeccioso em $95 \%$ dos pacientes, quatro casos (20\%) apresentam efeitos colaterais devido aos antibióticos, com disfunção hepática e depressão medular.

A nosso ver, a adição de antibióticos ao cimento para cobertura de bactérias gram-negativas deve ser direcionada e realizada, apenas, se houver identificação prévia do agente em cultura adequadamente colhida. Esta preocupação é importante do ponto de vista infectológico, pois evita as condições da proliferação de bactérias multirresistentes.

\subsection{CONTROLE INFECCIOSO}

Após o primeiro tempo cirúrgico, o controle infeccioso foi pior no grupo Dois Tempos em relação ao grupo Espaçador (tabela 33 e gráfico 33). Tal fato deve-se, provavelmente, à colonização do hematoma extenso que ocupou o espaço morto no grupo tratado sem espaçador. A recorrência de infecção no grupo Espaçador era de ser esperada pela gravidade dos casos.

Após o segundo tempo cirúrgico houve recidiva infecciosa somente no grupo Dois Tempos (tabelas e gráficos 3 e 5). A recidiva neste grupo, provavelmente, foi devida ao maior tempo cirúrgico do procedimento e às complicações decorrentes da dissecção dos planos fibróticos para colocação dos componentes.

As recidivas infecciosas do grupo Dois Tempos ocorreram entre cinco a 438 dias após o segundo tempo cirúrgico, com média de 118,8 dias (tabela 34 e gráfico 34). Este período é semelhante ao apontado por COLLYER;CAPELLO (1994), que encontram $83,3 \%$ de suas recidivas em menos de um ano. As cinco recidivas de NESTOR et al. (1994) ocorrem até 
dois anos após o segundo tempo cirúrgico. Entretanto, RAUT et al. (1995) encontram recidivas em seis pacientes com menos de dois anos, em 15 pacientes entre dois e cinco anos e em oito pacientes com mais de cinco anos de acompanhamento da cirurgia em tempo único.

A cirurgia em dois tempos controlou a infecção em $54,1 \%$ dos pacientes e a cirurgia em dois tempos com uso do espaçador controlou $91,2 \%$ dos casos (tabela 37 e gráfico 37 ).

Mesmo após dois anos de acompanhamento (tabela 38 e gráfico 38), o grupo Espaçador apresentou controle infeccioso mais satisfatório $(85,0 \%)$ do que o grupo Dois Tempos (42,1\%).

O sucesso do tratamento em dois tempos $(54,1 \%)$ ficou abaixo do relatado por outros autores que tratam infecções em dois tempos sem uso de espaçador ou pérolas de antibióticos como CARLSSON et al. (1978) com $78,0 \%$ de controle, SALVATI et al. (1982) com 89,0\% WEBER; LAUTENBACH (1986) com 72,0\%, ANTTI-POIKA et al. (1989)com 76,9\%, MCDONALD et al. (1989) com 87,0\%, NESTOR et al. (1994) com 82,0\%, LAl et al. (1996)com 80,0\%, LECUIRE et al. (1999)com 97,7\%, , JAHODA et al. (2003) com 94,3\% e PIRIOU et al. (2003) com 96,7\%

O resultado aproxima-se daqueles de HUNTER; DANDY (1977) com $33,3 \%$ de controle infeccioso, SANZÉN et al. (1988) com 65,0\% e CIERNY; DIPASQUALE (2002) com 64,0\%, que tratam pacientes com perdas ósseas graves, como no nosso caso. Entretanto, ENGLISH et al. (2002) controlam a infecção em $92,5 \%$ de pacientes tratados em dois tempos com técnica de Exeter e todos apresentam perdas ósseas, embora não quantificadas.

Conforme confirmamos, a retirada da prótese e limpezas cirúrgicas seriadas, com manutenção do paciente em Girdlestone é o método mais seguro de tratamento (tabela 39 e gráfico 39), pois não envolve mais a colocação de material estranho no paciente. Entretanto, apesar da melhora do quadro doloroso do paciente, os resultados funcionais da artroplastia de ressecção são uniformemente ruins, assim como a satisfação pessoal com a cirurgia (CLEGG, 1977; AHLGREN et al., 1980; BOURNE et al., 1984; 
GRAUER et al., 1989; LIEBERMAN et al., 1994; SCALVI et al., 1995; CASTELLANOS et al., 1998; SCHRODER et al., 1998).

As indicações de cirurgia em tempo único ou dois tempos não são muito claras e variam muito entre os vários centros de tratamento.

Concordamos com ELSON (1998), que tem larga experiência no tratamento em tempo único, e que afirma que ocorre uma situação perigosa quando um determindo autor faz-se de advogado de um único método de tratamento. Não deve existir nenhum elemento de competição na matéria e tudo depende da correta comparação dos resultados pessoais com aqueles dos outros pesquisadores. A escolha entre a cirurgia em tempo único ou dois tempos é de importância secundária porque o cirurgião experiente sabe o que pode alcançar usando o método escolhido.

Os critérios necessários para a realização da cirurgia em tempo único são: bactéria com baixo espectro de resistência a antibióticos; paciente saudável, com baixo risco infeccioso (como artrite reumatóide, diabetes, lesões cutâneas crônicas e obesidade); ausência de fístulas ativas e bom estoque ósseo (GARVIN; HANSSEN, 1995; LANGLAIS, 2003).

A cirurgia em dois tempos é o tratamento de escolha para as infecções crônicas, especialmente quando há fístulas ativas e perda óssea associadas , como afirmam SALVATI et al. (2003).

O controle infeccioso do grupo Espaçador ficou entre os 80,0 a $90,0 \%$, tidos como desejáveis por GARVIN et al. (1999), HOFMANN (1999), MITCHELL et al. (2003) e SALVATI et al. (2003).

Houve crescimento bacteriano em cinco pacientes com amostras colhidas durante o segundo tempo cirúrgico (anexo D, tabela e gráfico 4). Apenas um destes cinco casos sofreu recidiva infecciosa e esta estatística está de acordo como apontado por WEBER; LAUTENBACH (1986), com 12,0\% de culturas positivas no segundo tempo cirúrgico e sem recidivas, e BERRY; CHANDLER (1991) com 22,2\% de culturas positivas consideradas como contaminação e não associadas à nova infecção.

A ocorrência de culturas positivas não levou a maior índice de recidiva nos etudos de LAl et al. (1996), YOUNGER et al. (1997) e TAGGART et al. (2002). 
No segundo tempo o campo cirúrgico é novamente limpo e desbridado, como parte da preparação do leito receptor dos novos implantes. Mesmo havendo contaminação ou nichos bacterianos, a probabilidade de erradicação da infecção com estes procedimentos mecânicos é maior do que nos casos macroscopicamente purulentos, que enfrentamos no primeiro tempo cirúrgico.

Portanto, a ocorrência de culturas positivas no segundo tempo cirúrgico não pode ser considerada com uma falha do tratamento e não indica a retirada dos componentes, mas requer a atenção do ortopedista e do infectologista para, eventualmente, realizar antibioticoterapia ou tratamentos complementares.

\subsection{ASPECTOS FUNCIONAIS}

Lembramos que entraram na avaliação funcional final dos dois grupos apenas os pacientes com implantes preservados no último seguimento.

Ambos os grupos apresentavam escores médios iniciais piores que os da literatura, novamente confirmando a gravidade dos casos. Os dois grupos apresentaram melhora funcional equiparável aos dados da literatura.

O resultado funcional final, segundo o Escore de Harris para Quadril, foi melhor para o grupo Espaçador, porém sem significado estatístico (tabela 40 e gráfico 40).

A tendência de melhores resultados no grupo Espaçador poderia ser comprovada, se houvesse mais cirurgias com manutenção dos implantes no grupo Dois Tempos.

Esta tendência deveu-se, provavelmente, à vantagem da reabilitação ser realizada imediatamente no período intermediário. Além da reabilitação precoce, no período intermediário, o uso do espaçador levou à menor agressão cirúrgica no segundo tempo cirúrgico, com manipulação pós-operatória imediata, menos dolorosa, e restabelecimento funcional precoce.

A média de discrepância de comprimento dos membros inferiores foi maior no grupo Dois Tempos (tabela 41 e gráfico 41 ).

O resultado foi aceitável, quando comparado ao de ALEXEEFF et al. (1996), que não encontram discrepância maior que $3,0 \mathrm{~cm}$ ao usarem 
espaçador e banco de tecidos no segundo tempo e CHARLTON et al. (2003), que após o tratamento com espaçador chegam à correção total em metade dos pacientes. LANGLAIS (2003) encontra encurtamento superior a $2,0 \mathrm{~cm}$ em metade de 222 pacientes tratados em dois tempos cirúrgicos, fato também observados em nossos casos sem espaçador.

A discrepância maior no grupo Dois Tempos deve-se à dificuldade de restabelecer o comprimento adequado após o membro infeiro ficar encurtado durante o período intermediário, o que leva à retração cicatricial e à fibrose de partes moles.

\subsection{CONSIDERAÇÕES FINAIS}

O resultado final foi melhor no grupo Espaçador, com $86,1 \%$ de bons resultados contra 33,3\% no grupo Dois Tempos (tabelas 42 e 43 e gráfico 43). O controle infeccioso, tanto após o primeiro, quanto após o segundo tempo cirúrgico, foi melhor no grupo tratado com espaçador - e este é o ponto principal do trabalho.

O espaçador de cimento com antibiótico possui duas funções principais:

1) Mecânica: evitando o encurtamento das partes moles em volta da articulação e mantendo o posicionamento do membro inferior;

2) Biológica: esterilizando as áreas infectadas circundantes pela liberação tópica de antibióticos.

A experiência do cirurgião e a morfologia variável dos defeitos ósseos, após a remoção dos implantes infectados, influenciam os resultados finais em todos autores, especialmente no que se refere ao formato do espaçador.

A ocorrência de luxação, alongamento ou encurtamento excessivo do membro inferior e a instabilidade mecânica são diretamente dependentes da forma como foi feito o espaçador.

As características mecânicas do espaçador são bem definidas, sendo um esqueleto metálico, como uma haste de Küntscher, essencial para assegurar a resistência mecânica. Este esqueleto deve ser dobrado imitando o ângulo do colo do fêmur original, para evitar luxação do espaçador. 
A extremidade proximal deve ser esférica e capaz de deslizar suavemente na cavidade acetabular, permitindo, ao mesmo tempo, mobilidade e estabilidade.

O segmento distal deve ser longo o suficiente para ficar estável no canal femoral e seu contato com o fêmur proximal é modelado de acordo com a falha óssea, para assegurar pouco movimento entre o implante e o osso.

O espaçador bem feito cria as condições locais para o segundo tempo cirúrgico e permite ao paciente sentar e realizar reabilitação para recuperação funcional mais rápida.

Os pacientes podem descarregar parcialmente peso no membro operado, desde que não haja defeitos acetabulares.

Novos estudos podem ser realizados para comparar, prospectivamente e aleatoriamente, o uso do espaçador à cirurgia em tempo único.

Apesar de não haver dados de literatura considerando as diferenças na morbidade e fatores econômicos entre cirurgia em tempo único e em dois tempos com uso de espaçador, estes parâmetros claramente são favoráveis à cirurgia em tempo único - mas apenas se ela é bem sucedida.

Além disso, as indicações de realização de tempo único cada vez ficam mais restritas, pela dúvida quanto à realização do procedimento em pacientes com fístulas ativas e lesões extensas de partes moles, além da impossibilidade de realização de enxertos ósseos em grande quantidade ou maciços.

A redução da morbidade é o benefício mais importante da cirurgia em tempo único. Este benefício é altamente prejudicado se o paciente apresenta recidiva infecciosa e é levado a uma nova cirurgia para retirada de implantes, que estão firmemente fixos ao leito ósseo. Durante a retirada dos componentes pode haver fraturas ósseas, com perda do estoque ósseo e maior risco de complicações clínicas.

Portanto, a prudência nos leva a crer que a avaliação deste método deve iniciar-se por comparar os dois tratamentos em pacientes sem fístulas ativas e com bom estoque ósseo, progredindo, se as pesquisas realmente indicarem bons resultados na terapêutica em tempo único, para casos com fístulas ativas e perdas ósseas leves. 
Apesar dos bons resultados das cirurgias em dois tempos, do ponto de vista infeccioso, é importante lembrar que o paciente permanece por um período mínimo de dois meses em que sua autonomia funcional e qualidade de vida ficam extremamente prejudicadas. Esta condição envolve internações prolongadas e reabilitação arrastada.

Não bastassem estes inconvenientes, o paciente sofre grandes riscos de sangramento, quando da realização do segundo tempo, pela presença de material cicatricial extenso, promovendo dificuldades para a dissecção cirúrgica e colocação dos componentes definitivos.

A ressecção de Girdlestone, hoje, deve ser definida mais como um método de resignação do que como uma alternativa de tratamento. Pode ser uma solução interina para o paciente aguardar o segundo tempo cirúrgico, embora, neste caso, a equalização do comprimento dos membros e a melhora no resultado funcional sejam piores que quando é usado o espaçador, no período intermediário.

Nos pacientes em mau estado geral ou nos idosos, em que pairam dúvidas sobre a colocação de novos implantes, podemos optar pela realização do espaçador de cimento. Ao escolhermos pela não realização do segundo tempo cirúrgico, o espaçador pode ser retirado, em uma cirurgia com baixa probabilidade de complicações clínicas.

Ao mantermos um paciente em Girdlestone e decidirmos realizar o segundo tempo cirúrgico, devemos levar em conta que o extenso tecido cicatricial presente, o encurtamento e a dificuldade para identificação dos parâmetros ósseos levam à alta dificuldade técnica para o cirurgião, pondo em risco não apenas o resultado funcional e infeccioso, mas também a vida do paciente. 


\section{CONCLUSÕES}


1. O tratamento das artroplastias infectadas de quadril em dois tempos com o uso do espaçador de cimento com antibiótico é superior à cirurgia em dois tempos realizada sem o espaçador.

2. O uso do espaçador proporciona melhor controle infeccioso e bons resultados funcionais. 


\section{BIBLIOGRAFIA}


AALTO, K.; OSTERMAN, K.; PELTOLA. H; RASANEN, J. Changes in erythrocyte sedimentation rate and C-reactive protein after total hip arthroplasty. Clin. Orthop., n.184, p.118-20, 1984.

ABENDSCHEIN, W. Salvage of infected total hip replacement: use of antibiotic/PMMA spacer. Orthopedics, v.15, n. 2, p.228-9, 1992.

ADAMS, K.; COUCH. L; CIERNY. G; CALHOUN. J; MADER, J.T. In vitro and in vivo evaluation of antibiotic diffusion from antibiotic-impregnated polymethylmethacrylate beads. Clin. Orthop.. n.278, p.244-52, 1992.

AHLGREN, S.A.; GUDMUNDSSON, G; BARTHOLDSSON, E. Function after removal of a septic total hip prosthesis. A survey of 27 Girdlestone hips. Acta Orthop. Scand., v.51, n.3, p. 541-5, 1980.

ALEXEEFF; M. MAHOMED, N.; MORSI, E.; GARBUZ, D.; GROSS, A. Structural allograft in two-stage revisions for failed septic hip arthroplasty. J. Bone Joint Surg. Br., v.78, n. 2, p. 213-6, 1996.

AMATO NETO; V.; LEVI, G.C.; LOPES, H.V.; MENDONÇA, J.S.; BLADRY,J.L.S. Antibióticos na prática médica. 5. ed. São Paulo, Roca, 2000. 304p.

ANTTI-POIKA, I.; SANTAVIRTA, S.; KONTTINEN, Y.T.; HONKANEN, V. Outcome of the infected hip arthroplasty. A retrospective study of 36 patients. Acta Orthop. Scand., v.60, n.6, p. 670-5.,1989.

BAKER, A.S.; GREENHAM, L.W. Release of gentamicin from acrylic bone cement. Elution and diffusion studies. J. Bone Joint Surg. Am., v.70, n. 10, p.1551-7, 1988.

BARRACK, R.L.; TANZER, M.; KATTAPURAM, S.V.; HARRIS, W.H. The value of contrast arthrography in assessing loosening of symptomatic uncemented total hip components. Skeletal Radiol., v. 23, n. 1, p. 37-41, 1994.

BARRACK, R.L. Rush pin technique for temporary antibiotic-impregnated cement prosthesis for infected total hip arthroplasty. J. Arthroplasty., v.17, n.5, p.600-3, 2002.

BAYSTON, R.; MILNER, R.D. The sustained release of antimicrobial drugs from bone cement. An appraisal of laboratory investigations and their significance. J. Bone Joint Surg. Br., v.64, n.4, p.460-4, 1982.

BERBARI, E.F.; HANSSEN, A.D.; DUFFY, M.C.; STECKELBERG, J.M.; ILSTRUP, D.M.; HARMSEN, W.S.; OSMON, D.R. Risk factors for prosthetic joint infection: case-control study. Clin. Infect. Dis., v.27, n.5, p. 1247-54, 1998.

BERNABÉ.A.C. Revisão na artroplastia total do quadril. Reavaliação clínica e radiográfica de $\mathbf{4 0}$ casos. São Paulo, 1996. 127p. Tese (Doutorado) - Faculdade de Medicina, Universidade de São Paulo. 
BERRY, D.J.; CHANDLER, H.P.; REILLY, D.T. The use of bone allografts in two-stage reconstruction after failure of hip replacements due to infection. $\mathbf{J}$. Bone Joint Surg. Am., n.73, v.10, p.1460-8, 1991.

BITTAR, E.S.; PETTY, W. Girdlestone arthroplasty for infected total hip arthroplasty. Clin. Orthop., v.170, n.83, p.7,1982.

BOURNE, R.B.; HUNTER, G.A.; RORABECK, C.H.; MACNAB, J.J. A six-year follow-up of infected total hip replacements managed by Girdlestone's arthroplasty. J. Bone Joint Surg. Br., v.66, n.3, p.340-3, 1984.

BRANDT, C.M.; SISTRUNK, W.W.; DUFFY, M.C.; HANSSEN, A.D.; STECKELBERG, J.M.; ILSTRUP, D.M.; OSMON, D.R. Staphylococcus aureus prosthetic joint infection treated with debridement and prosthesis retention. Clin. Infec.t Dis., v.24, n.5, p.914-9, 1997.

BRIEN, W.W.; SALVATI, E.A.; KLEIN, R.; BRAUSE, B.; STERN, S. Antibiotic impregnated bone cement in total hip arthroplasty. An in vivo comparison of the elution properties of tobramycin and vancomycin. Clin. Orthop., n.296, p:242-8, 1993.

BUCHHOLZ, H.W.; ELSON, R.A.; ENGELBRECHT, E.; LODENKAMPER, H.; ROTTGER, J.; SIEGEL,F. Management of deep infection of total hip replacement. J. Bone Joint Surg. Br., v.63, n.3, p.342-53,1981.

BUCHHOLZ,H.W., ELSON,R.A., HEINNERT,K. Antibiotic-loaded cement: current concepts. Clin. Orthop., n.190, p.96-108, 1984.

CALLAGHAN, J.J.; KATZ, R.P.; JOHNSTON, R.C. One-stage revision surgery of the infected hip. A minimum 10-year followup study. Clin. Orthop., n.369, p.139-43, 1999.

CANNER, G.C.; STEINBERG, M.E.; HEPPENSTALL, R.B.; BALDERSTON, R. The infected hip after total hip arthroplasty. J. Bone Joint Surg. Am., v.66, n.9,p.1393-9, 1984.

CARLSSON, A.S.; JOSEFSSON, G.; LINDBERG, L. Revision with gentamicinimpregnated cement for deep infections in total hip arthroplasties. J. Bone Joint Surg. Am., v.60, n.8, p.1059-64, 1978.

CHARLTON, W.P.; HOZACK, W.J.; TELOKEN, M.A.; RAO, R.; BISSETT, G.A.Complications associated with reimplantation after girdlestone arthroplasty. Clin. Orthop., n.407, p.119-26, 2003.

CASTELLANOS, J.; FLORES, X.; LLUSA, M.; CHIRIBOGA, C; NAVARRO, A. The Girdlestone pseudarthrosis in the treatment of infected hip replacements. Int. Orthop., v.22, n.3, p.178-81, 1998. 
CHARNLEY,J. Low friction arthroplasty of the hip. Theory and practice. New York, Springer-Verlag, 1979, 376p.

CHOHFI, M.; LANGLAIS, F. O cimento ortopédico associado à vancomicina : comportamento mecânico e difusão do antibiótico. Rev. Bras. Ortop., v.29, n.6, p. 363-370, 1994.

CHOHFI, M.; LANGLAIS, F.; TURÍBIO,F.M. Cimento com vancomicina: farmacocinética do antibiótico na ovelha e no homem. Rev. Bras. Ortop., v.31, n.2, p. 151-158, 1996.

CHOHFI, M.; LANGLAIS, F; FOURASTIER, J.; MINET, J.; THOMAZEAU, H.; CORMIER, M. Pharmacokinetics, uses, and limitations of vancomycin-loaded bone cement. Int. Orthop., v.22, n.3, p.171-7, 1998.

CIERNY, G. III; DIPASQUALE, D. Periprosthetic total joint infections: staging, treatment, and outcomes. Clin. Orthop., n.403, p.23-8, 2002.

CLEGG, J. The results of the pseudarthrosis after removal of an infected total hip prosthesis. J. Bone Joint Surg. Br., v.59. n.3, p.298-301, 1977.

COLLINS, D.N.; MCKENZIE, J.M. Infections at the site of a hip implant. Successful and unsuccessful management. Clin. Orthop., n. 269, p. 9-15,1991.

COLYER, R. A., CAPELLO, W. N.: Surgical treatment of the infected hip implant. Two-stage reimplantation with a one-month interval. Clin. Orthop., 298: 75-79, 1994

COSTERTON,J.W., CHENG,K.J., GEESEY,G.G., LADD,T.I., NICKEL,J.C., DASGUPTA,M., MARRIE,T.J. Bacterial biofilms in nature and disease. Ann. Rev. Microbiol., n.41, p. 435-64,1987.

COVENTRY; M.B. Treatment of infections occurring in total hip surgery. Orthop. Clin. North Am., v.6, n.4, p.991-1003, 1975.

CROCKARELL, J.R.; HANSSEN, A.D.; OSMON, D.R.; MORREY, B.F. Treatment of infection with debridement and retention of the components following hip arthroplasty. J. Bone Joint Surg. Am., v. 80, n.9, p.1306-13,1998.

DINARELLO,C.A. The acute-phase response In: GOLDMAN, L.G.;

BENNETT,J.C. Cecil textbook of medicine. 21. ed. Philadelphia, PA, E.U.A., W.B. Saunders Company, 2000, p.1567-1569.

DONATI, D.; BISCAGLIA, R. The use of antibiotic-impregnated cement in infected reconstructions after resection for bone tumours. J. Bone Joint Surg. Br., v.80. n.6, p.1045-50, 1998.

DRINKWATER, C.J.; NEIL, M.J. Optimal timing of wound drain removal following total joint arthroplasty. J. Arthroplasty., v.10, n.2.p.185-9, 1995. 
DUNCAN, C.P.; BEAUCHAMP, C. A temporary antibiotic-loaded joint replacement system for management of complex infections involving the hip.

Orthop. Clin. North Am.. v.24, n.4, p.751-9, 1993.

ELSON, R.A. Exchange arthroplasty for infection. Perspectives from the United Kingdom.Orthop. Clin. North Am.. v.24, n.4, p.761-7, 1993.

ELSON; R.A.; JEPHCOTT, A.E.; MCGECHIE, D.B.; VERETTAS, D. Antibioticloaded acrylic cement.J. Bone Joint Surg. Br. v.59, n.2, p.200-5, 1977.

ELSON, R.A. Sepsis: one -stage Exchange. In: CALLAGHAN,J.J., ROSENBERG,A.G., RUBASH,H.E. The Adult Hip. Philadelphia, PA, E.U.A., Lippincott-Raven, 1998, p.1307-16.

ENGLISH, H.; TIMPERLEY, A.J. DUNLOP, D.; GIE, G. Impaction grafting of the femur in two-stage revision for infected total hip replacement. J. Bone Joint Surg. Br., v.84, n.5, p.700-5, 2002.

ERCOLE,F.F; CHIANCA,T.C.M. Infecção de sítio cirúrgico em pacientes submetidos a artroplastias de quadril. Rev. Latinoam. Enfermagem, v.10, n.2, p.157-65, 2002.

EVANICH, J.; CAMARGO, M.P.; SCOTT, D.F.; HOFMANN, A.A. Treatment of Infected Hip Arthroplasty using an Articulating Antibiotic Spacer. In 67 CONGRESS OF THE AMERICAN ACADEMY OF ORTHOPEDIC SURGEONS, San Francisco, EUA, 1997, Proceedings, p. 456.

FENELON, G.C.; VON FOERSTER, G.; ENGELBRECHT, E. Disarticulation of the hip as a result of failed arthroplasty. A series of 11 cases. J. Bone Joint Surg. Br., v.62, n.4, p.441-6, 1980.

FISMAN; D.N.; REILLY, D.T.; KARCHMER, A.W.; GOLDIE, S.J. Clinical effectiveness and cost-effectiveness of 2 management strategies for infected total hip arthroplasty in the elderly. Clin. Infect. Dis., v.32, n.3, p.419-30, 2001.

FITZGERALD, R.H. JR.; NOLAN, D.R.; ILSTRUP, D.M.; VAN SCOY, R.E.; WASHINGTON, J.A. $2^{\text {ND; }}$ COVENTRY, M.B. Deep wound sepsis following total hip arthroplasty. J. Bone Joint Surg. Am. v.59, n.7, p.847-55, 1977.

FITZGERALD, R.H. Total hip arthroplasty sepsis. Prevention and diagnosis. Orthop. Clin. North Am., v.23, n. 2, p.259-64, 1992.

FITZGERALD, R.H., STEINBERG,M.E. Results In: STEIBERG,M., GARINO,J.P. Revision total hip arthroplasty. Lippincot Williams \& Wilkins, Philadelphia, E.U.A., 1999, p.435-40.

FREITAS, P.F.; CAMPOS, M.L.; CIPRIANO, Z.M. Aplicabilidade do índice de risco do sistema NNIS na predição da incidência de infecção do sítio cirúrgico (ISC) em um hospital universitário no sul do Brasil. Rev. Ass. Med. Brasil., v.46, n.4, p.359-62, 2000. 
GARVIN, K.L.; SALVATI, E.A.; BRAUSE, B.D. Role of gentamicin-impregnated cement in total joint arthroplasty. Orthop.Clin. North Am., v.19, n.3, p.605-10, 1988.

GARVIN, K.L.; EVANS, B.G.; SALVATI, E.A.; BRAUSE, B.D. Palacos gentamicin for the treatment of deep periprosthetic hip infections. Clin. Orthop., n. 298, p.97-105, 1994.

GARVIN,K.L., HANSSEN,A.D. Infection after total hip arthroplasty. Past, present, and future. J. Bone Joint Surg. Am., v.11, n.10, p.1576-88, 1995.

GILLESPIE, W.J. Prevention and management of infection after total joint replacement. Clin. Infect. Dis., v.25, n.6, p.1310-7, 1997.

GIRDLESTONE,G.R. Acute pyogenic arthritis of the hip: an operation giving free access and effective drainage. Lancet, v.1, p.419-21.

GONZALEZ DELLA VALLE, A.; BOSTROM, M.; BRAUSE, B; HARNEY, C.; SALVATI, E.A. Effective bactericidal activity of tobramycin and vancomycin eluted from acrylic bone cement. Acta Orthop. Scand., v.72, n.3, p.237-40, 2001.

GOULD, E.S.; POTTER, H.G.; BOBER, S.E. Role of routine percutaneous hip aspirations prior to prosthesis revision. Skeletal Radiol., v.19, n.6, p. 427-30, 1990.

GRAZIANI, A.L., HINES, J.M., MORGAN, A.S., MCGREGOR, R.R., ESTERHAL, J.L. Infecting organisms and antibiotics In: STEIBERG, M., GARINO, J.P. Revision total hip arthroplasty. Lippincot Williams \& Wilkins, Philadelphia, E.U.A., 1999, p.407-17.

GRAUER, J.D.; AMSTUTZ, H.C.; O'CARROLL, P.F.; DOREY, F.J. Resection arthroplasty of the hip. J. Bone Joint Surg. Am. v.71, n.5, p.669-78, 1989.

GRISTINA, A.G.; KOLKIN, J. Total joint replacement and sepsis. J. Bone Joint Surg. Am., v.65-A, n.1, p.128-34,1983.

GUSTILO, R.B.; PASTERNAK, H.S. Revision total hip arthroplasty with titanium ingrowth prosthesis and bone grafting for failed cemented femoral component loosening. Clin. Orthop., n. 235, p.111-9, 1988.

HADDAD, F.S.; MASRI, B.A.; GARBUZ, D.S.; DUNCAN, C.P. The treatment of the infected hip replacement. The complex case. Clin. Orthop., n.369, p. 14456, 1999.

HADDAD, F.S.; MUIRHEAD-ALLWOOD, S.K.; MANKTELOW, A.R.; BACARESE-HAMILTON, I. Two-stage uncemented revision hip arthroplasty for infection J. Bone Joint Surg. Br., v. 82, p.689-94, 2000. 
HANSSEN,A.D.; RAND,J.A. Evaluation and treatment of infection at the site of a total hip or knee arthroplasty. Inst. Course Lect., v.48, p.111-22, 1999.

HADDAD, F.S; MUIRHEAD-ALLWOOD, S.K.; MANKTELOW, A.R.;

BACARESE-HAMILTON, I. Two-stage uncemented revision hip arthroplasty for infection. J. Bone Joint Surg. Br., v. 82, p. 689-94, 2000.

HANSSEN, A.D.; OSMON, D.R. Assessment of patient selection criteria for treatment of the infected hip arthroplasty. Clin. Orthop., n.381, p.91-100, 2000.

HANSSEN, A.D.; OSMON, D.R. Evaluation of a staging system for infected hip arthroplasty. Clin. Orthop., n.403, p.16-22, 2002.

HARDINGE, K. The direct lateral approach to the hip.J. Bone Joint Surg. Br., v.64, n.1, p.17-9,1982.

HARRIS, W.H. Traumatic arthritis of the hip after dislocation and acetabular fractures: treatment by mold arthroplasty. An end-result study using a new method of result evaluation. J. Bone Joint Surg. Am., v.51, p. 737-55, 1969.

HARTFORD, J.M.; GOODMAN, S.B. The use of femoral intramedullary nailing as an interim or salvage technique during complicated total hip replacement. J. Arthroplasty. v..3, n.4, p.467-72, 1998.

HECK, D.; ROSENBERG, A.; SCHINK-ASCANI, M.; GARBUS, S.; KIEWITT, T. Use of antibiotic-impregnated cement during hip and knee arthroplasty in the United States. J. Arthroplasty., v.10, n.4, p.470-5, 1995.

HOFMANN, A.A. Two-stage exchange is better than direct exchange in the infected THA. Orthopedics., v.22, n.10, p.918, 1999.

HOPE, P.G.; KRISTINSSON, K.G.; NORMAN, P.; ELSON, R.A. Deep infection of cemented total hip arthroplasties caused by coagulase-negative staphylococci. J. Bone Joint Surg. Br., v.71, n.5, p.851-5, 1989.

HOUSHIAN, S.; ZAWADSKI, A.S.; RIEGELS-NIELSEN, P. Duration of postoperative antibiotic therapy following revision for infected knee and hip arthroplasties. Scand. J. Infect. Dis., v.32, n.6, p.685-8, 2000.

HOVELIUS, L,; JOSEFSSON, G. An alternative method for exchange operation of infected arthroplasty. Acta Orthop. Scand., v.50, n.1, p.93-6, 1979.

HUGHES, P.W.; SALVATI, E.A.; WILSON, P.D. JR; BLUMENFELD, E.L. Treatment of subacute sepsis of the hip by antibiotics and joint replacement. Criteria for diagnosis with evaluation of twenty-six cases. Clin. Orthop., n.141, p.143-57, 1979.

HUNTER, G.; DANDY, D. The natural history of the patient with an infected total hip replacement.J. Bone Joint Surg. Br. v.59, n.3, p.293-7, 1977. 
JACKSON, W.O.; SCHMALZRIED, T.P. Limited role of direct exchange arthroplasty in the treatment of infected total hip replacements. Clin. Orthop.. n.381, p.101-5, 2000.

JAHODA, D.; SOSNA, A.; LANDOR, I.; VAVRIK, P.; POKORNY, D.; HUDEC, T. [Two-stage reimplantation using spacers--the method of choice in treatment of hip joint prosthesis-related infections. Comparison with methods used from 1979 to 1998] Acta. Chir. Orthop. Traumatol. Cech., v.70, n.1, p.17-24, 2003.

KAMME, C.; LINDBERG, L. Aerobic and anaerobic bacteria in deep infections after total hip arthroplasty: differential diagnosis between infectious and noninfectious loosening. In. Orthop. n.154, p.201-7, 1981.

KENDALL, R.W.; DUNCAN, C.P.; SMITH, J.A.; NGUI-YEN, J.H. Persistence of bacteria on antibiotic loaded acrylic depots. A reason for caution. Clin. Orthop., n.329, p.273-80, 1996.

KILGUS, D.J.; HOWE, D.J.; STRANG, A. Results of periprosthetic hip and knee infections caused by resistant bacteria. Clin. Orthop., n.404, p.116-24, 2002.

KLEKAMP, J.; DAWSON, J.M.; HAAS; D.W.; DEBOER, D.; CHRISTIE, M. The use of vancomycin and tobramycin in acrylic bone cement: biomechanical effects and elution kinetics for use in joint arthroplasty. J. Arthroplasty,, v.14, n.3, p.339-46, 1999.

KOO, K.H.; YANG, J.W.; CHO, S.H.; SONG, H.R.; PARK, H.B.; HA, Y.C.; CHANG, J.D.; KIM, S.Y.; KIM, Y.H. Impregnation of vancomycin, gentamicin, and cefotaxime in a cement spacer for two-stage cementless reconstruction in infected total hip arthroplasty. J. Arthroplasty,, v.16, n.7, p.882-92, 2001.

KOSTUIK, J.; ALEXANDER, D. Arthrodesis for failed arthroplasty of the hip. Clin. Orthop., n.188, p.173-82, 1984.

KRAAY, M.J.; GOLDBERG, V,M,; FIGGIE, H.E. $3^{\text {RD }}$. Use of an antibiotic impregnated polymethyl methacrylate intramedullary spacer for complicated revision total hip arthroplasty. J. Arthroplasty,, v.7 Suppl, p.397-402, 1992.

KUECHLE, D.K.; LANDON, G.C.; MUSHER, D.M.; NOBLE, P.C. Elution of vancomycin, daptomycin, and amikacin from acrylic bone cement. Clin.

Orthop., n.264, p.302-8, 1991.

LANGLAIS, F.; BUNETEL, L.; SEGUI, A; SASSI, N.; CORMIER, M. Ciments orthopédiques aux antibiotiques. Pharmacocinétique et taux osseux. Rev. Chir. Orthop. Reparatrice Appar. Mot., v.74, n.6, p.493-503,1988.

LAI, K.A.; SHEN, W.J.; YANG, C.Y.; LIN, R.M.; LIN, C.J.; JOU, I.M. Two-stage cementless revision THR after infection. 5 recurrences in 40 cases followed 2.57 years. Acta Orthop. Scand.,. v.67, n.4, p.325-8, 1996. 
LANGLAIS, F. Can we improve the results of revision arthroplasty for infected total hip replacement? J. Bone Joint Surg. Br., v.85-B, n.5, p. 637-640, 2003.

LARSSON, S.; THELANDER, U.; FRIBERG, S. C-reactive protein (CRP) levels after elective orthopedic surgery. Clin. Orthop., n.275, p.237-42, 1992.

LAUTENSCHLAGER, E.P.; MARSHALL, G.W.; MARKS SCWARTZ, J.; NELSON, C.L. Mechanical strengh of acrylic bone cements impregnated with antibiotics. J. Biomed. Mater. Res., v.10, n.6, p.9, p.837-845, 1976.

LAUTENSCHLAGER, E.P.; JACOBS, J.J.; MARSHALL, G.W.; MEYER, P.R. JR. Mechanical properties of bone cements containing large doses of antibiotic powders. J. Biomed. Mater. Res., n.10, v.6, p.929-38, 1976.

LECUIRE, F.; COLLODEL, M.; BASSO, M.; RUBINI, J.; GONTIER, D.; CARRERE, J. Reprise des prothèses totales de hanche infectées par ablation réimplantation d'une prothèse sans ciment. Experiénce de 57 cas. Ver. Chir. Orthop. Reparatrice Appar. Mot., v.85, p.4, p.337-48, 1999.

LEE, S.S.; UENG, S.W.; SHIH, C.H. Vastus lateralis flaps for chronic recalcitrant hip infection. Int. Orthop., v.20, n.6, p.373-7, 1996.

LENTINO, J.R. Prosthetic joint infections: bane of orthopedists, challenge for infectious disease specialists. Clin. Infect. Dis., v.36, n.9, p.1157-61, 2003.

LEUNIG, M.; CHOSA, E.; SPECK, M.; GANZ, R. A cement spacer for two-stage revision of infected implants of the hip joint. Int. Orthop., v.22, n.4, p.209-14, 1998.

LEVIN, P.D. The effectiveness of various antibiotics in methyl methacrylate. J. Bone Joint Surg. Br., v.57, n.2, p.234-7, 1975.

LIEBERMAN, J. R.; CALLAWAY, G. H.; SALVATI, E. A.; PELLICCI, P. M.; BRAUSE, B. D. Treatment of the infected total hip arthroplasty with a two-stage reimplantation protocol. Clin. Orthop., n.301, p.205-212, 1994.

LIMA, A.L. Infecções hospitalares em 46 pacientes submetidos à artroplastia total de quadril. São Paulo, 1995. 127p. Tese (Mestrado) Faculdade de Medicina, Universidade de São Paulo.

LIMA, A.L., BARONE,A.A. Infecções hospitalares em 46 pacientes submetidos a artroplastia total do quadril. Acta Ortop. Bras. ,v.9, n.1, p.36-41, 2001.

LOTY, B.; POSTEL, M.; EVRARD, J.; MATRON, P.; COURPIED, J.P.; KERBOULL, M.; TOMENO, B. Remplacements en un temps des prothèses totales de hanches infectées et reconstructions osseuses par allogreffes. Etude de 90 reprises dont 46 avec allogreffes osseuses. Int. Orthop., v.16, n.4, p.330-8, 1992. 
MAGNAN, B.; REGIS, D.; BISCAGLIA, R.; BARTOLOZZI, P. Preformed acrylic bone cement spacer loaded with antibiotics: use of two-stage procedure in 10 patients because of infected hips after total replacement. Acta Orthop. Scand., v.72, n.6, p.591-4, 2001.

MCDONALD, D.J.; FITZGERALD, R.H. JR; ILSTRUP, D.M. Two-stage reconstruction of a total hip arthroplasty because of infection. J. Bone Joint Surg. Am., v.71, n.6, p.828-34, 1989.

MCPHERSON, E.J.; WOODSON, C.; HOLTOM, P.; ROIDIS, N.; SHUFELT, C.; PATZAKIS, M. Periprosthetic total hip infection: outcomes using a staging system. Clin. Orthop., n.403, p.8-15, 2002.

MARKS, K.E.; NELSON, C.L.; LAUTENSCHLAGER, E.P. Antibioticimpregnated acrylic bone cement. J. Bone Joint Surg. Am., v.58, n.3, p.35864, 1976.

MASRI, B.A.; DUNCAN, C.P.; BEAUCHAMP, C.P.; PARIS, N.J.; ARNTORP, J. Effect of varying surface patterns on antibiotic elution from antibiotic-loaded bone cement. J. Arthroplasty,, v.10, n.4, p.453-9, 1995.

MASRI, B.A.; DUNCAN, C.P.; BEAUCHAMP, C.P. Long-term elution of antibiotics from bone-cement: an in vivo study using the prosthesis of antibioticloaded acrylic cement (PROSTALAC) system. J. Arthroplasty,, v.13, n.3, p.331-8, 1998.

MASRI, B.A.; DUNCAN, C.P. Sepsis: Antibiotic-loaded Implants. In: CALLAGHAN,J.J., ROSENBERG,A.G., RUBASH,H.E. The Adult Hip. Philadelphia, PA, E.U.A., Lippincott-Raven, 1998, p.1331-42.

MASTERSON, E.L., MASRI, B.A., DUNCAN, C.P. Treatment of infection at the site of total hip replacement. Instr. Course Lect., n.47, p.297-306, 1998.

MIGAUD, H.; CHANTELOT, C.; BESSON, A.; GOUGEON, F.; DUBOIS, H.H.; DUQUENNOY, A. Temporary antibiotic-loaded cemented prosthesis for twostage septic hip arthroplasty . Rev. Chir. Orthop. Reparatrice Appar. Mot., v.84, n.5, p.466-8, 1997.

MILEY, G.B.; SCHELLER, A.D. JR; TURNER, R.H. Medical and surgical treatment of the septic hip with one-stage revision arthroplasty. Clin. Orthop., n.170, p.76-82, 1982.

MIMS ,C.; WAKELIN, D.; PLAYFAIR, J; WILLIAMS, R.; IVAN, R. Microbiologia Médica. 2. ed. São Paulo, Editora Manole, 1999. 583p.

MIRANDA, F.G.M. Artroplastia total do quadril com prótese não cimentada tipo AML: estudo de $\mathbf{3 1 5}$ cirurgias. São Paulo, 1995. 106p. Tese (Doutorado) - Faculdade de Medicina, Universidade de São Paulo. 
MITCHELL, P.A., MASRI, B.A., GARBUZ, D.S., GREIDANUS, N.V., DUNCAN, C.P. Cementless revision for infection following total hip arthroplasty.

Instr. Course Lect., v.52, p.323-30, 2003.

MØLLER, L.P.; SOLGAARD, S.; PETERSEN, J.B.; RETPEM, J.B. Treatment of the infected total hip arthoplasty with a temporary gentamicin spacer. Hip International, v.6, n.1, p. 24-8, 1996.

MORSCHER, E. Solo espianto o reimplanto per la mobilizzazione settica? Chir. Organi Mov., v.79, n. 4, p.425-8, 1994.

NESTOR, B. J.; HANSSEN, A. D.; FERRER-GONZALEZ, R.; FITZGERALD, R. H., JR.: The use of porous prostheses in delayed reconstruction of total hip replacements that have failed because of infection. J. Bone and Joint Surg. Am., v.76, p.349-359, 1994.

NEUT, D.; VAN DE BELT, H.; STOKROOS, I.; VAN HORN, J.R.; VAN DER MEI, H.C.; BUSSCHER, H.J. Biomaterial-associated infection of gentamicinloaded PMMA beads in orthopaedic revision surgery. J. Antimicrob.

Chemother., v.47, n.6, p.885-91, 2001.

NISKANEN, R.O.; KORKALA, O.; PAMMO, H. Serum C-reactive protein levels after total hip and knee arthroplasty. J. Bone Joint Surg. Br., v.78, n.3, p.4313, 1996.

OXBORROW, N.J.; STAMER, J.; ANDREWS, M.; STONE, M.H. New uses for gentamicin-impregnated polymethyl methacrylate spacers in two-stage revision hip arthroplasty. J. Arthroplasty, v.12, n.6, p.709-10, 1997.

PAGNANO, M.W.; TROUSDALE, R.T.; HANSSEN, A.D. Outcome after reinfection following reimplantation hip arthroplasty. Clin. Orthop., n.338, p.192-204, 1997.

PENNER, M.J.; MASRI, B.A.; DUNCAN, C.P. Elution characteristics of vancomycin and tobramycin combined in acrylic bone-cement. J. Arthroplasty, v.11, n.8, p.939-44, 1996.

PIRIOU, P.; DE LOYNES, B. GARREAU DE LOUBRESSE, C.; JUDET, T. Intérêt de la scintigraphie couplée gallium technétium afin d'optimisier le délai de réimplantation prothétique en deux temps des infections sur arthroplastie de hanche. A propos d'une série continue de 30 cas. Rev. Chir. Orthop.

Reparatrice Appar. Mot., v. 89, n.4, p. 287-96, 2003.

RAUT, V,V,; SINEY, P.D.; WROBLEWSKI, B.M. One-stage revision of infected total hip replacements with discharging sinuses. J. Bone Joint Surg. Br., v. 76, p. 721-4, 1994.

RAUT, V,V,; SINEY, P.D.; WROBLEWSKI, B.M. One-stage revision of total hip arthroplasty for deep infection. Long-term followup. Clin. Orthop., n.321, p.2027, 1995. 
REESE, R.E.; SENTOCHINK, D.E.; DOUGLAS, R.G. JR; BETTS, R.F. Manual de antibióticos. Rio de Janeiro, MEDSI,1990. p.202-208.

SALVATI, E.A.; CHEKOFSKY, K.M.; BRAUSE, B.D.; WILSON, P.D. JR. Reimplantation in infection: a 12-year experience. Clin. Orthop., v.170, n.6275, 1982.

SALVATI, E.A.; CALLAGHAN, J.J.; BRAUSE, B.D.; KLEIN, R.F.; SMALL, R.D. Reimplantation in infection. Elution of gentamicin from cement and beads. Clin. Orthop., n.207, p.83-93, 1986.

SALVATI, E.A.; DELLA VALLE, A.G; MASRI, B.A.; DUNCAN, C.P. The infected Total Hip Arthroplasty. Instr. Course Lect., v.52, p.223-45, 2003.

SANZÉN, L.; CARLSSON, A.S.; JOSEFSSON, G.; LINDBERG, L.T. Revision operations on infected total hip arthroplasties. Two- to nine-year follow-up study. Clin. Orthop., n.229, p.165-72,1988.

SANZÉN, L.; CARLSSON, A.S. The diagnostic value of C-reactive protein in infected total hip arthroplasties. J. Bone Joint Surg. Br., v.71, n.4, p.638-41, 1989.

SANZÉN, L.; SUNDBERG, M. Periprosthetic low-grade hip infections.

Erythrocyte sedimentation rate and C-reactive protein in 23 cases. Acta

Orthop. Scand., v.68, n.5, p.461-5, 1997.

SCALVI, A.; CAMPACCI, A.; MARCER, M.; CASSINI, M.; GUERRA, C.;

FERRARESI, M.; GHASEMI, M.R. Girdlestone arthroplasty for loosening of the total hip prosthesis: evaluation and results. Chir. Organi Mov., v.80, n.3, p.27985, 1995.

SCHRODER, J.; SARIS. D.; BESSELAAR, P.P.; MARTI, R.K. Comparison of the results of the Girdlestone pseudarthrosis with reimplantation of a total hip replacement. Int. Orthop., v.22, n.4, p.215-8, 1998.

SCHWARTSMANN, C.R. Via de acesso ântero-lateral sem osteotomia do trocanter maior para artroplastia total do quadril. São Paulo, 1984. 118p. Tese (Doutorado) - Faculdade de Medicina, Universidade de São Paulo.

SCHMARLZRIED, T.P. Careful patient selection is the key for direct exchange in the infected THA. Orthopedics., v.22, n.10, p. 919, 1999.

SHIH, L.Y.; WU, J.J.; YANG, D.J. Erythrocyte sedimentation rate and C-reactive protein values in patients with total hip arthroplasty. Clin. Orthop., n.225, p.238-46, 1986.

SPANGEHL, M.J.; MASRI, B.A.; O'CONNELL, J.X.; DUNCAN, C.P.

Prospective anylisis of preoperative and intraoperative investigations for the 
diagnosis of infection at the sites of two hundred and two revision total hip arthroplasties. J. Bone Joint Surg. Am., v.81, p. 672-83, 1999.

TAGGART, T.; KERRY, R.M.; NORMAN, P.; STOCKLEY, I. The use of vancomycin-impregnated cement beads in the management of infection of prosthetic joints. J. Bone Joint Surg. Br., v.84, n.1, p.70-2, 2002.

TATTEVIN, P.; CREMIEUX, A.C.; POTTIER, P.; HUTEN, D.; CARBON, C. Prosthetic joint infection: when can prosthesis salvage be considered? Clin. Infect. Dis., v.29, n.2, p.292-5, 1999.

THOMAS, D.J.; BANNISTER, G. Exchange arthroplasty best for infected total hip replacement. Hip International, v.1, n.1, p. 17-20, 1991.

TSUKAYAMA, D.T.; ESTRADA, R.; GUSTILO, R.B. Infection after total hip arthroplasty. A study of the treatment of one hundred and six infections. J. Bone Joint Surg. Am., v.78, n.4, p.512-23, 1996.

URE, K.J.; AMSTUTZ, H.C.; NASSER, S.; SCHMALZRIED, T.P. Directexchange arthroplasty for the treatment of infection after total hip replacement. An average ten-year follow-up. J. Bone Joint Surg. Am., v.80, n.7, p.961-8, 1998.

VAN RAAIJ, T.M.; VISSER, L.E.; VULTO, A.G.; VERHAAR, J.A. Acute renal failure after local gentamicin treatment in an infected total knee arthroplasty. $\mathbf{J}$. Arthroplasty,. v.17, n.7, p.948-50, 2002.

VAN DE BELT, H.; NEUT, D.; SCHENK, W.; VAN HORN, J.R.; VAN DER MEI, H.C.; BUSSCHER, H.J. Gentamicin release from polymethylmethacrylate bone cements and Staphylococcus aureus biofilm formation. Acta Orthop. Scand.,. v.71, n.6, p.625-9, 2000.

VAN DE BELT, H.; NEUT, D.; SCHENK. W.; VAN HORN, J.R.; VAN DER MEI, H.C.; BUSSCHER, H.J. Infection of orthopedic implants and the use of antibiotic-loaded bone cements. Acta Orthop. Scand., v.72, n.6, p.557-71, 2001.

WAHLIG, H.; DINGELDEIN, E.; BUCHHOLZ, H.W.; BUCHHOLZ, M.;

BACHMANN, F. Pharmacokinetic study of gentamicin-loaded cement in total hip replacements. Comparative effects of varying dosage.J. Bone Joint Surg. Br., v.66, n.2, p.175-9, 1984.

WANG, J.W.; CHEN, C.E. Reimplantation of infected hip arthroplasties using bone allografts. Clin. Orthop.. n.335, p.202-10, 1997.

WEBER, F.A.; LAUTENBACH, EE. Revision of infected total hip arthroplasty. Clin. Orthop.. n.211, p.108-15,1986. 
WEINSTEIN, A.M.; BINGHAM, D.N.; SAUER, B.W.; LUNCEFORD, E.M. The effect of high pressure insertion and antibiotic inclusions upon the mechanical properties of polymethylmethacrylate. Clin. Orthop.. n.121, p.67-73, 1976.

WENTWORTH, S.J.; MASRI, B.A.; DUNCAN, C.P.; SOUTHWORTH, C.B. Hip prosthesis of antibiotic-loaded acrylic cement for the treatment of infections following total hip arthroplasty. J. Bone Joint Surg. Am., v.84, Suppl. 2, p.1238,2002

WRIGHT, T.M.; SULLIVAN, D.J.; ARNOCZKY, S.P. The effect of antibiotic additions on the fracture properties of bone cements. Acta Orthop. Scand.,. v.55, n.4, p.414-8, 1984.

WROBLEWSKI, B. M. One stage revision of infected cemented total hip arthroplasty. Clin. Orthop., v.212, p.103-107, p.1986.

YANIV, M.; DABBI, D.; AMIR, H.; COHEN, S.; MOZES, M.; TSUBERI, H.; FRIETKIN, M.; DEKEL, S.; OFEK, I. Prolonged leaching time of peptide antibiotics from acrylic bone cement.

Clin. Orthop.. n.363, p.232-9, 1999.

YOUNGER, A. S. E.; MASRI, B. A.; DUNCAN, C. P.; MCGRAW, R. W. The outcome of two-stage arthroplasty using a custom-made interval spacer to treat the infected hip. J. Arthroplasty, n.12, p.615-623, 1997.

ZILKENS, K.W.; CASSER, H.R.; OHNSORGE, J. Treatment of an old infection in a total hip replacement with an interim spacer prosthesis, Arch. Orthop.

Trauma Surg., v.109, n.2, p.94-6, 1990. [resumo] 


\section{ANEXO A \\ DADOS PRÉ-OPERATÓRIOS}

COMPLEMENTARES 
TABELA 1

DISTRIBUIÇÃO DE FREQÜÊNCIA, ABSOLUTA (n) E RELATIVA (\%), DE HOSPITAL DE ORIGEM DOS PACIENTES DE ACORDO COM O GRUPO, DOIS TEMPOS E ESPAÇADOR. COMPARAÇÃO PELO TESTE DE QUI-QUADRADO $(\alpha=0,05)$

\begin{tabular}{|c|c|c|c|c|c|c|}
\hline \multirow{2}{*}{$\begin{array}{c}\text { HOSPITAL DE } \\
\text { ORIGEM }\end{array}$} & \multicolumn{2}{|c|}{ DOIS TEMPOS } & \multicolumn{2}{|c|}{ ESPAÇADOR } & \multicolumn{2}{|c|}{ TOTAL } \\
\hline & $n$ & $\%$ & $\bar{n}$ & $\%$ & $\mathrm{n}$ & $\%$ \\
\hline IOT-HC-FMUSP & 11 & 18,0 & 13 & 21,3 & 24 & 39,4 \\
\hline Fora & 14 & 23,0 & 23 & 37,7 & 37 & 60,6 \\
\hline TOTAL & 25 & 41,0 & 36 & 59,0 & 61 & 100,0 \\
\hline
\end{tabular}

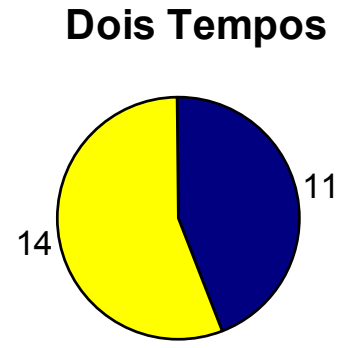

IOT-HC-FMUSP

\section{Espaçador}

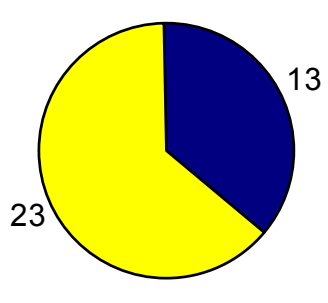

$\square$ Fora

GRÁFICO 1 Hospital de origem dos pacientes 
TABELA 2

ESTATÍSTICA DESCRITIVA DO NÚMERO DE CIRURGIAS PRÉVIAS REALIZADAS NO QUADRIL INFECTADO DE ACORDO COM O GRUPO, DOIS TEMPOS E ESPAÇADOR, E TOTAL. COMPARAÇÃO PELO TESTE U DE MANN WHITNEY $(\alpha=0,05)$ NUMERO DE CIRURGIAS PRÉVIAS

(QUADRIL INFECTADO)

\begin{tabular}{lccc}
\cline { 2 - 4 } & DOIS TEMPOS & ESPAÇADOR & TOTAL \\
\hline \hline M & 1,9 & 3,0 & 2,5 \\
DP & 1,2 & 2,4 & 2,0 \\
EPM & 0,2 & 0,4 & 0,2 \\
MAX & 5 & 14 & 14 \\
MIN & 1 & 1 & 1 \\
N & 25 & 36 & 61 \\
\hline U de Mann Whitney & & $\mathrm{U}=302,5$ &
\end{tabular}

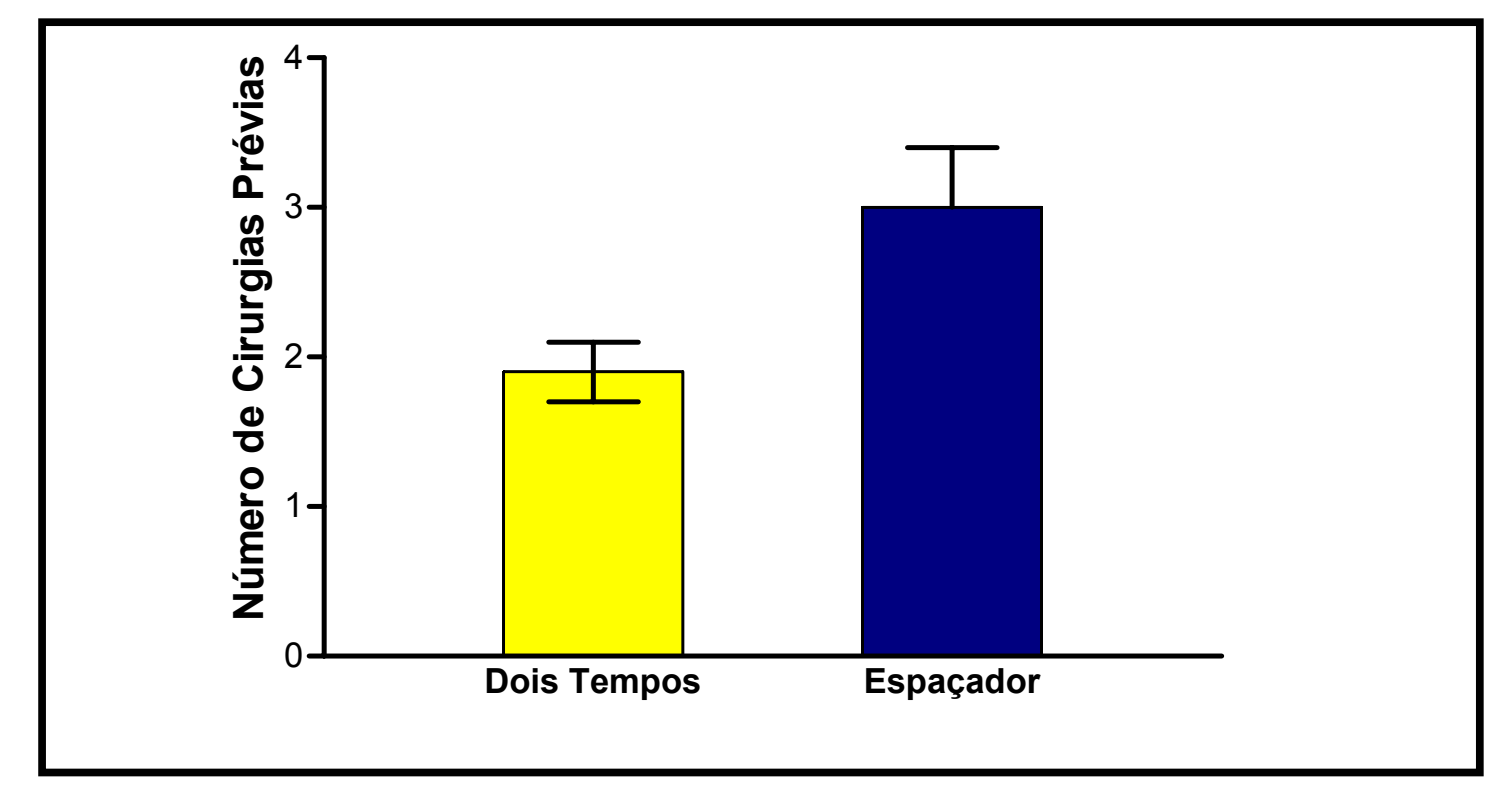

GRÁFICO 2 Número de cirurgias prévias realizadas no quadril infectado 
TABELA 3 ESTATÍSTICA DESCRITIVA DO NÚMERO DE TENTATIVAS DE TRATAMENTO DE INFECÇÃO EM UM MESMO PACIENTE, SUBMETIDO A TRATAMENTO PRÉVIO EXCETO LIMPEZA CIRÚRGICA, DE ACORDO COM O GRUPO, DOIS TEMPOS E ESPAÇADOR E TOTAL. COMPARAÇÃO PELO TESTE U DE MANN WHITNEY $(\alpha=0,05)$

\begin{tabular}{|c|c|c|c|}
\hline & \multicolumn{3}{|c|}{ TENTATIVAS PRÉVIAS DE TRATAMENTO } \\
\hline & DOIS TEMPOS & ESPAÇADOR & TOTAL \\
\hline M & 1,6 & 1,8 & 1,8 \\
\hline DP & 0,8 & 1,3 & 1,2 \\
\hline EPM & 0,2 & 0,3 & 0,2 \\
\hline MAX & 3 & 7 & 7 \\
\hline MIN & 0 & 1 & 1 \\
\hline $\mathrm{N}$ & $12^{(1)}$ & $25^{(2)}$ & 37 \\
\hline $\begin{array}{l}U_{\text {(1) }} 11 \mathrm{ce} \\
\text { (2) } 8 \mathrm{cas}\end{array}$ & \multicolumn{2}{|c|}{$U=140,5$} & $p=0,77$ \\
\hline
\end{tabular}

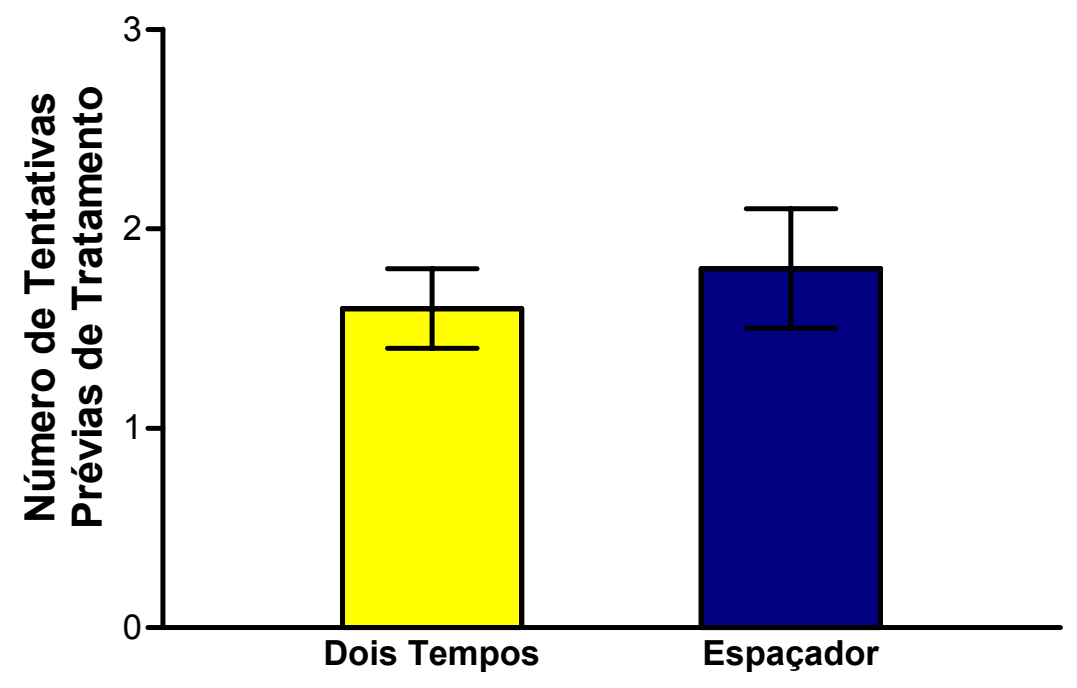

GRÁFICO 3 Número de tentativas de tratamento de infecção em um mesmo paciente, submetido a tratamento prévio exceto limpeza cirúrgica 
TABELA 4 DISTRIBUIÇÃO DE FREQÜÊNCIA, ABSOLUTA (n) E RELATIVA (\%), DAS TENTATIVAS DE TRATAMENTO REALIZADAS NOS PACIENTES DE AMBOS OS GRUPOS, DOIS TEMPOS E ESPAÇADOR

TENTATIVAS DE TRATAMENTO

\begin{tabular}{lcc}
\cline { 2 - 3 } & $\mathrm{n}$ & $\%$ \\
\hline \hline Limpeza cirúrgica & 50 & 82,0 \\
Revisão em dois tempos & 6 & 9,8 \\
Revisão em tempo único & 4 & 6,6 \\
Revisão em dois tempos com espaçador & 1 & 1,6 \\
\hline TOTAL & $\mathbf{6 1}$ & $\mathbf{1 0 0 , 0}$ \\
\hline
\end{tabular}

\section{Tentativas de Tratamento}

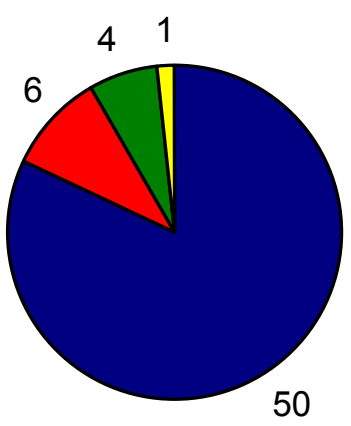

Limpeza cirúrgica

Revisão em dois tempos

Revịãa em tempo único

GRÁFICO 4 Tentativas de tratamento realizadas nos pacientes de ambos os grupos 
TABELA 5

DISTRIBUIÇÃO DE FREQÜÊNCIA, ABSOLUTA (n) E RELATIVA (\%), DA OCORRÊNCIA DE DOENÇAS ASSOCIADAS DE ACORDO COM O GRUPO, DOIS TEMPOS E ESPAÇADOR. COMPARAÇÃO PELO TESTE DE QUI-QUADRADO $(\alpha=0,05)$

\begin{tabular}{|c|c|c|c|c|c|c|}
\hline \multirow{2}{*}{$\begin{array}{c}\text { DOENÇA } \\
\text { ASSOCIADA }\end{array}$} & \multicolumn{2}{|c|}{ DOIS TEMPOS } & \multicolumn{2}{|c|}{ ESPAÇADOR } & \multicolumn{2}{|c|}{ TOTAL } \\
\hline & $\mathrm{n}$ & $\%$ & $\mathrm{n}$ & $\%$ & $\bar{n}$ & $\%$ \\
\hline Ausente & 11 & 18,0 & 19 & 31,1 & 30 & 49,2 \\
\hline Presente & 14 & 22,9 & 17 & 27,9 & 31 & 50,8 \\
\hline TOTAL & 25 & 41,0 & 36 & 59,0 & 61 & 100,0 \\
\hline
\end{tabular}

Dois Tempos

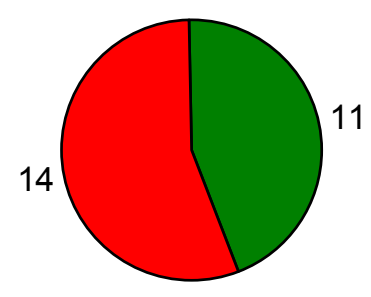

$\square$ Ausente
Espaçador

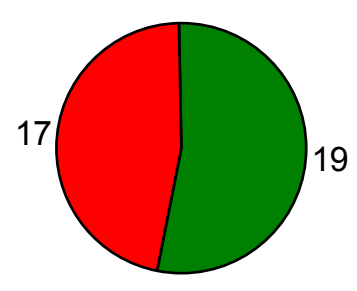

Presente

GRÁFICO 5 Ocorrência de doenças associadas 
TABELA 6

DISTRIBUIÇÃO DE FREQÜÊNCIA, ABSOLUTA (n) E RELATIVA (\%), DE DOENÇAS ASSOCIADAS EM PACIENTES DE AMBOS OS GRUPOS, DOIS TEMPOS E ESPAÇADOR

\begin{tabular}{lcc}
\hline & \multicolumn{2}{c}{ DOENÇAS ASSOCIADAS } \\
\cline { 2 - 3 } & $\mathrm{n}$ & $\%$ \\
\hline \hline Hipertensão arterial sistêmica & 9 & 24,3 \\
Diabetes melito & 6 & 16,2 \\
Doenças reumáticas & 6 & 16,2 \\
Tumores malignos & 5 & 13,5 \\
Cardiopatia & 4 & 10,8 \\
Anemia falciforme & 2 & 5,4 \\
Enfisema pulmonar & 2 & 5,4 \\
Sepse & 1 & 2,7 \\
Hanseníase & 1 & 2,7 \\
Hiperparatireoidismo & 1 & 2,7 \\
\hline TOTAL & 37 & 100,0 \\
\hline
\end{tabular}

\section{Doenças Associadas}

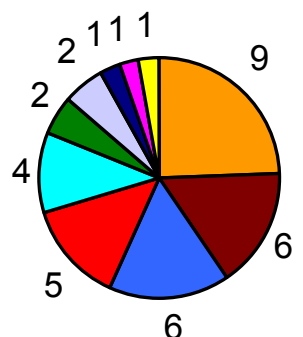

$\square$ Hipertensão arterial sistêmica

$\square$ Doenças reumáticas

口Diabetes melito

$\square$ Cardiopatia

$\square$ Tumores malignos

$\square$ Enfisema pulmonar

$\square$ Anemia falciforme

$\square$ Hanseníase

- Sepse

$\square$ Hiperparatireoidismo

GRÁFICO 6 Doenças associadas em pacientes de ambos os grupos 
TABELA 7

ESTATÍSTICA DESCRITIVA DA AVALIAÇÃO FUNCIONAL PRÉ-OPERATÓRIA SEGUNDO O ESCORE DE HARRIS PARA QUADRIL (HHS) DE ACORDO COM O GRUPO, DOIS TEMPOS E ESPAÇADOR. COMPARAÇÃO PELO TESTE U DE MANN WHITNEY $(\alpha=0,05)$

ESCORE DE HARRIS PARA QUADRIL (HHS)

PRÉ-OPERATÓRIO

\begin{tabular}{lcc}
\cline { 2 - 3 } & DOIS TEMPOS & ESPAÇADOR \\
\hline \hline M & 16,0 & 18,5 \\
DP & 8,4 & 13,4 \\
EPM & 1,7 & 2,2 \\
MAX & 39 & 51 \\
MIN & 5 & 3 \\
N & 25 & 36 \\
\hline U de Mann Whitney & U $=437,0$ & $p=0,85$
\end{tabular}

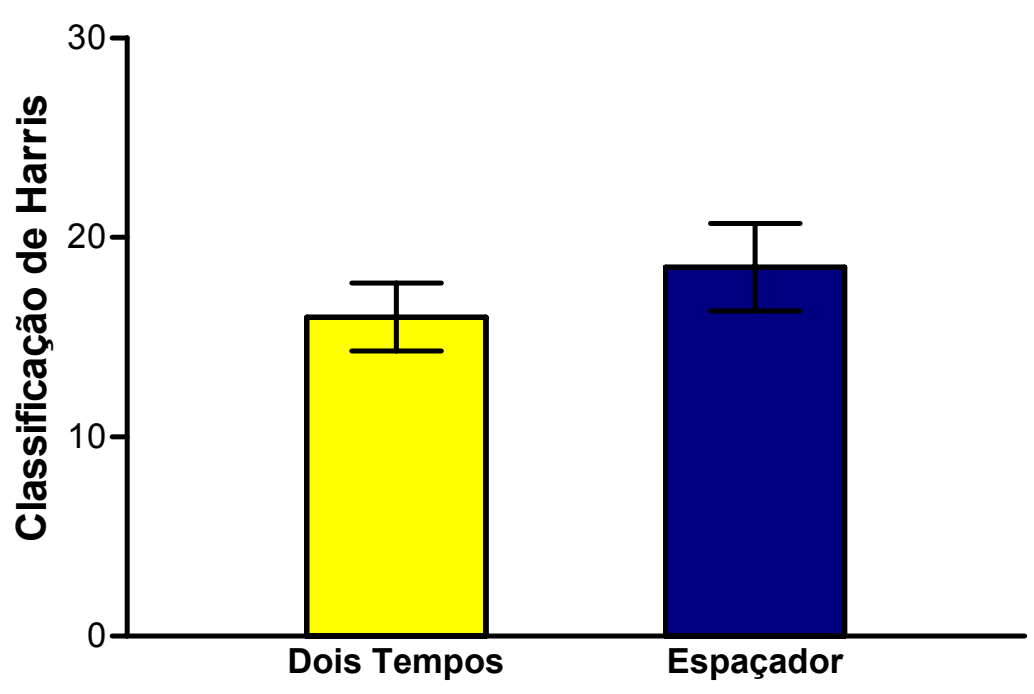

GRÁFICO 7 Avaliação funcional pré-operatória segundo o escore de Harris para quadril (HHS) 
TABELA 8 ESTATÍSTICA DESCRITIVA DOS PARAMETROS LABORATORIAIS GERAIS DE INFECÇÃO NO PRÉOPERATÓRIO, CONTAGEM DE LEUCÓCITOS (leucócitos/ml), VELOCIDADE DE HEMOSSEDIMENTAÇÃO (Westergreen, $\mathrm{mm} / \mathrm{h}$ ) E PROTEÍNA C-REATIVA (mg/dl)

\begin{tabular}{lccc}
\hline & $\begin{array}{c}\text { CONTAGEM DE } \\
\text { LEUCÓcITOS } \\
\text { (leucócito/ml) }\end{array}$ & $\begin{array}{c}\text { VELOCIDADE DE } \\
\text { HEMOSSEDIMENTAÇÃO }\end{array}$ & $\begin{array}{c}\text { PROTEÍNA } \\
\text { C-REATIVA } \\
(\mathrm{mg} / \mathrm{dl})\end{array}$ \\
\hline \hline $\mathrm{M}$ & 8425,4 & 60,0 & 42,2 \\
DP & 2702,6 & 18,3 & 27,0 \\
EPM & 346,0 & 2,3 & 3,8 \\
MAX & 19800 & 101 & 178 \\
MIN & 3950 & 15 & 8,9 \\
$\mathrm{~N}$ & 61 & 61 & $51^{(1)}$ \\
\hline
\end{tabular}

(1) material para análise não coletado em 10 casos
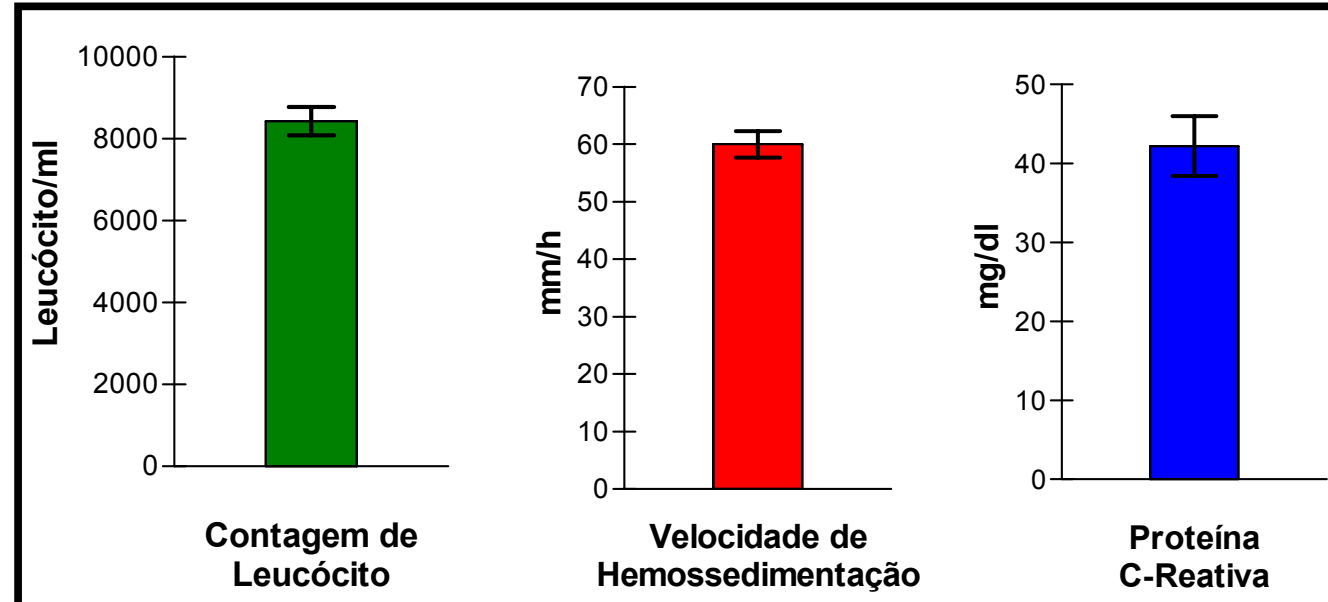

GRÁFICO 8 Contagem de leucócitos (leucócitos $/ \mathrm{ml}$ ), velocidade de hemossedimentação (Westergreen, $\mathrm{mm} / \mathrm{h}$ ) e proteína c-reativa $(\mathrm{mg} / \mathrm{dl})$ 
TABELA 9

ESTATÍSTICA DESCRITIVA DA CONTAGEM DE LEUCÓCITOS (leucócitos/ml) REALIZADA NO PRÉOPERATÓRIO DE ACORDO COM O GRUPO, DOIS TEMPOS E ESPAÇADOR. COMPARAÇÃO PELO TESTE U DE MANN WHITNEY $(\alpha=0,05)$ CONTAGEM DE LEUCÓCITOS PRÉ-OPERATÓRIA

(leucócitos/ml)

\begin{tabular}{lcc}
\cline { 2 - 3 } & DOIS TEMPOS & ESPAÇADOR \\
\hline \hline M & 8528,0 & 8354,2 \\
DP & 2963,2 & 2547,1 \\
EPM & 592,6 & 424,5 \\
MAX & 19800 & 15900 \\
MIN & 4800 & 3950 \\
N & 25 & 36 \\
\hline U de Mann Whitney & U $=447,5$ & $p=0,98$
\end{tabular}

$U=447,5$

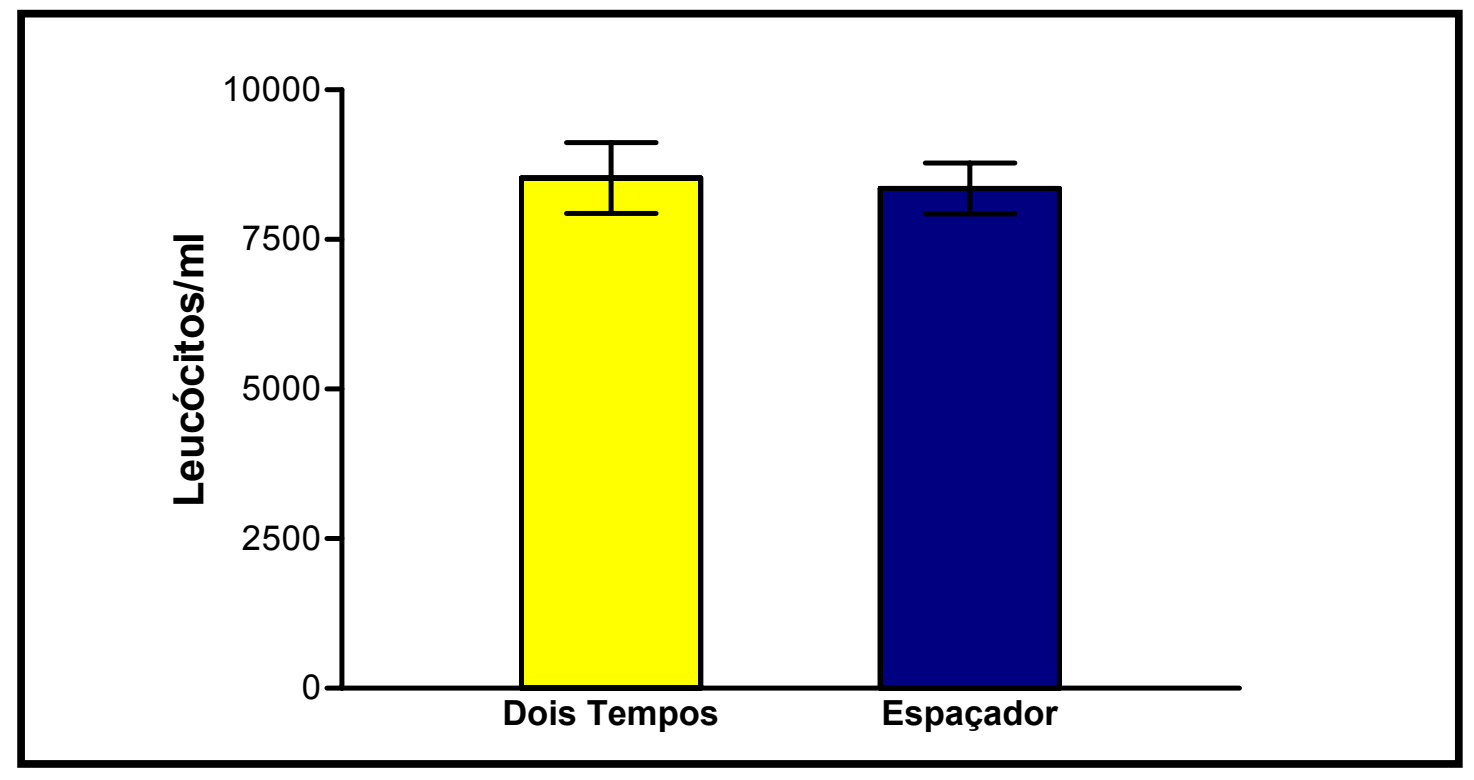
GRÁFICO 9 Contagem de leucócitos (leucócitos $/ \mathrm{ml}$ ) realizada no pré-
operatório 
TABELA 10

ESTATÍSTICA DESCRITIVA DA VELOCIDADE DE HEMOSSEDIMENTAÇÃO SEGUNDO O MÉTODO WESTERGREEN $(\mathrm{mm} / \mathrm{h})$ DE ACORDO COM O GRUPO, DOIS TEMPOS E ESPAÇADOR. COMPARAÇÃO PELO TESTE U DE MANN WHITNEY $(\alpha=0,05)$

VELOCIDADE DE HEMOSSEDIMENTAÇÃO

PRÉ-OPERATÓRIA (WESTERGREEN, $\mathrm{mm} / \mathrm{h}$ )

\begin{tabular}{lcc}
\cline { 2 - 3 } & DOIS TEMPOS & ESPAÇADOR \\
\hline \hline M & 63,4 & 57,6 \\
DP & 14,2 & 20,5 \\
EPM & 2,8 & 3,4 \\
MAX & 101 & 97 \\
MIN & 43 & 15 \\
N & 25 & 36 \\
\hline U de Mann Whitney & $\mathrm{U}=382,0$ & $\mathrm{p}=0,32$
\end{tabular}

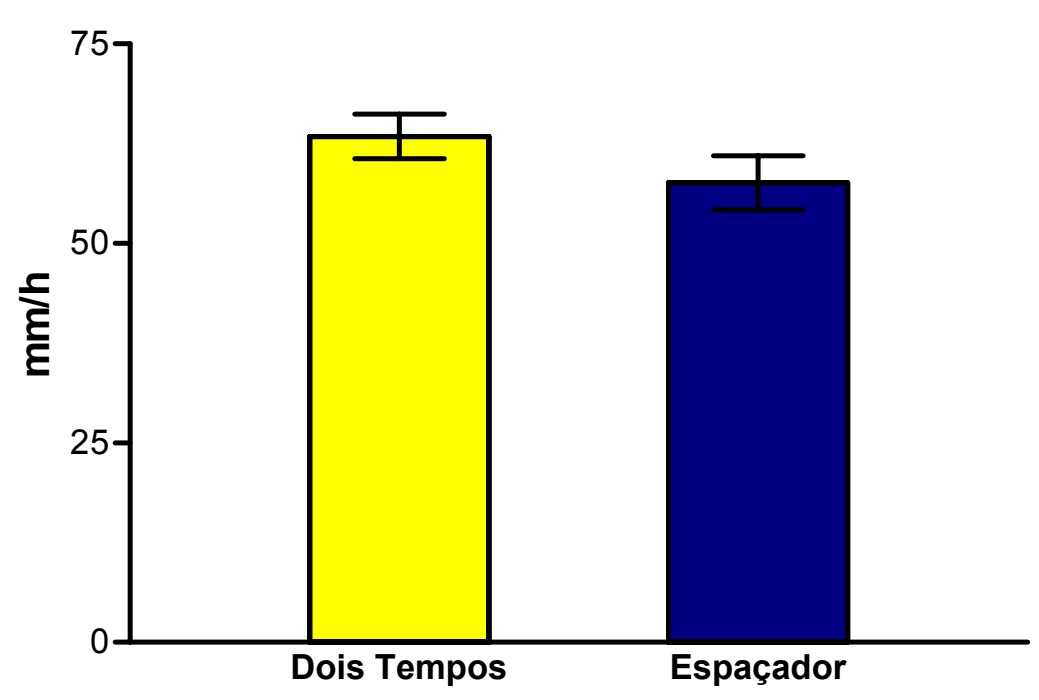

GRÁFICO10 Velocidade de hemossedimentação segundo o método Westergreen $(\mathrm{mm} / \mathrm{h})$ 
TABELA 11

ESTATÍSTICA DESCRITIVA DO NÍVEL DE PROTEÍNA C-REATIVA (mg/dl) NO PRÉ-OPERATÓRIO DE ACORDO COM O GRUPO, DOIS TEMPOS E ESPAÇADOR. COMPARAÇÃO PELO TESTE U DE MANN WHITNEY $(\alpha=0,05)$ PROTEÍNA C-REATIVA

PRÉ-OPERATÓRIA (mg/dl)

\begin{tabular}{lcc} 
& DOIS TEMPOS & ESPAÇADOR \\
\hline \hline$M$ & 43,5 & 41,3 \\
DP & 14,5 & 33,3 \\
EPM & 3,2 & 6,1 \\
MAX & 76,7 & 178 \\
MIN & 21,8 & 8,9 \\
$N$ & $21^{(1)}$ & $30^{(2)}$ \\
\hline U de Mann Whitney & $\mathrm{p}=0,12$ \\
(1) material para análise não coletado em 4 casos &
\end{tabular}

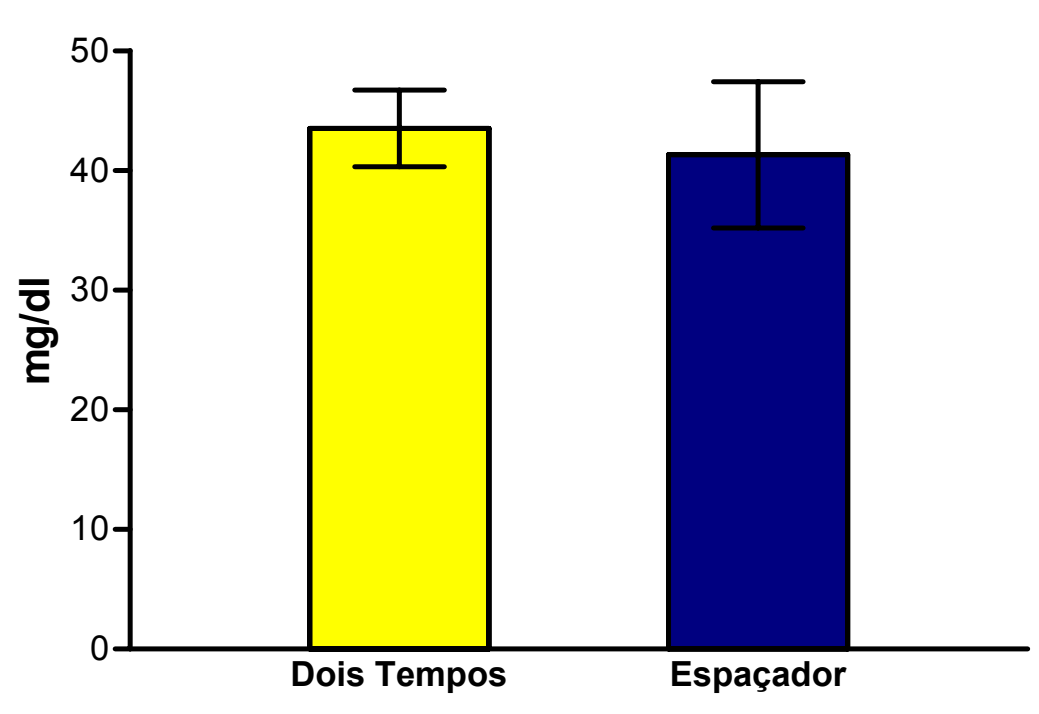

GRÁFIC011 Nível de proteína c-reativa $(\mathrm{mg} / \mathrm{dl})$ no pré-operatório 


\section{ANEXO B}

FICHA DE ACOMPANHAMENTO

ESPAÇADOR DE CIMENTO COM ANTIBIÓTICO NO TRATAMENTO DA INFECÇÃO NA ARTROPLASTIA DE QUADRIL

1.DADOS DO PACIENTE

1.1 NOME

1.2 INICIAIS

1.3 DATA DE NASCIMENTO

1.4 IDADE NA $1^{\mathrm{a}}$ CONSULTA ANOS

$1.5 \mathrm{SEXO}$ $\mathrm{M} \quad \mathrm{F}$

1.6 ENDEREÇO

1.7 TELEFONE

\section{AVALIACCÃO INICIAL}

2.1 EXAME FÍSICO (DATA

2.1.1 HARRIS HIP SCORE (TOTAL)

2.1.2 PRESENÇA DE FÍSTULA $\mathrm{S} \_\mathrm{N}$

2.1.3 SE PRESENTE, ATIVIDADE $\mathrm{S}$

2.2 AVALIAÇÃO RADIOGRÁFICA

2.2.1 RX SIMPLES

2.2.1.1 LINHAS DE RADIOLUZÊNCIA

2.2.1.1.1 FEMORAL GRUEN ZONA

2.2.1.1.2 ACETABULAR DE LEE ZONA

2.2.1.2 PERDA ÓSSEA
2.2.1.2.1 FEMORAL
2.2.1.2.2 ACETABULAR GRAU GRAU

\subsubsection{OUTROS SINAIS}

2.2.2 OUTROS EXAMES:

\subsection{EXAMES COMPLEMENTARES}

2.3.1 HB HT LEUCÓCITOS 
2.3.2 VHS $\mathrm{mm} / 1^{\mathrm{a}}$ hora

2.3.3 PCR

2.3.4 OUTROS EXAMES

\section{PRIMEIRO TEMPO CIRÚRGICO}

3.1 DATA

3.2 CIRURGIA REALIZADA

3.3 TEMPO DE CIRUGIA

3.4 ANTIBIOTICOPROFILAXIA

3.5 ASPECTO DO QUADRIL

3.5.1 DESCRIÇÃO

3.5.2 PERDA ÓSSEA

3.5.1.1 ACETABULAR

3.5.1.2 FEMORAL

3.6 TIPO DE ESPAÇADOR

3.6.1 HASTE KF/KT PRÓTESE ANTIGA

3.6.2 QUANTIDADE PARA ACETÁBULO

3.6.3 QUANTIDADE PARA FÊMUR

3.6.4 ANTIBIÓTICOS UTILIZADOS

\subsection{CULTURAS}

3.7.1 ACETÁBULO

3.7.2 FÊMUR

3.7.3 MATERIAL

4. INTERVALO ENTRE CIRURGIAS

4.1 DURAÇÃO DIAS

4.2 EXAMES LABORATORIAIS

\begin{tabular}{|r|l|l|l|l|l|l|}
\hline DATA & & & & & & \\
\hline VHS & & & & & & \\
\hline PCR & & & & & & \\
\hline
\end{tabular}

4.3 HARRIS HIP SCORE PRÉ-OPERATÓRIO ( $2^{\circ}$ TEMPO)

4.4 ANTIBIOTICOTERAPIA

\subsubsection{ENDOVENOSA}

4.4.1.1 ANTIBIÓTICOS

4.4.1.2 DURAÇÃO DIAS 


\subsubsection{ORAL}

4.4.2.1 ANTIBIÓTICOS

4.4.2.2 DURAÇÃO DIAS

4.5 TEMPO DE HOSPITALIZAÇÃO DIAS

4.6 INTERCORRÊNCIAS

4.7 CARGA PARCIAL SIM NÃO (OBS:

5. SEGUNDO TEMPO CIRÚRGICO

5.1 DATA

5.2ANTIBIOTICOPROFILAXIA

5.3 ASPECTO DO QUADRIL

5.3.1 DESCRIÇÃO

5.3.2 PERDA ÓSSEA

ACETABULAR

FEMORAL

5.6 TIPO DE CIRURGIA REALIZADA

5.6.1 HASTE FEMORAL

5.6.2 COMP. ACETABULAR

5.6.3 CABEÇA COLO

5.6.4 ENXERTIA

5.7 CULTURAS (RESULTADO)

6. ACOMPANHAMENTO

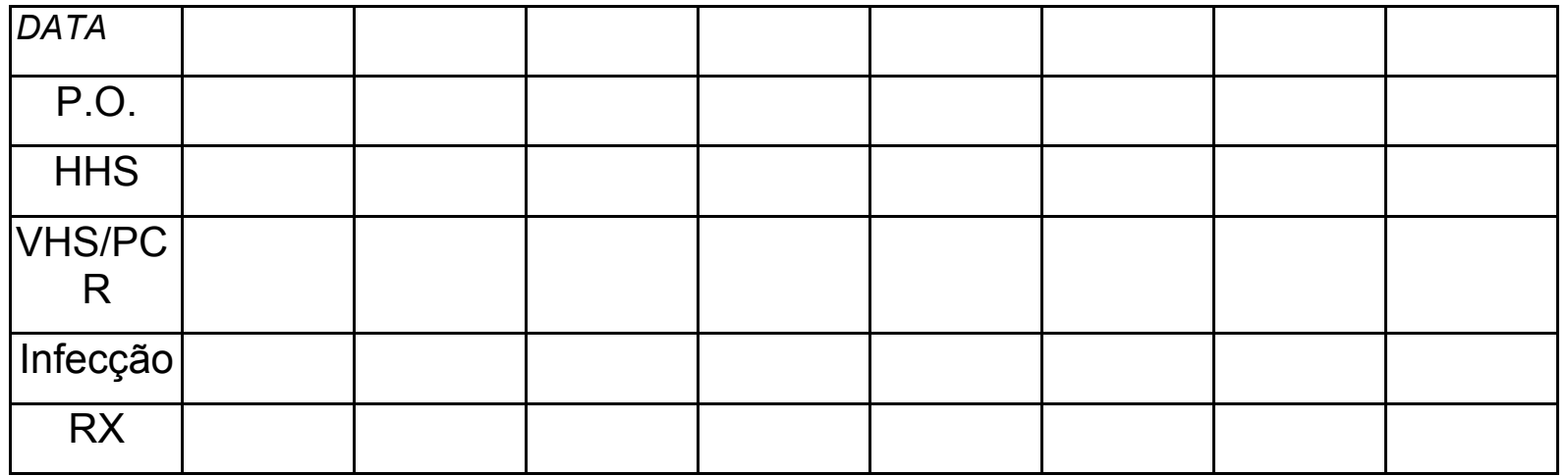




\section{ANEXO C}

\section{LISTAGENS 1 E 2}

\section{DADOS PÓS-OPERATÓRIOS}




\section{DESCRIÇÃO DAS ABREVIAÇÕES DAS LISTAGENS 1 E 2}

\begin{tabular}{|c|c|}
\hline $\bar{N}$ & Número do caso \\
\hline T1 1 & Tempo de duração do primeiro tempo cirúrgico (minutos) \\
\hline D 1 & Volume de drenagem coletado após primeiro tempo cirúrgico $(\mathrm{ml})$ \\
\hline $\mathrm{P} 1$ & Papas de hemácias infundidas após primeiro tempo cirúrgico (número) \\
\hline $\mathrm{U} 1$ & Tempo de internação em U. T.I . após o primeiro tempo cirúrgico (dias) \\
\hline INT1 & Tempo de internação após primeiro tempo cirúrgico (diasH-tranf.p/Hosp.Auxiliar) \\
\hline 101 & Ocorrência de complicações durante o primeiro tempo cirúrgico (S - sim) \\
\hline $\mathrm{PO1}$ & Ocorrência de complicações após o primeiro tempo cirúrgico (S - sim) \\
\hline EV & Tempo de duração da antibioticoterapia endovenosa (dias) \\
\hline VO & Tempo de duração da antibioticoterapia via oral (dias) \\
\hline TI1 & Tempo decorrido entre o primeiro tempo cirúrgico e a recidiva infecciosa (dias) \\
\hline Int & Intervalo de tempo entre os dois tempos cirúrgicos \\
\hline T2 & Tempo de duração do segundo tempo cirúrgico (minutos) \\
\hline ATQ & $\begin{array}{l}\text { Tipo de artroplastia colocada no segundo tempo cirúrgico (CIM-cimentada; S/C-sem } \\
\text { cimento; HÍB-híbrida) }\end{array}$ \\
\hline EO & Utilização de enxerto ósseo homólogo (S- sim) \\
\hline D 2 & Volume de drenagem coletado após o segundo tempo cirúrgico (ml) \\
\hline $\mathrm{P} 2$ & Papas de hemácias infundidas após o segundo tempo cirúrgico (número) \\
\hline $\mathrm{CP}$ & Culturas positivas colhidas durante o segundo tempo cirúrgico (S- sim) \\
\hline $\mathrm{IO} 2$ & Ocorrência de complicações durante o segundo tempo cirúrgico (S - sim) \\
\hline $\mathrm{PO} 2$ & Ocorrência de complicações após o segundo tempo cirúrgico (S - sim) \\
\hline $\mathrm{U} 2$ & Tempo de internação em U. T.I. após o segundo tempo cirúrgico (dias) \\
\hline INT2 & Tempo de internação após o segundo tempo cirúrgico (dias) \\
\hline TI2 & Tempo decorrido entre o segundo tempo cirúrgico e a recidiva infecciosa (dias) \\
\hline CURA & Controle do processo infeccioso com o tratamento proposto (sim/não/o-óbito) \\
\hline AC1 & Seguimento entre o segundo tempo cirúrgico e o último retorno (dias) \\
\hline AC2 & Seguimento entre o primeiro tempo cirúrgico e o último retorno (dias,OB-óbito) \\
\hline $\mathrm{HF}$ & Escore de Harris para quadril final (pacientes com segundo tempo cirúrgico) \\
\hline DF & Discrepância de comprimento dos membros inferiores (idem) \\
\hline $\mathrm{HG}$ & Escore de Harris para quadril final para pacientes em Girdlestone não infectado \\
\hline R1 & $\begin{array}{l}\text { Resultado final (ASI-artroplastia sem infecção; ASIL-artroplastia sem infecção luxada; Al- } \\
\text { artroplastia infectada;GSI-Girdlestone sem infecção; GI-Girdlestone infectado; ORT-óbito } \\
\text { relacionado ao tratamento; ONRT-óbito não relacionado ao tratamento;ORI-óbito } \\
\text { relacionado à infecção) }\end{array}$ \\
\hline $\mathrm{R} 2$ & Resultado final (B- bom; M-mau) \\
\hline
\end{tabular}


LISTAGEM 1 - DADOS DO TRATAMENTO DO GRUPO DOIS TEMPOS

\begin{tabular}{|c|c|c|c|c|c|c|c|c|c|c|c|c|c|c|c|c|c|c|c|c|c|c|c|c|c|c|c|c|c|c|}
\hline $\mathrm{N}$ & T1 & D 1 & P 1 & U1 & INT1 & 101 & PO1 & EV & VO & TI1 & Int & T2 & ATQ & EO & D 2 & P 2 & $\mathrm{CP}$ & 102 & PO2 & \begin{tabular}{|l|}
$\mathrm{U} 2$ \\
\end{tabular} & INT2 & $\mathrm{TI} 2$ & CURA & $A C 1$ & AC2 & HF & DF & $H G$ & RF1 & RF2 \\
\hline 1 & 240 & 760 & 2 & 1 & 36 & & $S$ & 21 & 180 & 112 & & & & & & & & & & & & & Não & & 1520 & & & 40 & GSI & $M$ \\
\hline 2 & 240 & 1085 & 5 & 2 & 28 & & $S$ & 18 & 60 & & 316 & 180 & $\mathrm{~S} / \mathrm{C}$ & & 480 & 2 & $\mathrm{~N}$ & $\mathrm{~N}$ & $\mathrm{~N}$ & 1 & 9 & & Sim & 1610 & $\mid 1926$ & 68 & 2 & & ASI & $B$ \\
\hline 3 & 160 & 1310 & 4 & 1 & 21 & & & 21 & 180 & & 150 & 220 & HÍB & $\mathrm{S}$ & 540 & 3 & $S$ & $\mathrm{~N}$ & $\mathrm{~N}$ & 2 & 14 & & Sim & 1487 & 1637 & 81 & 3 & & ASI & $B$ \\
\hline 4 & 270 & 490 & 5 & 0 & 76 & & $\mathrm{~S}$ & 75 & & 28 & 365 & 240 & DT & & 500 & 2 & $\mathrm{~N}$ & $\mathrm{~S}$ & $\mathrm{~N}$ & 1 & 7 & & Não & & 365 & & & 21 & GSI & $M$ \\
\hline 5 & 180 & 200 & 2 & 1 & 21 & & & 21 & 120 & & 109 & 300 & $\mathrm{~S} / \mathrm{C}$ & & 550 & 0 & $\mathrm{~N}$ & $\mathrm{~N}$ & $\mathrm{~N}$ & 1 & 8 & & Sim & 302 & 411 & 79 & 1 & & ASI & $B$ \\
\hline 6 & 150 & 430 & 0 & 0 & 23 & $S$ & & 23 & 150 & & 322 & 240 & HÍB & $\mathrm{S}$ & 450 & 2 & $\mathrm{~N}$ & $\mathrm{~N}$ & $\mathrm{~S}$ & 2 & 10 & & Sim & 1302 & 1624 & 70 & 3 & & ASI & $B$ \\
\hline 7 & 250 & 400 & 3 & 3 & 47 & & $S$ & 47 & 90 & 21 & & & & & & & & & & & & & Sim & 1641 & 1641 & & & 44 & GSI & $M$ \\
\hline 8 & 190 & 590 & 3 & 2 & 29 & & $S$ & 29 & 150 & & & & & & & & & & & & & & Sim & 444 & 444 & & & 48 & GSI & $M$ \\
\hline 9 & 180 & 400 & 3 & 2 & 98 & & $S$ & 83 & & 14 & & & & & & & & & & & & & Não & & 2502 & & & & Gl & $M$ \\
\hline 10 & 150 & 740 & 5 & 3 & 23 & $S$ & & 23 & 90 & & 109 & 240 & HÍB & $\mathrm{S}$ & 880 & 7 & $\mathrm{~N}$ & $\mathrm{~N}$ & $\mathrm{~S}$ & 29 & 29 & 7 & Não & & ÓB & & 2 & & ÓRI & $M$ \\
\hline 11 & 120 & 870 & 6 & 2 & 25 & & & 25 & 180 & & 171 & 240 & $\mathrm{~S} / \mathrm{C}$ & & 560 & 3 & $\mathrm{~N}$ & $\mathrm{~N}$ & $S$ & 2 & 14 & 438 & Não & 600 & 771 & & 4 & 49 & GSI & $M$ \\
\hline 12 & 180 & 480 & 3 & 2 & 30 & & & 30 & 150 & & 274 & 240 & $\mathrm{~S} / \mathrm{C}$ & & 450 & 2 & $\mathrm{~N}$ & $\mathrm{~N}$ & $\mathrm{~S}$ & 3 & 13 & & Sim & 1389 & 1663 & 67 & 2 & & ASI & $B$ \\
\hline 13 & 200 & 700 & 9 & 4 & 25 & & $S$ & 21 & 180 & & 73 & 360 & CIM & $S$ & 550 & 3 & $\mathrm{~N}$ & $\mathrm{~N}$ & $\mathrm{~N}$ & 2 & 10 & & Sim & 1081 & 1154 & 80 & 3 & & ASI & $B$ \\
\hline 14 & 180 & 650 & 4 & 2 & 28 & & & 28 & 150 & & 120 & 240 & CIM & $S$ & 740 & 3 & $N$ & $\mathrm{~N}$ & $S$ & 3 & 9 & & Sim & 1115 & 1235 & 50 & 2,5 & & ASI & $B$ \\
\hline 15 & 380 & & 6 & & & $S$ & & & & & & & & & & & & & & & & & $\mathrm{O}$ & & ÓB & & & & ÓNRT & \\
\hline 16 & 150 & 490 & 2 & 1 & 53 & $S$ & $S$ & 47 & 90 & 7 & & & & & & & & & & & & & Não & & 378 & & & 60 & GSI & $\mathrm{M}$ \\
\hline 17 & 200 & 500 & 3 & 3 & 23 & & & 23 & & & 70 & 240 & CIM & $\mathrm{S}$ & 880 & 5 & $\mathrm{~N}$ & $\mathrm{~N}$ & $\mathrm{~S}$ & 2 & 10 & 25 & Não & 300 & 370 & 68 & 3,5 & & $\mathrm{Al}$ & $M$ \\
\hline 18 & 190 & \begin{tabular}{|l|}
780 \\
\end{tabular} & 7 & 3 & 30 & & $S$ & 347 & & 14 & & & & & & & & & & & & & Não & & 1100 & & & 55 & GSI & $\mathrm{M}$ \\
\hline 19 & 200 & 1230 & 8 & 3 & 21 & & & 21 & 90 & & 94 & 300 & HÍB & $\mathrm{S}$ & 980 & 10 & $N$ & $\mathrm{~N}$ & $\mathrm{~S}$ & 5 & & & $\mathrm{Sim} / \mathrm{O}$ & & ÓB & & & & ÓRT & $M$ \\
\hline 20 & 150 & 900 & 6 & 4 & 28 & & & 26 & 180 & & 393 & 400 & CIM & $S$ & 1100 & 8 & $\mathrm{~N}$ & $\mathrm{~S}$ & $\mathrm{~N}$ & 1 & & & $\mathrm{Sim} / \mathrm{O}$ & & ÓB & & & & ÓBT & $M$ \\
\hline 21 & 120 & 400 & 0 & 1 & 46 & & $S$ & 44 & 60 & 56 & & & & & & & & & & & & & Não & & 1345 & & & 38 & GSI & $\mathrm{M}$ \\
\hline 22 & 180 & 780 & 9 & 4 & 43 & & $S$ & 43 & 90 & & & & & & & & & & & & & & Sim & & 665 & & & 59 & GSI & $\mathrm{M}$ \\
\hline 23 & 150 & 600 & 0 & 0 & 21 & $S$ & & 21 & 180 & & & & & & & & & & & & & & Sim & & 1567 & & & 54 & GSI & $\mathrm{M}$ \\
\hline 24 & 210 & 670 & 3 & 1 & 21 & & & 21 & 150 & & 227 & 240 & CIM & & 290 & 2 & $\mathrm{~S}$ & $\mathrm{~N}$ & $\mathrm{~N}$ & 3 & 9 & & Sim & 180 & 407 & 58 & 3 & & ASI & $B$ \\
\hline 25 & 180 & 800 & 5 & 3 & $21 S$ & & & 190 & & & 610 & 300 & CIM & & 550 & 6 & $\mathrm{~N}$ & $\mathrm{~N}$ & $\mathrm{~S}$ & 5 & 10 & 5 & Não & & 1742 & & 2,5 & & $\mathrm{GI}$ & $M$ \\
\hline
\end{tabular}


LISTAGEM 2 - DADOS DO TRATAMENTO DO GRUPO ESPAÇADOR

\begin{tabular}{|c|c|c|c|c|c|c|c|c|c|c|c|c|c|c|c|c|c|c|c|c|c|c|c|c|c|c|c|c|c|}
\hline $\mathrm{N}$ & T1 & D 1 & P 1 & U1 & INT1 & 101 & $\mathrm{PO1}$ & EV & $\mathrm{VO}$ & TI1 & Int & T2 & ATQ & EO & \begin{tabular}{|l|} 
D 2 \\
\end{tabular} & P 2 & $\mathrm{CP}$ & \begin{tabular}{|l|}
102 \\
\end{tabular} & \begin{tabular}{|l|}
$\mathrm{PO} 2$ \\
\end{tabular} & U2 & INT2 & CURA & AC1 & $\mathrm{AC2}$ & $\mathrm{HF}$ & DF & $\mathrm{HG}$ & RF1 & RF2 \\
\hline 1 & 280 & 300 & 2 & 2 & 14 & $\mathrm{~N}$ & $\mathrm{~N}$ & 14 & & 56 & & & & & & & & & & & & Não & & 1450 & & & 50 & GSI & $M$ \\
\hline 2 & 300 & 780 & 4 & 2 & 13 & $\mathrm{~N}$ & S & 12 & 60 & & 60 & 180 & CIM & $S$ & 300 & 0 & $\mathrm{~N}$ & $\mathrm{~N}$ & $\mathrm{~N}$ & 0 & 7 & Sim & 1305 & 1365 & 90 & 0,5 & & ASI & B \\
\hline 3 & 210 & 720 & 4 & 0 & 10 & $S$ & $\mathrm{~N}$ & 10 & 90 & & 165 & 180 & HIB & $S$ & 780 & 5 & S & $\mathrm{N}$ & $\mathrm{N}$ & 1 & 16 & Sim & 544 & 709 & 68 & 4 & & ASI & B \\
\hline 4 & 255 & 700 & 4 & 1 & 9 & $\mathrm{~N}$ & S & 9 & \begin{tabular}{|l|}
139 \\
\end{tabular} & & 139 & 185 & HIB & $S$ & 530 & 3 & $\mathrm{~N}$ & $N$ & S & 0 & 9 & Sim & 653 & 792 & 71 & 8 & & ASI & B \\
\hline 5 & 170 & 500 & 3 & 1 & 15 & $\mathrm{~N}$ & $\mathrm{~N}$ & 15 & 60 & & 300 & 210 & CIM & $S$ & 210 & 0 & $\mathrm{~N}$ & $\mathrm{~N}$ & $\mathrm{~N}$ & 1 & 9 & Sim & 327 & 627 & 69 & 1 & & ASI & B \\
\hline 6 & 190 & 480 & 3 & 2 & 15 & $\mathrm{~N}$ & $S$ & 15 & & & 77 & 330 & CIM & $S$ & 200 & 1 & $\mathrm{~N}$ & $\mathrm{~N}$ & $\mathrm{~N}$ & 1 & 4 & Sim & 804 & 881 & 87 & 0 & & ASI & B \\
\hline 7 & 300 & 1550 & 9 & 3 & 21 & $\mathrm{~N}$ & $S$ & 21 & 30 & & 330 & 300 & HIB & $S$ & 300 & 5 & $N$ & $\mathrm{~N}$ & $\mathrm{~N}$ & 2 & 6 & Sim & 831 & 1161 & 80 & 0 & & ASI & B \\
\hline 8 & 160 & 125 & 0 & 0 & 15 & $\mathrm{~N}$ & $N$ & 12 & 60 & & 81 & 180 & $\mathrm{~S} / \mathrm{C}$ & $S$ & 0 & 0 & $N$ & $N$ & $\mathrm{~N}$ & 0 & 5 & Sim & 488 & 569 & 94 & 0 & & ASI & B \\
\hline 9 & 240 & 900 & 5 & 2 & 29 & $S$ & $S$ & 10 & 180 & & 223 & 240 & HIB & $S$ & 650 & 5 & $\mathrm{~N}$ & $N$ & $S$ & 2 & 10 & Sim & 603 & 826 & 44 & 7 & & ASIL & $M$ \\
\hline 10 & 270 & 350 & 0 & 1 & 9 & $S$ & $\mathrm{~N}$ & 5 & 120 & & 125 & 120 & $\mathrm{~S} / \mathrm{C}$ & $\mathrm{N}$ & 120 & 2 & $\mathrm{~N}$ & $\mathrm{~N}$ & $S$ & 1 & 5 & Sim & 438 & 563 & 73 & 0 & & ASI & B \\
\hline 11 & 190 & 1010 & 2 & 3 & 6 & $\mathrm{~N}$ & $\mathrm{~N}$ & 5 & 180 & & 240 & 125 & $\mathrm{~S} / \mathrm{C}$ & $\mathrm{N}$ & 290 & 0 & $\mathrm{~N}$ & $\mathrm{~N}$ & $S$ & 0 & 7 & Sim & 813 & 1053 & 91 & 0 & & ASI & B \\
\hline 12 & 160 & 560 & 3 & 1 & 11 & $S$ & $\mathrm{~N}$ & 11 & 30 & & 186 & 150 & CIM & $\mathrm{N}$ & 440 & 2 & $\mathrm{~N}$ & $\mathrm{~N}$ & $\mathrm{~N}$ & 1 & 8 & Sim & 885 & 1071 & 75 & 0,5 & & ASI & B \\
\hline 13 & 150 & 390 & 1 & 1 & 14 & $\mathrm{~N}$ & $\mathrm{~N}$ & 14 & 180 & & 76 & 240 & CIM & $\mathrm{N}$ & 350 & 0 & $\mathrm{~N}$ & $\mathrm{~N}$ & $\mathrm{~N}$ & 0 & 7 & Sim & 1440 & 1516 & 94 & 0 & & ASI & B \\
\hline 14 & 210 & 570 & 3 & 1 & 17 & $\mathrm{~N}$ & $\mathrm{~N}$ & 17 & 180 & & 79 & 150 & CIM & $S$ & 400 & 4 & $\mathrm{~N}$ & $\mathrm{~N}$ & $S$ & 4 & 15 & Sim & 930 & 1009 & 59 & 3 & & ASI & B \\
\hline 15 & 240 & 700 & 1 & 1 & $10 \mathrm{H}$ & $\mathrm{N}$ & $\mathrm{N}$ & 25 & 60 & & 133 & 180 & $S / C$ & $S$ & 400 & 0 & $\mathrm{~N}$ & $\mathrm{~N}$ & $\mathrm{~N}$ & 1 & 5 & Sim & 555 & 688 & 87 & 2 & & ASI & B \\
\hline 16 & 240 & 1000 & 8 & 2 & $10 \mathrm{H}$ & $\mathrm{N}$ & $\mathrm{N}$ & 25 & 180 & & 89 & 210 & $S / C$ & $S$ & 450 & 1 & $\mathrm{~N}$ & $\mathrm{~N}$ & $\mathrm{~N}$ & 7 & 7 & Sim & 333 & 422 & 84 & 0 & & ASI & B \\
\hline 17 & 180 & 220 & 2 & 0 & $10 \mathrm{H}$ & $\mathrm{N}$ & $\mathrm{N}$ & 300 & & & 240 & 300 & HIB & $S$ & 560 & 3 & $S$ & $\mathrm{~N}$ & $\mathrm{~N}$ & 2 & $14 \mathrm{H}$ & Sim & 546 & 786 & 70 & 0 & & ASI & B \\
\hline 18 & 200 & 350 & 3 & 3 & $12 \mathrm{H}$ & $S$ & $\mathrm{~N}$ & 21 & 180 & & 119 & 180 & CIM & $\mathrm{N}$ & 360 & 1 & $\mathrm{~N}$ & $\mathrm{~N}$ & $\mathrm{~N}$ & 1 & 5 & Sim & 1261 & 1380 & \begin{tabular}{|l|}
47 \\
\end{tabular} & 4 & & ASI & B \\
\hline 19 & 180 & 400 & 5 & 1 & 8 & $\mathrm{~N}$ & $\mathrm{~N}$ & 8 & 180 & & 350 & 240 & CIM & $S$ & 260 & 2 & $\mathrm{~N}$ & $\mathrm{~N}$ & $S$ & 1 & 6 & Sim & 513 & 863 & 75 & 0 & & ASI & B \\
\hline 20 & 250 & 420 & 3 & 2 & 14 & $\mathrm{~N}$ & $\mathrm{~N}$ & 14 & 180 & & 165 & 240 & CIM & $\mathrm{N}$ & 600 & 3 & $\mathrm{~N}$ & $\mathrm{~N}$ & $\mathrm{~N}$ & 2 & 8 & Sim & 898 & 1063 & 93 & 0 & & ASI & B \\
\hline 21 & 240 & 400 & 0 & 0 & 10 & $\mathrm{~N}$ & $\mathrm{~N}$ & 10 & 180 & & 172 & 159 & $S / C$ & $\mathrm{~N}$ & 440 & 3 & $\mathrm{~N}$ & $\mathrm{~N}$ & $\mathrm{~N}$ & 0 & 5 & Sim & 277 & 449 & 77 & 0,5 & & ASI & B \\
\hline 22 & 300 & 730 & 1 & 0 & 9 & $\mathrm{~N}$ & $\mathrm{~N}$ & 9 & 180 & & 182 & 120 & $S / C$ & $\mathrm{~N}$ & 500 & 2 & $\mathrm{~N}$ & S & $\mathrm{N}$ & 1 & 5 & Sim & 230 & 412 & 82 & 3 & & ASI & B \\
\hline 23 & 360 & 810 & 8 & 2 & 23 & $\mathrm{~N}$ & $\mathrm{~N}$ & 23 & 180 & & 126 & 240 & $S / C$ & $S$ & 710 & 1 & $\mathrm{~N}$ & $\mathrm{~N}$ & $\mathrm{~N}$ & 3 & 5 & Sim & 339 & 465 & 58 & 5,5 & & ASI & B \\
\hline 24 & 300 & 430 & 5 & 3 & 30 & $\mathrm{~N}$ & $S$ & 30 & & & 180 & 150 & HIB & $\mathrm{N}$ & 450 & 3 & $S$ & $\mathrm{~N}$ & $S$ & 1 & 21 & Sim & 320 & 500 & 40 & 0 & & ASI & B \\
\hline 25 & 450 & 390 & 2 & 1 & 30 & $\mathrm{~N}$ & $\mathrm{~N}$ & 30 & 180 & & 140 & 240 & $\mathrm{~S} / \mathrm{C}$ & S & 620 & 5 & $\mathrm{~N}$ & $\mathrm{~N}$ & $\mathrm{~N}$ & 1 & 6 & Sim & 210 & 350 & 88 & 1 & & ASI & B \\
\hline 26 & 240 & 180 & 7 & 2 & 9 & $\mathrm{~N}$ & $\mathrm{~N}$ & 9 & 90 & & 149 & 210 & CIM & $S$ & 590 & 6 & $\mathrm{~N}$ & $\mathrm{~N}$ & $\mathrm{~N}$ & 1 & 5 & Sim & 1128 & 1277 & 82 & 0 & & ASI & B \\
\hline 27 & 240 & 100 & 0 & 0 & 8 & $\mathrm{~N}$ & $\mathrm{~N}$ & 8 & 180 & & 201 & 240 & CIM & $S$ & 600 & 8 & $\mathrm{~N}$ & $\mathrm{~N}$ & $S$ & 2 & 12 & Sim & 1020 & 1221 & 72 & 2 & & ASI & B \\
\hline 28 & 180 & 200 & 3 & 1 & 8 & $\mathrm{~N}$ & $\mathrm{~N}$ & 8 & 90 & & 210 & 120 & $\mathrm{~S} / \mathrm{C}$ & $\mathrm{N}$ & 180 & 2 & $\mathrm{~N}$ & $\mathrm{~N}$ & $\mathrm{~N}$ & 1 & 5 & Sim & 427 & 637 & 79 & 0 & & ASI & B \\
\hline 29 & 360 & 100 & 2 & 1 & 35 & $\mathrm{~N}$ & $S$ & 35 & & & & & & & & & & & & & & 0 & & OB & & & & ORT & $M$ \\
\hline 30 & 180 & 300 & 0 & 0 & 17 & $\mathrm{~N}$ & $\mathrm{~N}$ & 17 & 180 & & 67 & 200 & $\mathrm{~S} / \mathrm{C}$ & & 500 & 5 & $\mathrm{~N}$ & $\mathrm{~S}$ & $N$ & 1 & 17 & Sim & 286 & 353 & \begin{tabular}{|l|}
80 \\
\end{tabular} & 1 & & ASI & B \\
\hline 31 & 200 & 540 & 6 & 1 & 16 & $\mathrm{~N}$ & $\mathrm{~N}$ & 16 & 90 & & 227 & 180 & $S / C$ & & 150 & 2 & $\mathrm{~N}$ & $\mathrm{~N}$ & $\mathrm{~N}$ & 1 & 7 & Sim & 504 & 731 & 81 & 1,5 & & ASI & B \\
\hline 32 & 180 & 520 & 5 & 7 & 23 & $\mathrm{~N}$ & $\mathrm{~S}$ & 23 & & & & & & & & & & & & & & 0 & & OB & & & & ONRT & \\
\hline 33 & 180 & 400 & 4 & 1 & 7 & $\mathrm{~N}$ & $\mathrm{~N}$ & 7 & 180 & & 152 & 300 & HIB & 19 & 550 & 3 & $\mathrm{~N}$ & $\mathrm{~N}$ & $\mathrm{~N}$ & 3 & 8 & Sim & 767 & 919 & 68 & 1 & & ASI & B \\
\hline 34 & 150 & 390 & 2 & 0 & $13 \mathrm{H}$ & $\mathrm{N}$ & $\mathrm{N}$ & 60 & & & 64 & 190 & $S / C$ & 20 & 400 & 3 & $\mathrm{~N}$ & $\mathrm{~N}$ & $\mathrm{~N}$ & 1 & 6 & Sim & 202 & 266 & 72 & 1 & & ASI & B \\
\hline 35 & 240 & 300 & 2 & 2 & 95 & $\mathrm{~N}$ & $S$ & 95 & & 21 & & & & & & & & & & & & Não & & 1323 & & & 59 & GSI & $M$ \\
\hline 36 & 180 & 250 & 1 & 2 & 359 & $\mathrm{~N}$ & $\mathrm{~S}$ & 340 & & 7 & & & & & & & & & & & & Não & & 1005 & & & 44 & GSI & $M$ \\
\hline
\end{tabular}




\section{ANEXO D}

\section{DADOS PÓS-OPERATÓRIOS}

\section{COMPLEMENTARES}


TABELA 1

ESTATÍSTICA DESCRITIVA DO PERÍODO DE TEMPO (dia) DE TRAÇÃO ESQUELÉTICA NO GRUPO DOIS TEMPOS

PERÍODO SOB TRAÇÃO ESQUELÉTICA (dia)

DOIS TEMPOS

\begin{tabular}{lc}
\hline \hline M & 23,6 \\
DP & 5,7 \\
EPM & 1,2 \\
MAX & 40 \\
MIN & 18 \\
N & $24^{(1)}$ \\
\hline (1) 1 caso de óbito intra-operatório no primeiro tempo cirúrgico
\end{tabular}

(1) 1 caso de óbito intra-operatório no primeiro tempo cirúrgico

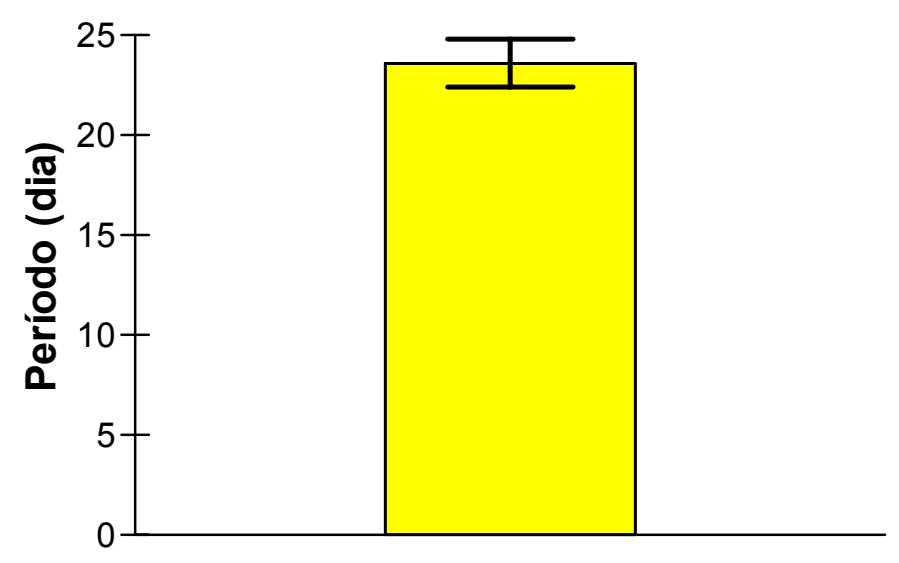

Dois Tempos

GRÁFICO 1 Período de tempo (dia) de tração esquelética 
TABELA 2

ESTATÍSTICA DESCRITIVA DO TEMPO DE DURAÇÃO (dia) DA ANTIBIOTICOTERAPIA POR VIA ENDOVENOSA DE ACORDO COM O GRUPO, DOIS TEMPOS E ESPAÇADOR. COMPARAÇÃO PELO TESTE U DE MANN WHITNEY $(\alpha=0,05)$

DURAÇÃO DA ANTIBIOTICOTERAPIA ENDOVENOSA

(dia)

\begin{tabular}{lcc}
\cline { 2 - 3 } & DOIS TEMPOS & ESPAÇADOR \\
\hline \hline M & 52,0 & 35,6 \\
DP & 72,6 & 72,1 \\
EPM & 14,8 & 12,0 \\
MAX & 347 & 340 \\
MIN & 18 & 5 \\
N & $24^{(1)}$ & 36 \\
\hline
\end{tabular}

de Mann Whitney

$\mathrm{U}=186,0$

$p \cong 0,00^{*}$

(1) 1 caso de óbito intra-operatório no primeiro tempo cirúrgico

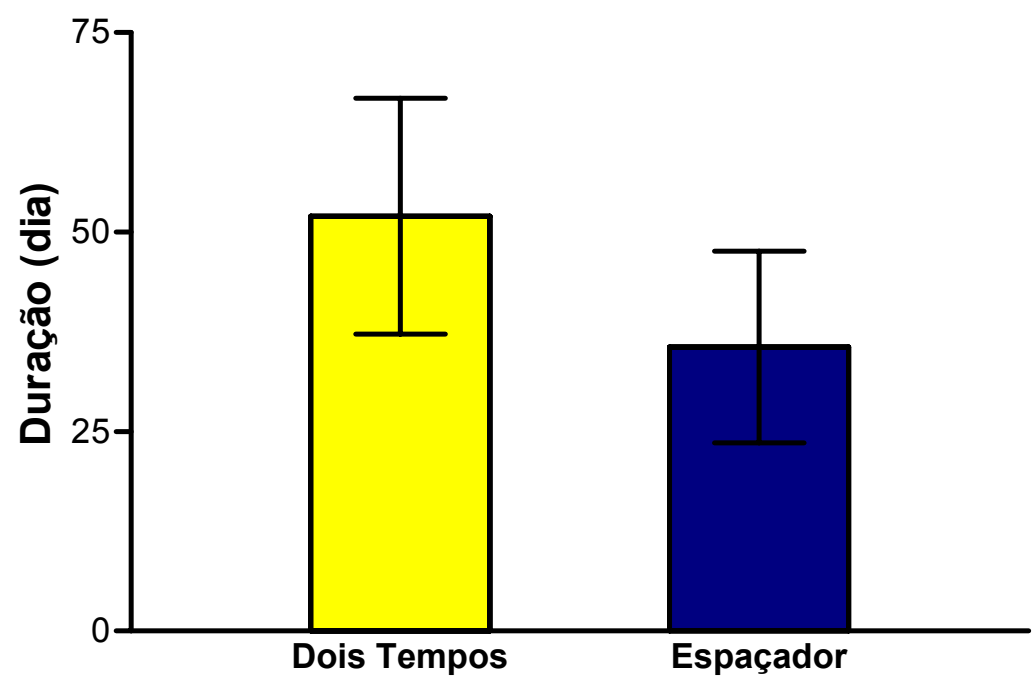

GRÁFICO 2 Duração (dia) da antibioticoterapia por via endovenosa 
TABELA 3

ESTATÍSTICA DESCRITIVA DO TEMPO DE DURAÇÃO (dia) DA ANTIBIOTICOTERAPIA POR VIA ORAL APÓS CESSAR A POR VIA ENDOVENOSA DE ACORDO COM O GRUPO, DOIS TEMPOS E ESPAÇADOR. COMPARAÇÃO PELO TESTE U DE MANN WHITNEY $(\alpha=0,05)$ DURAÇÃO DA ANTIBIOTICOTERAPIA VIA ORAL (APÓS ENDOVENOSA) (dia)

\begin{tabular}{lcc} 
& DOIS TEMPOS & ESPAÇADOR \\
\cline { 2 - 3 } M & 132,6 & 134,0 \\
DP & 43,9 & 56,6 \\
EPM & 10,1 & 10,9 \\
MAX & 180 & 180 \\
MIN & 60 & 30 \\
$N$ & $19(1)$ & $27^{(2)}$ \\
\hline $\begin{array}{l}\text { (1) de Mann Whitney } 1 \text { caso de óbito e 5 casos tratados somente com antibioticoterapia endovenosa } \\
\text { (2) } 2 \text { casos de óbito, 1 caso de abandono de tratamento e 6 casos tratados somente com } \\
\text { antibioticoterapia endovenosa }\end{array}$ &
\end{tabular}

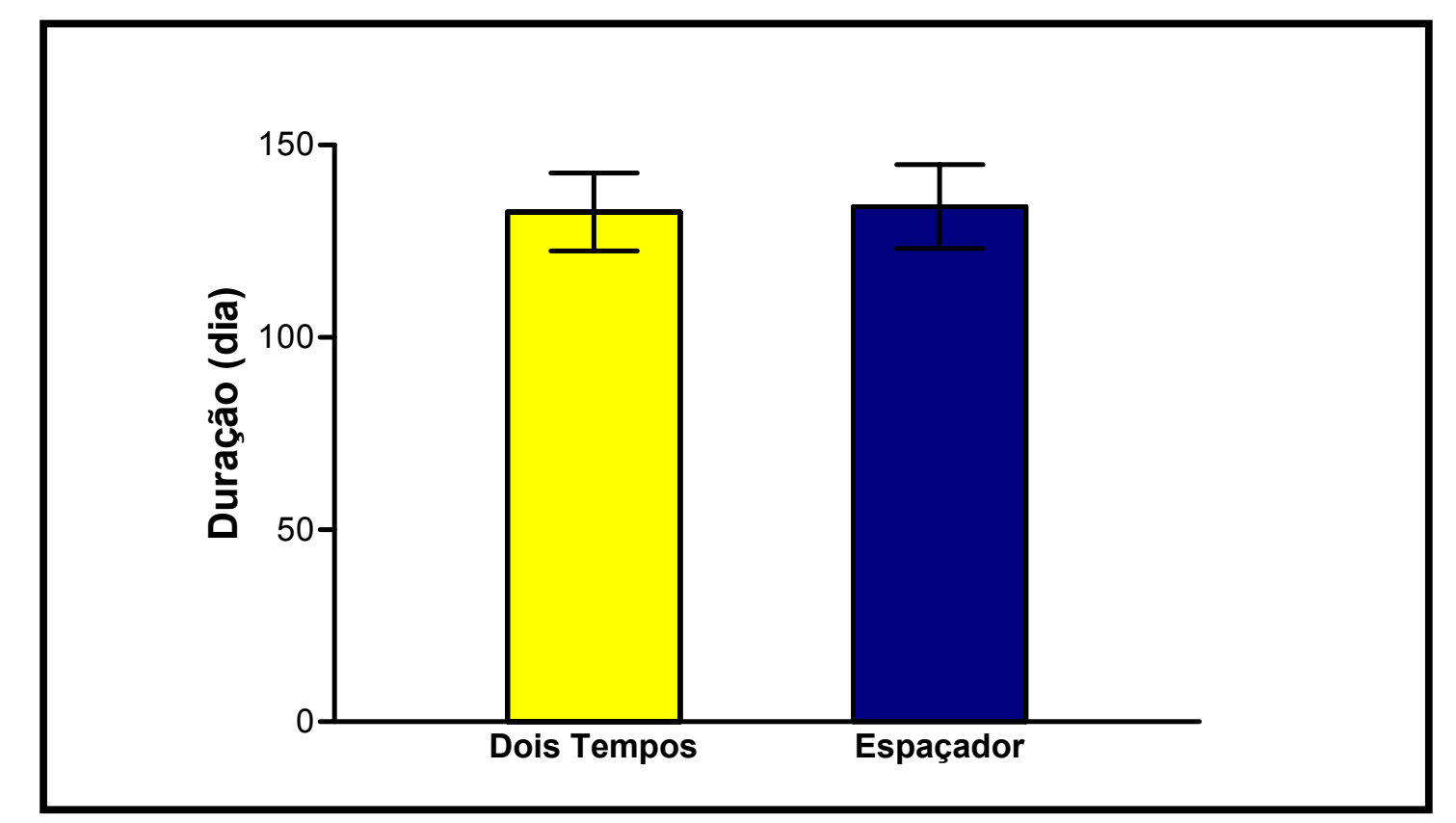

GRÁFICO 3 Duração (dia) da antibioticoterapia por via oral após cessar a por via endovenosa 
TABELA 4

DISTRIBUIÇÃO DE FREQÜÊNCIA, ABSOLUTA (n) E RELATIVA (\%), DA OCORRÊNCIA DE CRESCIMENTO BACTERIANO EM CULTURAS COLHIDAS DURANTE O SEGUNDO TEMPO CIRÚRGICO DE ACORDO COM O GRUPO, DOIS TEMPOS E ESPAÇADOR. COMPARAÇÃO PELO TESTE EXATO DE FISHER $(\alpha=$ $0,05)$

\begin{tabular}{|c|c|c|c|c|c|c|}
\hline & \multicolumn{6}{|c|}{ CULTURA POSITIVA } \\
\hline & \multicolumn{2}{|c|}{ DOIS TEMPOS } & \multicolumn{2}{|c|}{ ESPAÇADOR } & \multicolumn{2}{|c|}{ TOTAL } \\
\hline & $n$ & $\%$ & $n$ & $\%$ & $\mathrm{n}$ & $\%$ \\
\hline Sim & 2 & 4,8 & 3 & 6,5 & 5 & 10,9 \\
\hline Não & 13 & 28,3 & 28 & 60,9 & 41 & 89,1 \\
\hline TOTAL & $15^{(1)}$ & 32,6 & $31^{(2)}$ & 67,4 & 46 & 100,0 \\
\hline
\end{tabular}

(1) 1 caso de óbito intra-operatório no primeiro tempo cirúrgico, 2 casos mantidos em Girdlestone e 7 casos com recidiva de infecção

(2) 2 casos de óbito e 3 casos de recidiva de infecção

Dois Tempos

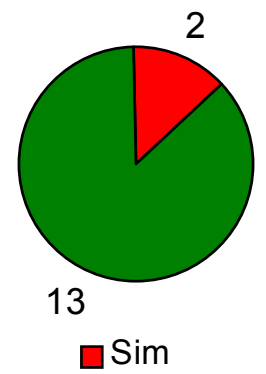

$\square \operatorname{Sim}$

\section{Espaçador}

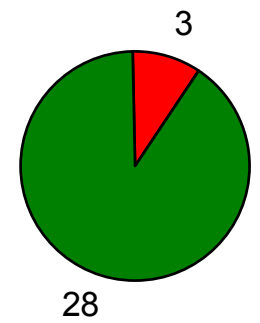

Não

GRÁFICO 4 Ocorrência de crescimento bacteriano em culturas colhidas durante o segundo tempo cirúrgico 
TABELA 5

DISTRIBUIÇÃO DE FREQÜÊNCIA, ABSOLUTA (n) E RELATIVA (\%), DA MORTALIDADE RELACIONADA AO TRATAMENTO, Á FALHA DESTE OU PELA MANUTENÇÃO DO QUADRO INFECCIOSO, DE ACORDO COM O GRUPO, DOIS TEMPOS E ESPAÇADOR. COMPARAÇÃO PELO TESTE EXATO DE FISHER $(\alpha=0,05)$

\begin{tabular}{|c|c|c|c|c|c|c|}
\hline & \multicolumn{6}{|c|}{ MORTALIDADE } \\
\hline & \multicolumn{2}{|c|}{ DOIS TEMPOS } & \multicolumn{2}{|c|}{ ESPAÇADOR } & \multicolumn{2}{|c|}{ TOTAL } \\
\hline & $n$ & $\%$ & $\mathrm{n}$ & $\%$ & $\mathrm{n}$ & $\%$ \\
\hline Sim & 3 & 5,0 & 1 & 1,7 & 4 & 6,7 \\
\hline Não & 21 & 35,0 & 35 & 58,3 & 56 & 93,3 \\
\hline TOTAL & $24^{(1)}$ & 40,0 & 36 & 60,0 & 60 & 100,0 \\
\hline
\end{tabular}

Fisher $p=0,29$

(1) 1 caso de óbito não relacionado ao tipo de tratamento

Dois Tempos

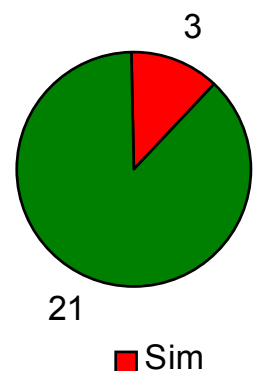

$\square \operatorname{Sim}$

\section{Espaçador}

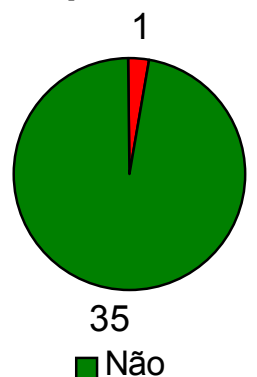

GRÁFICO 5 Mortalidade 


\section{APÊNDICES}




\section{APÊNDICE A}

\section{ESCORE DE HARRIS PARA QUADRIL (HARRIS HIP SCORE )}

\section{$\underline{\text { DOR }}$}

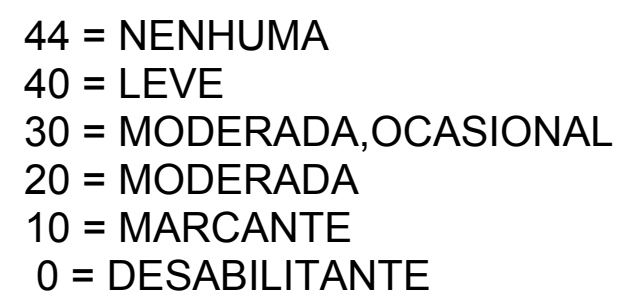

\section{FUNČ̃̃O}

$$
\begin{aligned}
& \text { CLAUDICAÇÃO } \\
& 11=\text { NENHUMA } \\
& 8=\text { LEVE } \\
& 5=\text { MODERADA } \\
& 0=\text { SEVERA }
\end{aligned}
$$

$$
\begin{aligned}
& \text { APOIO } \\
& \begin{aligned}
11= & \text { NENHUM } \\
7= & \text { BENGALA (LONGAS } \\
& \text { CAMINHADAS) } \\
3= & 1 \text { MOLETA } \\
2= & 2 \text { BENGALAS } \\
0= & 2 \text { MOLETAS }
\end{aligned}
\end{aligned}
$$

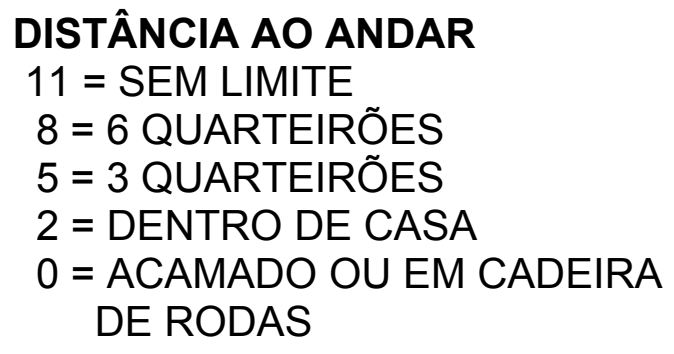

\section{ATIVIDADES}

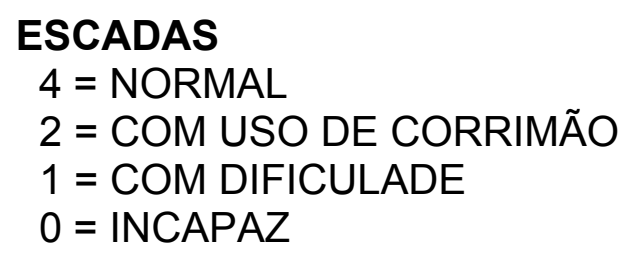

MEIAS E CALÇADOS

$4=$ FÁCIL

2 = DIFÍCIL

$0=$ INCAPAZ

\author{
SENTAR \\ 4 = FICA EM QUALQUER \\ CADEIRA POR 1 HORA \\ 2 = SOMENTE EM CADEIRA ALTA \\ $0=$ NÃO CONSEGUE SENTAR \\ CONFORTAVELMENTE \\ TRANSPORTE PÚBLICO \\ $1=$ UTILIZA \\ $0=N \tilde{A} O$ UTILIZA
}

\section{DEFORMIDADE}

SEM ADUÇÃO FIXA $<10=1$ SEM ROTAÇÃO INTERNA FIXA <10 =1 CONTRATURA EM FLEXÃO $<30=1$ DISCREPÂNCIA DE MMII $<3 \mathrm{~cm}=1$

\section{AMPLITUDE DE MOVIMENTO}

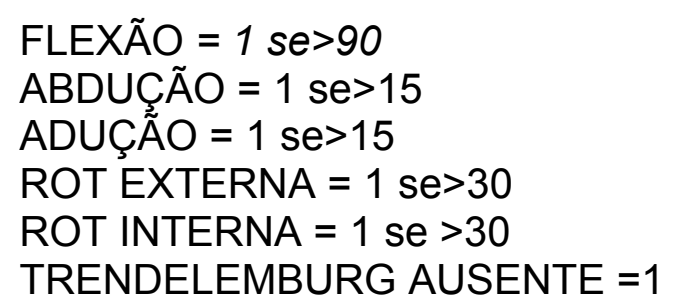




\section{APÊNDICE B}

\section{CLASSIFICAÇÃO DE GUSTILO E PASTERNAK PARA AS PERDAS ÓSSEAS EM ARTROPLASTIAS DE QUADRIL}

\section{PERDAS ACETABULARES}
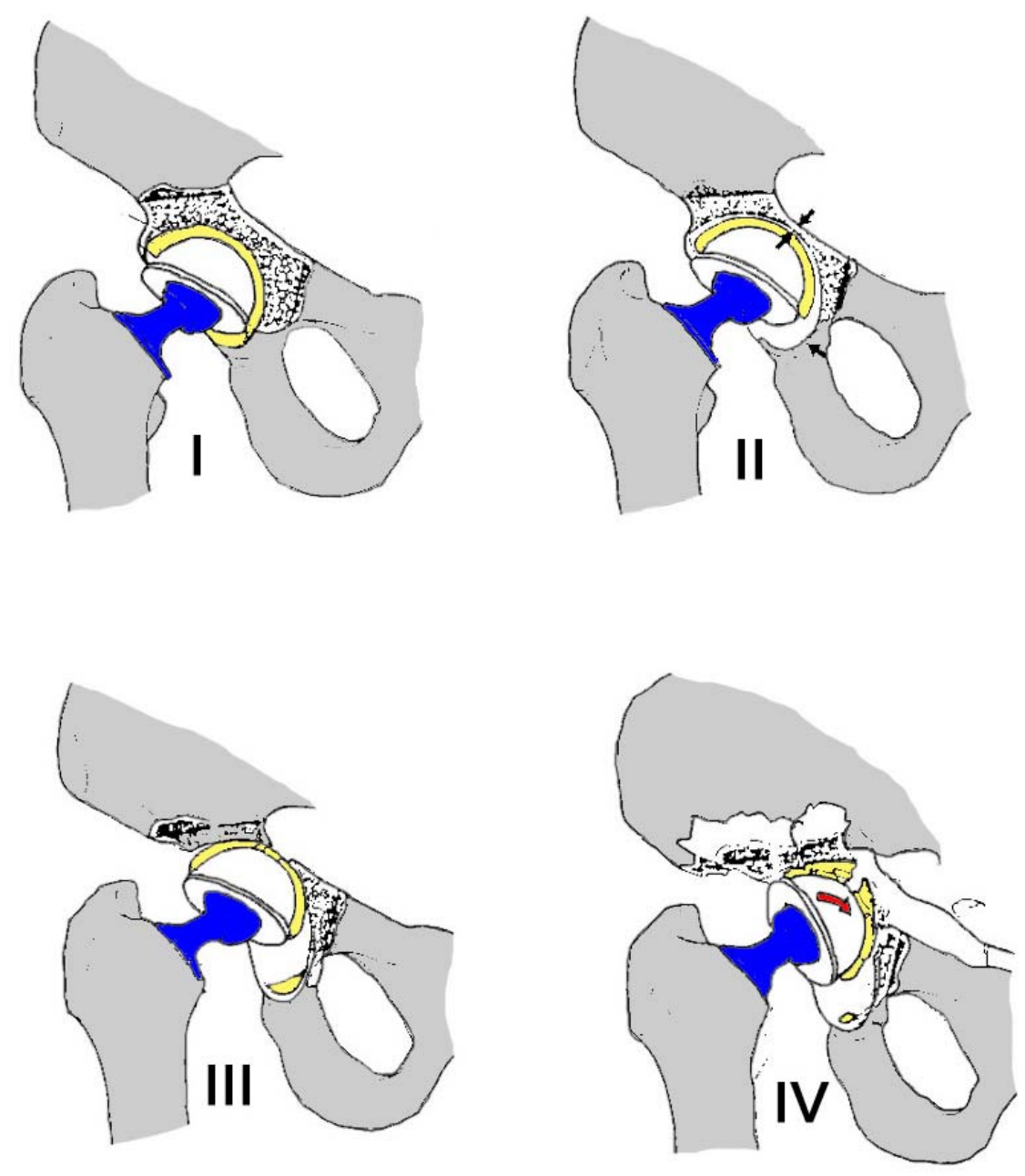

Grau I: Perda óssea mínima e soltura na interface cimento-prótese;

Grau II: Perda acentuada, com manutenção das paredes ósseas e soltura entre o cimento e osso;

Grau III: Perda acentuada com rotura de uma das paredes: superior, anterior, inferior, medial;

Grau IV: Colapso maciço e global ou defeito envolvendo duas ou mais paredes acetabulares. 


\section{PERDAS FEMORAIS}
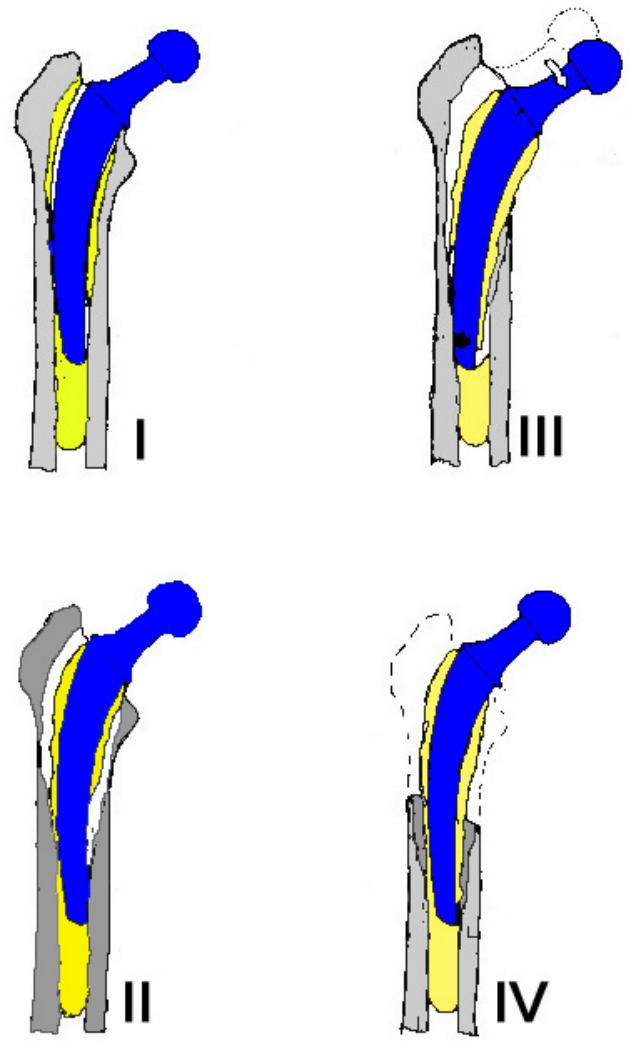

Grau I: Perda cortical mínima e soltura da interface cimento-metal-osso ou fratura da haste;

Grau II: Perda óssea cortical de até $50 \%$ da espessura cortical, com as paredes intactas;

Grau III: Rotura da cortical póstero-medial junto ao trocanter menor, indicando instabilidade;

Grau IV: Rotura circunferencial da cortical proximal do fêmur. 